THEORETICAL APPROACH FOR ENHANCED MASS TRANSFER EFFECTS IN-DUCT FLUE GAS DESULFURIZATION PROCESSES

Volume 2: Duct Spray Drying

Final Report

By

Wojciech Jozewlcz

Gary T. Rochelle

January 29, 1992

Work Performed Under Contract No. AC22-88PC88874

For

U.S. Department of Energy

Pittsburgh Energy Technology Center

Pittsburgh, Pennsylvania

By

Acurex Corporation

Research Triangle Park, North Carolina

and

University of Texas at Austin

Austin, Texas 


\section{DISCLAIMER}

This report was prepared as an account of work sponsored by an agency of the United States Government. Neither the United States Government nor any agency thereof, nor any of their employees, makes any warranty, express or implied, or assumes any legal liability or responsibility for the accuracy, completeness, or usefulness of any information, apparatus, product, or process disclosed, or represents that its use would not infringe privately owned rights. Reference herein to any specific commercial product, process, or service by trade name, trademark, manulfacturer, or otherwise does not necessarily' constitute or imply its endorsement, recommendation, or favoring by the United States Government or $\varepsilon$ ny agency thereof. The views and opinions of authors ex. pressed herein do not necessarily state or reflect those of the United States Government or any agency thereof.

This report has been reproduced directly from the best available copy.

Available to DOE and DOE contractors from the Office of Scientific and Technical Information, P.O. Box 62, Oak Ridge, TN 37831; prices available from (615)576.8401,

A vailable to the public from the National Technical Information Service, U.S. Department of Commerce, 5285 Port Royal Rd., Springfield, VA 22161. 


\title{
Theoretical Approach for Enhanced Mass Transfer Effects In-Duct Flue Gas Desulfurization Processes
}

\section{Volume II: Duct Spray Drying}

Final Report

\author{
Prepared for: \\ DOE Project Manager \\ Richard E. Tischer \\ Environmental Control Division \\ Pittsburgh Energy Technology Center \\ U.S. Department of Energy \\ Pittsburgh, PA 15236
}

Under Contract No. DE-AC22-88PC88874

Date Prepared: January 29, 1992

Prepared by:

Wojciech Jozewicz

Acurex Corporation

Environmental Systems Division

4915 Prospectus Drivo

P.O. Box 13109

Research Triangle Park, NC 27709

and

Gary T. Rochelle

University of Texas at Austin

Department of Chemical Engineering

Austin, TX 78712 


\begin{abstract}
Removal of sulfur dioxide $\left(\mathrm{SO}_{2}\right)$ from the flue gas of coal-buming power plants can be achieved by duct spray drying (DSD) using calcium hydroxide $\left[\mathrm{Ca}(\mathrm{OH})_{2}\right]$ slurries. A primary objective of this research was to discover the aspects of mass transfer into $\mathrm{Ca}(\mathrm{OH})_{2}$ slurries which limit $\mathrm{SO}_{2}$ absorption. A benchscale stirred tank reactor with a flat gas/liquid interface was used to simulate $\mathrm{SO}_{2}$ absorption in a slumy droplet. The absorption rate of $\mathrm{SO}_{2}$ from gas concentrations of 500 to $5,000 \mathrm{ppm}$ was measured at $55^{\circ} \mathrm{C}$ in clear solutions and slurries of $\mathrm{Ca}(\mathrm{OH})_{2}$ up to $1.0 \mathrm{M}$ (7 wt percent). Results are reported in terms of the enhancement factor, $\varnothing$. This research will allow prediction of conditions where the absorption of $\mathrm{SO}_{2}$ in $\mathrm{Ca}(\mathrm{OH})_{2}$ slurries can be enhanced by changes to liquid phase constituents (under which $\mathrm{SO}_{2}$ absorption is controlled by liquid film mass transfer). Experiments in the stirred tank have shown that $\mathrm{SO}_{2}$ absorption in a $1.0 \mathrm{M} \mathrm{Ca}(\mathrm{OH})_{2}$ slurry was completely dominated by gas film mass transfer. For conditions of a slurry droplet, the model predicts that absorption of $\mathrm{SO}_{2}$ is controlled by gas film mass transfer with a large excess of $\mathrm{Ca}(\mathrm{OH})_{2}$ but becomes controlled by liquid film resistance at greater than 50 percent $\mathrm{Ca}(\mathrm{OH})_{2}$ utilization.
\end{abstract}

An algorithm using penetration theory for the $\mathrm{SO}_{2}$ absorption and film theory for the $\mathrm{Ca}(\mathrm{OH})_{2}$ dissolution has been cisyeloped to model the $\mathrm{SO}_{2}$ absorption rate in a stirred tank reactor. This algorithm has been coded in FORTRAN and executed on a CRAY computer. Results have been calculated for conditions representative of DSD. The results are expressed as the average fraction gas film resistance. With short contact times $(0.1 \mathrm{~s})$, high slurry concentration $\left[1,000\right.$ mole $\left.\mathrm{Ca}(\mathrm{OH})_{2} / \mathrm{m}^{3}\right]$, or low $\mathrm{SO}_{2}$ concentration $(500 \mathrm{ppm})$, gas film resistance approaches 100 percent. With a typical gas film transfer coefficient at 2,000 ppm SO${ }_{2}$, gas film resistance decreases to less than 100 percent when the penetration distance of the absorption wave exceeds 10 to $20 \mu \mathrm{m}$. 
TABLE OF CONTENTS

Section $\quad$ Page

VOLUME I

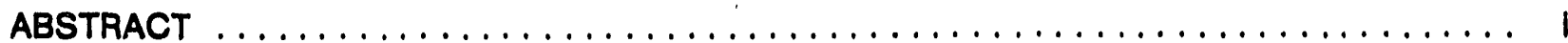

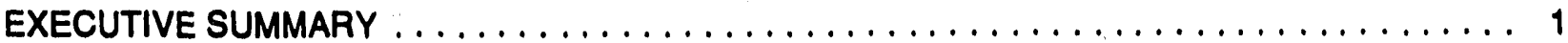

E.1 Duct Injection Program Overview $\ldots \ldots \ldots \ldots \ldots \ldots \ldots \ldots \ldots \ldots \ldots \ldots \ldots \ldots$

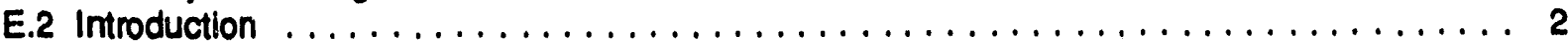

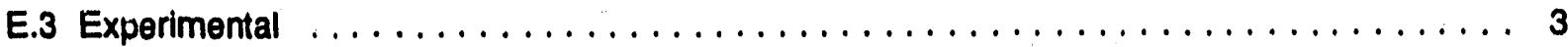

E.4 Mass Transfer Testing $\ldots \ldots \ldots \ldots \ldots \ldots \ldots \ldots \ldots \ldots \ldots \ldots \ldots \ldots \ldots$

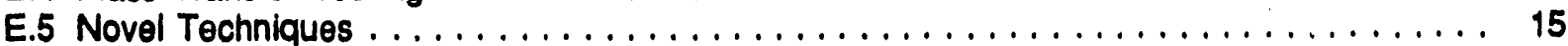

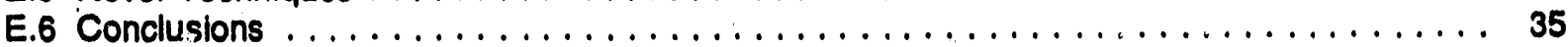

1. DUCT INJECTION PROGRAM OVERVIEW $\ldots \ldots \ldots \ldots \ldots \ldots \ldots \ldots \ldots \ldots \ldots \ldots$

2. INTRODUCTION $\ldots \ldots \ldots \ldots \ldots \ldots \ldots \ldots \ldots \ldots \ldots \ldots \ldots \ldots \ldots \ldots$

3. EXPERIMENTAL $\ldots \ldots \ldots \ldots \ldots \ldots \ldots \ldots \ldots \ldots \ldots \ldots \ldots \ldots \ldots \ldots$

3.1 Short Time Differential Reactor $\ldots \ldots \ldots \ldots \ldots \ldots \ldots \ldots \ldots \ldots \ldots \ldots \ldots \ldots \ldots$

3.2 Long Time Differential Reactor $\ldots \ldots \ldots \ldots \ldots \ldots \ldots \ldots \ldots \ldots \ldots \ldots \ldots \ldots$

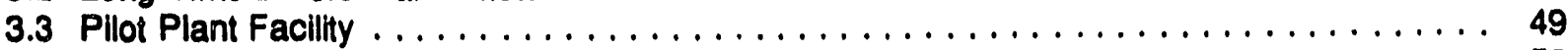

3.4 Baseline Sorbent Selection/Characterization . . . . . . . . . . . . . . . . . 52

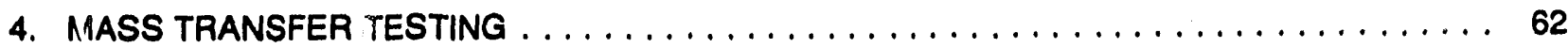

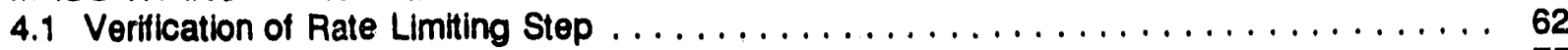

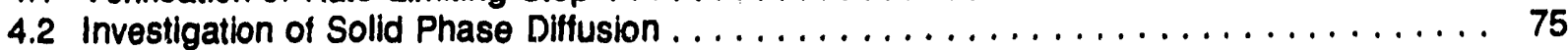

4.3 Effect of Moisture on Reactivity $\ldots \ldots \ldots \ldots \ldots \ldots \ldots \ldots \ldots \ldots \ldots \ldots \ldots$

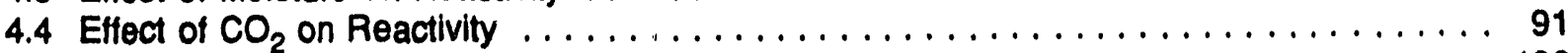

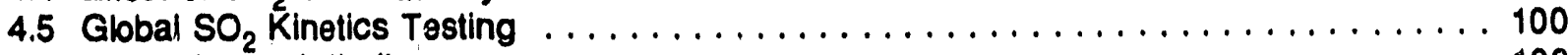

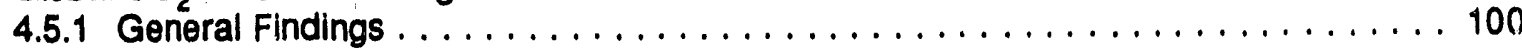

4.5.2 Effect of Residence Time . . . . . . . . . . . . . . . . . . . . . 103

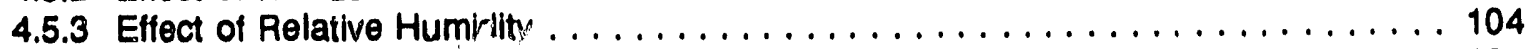

4.5.4 Effect of Initial Sorben : itioisture . . . . . . . . . . . . . . . . . . . . . . . . . 104

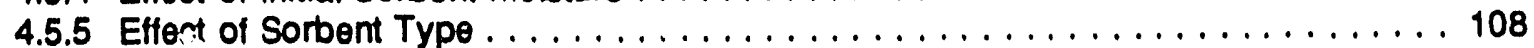

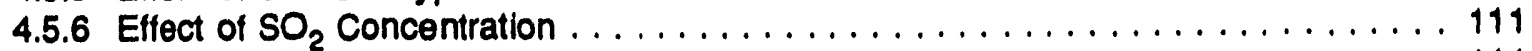

4.5.7 Effect of Sorbent Accumulation over Time $\ldots \ldots \ldots \ldots \ldots \ldots \ldots \ldots \ldots \ldots$ 
TABLE OF CONTENTS (continued)

Section Page

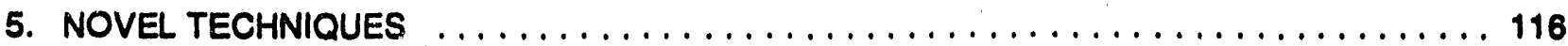

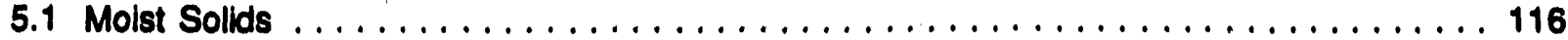

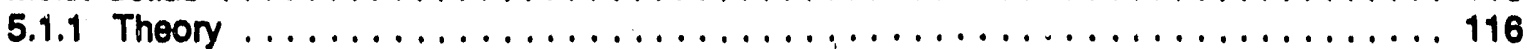

5.1.1.1 Assumptions for Theoretical Development .............. 116

5.1.1.2 Derivation ............................... 117

5.1.1.3 Effects of Equilibrium Reaction ..................... 119

5.1.1.4 Derivation of Modified Equilibrium Conversion Estimate . . . . . . . . . 121

5.1.2 Long Time Differential Reactor Results and Discussion . . . . . . . . . . . . 122

5.1.2.1 Sorbents with Ambient Moisture . . . . . . . . . . . . . . . . . . 123

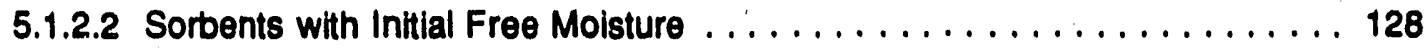

5.1.2.3 Comparison: Adidtive Model vs. Experiment . . . . . . . . . . . . 141

5.1.2.4 Comparison: Interactive Model vs. Experiment . . . . . . . . . . . . 148

5.1.2.5 Conversion of Fly Ast $/ \mathrm{Ca}(\mathrm{OH})_{2}$ Sorbent by Reaction with $\mathrm{CO}_{2} \ldots \ldots \ldots 159$

5.1.3 Short Time Differential Reactor Resulis and Discussion . . . . . . . . . . . . . 159

5.1.3.1 Effect of Sorbent Type . . . . . . . . . . . . . . . . . . . . . . . 162

5.1.3.2 Combined Effect of the Amount of Initial Freo Moisture and Sorbent Surface

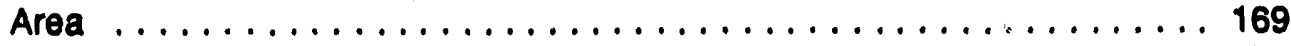

5.1.3.3 Etfect of the Approach to Saturation . . . . . . . . . . . . . 178

5.1 .3 .4 Effect of Fly Ash Source $\ldots \ldots \ldots \ldots \ldots \ldots \ldots \ldots \ldots \ldots \ldots . \ldots \ldots$

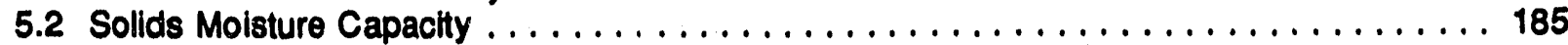

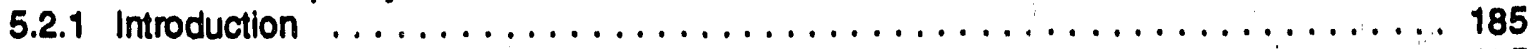

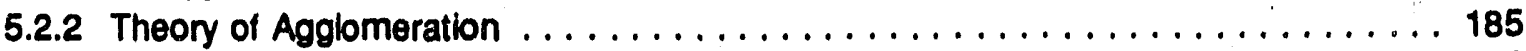

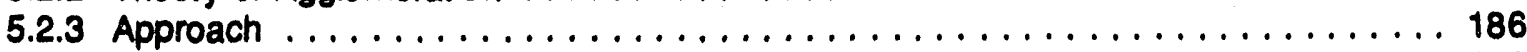

5.2.4 Results for Individual Reactants and Dry Mixtures . . . . . . . . . . . . . 189

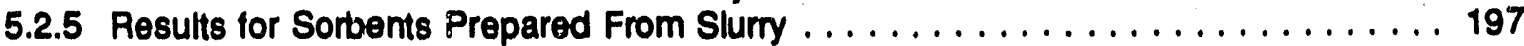

5.3 Recycle Operation .................................. 212

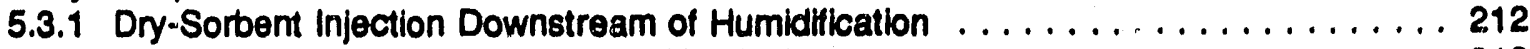

5.3.2 Dry-Sorbent Injection Upstream of Humidification $\ldots \ldots \ldots \ldots \ldots \ldots \ldots \ldots \ldots \ldots$

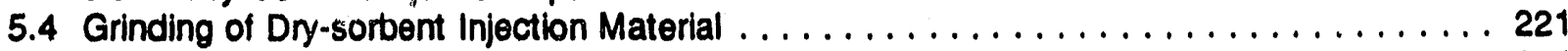

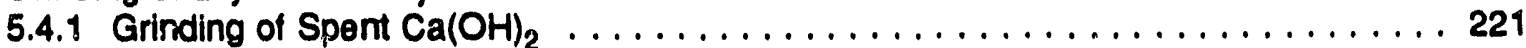

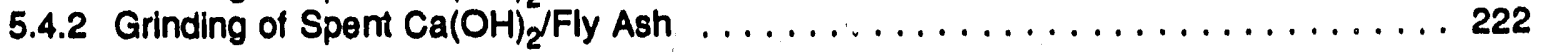

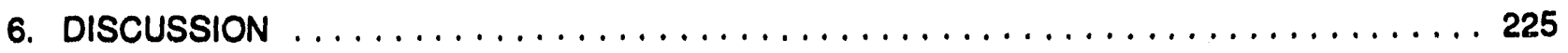

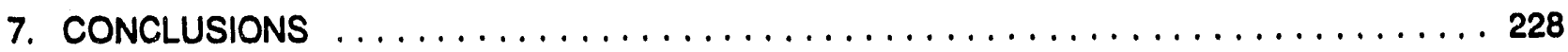

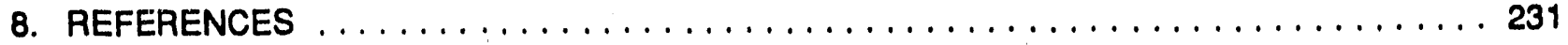


Section Page

VOLUME \|

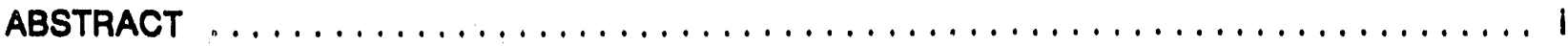

EXECUTIVE SUMMARY $\ldots \ldots \ldots \ldots \ldots \ldots \ldots \ldots \ldots \ldots \ldots \ldots \ldots \ldots \ldots \ldots \ldots$

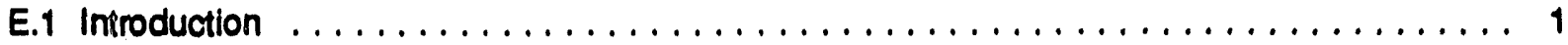

E.2 Theory of $\mathrm{SO}_{2}$ Absorption in $\mathrm{Ca}(\mathrm{OH})_{2}$ Slurries $\ldots \ldots \ldots \ldots \ldots \ldots \ldots \ldots \ldots \ldots$

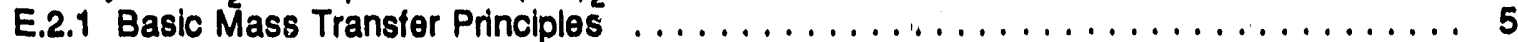

E.2.2 Enhancement Predicted by Surface Renewal Theory . . . . . . . . . . . . . . 6

E.2.3 Slurry Absorption Model $\ldots \ldots \ldots \ldots \ldots \ldots \ldots \ldots \ldots \ldots \ldots$. . . . . . . . . . . .

E.3 Experimental .................................. 9

E.3.1 Design of Reactor and Supporting Equipment .................. 9

E.3.2 Mass Transter Propertles of the Stirred Tank Reactor . . . . . . . . . . . . . . . 11

E.3.3 Comparison of Mass Transter Properties of the Stirred Tank to that in a Slurry Droplet 18

E.4 Results of Experiments in Clear Solutions $\ldots \ldots \ldots \ldots \ldots \ldots \ldots \ldots \ldots \ldots \ldots \ldots$

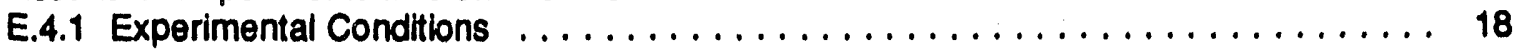

E.4.2 Enhancement in Water . . . . . . . . . . . . . . . . . . . . . 19

E.4.3 Enhancement in $0.1 \mathrm{M} \mathrm{CaCl}_{2}$ Solution ....................... 19

E.4.4 Enhancement in $2.5 \mathrm{mM} \mathrm{Ca}(\mathrm{OH})_{2}$ Solution Containing $0.1 \mathrm{M} \mathrm{CaCl}_{2} \ldots \ldots \ldots \ldots 20$

E.4.5 Enhancement in $17 \mathrm{mM} \mathrm{Ca}(\mathrm{OH})_{2}$ Solution Containing $0.1 \mathrm{M} \mathrm{CaCl}_{2} \ldots \ldots \ldots \ldots 20$

E.4.6 Enhancement in Solutions of Varying lonic Strength ............... 21

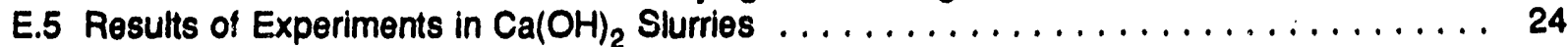

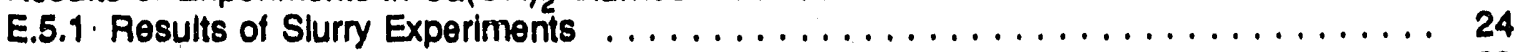

E.5.2 Validation of Slurry Absorption Model For $\mathrm{Ca}(\mathrm{OH})_{2}$ Slurries $\ldots \ldots \ldots \ldots \ldots \ldots .28$

E.5.3 Discussion of Slumy Absorption Experiments .................. 30

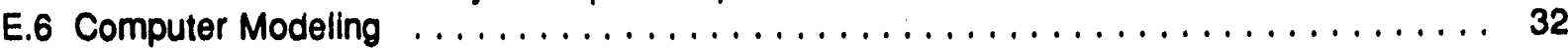

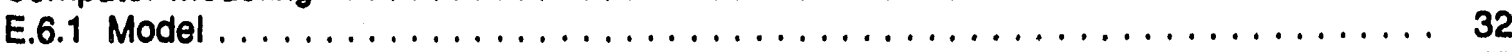

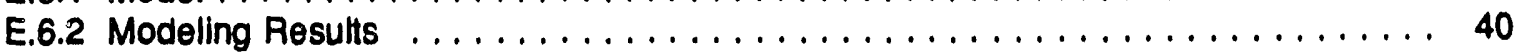

E.7 Conclusions and Recommendations $\ldots \ldots \ldots \ldots \ldots \ldots \ldots \ldots \ldots \ldots \ldots \ldots \ldots$

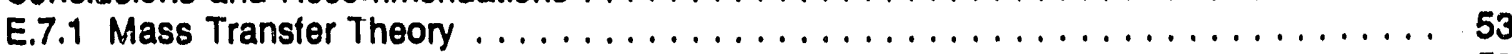

E.7.2 Stirred Tank Reactor Experiments $\ldots \ldots \ldots \ldots \ldots \ldots \ldots \ldots \ldots \ldots \ldots \ldots \ldots$

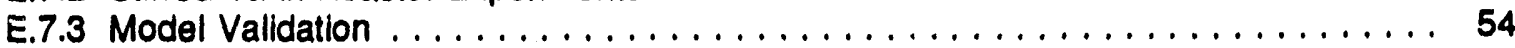

E.7.4 Computer Modeling . . . . . . . . . . . . . . . . . . . . . . . . 54

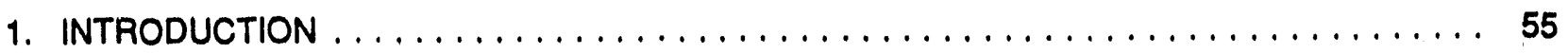

2. THEORY OF $\mathrm{SO}_{2}$ ABSORPTION IN $\mathrm{Ca}(\mathrm{OH})_{2}$ SLURRIES $\ldots \ldots \ldots \ldots \ldots \ldots \ldots \ldots \ldots$

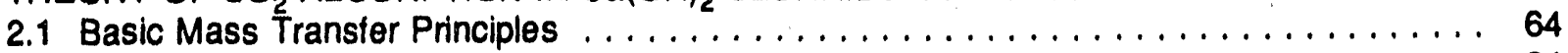

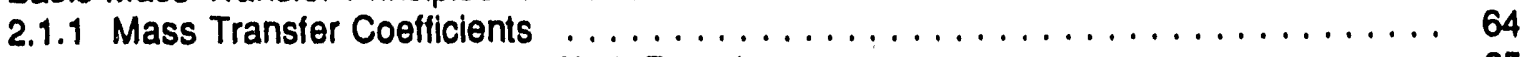

2.1.2 Enhancement of Absorption With Reaction .................. 65 
TABLE OF CONTENTS (continued)

Section

Page

2.1.3 Gas Film Resistance . . . . . . . . . . . . . . . . . . . . . . . 66

2.2 Enhancement Predicted by Surface Renewal Theory $\ldots \ldots \ldots \ldots \ldots \ldots \ldots \ldots \ldots, \ldots 7$

2.2.1 Enhancement in Water ............................ 68

2.2.2 Enhancement in $\mathrm{CaCl}_{2}$ Solution ........................ 69

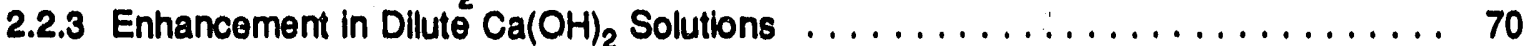

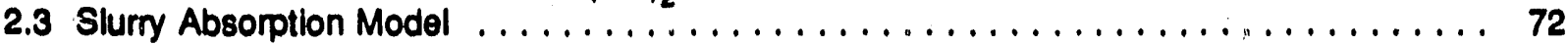

2.3.1 Absorption With Reaction $\ldots \ldots \ldots \ldots \ldots \ldots \ldots \ldots \ldots \ldots \ldots \ldots \ldots \ldots$

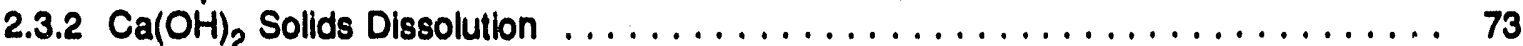

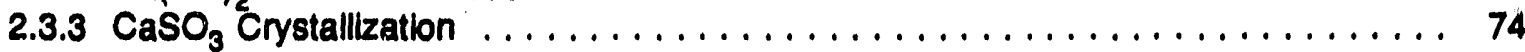

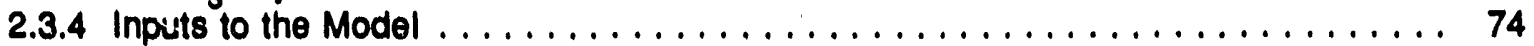

2.3.5 Model Output . ............................... 76

3. EXPERIMENTAL $\ldots \ldots \ldots \ldots \ldots \ldots \ldots \ldots \ldots \ldots \ldots \ldots \ldots \ldots \ldots \ldots$

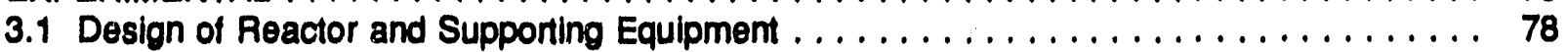

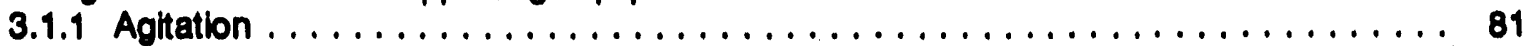

3.1.2 System Improvements ............................. 82

3.1.3 Gas Phase Analysis and Material Balance $\ldots \ldots \ldots \ldots \ldots \ldots \ldots \ldots . \ldots . \ldots$

3.1.4 Liquid Phase Analysis ................................ 86

3.2 Mass Transter Properties of the Stirred Tank Reactor $\ldots \ldots \ldots \ldots \ldots \ldots \ldots \ldots \ldots$

3.2.1 Gas Film Mass Transter Properties $\ldots \ldots \ldots \ldots \ldots \ldots \ldots \ldots \ldots \ldots \ldots$

3.2.1.1 Experimental Results $\ldots \ldots \ldots \ldots \ldots \ldots \ldots \ldots \ldots \ldots, \ldots \ldots$

3.2.1.2 Discussion $\ldots \ldots \ldots \ldots \ldots \ldots \ldots \ldots \ldots \ldots \ldots \ldots \ldots \ldots \ldots$

3.2.2 Liquid Film Mass Transter Properties . . . . . . . . . . . . . . . . 96

3.2.2.1 Experimental Results $\ldots \ldots \ldots \ldots \ldots \ldots \ldots \ldots \ldots \ldots \ldots \ldots \ldots \ldots . \ldots \ldots$

3.2.2.2 Discussion ................................ 103

4. RESULTS OF EXPERIMENTS IN CLEAR SOLUTIONS $\ldots \ldots \ldots \ldots \ldots \ldots \ldots \ldots \ldots$

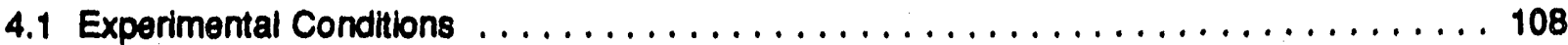

4.2 Enhancement in Water ...................................... 110

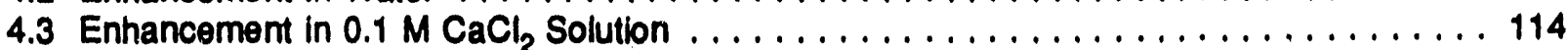

4.4 Enhancement in $2.5 \mathrm{mM} \mathrm{Ca}(\mathrm{OH})_{2}$ Solution Containing $0.1 \mathrm{M} \mathrm{CaCl}_{2} \ldots \ldots \ldots \ldots \ldots \ldots 119$

4.5 Enhancement in $17 \mathrm{mM} \mathrm{Ca}(\mathrm{OH})_{2}$ solution Containing $0.1 \mathrm{M} \mathrm{CaCl}_{2} \ldots \ldots \ldots \ldots \ldots \ldots 124$

4.6 Enhancement in Solutions of Varying lonic Strength $\ldots \ldots \ldots \ldots \ldots \ldots \ldots \ldots \ldots \ldots$

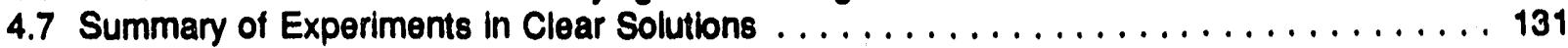

4.7.1 Enhancement and Gas Film Resistance . . . . . . . . . . . . . . . . . . 134

4.7.2 Slurry Absorption Model and Theory . . . . . . . . . . . . . . . . . 137

5. RESULTS OF EXPERIMENTS IN Ca(OH $)_{2}$ SLUURRIES $\ldots \ldots \ldots \ldots \ldots \ldots \ldots \ldots \ldots$

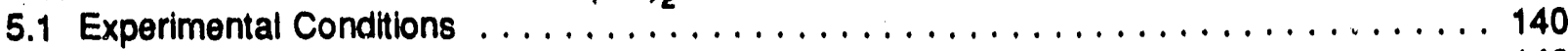

5.2 Results of Slurry Experiments . . . . . . . . . . . . . . . . . . . . 142

5.2.1 Enhancement in Increasing Concentrations of Reagent Grade $\mathrm{Ca}(\mathrm{OH})_{2} \ldots \ldots \ldots 143$

5.2.2 Enhancement in Slurries Made From Mississippi $\mathrm{Ca}(\mathrm{OH})_{2} \ldots \ldots \ldots \ldots \ldots . \ldots 147$ 
TABLE OF CONTENTS (concluded)

Soction

5.2 .3 Enhancement in Three Different Lime Types . . . . . . . . . . . . . . . . . 152

5.3 Validation of Slurry Absorption Model for $\mathrm{Ca}(\mathrm{OH})_{2}$ Slurries $\ldots \ldots \ldots \ldots \ldots \ldots \ldots \ldots 156$

5.3.1 Inputs that Establish Slurry Properties ...................... 156

5.3.2 Enhancement Predicted by Slurry Absorption Model . . . . . . . . . . . . . . 157

5.3.3 Sollds Settling in the Boundary Layer ... . . . . . . . . . . . . . . . . . . . 162

5.4 Summary of Slurry Absorption Experiments $\ldots \ldots \ldots \ldots \ldots \ldots \ldots \ldots \ldots \ldots \ldots$

5.4.1 Effect of Solids Concentration on Enhancement and Gas Film Resistance in the Stirred

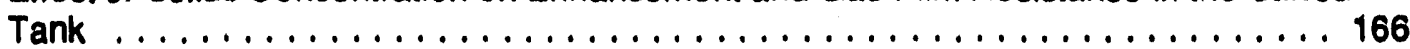

5.4.2 Effect of Solids Concentration on Enhancement and Gas Film Resistance in a Slurry Droplet ...................................... 167

5.4.3 Alternate Interpretation of Slurny Absorption Model Data .............. 175

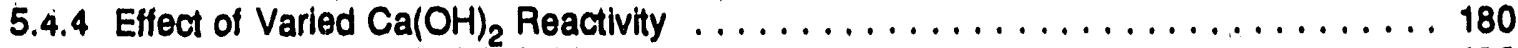

5.4.5 Slurry Absorption Model Validation . . . . . . . . . . . . . . . . . . 182

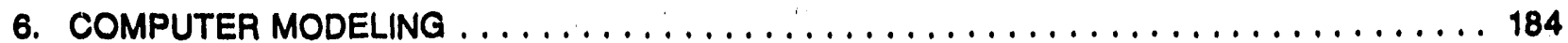

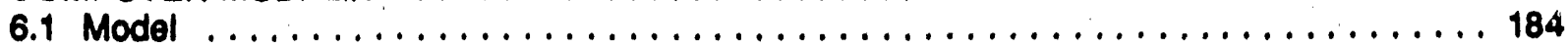

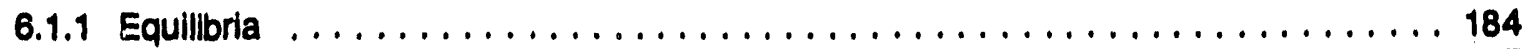

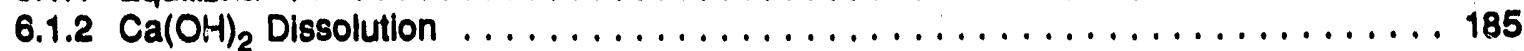

$6.1 .3 \mathrm{CaSO}_{3}$ Crystallization $\ldots \ldots \ldots \ldots \ldots \ldots \ldots \ldots \ldots \ldots \ldots \ldots \ldots \ldots \ldots . \ldots \ldots$

$6.1 .4 \mathrm{SO}_{2}$ Absorption . . . . . . . . . . . . . . . . . . . . . . . . . . 189

6.1.5 Numerical Solution ................................ 192

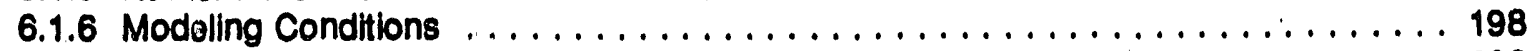

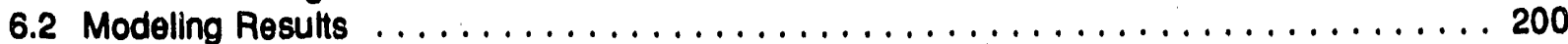

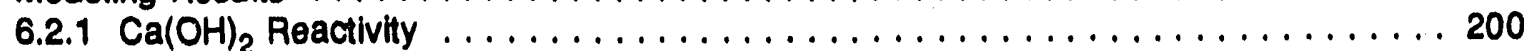

6.2.2 Concentration Profiles Without $\mathrm{Ca}(\mathrm{OH})_{2}(s)$ in the Liquid Bulk . . . . . . . . . . 203

6.2.3 Concentration Profiles With $\mathrm{Ca}(\mathrm{OH})_{2}(\mathrm{~s})$ in the Bulk Liquid . . . . . . . . . . . . 206

6.2.4 Partial Pressure of $\mathrm{SO}_{2}$ at the Gas Liquid Intertace . . . . . . . . . . . . . . . 209

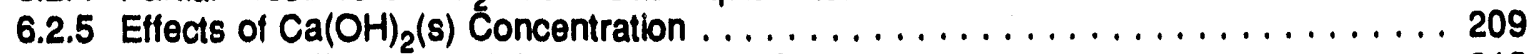

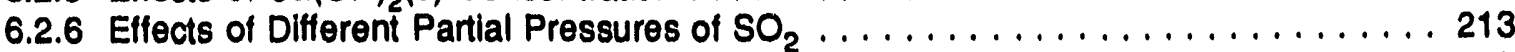

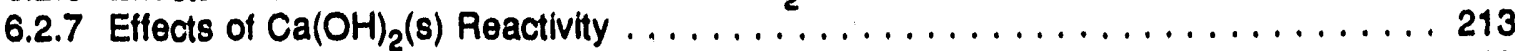

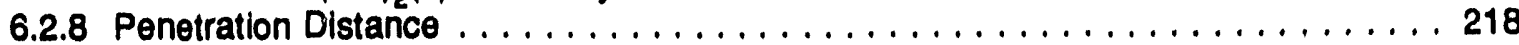

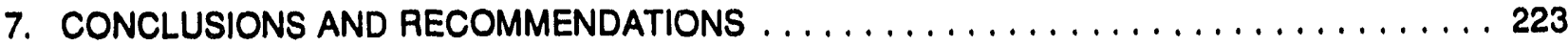

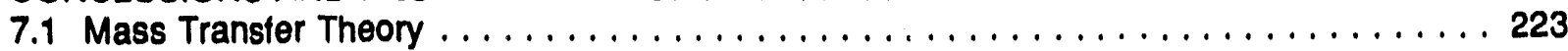

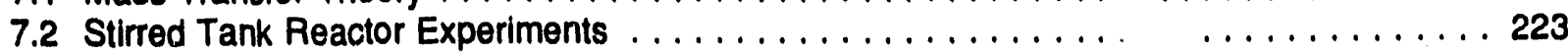

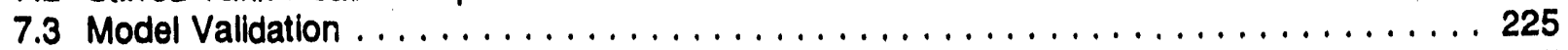

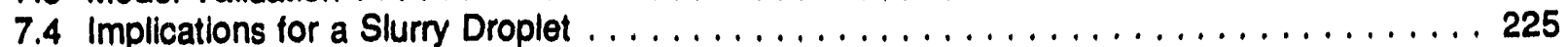

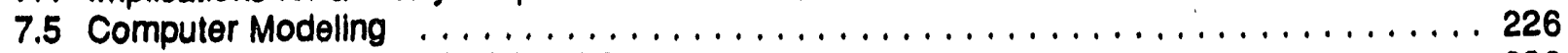

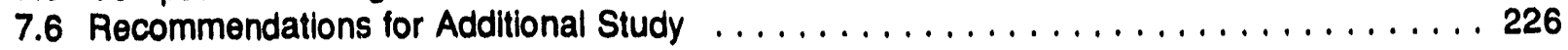

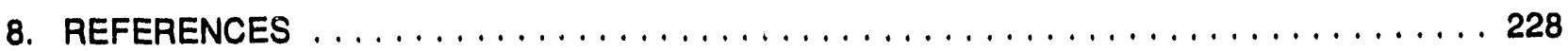




\section{LIST OF FIGURES}

Flqure

Page

E-1. Schematic of the In-duct injection process. . . . . . . . . . . . . . . . . . . . . .

E-2. Stirred tank reactor and supporting equlpment. . . . . . . . . . . . . . . . . . . . . . 10

E-3. Dependence of $\mathrm{k}_{\mathrm{g}}$ on $\mathrm{SO}_{2}$ concentration. . . . . . . . . . . . . . . . . . . . . . . . 12

E-4. Dependence of $k_{g}$ on gas agitation speed at $25^{\circ} \mathrm{C}$ and $55^{\circ} \mathrm{C}$ (2.0-in dlameter propeller). ... 13

E-5. Dependence of $k_{g}$ on gas agitation speed at $25^{\circ} \mathrm{C}$ and $55^{\circ} \mathrm{C}(2.5$-in diameter propeller). . . 14

E-6. Dependence of $\mathrm{k}_{1}^{\mathrm{s}}$ on $\mathrm{SO}_{2}$ concentration at $25{ }^{\circ} \mathrm{C} \ldots \ldots \ldots \ldots \ldots$

E-7. Dependence of $k_{\text {j }}^{0}$ on agitation speed. . . . . . . . . . . . . . . . . . . . . . . . 17

E-8. Enhancement of $\mathrm{SO}_{2}$ absorption in $17 \mathrm{mM} \mathrm{Ca}(\mathrm{OH})_{2} / 0.1 \mathrm{M} \mathrm{CaCl}_{2}$ solution. . . . . . . . . . . . 22.

E-9. Comparison of enhancement of $\mathrm{SO}_{2}$ absomption in $17 \mathrm{mM} \mathrm{Ca}(\mathrm{OH})_{2}$ solutions at various

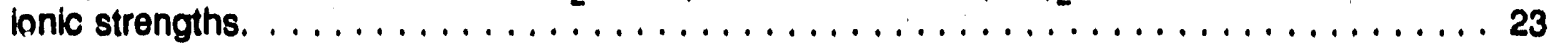

E-10. Comparison of enhancement in Mississippi $\mathrm{Ca}(\mathrm{OH})_{2}$ slurry at higher $\mathrm{Ca}(\mathrm{OH})_{2}$ concentrations. 26

E-11. Comparison of enhancement in slurry from hree different sources of $\mathrm{Ca}(\mathrm{OH})_{2}$ at $0.1 \mathrm{M}$

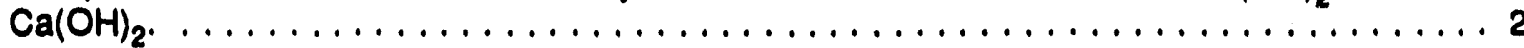

E-12. Effect of particle size on enhancement predicted by slurry absorption model for $0.1 \mathrm{M} \mathrm{Ca(OH})_{2}$ sturry. . . . . . . . . . . . . . . . . . . . . . . . . . . . . . . . . . . . . 29

E-13. Effect of slurry $\mathrm{Ca}(\mathrm{OH})_{2}$ concentration on enhancement predicted by slurry absorption modol for tests performed in the stirred tank (corresponding $d_{d r o p l e t}=800 \mu \mathrm{m}, d_{p}=5-10 \mu m, \theta=0.9$ s). . . . . . . . . . . . . . . . . . . . . . . . . . . . . . . . . . . . . 31

E-14. Effect of slumy $\mathrm{Ca}(\mathrm{OH})_{2}$ concentration on gas film resistance predicted by siurry absorption model for tests performed in the stirred tank (corresponding $d_{d r o p l e t}=800 \mu \mathrm{m}, d_{p}=5-10 \mu \mathrm{m}$,

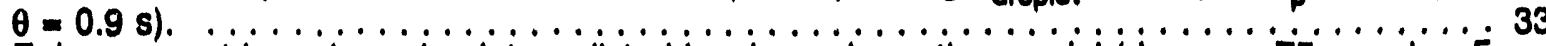

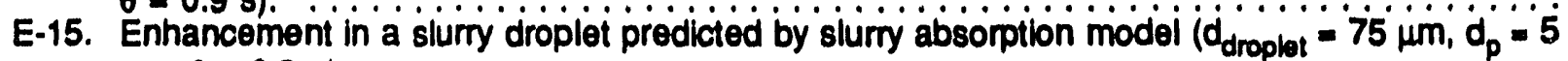

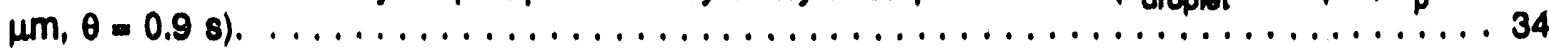

E-16. Effect of $\mathrm{Ca}(\mathrm{OH})_{2}$ concentration in a slurry droplet on enhancement predicted by slumy absomption model $\left(d_{\text {droplot }}=75 \mu \mathrm{m}, d_{0}=5 \mu \mathrm{m}, \theta=0.9 \mathrm{~s}\right) \ldots \ldots \ldots \ldots \ldots \ldots$

E-17. Gas film resistance as a function of $\mathrm{Ca}(\mathrm{OH})_{2}$ utilization: using DI $\Delta[S(\mathrm{IV})]=7.0 \times 10^{-8} \mathrm{~mole} / \mathrm{m} 8$ (equation 5-14).

\section{7} 34

E-18. The gas film resistance versus the contact time. The different curves correspond to different
particle sizes of $\mathrm{Ca}(\mathrm{OH})_{2} .200 \mathrm{~Pa} \mathrm{SO}_{2}, \mathrm{O}$ and $200 \mathrm{molm}^{3} \mathrm{Ca}(\mathrm{OH})_{2}, 100 \mu \mathrm{m}$ droplet, $0.5-5.0$
E-19. The gas film resistance versus the contact time. The different curves correspond to different

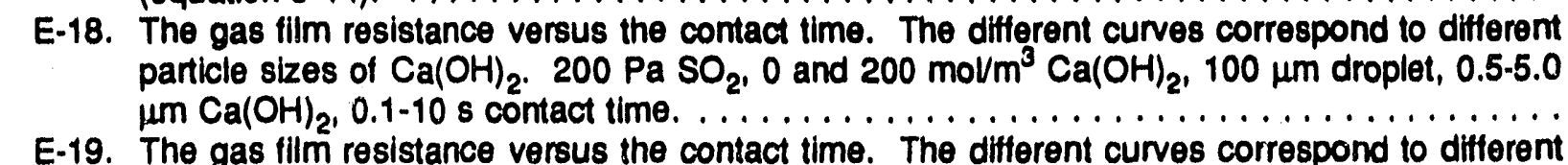

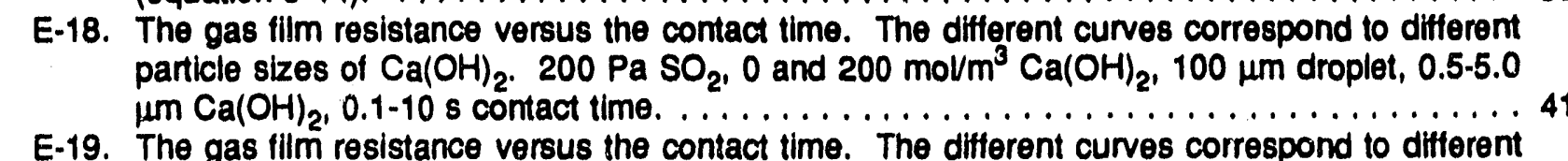
36 particle sizes of $\mathrm{Ca}(\mathrm{OH})_{2} .200 \mathrm{~Pa} \mathrm{SO}_{2}, \mathrm{O}$ and $200 \mathrm{~mol} / \mathrm{m}^{3} \mathrm{Ca}(\mathrm{OH})_{2}, 10 \mu \mathrm{m}$ droplet, 0.5-5.0 $\mu \mathrm{m}$ $\mathrm{Ca}(\mathrm{OH})_{2}, 0.1-10 \mathrm{~s}$ contact time. . . . . . . . . . . . . . . . . . . . . . . . . . . . 42

E-20. Concentrations profiles corresponding to 45 percent gas film resistance. No $\mathrm{Ca}(\mathrm{OH})_{2}(\mathrm{~s})$ in the liquid bulk. $200 \mathrm{~Pa} \mathrm{SO}_{2}, 100 \mu \mathrm{m}$ droplet, 1.68 contact time. . . . . . . . . . . . . . . 43

E-21. Concentration profiles corresponding to a gas film resistance of 45 percent. $\mathrm{No} \mathrm{Ca}(\mathrm{OH})_{2}(8)$ in the liquid bulk. $200 \mathrm{~Pa} \mathrm{SO}, 100 \mu \mathrm{m}$ droplet, $1.6 \mathrm{~s}$ contact time. . . . . . . . . . . . . . . . . 44

E-22. Concentration profiles corresponding to 45 percent gas film resistance with $\mathrm{Ca}(\mathrm{OH})_{2}(\mathrm{~s})$ in the liquid bulk. $200 \mathrm{~Pa} \mathrm{SO}_{2}, 500 \mathrm{~mol} / \mathrm{m}^{3} \mathrm{Ca}(\mathrm{OH})_{2}, 100 \mu \mathrm{m}$ droplet, $2.0 \mu \mathrm{m} \mathrm{Ca}(\mathrm{OH})_{2}, 8.1$ s contact time. 


\section{LIST OF FIGURES (continued)}

E-23. Concentration proflles corresponding to 45 percent gas film resistance with $\mathrm{Ca}(\mathrm{OH})_{2}(8)$ in the liquild bulk. $200 \mathrm{~Pa} \mathrm{SO}_{2}, 500 \mathrm{molm} 3 \mathrm{Ca}(\mathrm{OH})_{2}, 100 \mu \mathrm{m}$ droplet, $2.0 \mu \mathrm{m} \mathrm{Ca}(\mathrm{OH})_{2}, 8.1$ s contact

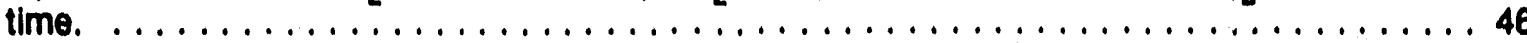

E-24. Gas film resistance versus contact time for different concentrations of $\mathrm{Ca}(\mathrm{OH})_{2}(8) .200 \mathrm{~Pa} \mathrm{SO}_{2}$, $100 \mu \mathrm{m}$ droplet, $5 \mu \mathrm{m} \mathrm{Ca}(\mathrm{OH})_{2} \ldots \ldots \ldots \ldots \ldots \ldots \ldots \ldots \ldots \ldots . \ldots \ldots$

E-25. Gas film resistance versus the ratio between $k_{f}$ and $k_{1}$ for different reactivities of $\mathrm{Ca}(\mathrm{OH})_{2}(8)$. $k_{\mathrm{f}}$ corresponds to a $100 \mu \mathrm{m}$ droplet. $200 \mathrm{~Pa} \mathrm{SO} \mathrm{S}_{2}, 200 \mathrm{moVm} \mathrm{m}^{3} \mathrm{Ca}(\mathrm{OH})_{2}, 100 \mu \mathrm{m}$ droplet, 0.5-5

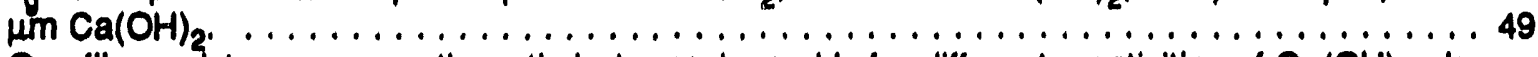

E-26. Gas film resistance versus the ratio between $k_{0}$ and $k_{1}$ for different reactivities of $\mathrm{Ca}(\mathrm{OH})_{2} . k_{g}$ corresponds to a $10 \mu \mathrm{m}$ droplet. $200 \mathrm{~Pa} \mathrm{SO}_{2}, 200 \mathrm{moVm} \mathrm{m}^{3} \mathrm{Ca}(\mathrm{OH})_{2}, 10 \mu \mathrm{m}$ droplet, $0.5-5 \mu \mathrm{m}$

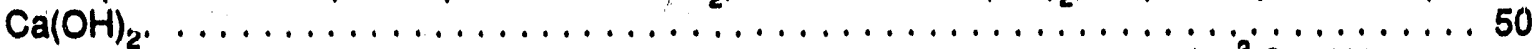

E-27. Gas film resistance versus penetration distance. $200 \mathrm{~Pa} \mathrm{SO}_{2}, 200-1,000 \mathrm{mov}^{3} \mathrm{Ca}_{\mathrm{a}}(\mathrm{OH})_{21} 100$

E-28. Gas film resistance versus penetration distance. $200 \mathrm{~Pa} \mathrm{SO}_{2}, 200-1,000 \mathrm{mov} \mathrm{m}^{3} \mathrm{Ca}(\mathrm{OH})_{2},{ }_{10}{ }^{51}$

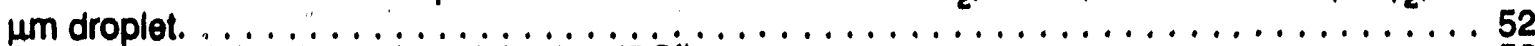

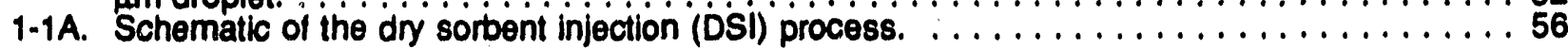

1-1B. Shematic of the duct spray drying (DSD) process $\ldots \ldots \ldots \ldots \ldots \ldots \ldots \ldots \ldots \ldots$

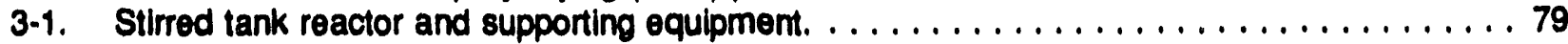

3-2. Propeller designs used in stirred tank reactor. . . . . . . . . . . . . . . . . . 83

3-3. Dependence of $\mathrm{k}_{\mathrm{q}}$ on $\mathrm{SO}_{2}$ concentration. $\ldots \ldots \ldots \ldots \ldots \ldots \ldots \ldots \ldots \ldots \ldots$

3-4. Dependence of $k_{g}$ on gas agitation speed at $25^{\circ} \mathrm{C}$ and $55^{\circ} \mathrm{C}$ (2.0-in diameter propeller). . 91

3.5. Dependence of $k_{0}$ on gas agitation speed at $25^{\circ} \mathrm{C}$ and $55^{\circ} \mathrm{C}$ (2.5-in diameter propeller). . . 94

3-6. Comparison of $k_{0}$ at $55^{\circ} \mathrm{C}$ with two propeller sizes. $\ldots \ldots \ldots \ldots \ldots \ldots \ldots \ldots \ldots \ldots$

3-7. Dependence of $\mathrm{k}^{\circ}$ on $\mathrm{SO}_{2}$ concentration at $25^{\circ} \mathrm{C} \ldots \ldots \ldots \ldots \ldots \ldots \ldots \ldots \ldots$

3-8. Dependence of $k^{\circ}$, on liquid agitation speed at $25^{\circ} \mathrm{C}$ and $55^{\circ} \mathrm{C} \ldots \ldots \ldots \ldots \ldots \ldots \ldots$

3-9. Contact time as a function of liquid agitation sperd. . . . . . . . . . . . . . . . . 101

3-10. Comparison of $k^{\circ}$ measured in several studies as a function of liquid agitation speed. . . . 104

4-1. Enhancement of $\mathrm{SO}_{2}$ absorption in water. $\ldots \ldots \ldots \ldots \ldots \ldots \ldots \ldots \ldots \ldots \ldots \ldots$

4-2. Enhancement of $\mathrm{SO}_{2}$ absomption in $0.1 \mathrm{M} \mathrm{CaCl}_{2}$ solution. $\ldots \ldots \ldots \ldots \ldots \ldots \ldots \ldots 118$

4-3. Enhancement of $\mathrm{SO}_{2}$ absorption in $2.5 \mathrm{mM} \mathrm{Ca}(\mathrm{OH})_{2} / 0.1 \mathrm{M} \mathrm{CaCl}_{2}$ solution. $\ldots \ldots \ldots \ldots .123$

4-4. Enhancement of $\mathrm{SO}_{2}$ absorption in $17 \mathrm{mM} \mathrm{Ca}(\mathrm{OH})_{2} / 0.1 \mathrm{M} \mathrm{CaCl}_{2}$ solution. . . . . . . . . 128

4-5. Effect of low $\mathrm{D}_{\mathrm{OH}}$ - on enhancement of $\mathrm{SO}_{2}$ absorption in $2.5 \mathrm{mM} \mathrm{Ca}(\mathrm{OH})_{2} / 0.1 \mathrm{M} \mathrm{CaCl} \mathrm{Cl}_{2}$ solution. .......................................... 130

4-6. Comparison of enhancement of $\mathrm{SO}_{2}$ absorption in $17 \mathrm{mM} \mathrm{Ca}(\mathrm{OH})_{2}$ solutions at various lonic strengths. ........................................ 133

4-7. Enhancement of $\mathrm{SO}_{2}$ absorption in clear solutions as a function of bulk $\mathrm{SO}_{2}$ concentration (model: $\theta=0.9 \mathrm{~s}$, data: $\theta=0.9-2.5 \mathrm{~s}$ ). . . . . . . . . . . . . . . . . . 135

4-8. Gas film resistance in clear solutions of $\mathrm{Ca}(\mathrm{OH})_{2}$ as a function of bulk $\mathrm{SO}_{2}$ concentration

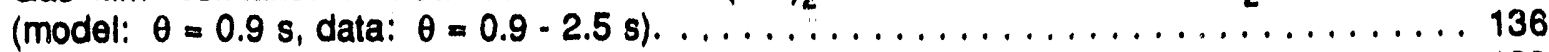

4-9. Gas film resistance in $17 \mathrm{mM} \mathrm{Ca}(\mathrm{OH})_{2}$ as a function contact time. . . . . . . . . . 138

5-1. Comparison of tests performed in reagent grade slurry. . . . . . . . . . . . . . . 146

5-2. Estimated error associated with tests performed in $0.1 \mathrm{M} \mathrm{Ca}(\mathrm{OH})_{2} \mathrm{MCB}$ reagent grade slurry. 148 


\section{LIST OF FIGURES (continued)}

Floure

5-3. Comparison of enhancement in Mississippl hydrate and reagent grade slurry at $0.1 \mathrm{M}$

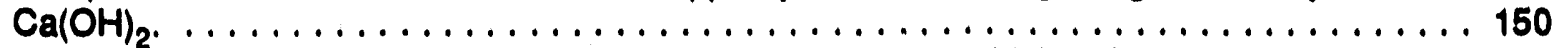

5-4. Comparison of enhancement in Mississippi $\mathrm{Ca}(\mathrm{OH})_{2}$ slurny at higher $\mathrm{Ca}(\mathrm{OH})_{2}$ concentrations. 153

5-5. Comparison of enhancement in slurry from three different sources of $\mathrm{Ca}(\mathrm{OH})_{2}$ at $0.1 \mathrm{M}$

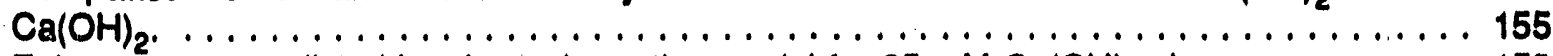

5-6. Enhancement predicted by slurry absorption model for $35 \mathrm{mM} \mathrm{Ca}(\mathrm{OH})_{2}$ slurry. . . . . . . . 158

5-7. Effect of particle size on enhancement predicted by slurry absorption model for $0.1 \mathrm{M} \mathrm{Ca}(\mathrm{OH})_{2}$

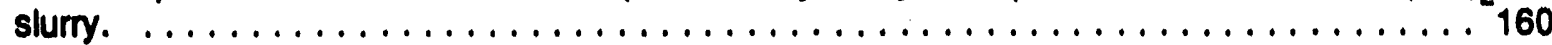

5-8. Enhancement predicted by slurry absorption model for $0.4 \mathrm{M} \mathrm{Ca}(\mathrm{OH})_{2}$ slurry. . . . . . . . . 161

5-9. Effect of slurry $\mathrm{Ca}(\mathrm{OH})_{2}$ concentration on enhancement predicted by slurry absorption model for tests performed in the stirred tank (corresponding $d_{\text {droplet }}=800 \mu \mathrm{m}, d_{p}=5-10 \mu \mathrm{m}, \theta=0.9$ s). .......................................... 167

5-10. Effect of slumy $\mathrm{Ca}(\mathrm{OH})_{2}$ concentration on gas film resistance predicted by slurry absorption model for tests performed in the stirred tank (corresponding $d_{d r o p l e t}=800 \mu \mathrm{m}, d_{p}=5-10 \mu \mathrm{m}$,

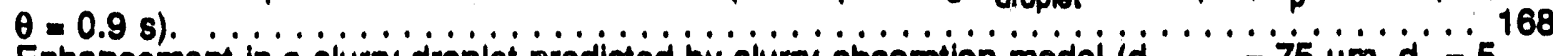

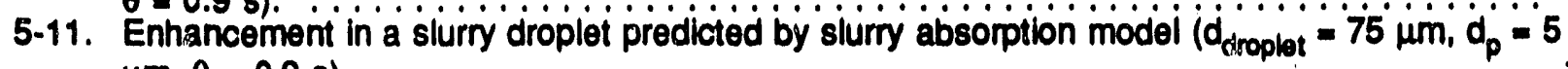

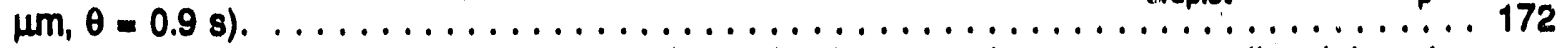

5-12. Effect of $\mathrm{Ca}(\mathrm{OH})_{2}$ concentration in a slumy droplet on enhancement predicted by slurry absorption model $\left(d_{\text {droplet }}=75 \mu \mathrm{m}, d_{p}=5 \mu \mathrm{m}, \theta=0.9 \mathrm{~s}\right) \ldots \ldots \ldots \ldots \ldots \ldots \ldots$

5-13. Eftect of $\mathrm{Ca}(\mathrm{OH})_{2}$ concentration in a slumy droplet on gas film resistance predicted by slurry absorption model $\left(d_{d r o p l e t}=75 \mu \mathrm{m}, d_{p}=5 \mu \mathrm{m}, \theta=0.98\right) \ldots \ldots \ldots \ldots \ldots \ldots \ldots \ldots$

5-14. Spherical droplet with shrinking core of $\mathrm{Ca}(\mathrm{OH})_{2} \ldots \ldots \ldots \ldots \ldots \ldots \ldots \ldots \ldots \ldots$

5-15. Values of $D I \Delta[S(I V)]$ derived from the slumy absorption model. . . . . . . . . . . . . 179

5-16. Gas film resistance as a function of $\mathrm{Ca}(\mathrm{OH})_{2}$ utillzation: using $\mathrm{Di} \Delta \mathrm{\Delta}[\mathrm{S}(\mathrm{IV})]=7.0 \times 10^{-8} \mathrm{~mole} / \mathrm{m} s$

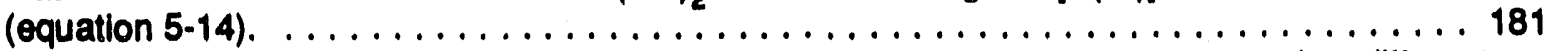

6-1. The gas film resistance versus the contact time. The different curves correspond to different particle sizes of $\mathrm{Ca}(\mathrm{OH})_{2} .200 \mathrm{~Pa} \mathrm{SO} \mathrm{S}_{2}, 0$ and $200 \mathrm{~mol} / \mathrm{m}^{3} \mathrm{Ca}(\mathrm{OH})_{2}, 100 \mu \mathrm{m}$ droplet, $0.5-5.0$ $\mu \mathrm{m} \mathrm{Ca}(\mathrm{OH})_{2}, 0.1-10 \mathrm{~s}$ contact time. . . . . . . . . . . . . . . . . . . . . . . . 201

6-2. The gas film resistance versus the contact time. The different curves correspond to different particle sizes of $\mathrm{Ca}(\mathrm{OH})_{2} .200 \mathrm{~Pa} \mathrm{SO}_{2}, 0$ and $200 \mathrm{~mol} / \mathrm{m}^{3} \mathrm{Ca}(\mathrm{OH})_{2}, 10 \mu \mathrm{m}$ droplet, $0.5-5.0 \mu \mathrm{m}$ $\mathrm{Ca}(\mathrm{OH})_{2}, 0.1-10 \mathrm{~s}$ contact time. . . . . . . . . . . . . . . . . . . . . . . . 202

6-3. Concentrations profiles corresponding to 45 percent gas film resistance. No $\mathrm{Ca}(\mathrm{OH})_{2}$ (s) in the liquid bulk. $200 \mathrm{~Pa} \mathrm{SO} \mathrm{P}_{2}, 100 \mu \mathrm{m}$ droplet, $1.6 \mathrm{sec}$ contact time. . . . . . . . . . . . . 204

6-4. Concentration profiles corresponding to a gas film resistance of 45 percent. $\mathrm{No} \mathrm{Ca}(\mathrm{OH})_{2}(8)$ in the liquid bulk. $200 \mathrm{~Pa} \mathrm{SO}_{2}, 100 \mu \mathrm{m}$ droplet, 1.6 sec contact time. . . . . . . . . . . . . 205

6-5. Concentration profiles corresponding to 45 percent gas film resisiance with $\mathrm{Ca}(\mathrm{OH})_{2}$ (s) in the liquid bulk. $200 \mathrm{~Pa} \mathrm{SO}_{2}, 500 \mathrm{~mol} / \mathrm{m}^{3} \mathrm{Ca}(\mathrm{OH})_{2}, 100 \mu \mathrm{m}$ droplet, $2.0 \mu \mathrm{m} \mathrm{Ca}(\mathrm{OH})_{2}, 8.1 \mathrm{sec}$ contact time. . . . . . . . . . . . . . . . . . . . . . . . . . . . . . . 207

6-6. Concentration profiles corresponding to 45 percent gas film resistance with $\mathrm{Ca}(\mathrm{OH})_{2}(8)$ in the liquid bulk. $200 \mathrm{~Pa} \mathrm{SO}, 500 \mathrm{moVm} \mathrm{m}^{3} \mathrm{Ca}(\mathrm{OH})_{2}, 100 \mu \mathrm{m}$ droplet, $2.0 \mu \mathrm{m} \mathrm{Ca}(\mathrm{OH})_{2}, 8.1 \mathrm{sec}$ contact time. 


\section{LIST OF FIGURES (concluded)}

Fiqure

6-7. Concentration profiles of $\mathrm{Ca}(\mathrm{OH})_{2}$ (s). $200 \mathrm{~Pa} \mathrm{SO}_{2}, 500 \mathrm{~mol} / \mathrm{m}^{3} \mathrm{Ca}(\mathrm{OH})_{2}, 100 \mu \mathrm{m}$ droplet, 2

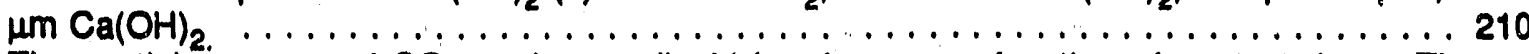

6-8. The partial pressure of $\mathrm{SO}_{2}$ at the gas-liquid interface as a function of contact time. The numbers are corresponding penetration depths. $200 \mathrm{~Pa} \mathrm{SO}_{2}, 500 \mathrm{~m}$ (ol/ $\mathrm{m}^{3} \mathrm{Ca}(\mathrm{OH})_{2}, 100 \mu \mathrm{m}$

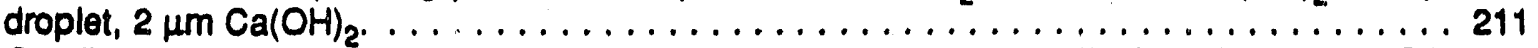

6-9. Gas film resistance versus contact time for different concentrations of $\mathrm{Ca}(\mathrm{OH})_{2}(8) .200 \mathrm{~Pa} \mathrm{SO} \mathrm{S}_{2}$

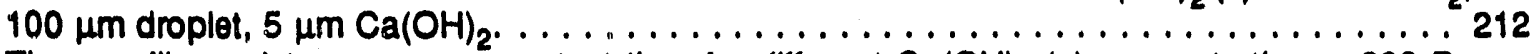

ö-10. The gas film resistance versus contact time for different $\mathrm{Ca}(\mathrm{OH})_{2}$ (s) concentrations. $200 \mathrm{~Pa}$ $\mathrm{SO}_{2}, 0-1,000 \mathrm{~mol} / \mathrm{m}^{3} \mathrm{Ca}(\mathrm{OH})_{2}, 100 \mu \mathrm{m}$ droplet, $2 \mu \mathrm{m} \mathrm{Ca}(\mathrm{OH})_{2}, 0.1-10$ sec contact time. . 214

6-11. The gas film resistance versus contact time for different partial pressures of $\mathrm{SO}_{2} .50-500 \mathrm{~Pa}$ $\mathrm{SO}_{2}, 500 \mathrm{mov} / \mathrm{m} \mathrm{Ca}(\mathrm{OH})_{2}, 100 \mu \mathrm{m}$ droplet, $2 \mu \mathrm{m} \mathrm{Ca}(\mathrm{OH})_{2} . \ldots \ldots \ldots \ldots \ldots \ldots . \ldots \ldots$

6-12. Gas film resistance versus the ratio between $k_{\mathrm{g}}$ and $\mathrm{k}_{1}$ for diffirent reactivitios of $\mathrm{Ca}(\mathrm{OH})_{2}$ (s). $\mathrm{k}_{\mathrm{g}}$ corresponds to a $100 \mu \mathrm{m}$ droplet. $200 \mathrm{~Pa} \mathrm{SO}, 200 \mathrm{rnolm}^{3} \mathrm{Ca}(\mathrm{OH})_{2}, 100 \mu \mathrm{m}$ droplet, $0.5-5$

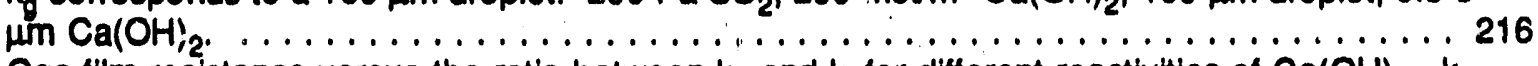

6-13. Gas film resistance versus the ratio between $k_{0}$ and $k_{4}$ for different reactivities of $\mathrm{Ca}(\mathrm{OH})_{2} . \mathrm{k}_{\mathrm{g}}$ corresponds to a $10 \mu \mathrm{m}$ droplet. $200 \mathrm{~Pa} \mathrm{SO}_{2}, 200 \mathrm{movm}^{3} \mathrm{Ca}(\mathrm{OH})_{2}, 10 \mu \mathrm{m}$ droplet, 0.5-5 $\mu \mathrm{m}$

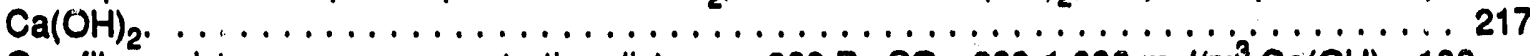

6-14. Gas film resistance versus penetration distance, $200 \mathrm{~Pa} \mathrm{SO}_{2}, 200-1,000 \mathrm{molm} \mathrm{m}^{3} \mathrm{Ca}(\mathrm{OH})_{2}, 100$

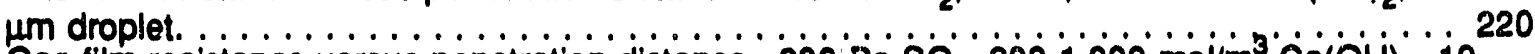

6-15. Gas film resistance versus penetration distance. $200 \mathrm{~Pa} \mathrm{so}_{2}, 200-1,000 \mathrm{mov}^{3} \mathrm{Ca}\left(\mathrm{OH}_{1}\right)_{2}{ }_{10}{ }_{10}$ $\mu \mathrm{m}$ droplet. . . . . . . . . . . . . . . . . . . . . . . . . . . . . . . 221

6-16. Gas film resistance versus penetration distance for difterent partial pressures of $\mathrm{SO}_{2} .50-500$ $\mathrm{Pa} \mathrm{SO}, 200-1,000 \mathrm{~mol} / \mathrm{m}^{3} \mathrm{Ca}(\mathrm{OH})_{2}, 10 \mu \mathrm{m}$ droplet, $0.5-5 \mu \mathrm{m} \mathrm{Ca}(\mathrm{OH})_{2} . \ldots \ldots \ldots . . .222$ 


\section{LIST OF TABLES}

$\underline{T a b l e}$

Page

E-1. Input Variables for the Slurry Absorption Model Used in Clear Solution Tests . . . . . . . . . 8

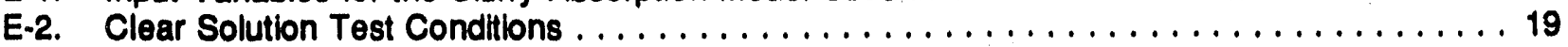

2-1. Input Variables for the Slurry Absorption Model Used in Clear Solution Tests . . . . . . . . . 74

2-2. Estimate Dlffusivities of Important Species Used by the Slurry Absorption Model $\left(\mathrm{cm}^{2} / \mathrm{s} \times\right.$

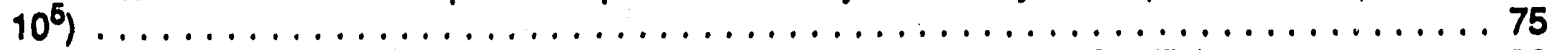

3-1. Comparison of Experimentally Determined Gas Film Mass Transfer Coefficients . . . . . . . . . 96

3-2. Comparison of Experimentally Determined Liquid Film Mase Transfer Coefficisnts . . . . . . 103

4-1. Clear Solution Test Conditions . . . . . . . . . . . . . . . . . . . . . . . . . . 108

4-2. Enhancement of $\mathrm{SO}_{2}$ Absorption in Water at Various Liquid Agitation Speeds $\left(\mathrm{K}_{\mathrm{g}}=1.51 \times 10^{-5}\right.$

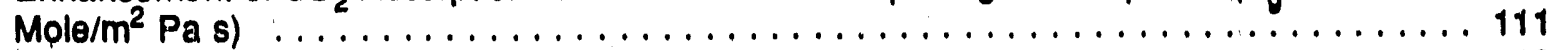

4.3. Conditions for Slurry ABsorption Model for Absorption of $\mathrm{SO}_{2}$ in Water . . . . . . . . . . 112

4-4. Enhancement of $\mathrm{SO}_{2}$ Absorption in $0.1 \mathrm{M} \mathrm{CaCl}_{2}$ at Various Liquid Agitation Speeds . . . . . . 115

4-5. Enhancement of $\mathrm{SO}_{2}$ Absorption in $0.1 \mathrm{M} \mathrm{CaCl}_{2}$ at Various $\mathrm{SO}_{2}$ Concentrations $\ldots \ldots \ldots 115$

4-6. Conditions for Slurry Absorption Model for Absorption of $\mathrm{SO}_{2}$ in $0.1 \mathrm{M} \mathrm{CaCl}_{2} \ldots \ldots \ldots \ldots 117$

4-7. Presence of Abscrbed Sulfur Species in $0.1 \mathrm{M} \mathrm{CaCl} 2$ Solutions at Various $\mathrm{SO}_{2}$

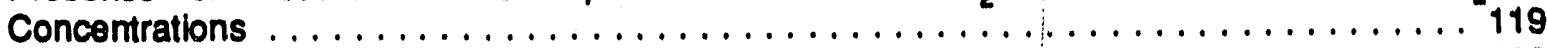

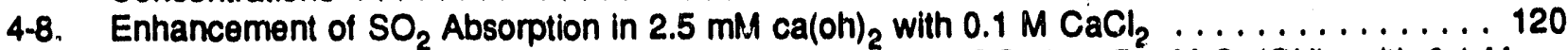

4-9. Conditions for Slurny Absorption Model for Absorption of $\mathrm{SO}_{2}$ in 2.5 inivi $\mathrm{Ca}(\mathrm{OH})_{2}$ with $0.1 \mathrm{M}$

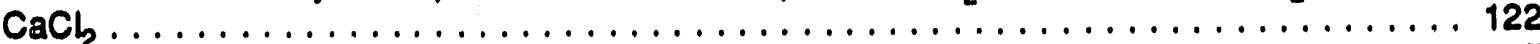

4-10. Enhancement of $\mathrm{SO}_{2}$ Absorption in $17 \mathrm{mM} \mathrm{Ca}(\mathrm{OH})_{2}$ with $0.1 \mathrm{M} \mathrm{CaCl}_{2} \ldots \ldots \ldots \ldots \ldots \ldots 125$

4-11. Condtions for Slurry Absorption Model for Absorption of $\mathrm{SO}_{2}$ in $17 \mathrm{mM} \mathrm{Ca}(\mathrm{OH})_{2}$ with $0.1 \mathrm{M}$

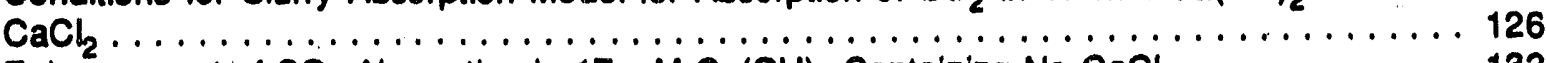

4-12. Enhancement of $\mathrm{SO}_{2}$ Absorption in $17 \mathrm{mM} \mathrm{Ca}(\mathrm{OH})_{2}$ Containing $\mathrm{No} \mathrm{CaCl}_{2} \ldots \ldots \ldots \ldots$

4-13. Enhancement of $\mathrm{SO}_{2}$ Absorption in $17 \mathrm{mM} \mathrm{Ca}(\mathrm{OH})_{2}$ Containing $0.1 \mathrm{M} \mathrm{NaCl} \ldots \ldots \ldots 132$

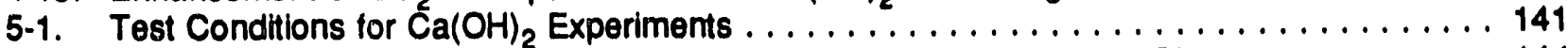

5-2. Results of Tests Performed in $35 \mathrm{mM} \mathrm{Ca(OH})_{2}$ MCB Reagent Grade Slurry . . . . . . . . . . 144

5-3. Results of Tests Pertormed in $0.1 \mathrm{M} \mathrm{Ca}(\mathrm{OH})_{2} \mathrm{MCB}$ Reagent Grade Slurry . . . . . . . . . 145

5-4. Results of Tests Performed in $0.1 \mathrm{M} \mathrm{Ca}(\mathrm{OH})_{2}$ Mississippi $\mathrm{Ca}(\mathrm{OH})_{2}$ Slurry $\ldots \ldots \ldots \ldots \ldots 149$

5-5. Results of Tests Performed in $0.4 \mathrm{M} \mathrm{Ca}(\mathrm{OH})_{2}$ Mississippi $\mathrm{Ca}(\mathrm{OH})_{2}$ Slurry . . . . . . . . 151

5-6. Results of Tests Pertormed in $0.1 \mathrm{M} \mathrm{Ca}(\mathrm{OH})_{2}$ Mississippi Slaked Lime Slurry . . . . . . . . . 154

5-7. Predicted Gas Film Resistance in $1.0 \mathrm{M} \mathrm{Ca}(\mathrm{OH})_{2}$ Slurry at Various $\mathrm{SO}_{2}$ Concentrations ... 162

5-8. Penetration Distances and Maximum Settling Velocities Predicted by the Slurry Absorption

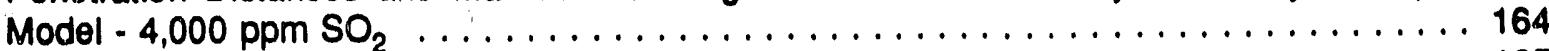

5-9. Measured Settling Velocities of Three Slumy Types $\ldots \ldots \ldots \ldots \ldots \ldots \ldots \ldots \ldots \ldots$

6-1. Typical Bulk Solution Composition and Activity Coetficients . . . . . . . . . . . . . . . 199

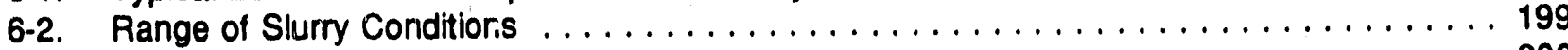

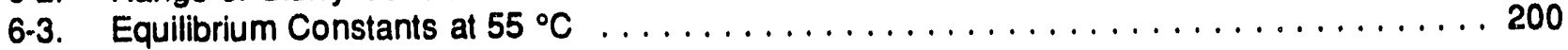




\section{EXECUTIVE SUMMARY}

\section{E.1 INTRODUCTION}

Emission control technologies for power plants fall into three categories, deperiding on where they are applied: before, during or after combustion. Post-combustion, flue gas desulfurization (FGD) processes using calcium-based sorbents have gained interest as promising techniques. Such processes applied to older power plants must be inexpensive and must be atre to retrofit the existing power plant equipment. The DOE-PETC has initiated a comprehensive effort aimed at developirig in-duct injection technology to a point of commersial readiness for wae by power -'lants requiring $\mathrm{SO}_{2}$ control in the near future.

A schematic of a typical in-duct injection process is shown in Figure E-1. Sorbent, typically calcium hydroxide $\left[\mathrm{Ca}(\mathrm{OH})_{2}\right]$, is injected into flue gas which is typically at $130-180^{\circ} \mathrm{C}$ downstream of the air preheater and upstream of the particulate collection device. The dry, reacted sorbent is collected in the existing particulate collector, commonly an electrostatic precipitator, and forms a non-hazardous, dry solid waste product. Since water is required for the reaction of $\mathrm{SO}_{2}$ and sorbent, the flue gas must either be humidified [dry sorbent injection (DSI)], or the sorbent must be mixed with water and injected as a slurry [duct spray drying (DSD)]. In either case, the water that is injected reduces the temperature to about $50-70^{\circ} \mathrm{C}$.

While this in-duct injection technology may be simple to apply and has low capital costs compared to commercially-available wet scrubbing processes, the economics of this process can be improved substantially by enhancing sorbent utilization. The in-duct injection process, although simple 


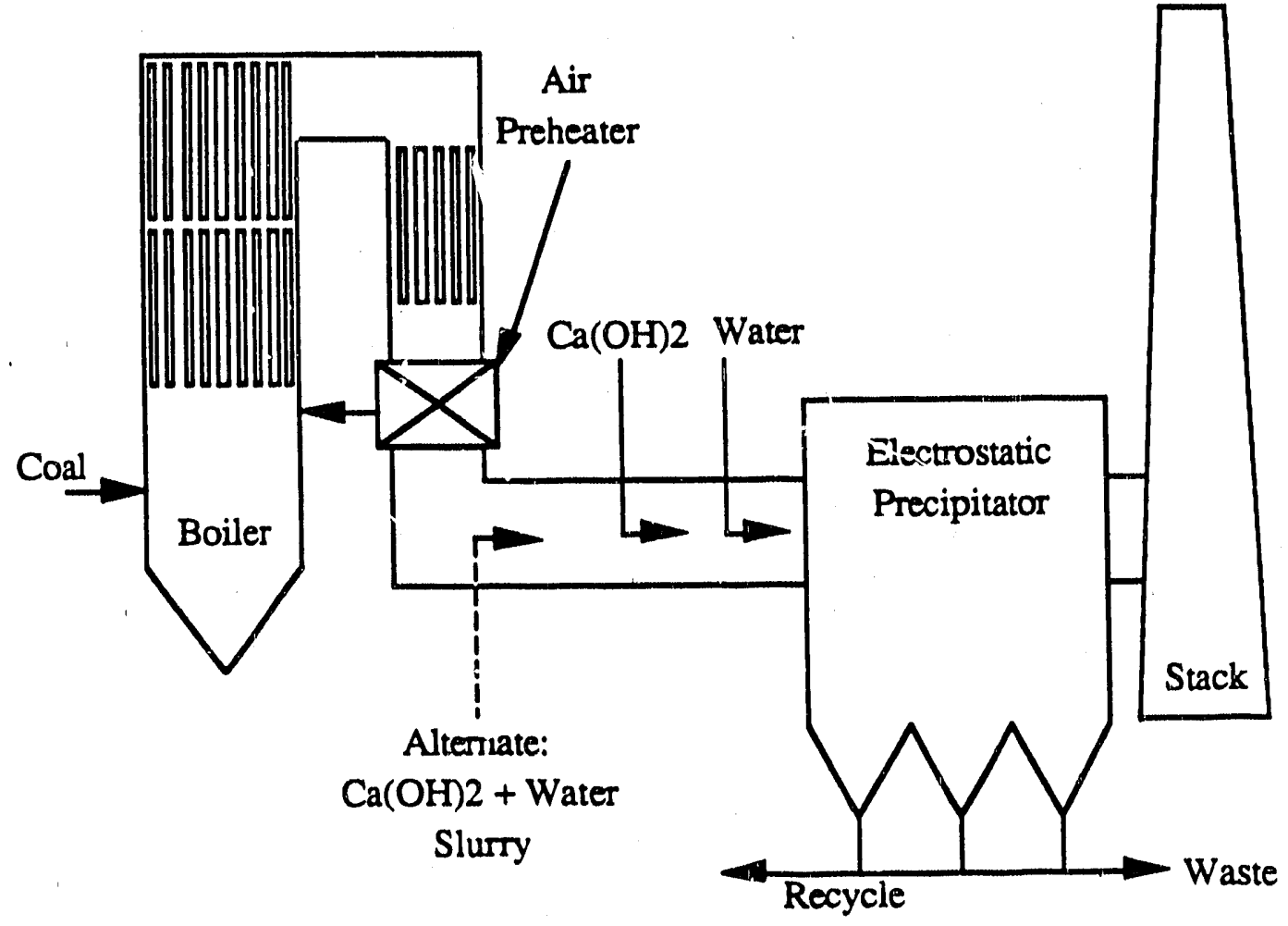

Figure E-1. Schematic of the in-duct injection process. 
In concept, is a very complicaled process to describe fully in a theoretical sense, and additional study will be necessary to produce a comprehensive model of this process.

The general fhysical or "global" mechanisms are important for predicting the $\mathrm{SO}_{2}$ removal potential of DSD. However, these mechanisms are not the focus of this research. Equally important for prediction of $\mathrm{SO}_{2}$ absorption in these processes is understanding and modeling the absorption of $\mathrm{SO}_{2}$ into a single droplet in the absence of the more complicated global effects. Once the basic mass transfer principles which control $\mathrm{SO}_{2}$ absorption and reaction are understood and described, these principles can serve as a basis upon which to couple the theory describing the global mechanisms. This study focuses on describing $\mathrm{SO}_{2}$ absorption into a single droplet in order to learn more about how the absorption might be enhanced. The experimental work pertormed in the stirred tank reactor was intended to simulate absurption of $\varepsilon 7_{2}$ into a slurry droplet.

Also, a computer model of $\mathrm{SO}_{2}$ absorption into $\mathrm{Ca}(\mathrm{OH})_{2}$ slurries based on mass transfer theories and engineering principles was developed as part of this project. This computer program will be used to predict the relative contribution of gas and liquid mass transfer, solid dissolution, and otner chemical processes which control $\mathrm{SO}_{2}$ absorption into a slurry droplet under a variety of conditions. The experimental work supports this effori by providing measurements of the absorption of $\mathrm{SO}_{2}$ which are used to validate the model.

Three theories have prevailed which describe the type of mass transfer associated with $\mathrm{SO}_{2}$ absomption into liquid solutions. The oldest and simplest, which serves as a basis for most masstransfer theories, is the film theory. In this theory, a concentration gradient is assumed from the interface to the bulk solution over a thin film. In the penetration theory, mass transfer is determined by how much contact time a fluid element spends at the gas/liquid interface. Another theory for description of gas absorption is the surface-renewal theory, which is a generalized version of the penetration theory. This theory is used to predict the mass transfer that governs $\mathrm{SO}_{2}$ absorption in the stirred tank. Results of some studies which described and measured gas absorption in slurries and alkaline solutions are presented in this report and compared to the measured absorption in the stirred 
tank. Most of the current models of $\mathrm{SO}_{2}$ absorption in slurry droplets have not treated the absorption and reaction of $\mathrm{SO}_{\mathrm{c}}$ in a rigorous fashion. Some begin with the assumption that the absorption is controlled by gas film resistance and do not fully address the liquid film resistances based on the complex chemical reactions, or on the dissolution of $\mathrm{Ca}(\mathrm{OH})_{2}$. Some allow only a monosized droplet distribution, although other models have shown the importance of accounting for the size distribution of droplets in a typical spray. There are considerable differences in the conclusions reached as a result of these modeling efforts. Those that attempt to describe the complex global mechanisms of the absorption in detall typically simplify the calculation of absorption and reaction of $\mathrm{SO}_{2}$ by making assumptions that may not be sufficient. The objective of this program was to conduct measurements intended to discover mass transfer processes that limit the absorption and investigate other chemical and physical processes that might affect absorption of $\mathrm{SO}_{2}$ as well as the role of sorbent reactivity. The experimental data was used to validate the slumy absorption model that was developed in parallel to the experimental work.

\section{E.2 THEORY OF $\mathrm{SO}_{2}$ ABSORPTION IN Ca(OH $)_{2}$ SLURRIES}

The reaction of $\mathrm{SO}_{2}$ with alkaline species occurs in the dissolved or aqueous state. Therefore a number of experirnents were designed to measure and describe absorption into the aqueous ciear solution.

The absorption and reaction of $\mathrm{SO}_{2}$ becomes more complicated in the presence of an excess of solids. In a $\mathrm{Ca}(\mathrm{OH})_{2}$ slurry, there is an aqueous solution saturated with $\mathrm{Ca}(\mathrm{OH})_{2}$ and containing the remaining excess solids. Reaction with $\mathrm{SO}_{2}$ consumes dissolved $\mathrm{Ca}(\mathrm{OH})_{2}$, which must be replenished. The dissolution rate of $\mathrm{Ca}(\mathrm{OH})_{2}$ is fast but may not be fast enough to maintain a completely saturated bulk solution. Another factor that may be imiportant in influencing the absorption rate of $\mathrm{SO}_{2}$ into slurries is the rate at which $\mathrm{CaSO}_{3}$ crystallizes. As the slurry absorbs and reacts with $\mathrm{SO}_{2}$, the amount of $\mathrm{CaSO}_{3}$ increases in solution and eventually precipitates when the point of saturation is achieved. Enhancement from crystallized $\mathrm{CaSO}_{3}$ is much less than the enhancement from $\mathrm{CaSO}_{3}$ in solution. 
The crystallization of $\mathrm{CaSO}_{3}$ and how it affects $\mathrm{SO}_{2}$ absorption must therefore also be considered in absorption modeling.

A model was developed to predict the absolption of $\mathrm{SO}_{2}$ into $\mathrm{Ca}(\mathrm{OH})_{2}$ slurries with all of these factors considered. The model combines equations to describe the absorption and reaction of $\mathrm{SO}_{2}$, the dissolution rate of $\mathrm{Ca}(\mathrm{OH})_{2}$ solids, and the crystallization rate of $\mathrm{CaSO}_{3}$. Experimental results were used to validate the model.

\section{E.2.1 Basic Mass Transfer Principles}

The absorption of $\mathrm{SO}_{2}$ proceeds in two steps. First, $\mathrm{SO}_{2}$ in the gas phase must diffuse from the bulk gas mixture to the interface. Next, it must diffuse from the interface into the liquid. At the interface, the flux of $\mathrm{SO}_{2}$ from the gas must equal the flux of $\mathrm{SO}_{2}$ into the liquid. A key objective of this research is to determine the degree to which the gas phase and liquid phase driving forces are limiting or controlling the absorption. The absorption is frequently referred to as "gas film controlled" or "liquid film controlled" for this reason. As aqueous $\mathrm{SO}_{2}$ is reacted, the absorption of $\mathrm{SO}_{2}$ is enhanced by reducing the mass transfer resistance and increasing the driving force for absorption. The degree to which liquid phase mass transfer is enhanced is quantified in terms of the enhancement factor. The enhancement factor is the ratio of the measured absorption rate with reaction to the expected absorption rate without reaction.

The percent of gas film resistance reflects the degree to which gas film mass transfer dominates the absorption of $\mathrm{SO}_{2}$. When gas film mass transfer dominates the absorption, changes to the liquid phase composition cannot enhance mass transfer further. The transfer of $\mathrm{SO}_{2}$ from the bulk gas phase to the surface of the liquid is the limiting or controlling mechanism. As gas film resistance approaches 100 percent, the interface concentration of $\mathrm{SO}_{2}$ is insignificant. In other words, the liquid phase is so reactive toward $\mathrm{SO}_{2}$ that as soon as the $\mathrm{SO}_{2}$ is absorbed, it reacts immediately.

Ultimately, this would be the most desirable condition because the absorption rate is maximized. The research focuses on determining conditions where the mass transfer is not gas film controlled so that 
enhancement of absorption under these conditions might be improved by altering liquid phase characteristics.

\section{E.2.2 Enhancement Predicted by Surface Renewal Theory}

Predicting the absorption rate of $\mathrm{SO}_{2}$ is complicated by the fact that the absorption is an unsteady state process. Therefore a series of unsteady state material and charge balances must be solved to determine the concentration of constituents that influence absorption. Solutions are calculated besed on assumed boundary conditioris. Boundary conditions are developed from one of a number of theories which have been proposed to describe mass transfer across a fluid surface.

A review of proposed mass transfer models for absorption in stirred tanks found that the surface renewal theories could be approximated closely by solving the simpler film theory and replacing the species diffusivities by their square roots. The surface renewal theory solution or $\mathrm{SO}_{2}$ absorption in water assumes, first, that $\mathrm{H}_{2} \mathrm{O}$ is not included in the species balance, and, second, that the bisulfite and hydrogen lons diffuse at the same rate. Thus, the approximate solution takes the form:

$$
\varnothing=1+\frac{\sqrt{D_{H O_{3}^{-}}}}{\sqrt{D_{\mathrm{SO}_{2}}}} \frac{\sqrt{K_{c} / 4}}{\sqrt{\left[\mathrm{SO}_{2}\right]_{i}}-\sqrt{\left[\mathrm{SO}_{2}\right]_{0}}}
$$

This relationship shows a linear dependence of $\varnothing$ on $1 / \sqrt{\left[\mathrm{SO}_{2}\right]_{1}}$ when $\left[\mathrm{SO}_{2}\right]_{0}$ can be neglected. In a solution of pure water, $\mathrm{HSO}_{3}{ }^{-}$formed by absorption and reaction of $\mathrm{SO}_{2}$ must diffuse af the same rate as the $\mathrm{H}^{+}$ions that are formed by the reaction. This effect is referred to as ion-pairing.

For $\mathrm{SO}_{2}$ absorption into a solution containing $\mathrm{CaCl}_{2}$, the bisulfite and hydrogen ions diffuse independently. Thus, the approximate solution gives this relationship:

$$
\varnothing=1+\frac{\sqrt{D_{H_{S O}^{-}}}}{\sqrt{D_{S O_{2}}}} \frac{\left[\mathrm{HSO}_{3}^{-}\right]_{i}-\left[\mathrm{HSO}_{3}^{-}\right]_{0}}{\left[\mathrm{SO}_{2}\right]_{i}-\left[\mathrm{SO}_{2}\right]_{0}}
$$


The bulk concentrations of aqueous $\mathrm{SO}_{2}$ and bisulfite can be neglected in most cases. The interfacial bisulfite concentration is determined from the equilibrium relationship. The hydrogen lon concentration is determ ned by material and charge balances at the intertace. Because $\left[\mathrm{HSO}_{3}{ }^{-}\right]_{1}$ depends on the

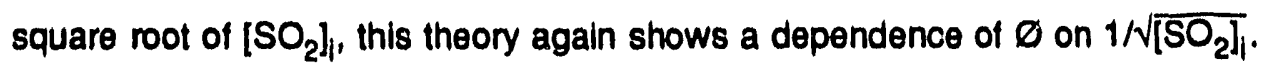

The surface renewal theory was also applied to absorption in solutions containing dissolved $\mathrm{Ca}(\mathrm{OH})_{2}$. Formation of sulfite is significant in $\mathrm{Ca}(\mathrm{OH})_{2}$ solutions. Therefore, the enhancement in $\mathrm{Ca}(\mathrm{OH})_{2}$ solutions can be expressed by the following relationship:

$$
\begin{aligned}
\varnothing=1 & +\frac{\sqrt{D_{\mathrm{HSO}_{3}^{-}}}}{\sqrt{D_{\mathrm{SO}_{2}}}}\left(\frac{\left[\mathrm{HSO}_{3}^{-}\right]_{i}-\left[\mathrm{HSO}_{3}^{-}\right]_{0}}{\left[\mathrm{SO}_{2}\right]_{i}-\left[\mathrm{SO}_{2}\right]_{0}}\right) \\
& +\frac{\sqrt{\left.D_{\mathrm{SO}_{3}^{2-}}\right]_{l}}}{\sqrt{D_{\mathrm{SO}_{2}}}}\left(\frac{\left[\mathrm{SO}_{3}^{2-}\right]_{l}-\left[\mathrm{SO}_{3}^{2-}\right]_{0}}{\left[\mathrm{SO}_{2}\right]_{i}-\left[\mathrm{SO}_{2}\right]_{0}}\right)
\end{aligned}
$$

The alkaline solution reacts with aqueous $\mathrm{SO}_{2}$ very quickly. In all solutions containing $\mathrm{Ca}(\mathrm{OH})_{2}$ that were tested, $\left[\mathrm{SO}_{2}\right]_{0}$ and $\left[\mathrm{HSO}_{3}{ }^{-}\right]_{0}$ were found to be insignificant. The interfacial concentrations of sulfite and bisulfite are not known but are related to $\left[\mathrm{H}^{+}\right]_{i}$ and $\left[\mathrm{SO}_{2}\right]_{i}$ by the equilibrium relations. When the appropriate bulk concentrations are neglected and the two equilibrium expressions are applied to equation (E-3), the equation for the enhancement factor becomes:

$$
\varnothing=\frac{\sqrt{D_{\mathrm{HSO}_{3}^{-}}}}{\sqrt{D_{\mathrm{SO}_{2}}}} \frac{K_{c 1}}{\left[H^{+}\right]_{i}}+\frac{\sqrt{D_{\mathrm{SO}_{3}^{2-}}}}{\sqrt{D_{\mathrm{SO}_{2}}}}\left(\frac{K_{c 1} K_{c 2}}{\left[H^{+}\right]_{i}^{2}}+\left[\mathrm{SO}_{3}^{2-}\right]_{0}\right)
$$

\section{E.2.3 Slurry Absorption Model}

The slury absorption model was developed as part of this research. Experimerits pertormed for this research are intended to verify the model and draw attention to factors which affect $\mathrm{SO}_{2}$ absorption in $\mathrm{Ca}(\mathrm{OH})_{2}$ solutions and slurries. The slurry absorption model consists of three parts. The 
first part simulates absorption of $\mathrm{SO}_{2}$ into the solution, which is enhanced by chemical reaction. The second part includes dissolution of $\mathrm{Ca}(\mathrm{OH})_{2}$ solids in the solution. The third part consists of $\mathrm{CaSO}_{3}$ crystallization calculated from a rate expression developed experimentally. The model has been run successfully to simulate the clear solution experiments performed in the stirred tank reactor to verify the first part of the model. The model was also nun for conditions which simulate the experiments performed in slurry solutions to verity the second part of the model. No experiments were run specifically to verify the third part of the model.

The model uses the penetration theory to develop the boundary conditions necessary to solve the unsteady state differential mass balance equations for the absorption of $\mathrm{SO}_{2}$. The unsteady state material balances are included for total S(IV) species, calcium species, and chloride. A charge balance at the interface is made by adjusting the level of chloride in the solution. Also, the fluxes of calcium and chloride are set equal to zero at the interface. The unsteady state material balance for calcium requires that the rate of dissolution of $\mathrm{Ca}(\mathrm{OH})_{2}$ be known. The dissolution rate of $\mathrm{Ca}(\mathrm{OH})_{2}$ varies with time and distance from the interface. The operating conditions and solution compositions used in the stirred tank experiments had to be specifled as inputs to the model. Table E-1 lists the input variables for the clear solution experiments.

Model runs for various solution composition were performed with the bulk gas phase $\mathrm{SO}_{2}$ concentration, $\mathrm{PSO}_{\mathrm{SO}}$ set at $500,1,000,2,000,3,000,4,000$, and 5,000 ppm. The pH and ion concentrations were set to values which represented the liquid phase at steady state in the stirred tank reactor. The model provides several forms of output. Since the absorption rate is generally a function of the contact time, the model lists the output for ten periods of time over a specified range of time. The model calculates an average absorption rate.

TABLE E-1. INPUT VARIABLES FOR THE SLURFIY ABSORPTION MODEL. USED IN CLEAR SOLUTION TESTS

\begin{tabular}{|l|c|}
\hline Operating Conditions & $\mathrm{PsO}_{2}, \mathrm{~K}_{\mathrm{g}}$ contact time, temperature, $\mathrm{pH}$ \\
\hline Solution Composition & $\mathrm{Cs}^{2+}, \mathrm{Mg}^{2+}, \mathrm{ila}^{+}, \mathrm{K}^{+}, \mathrm{SO}_{3}{ }^{2-}, \mathrm{SO}_{4}{ }^{2-}, \mathrm{CO}_{3}{ }^{2-}, \mathrm{Cl}^{-}, \mathrm{H}_{2} \mathrm{O}$ \\
\hline
\end{tabular}




\section{E.3 EXPERIMENTAL}

The reactor system is designed to provide a bulk gas phase with a known $\mathrm{SO}_{2}$ concentration in contaot with liquid solutions. The area of gas/liquid contact at the interface is known by maintaining a flat, undisturbed surface. The reactor was designed to approximate the mass transfer properties that are common to slurry droplets. Measurements of the range of gas and liquid film mass transfer coefficlents available in the reactor were made. Mass transfer coefficients can be varied in the reactor by changing gas and liquild agitator speeds. The reactor is capable of providing a range of liquid film mass transter coefficients corresponding to contact times from 0.7 to $6.6 \mathrm{~s}$ at $55^{\circ} \mathrm{C}$. The maximum gas film mass transfer coefficient available in the reactor is about one order-ot-magnitude smaller than would be for a typical slurry droplet.

\section{E.3.1 Design of Reactor and Supporting Equipment}

The stirred tank reactor and supporting equipment used to measure the absomtion rate of $\mathrm{SO}_{2}$ are pictured in Figure E-2. The gas/liquid contact area was $81 \mathrm{~cm}^{2}$. The base plate also contains ports for llquid inlet and outlet. The top plate contains filted ports for the gas inlet and outlet and the thermocouple.

Gas was continuously removed from the reactor for $\mathrm{SO}_{2}$ analysis. Liquid was typically fed continuously to the reactor, atthough some experiments were pertormed with liquid introduced in batch mode. An important feature of the reactor design is that the gas and liquid phases are stirred independently. Experiments required that gas agtation be maximized to maintain a high gas film mass transfer coefficient.

The $\mathrm{SO}_{2}$ absorption rate was determined primarily by gas phase material balance. The material balance was based on supplying a known concentration of $\mathrm{SO}_{2}$ to the reactor and measuring the reactor outlet (bulk) gas concentration. Also, a cross-check of the accuracy of the gas phase material balance was made by directly analyzing the abscrbed total S(IV) in the liquid. Two types of liquid phase analyses were pertormed. Direct ttration with lodine and lon chromatography were used to determine total sulfur of liquid samples. 


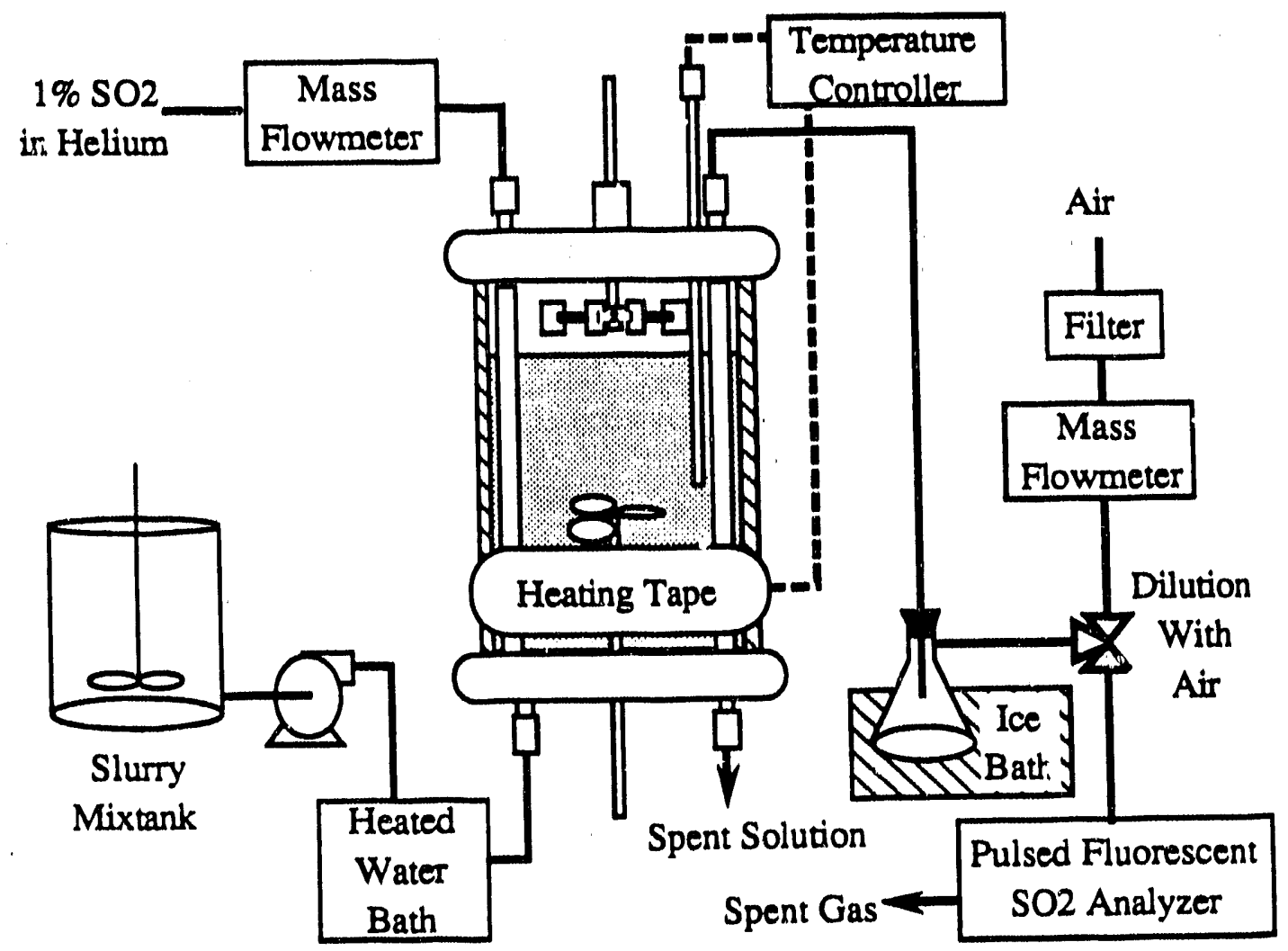

Figure E-2. Stirred tank reactor and supporting equipment. 


\section{E.3.2 Mass Transter Properties of the Stirred Tank Reaotor}

The reactor has a characteristic gas film mass transfer coefficient, $k_{g}$, and a liquid film mass transfer coettiolent, $k_{1}^{\circ}$, which depend on specifio operating conditions. A series of initial experiments were performed to determine these mass transfer properties of the reactor and relate them to variable operating conditions such as agitation speeds. In tests run to determine the gas film coefficient, the reactor was filled with 1.1 $\mathrm{L}$ of $1.0 \mathrm{M} \mathrm{NaOH}$ for reaction in batch mode. The gas phase was stirred with the 2-in diameter propeller blade. Results showed that $\mathrm{k}_{\mathrm{g}}$ was not a function of $\mathrm{SO}_{2}$ concentration. The $k_{\mathrm{g}}$ also did not vary measurably because of changing temperature from $25^{\circ} \mathrm{C}$ to $55^{\circ} \mathrm{C}$. The $\mathrm{K}_{\mathrm{g}}$ was, however, strongly dependent on gas agttation speed. The $k_{g}$ could also be aftected by changes in the liquid level in the reactor (l.e., changes in gas volume), however this was maintained constant throughout all experiments. The results at various $\mathrm{SO}_{2}$ concentrations are shown in Figure E-3 and show that $k_{g}$ can be repeatedly measured to within \pm 2.5 percent.

Next, the liquid agitator was held constant at approximately $500 \mathrm{rm}$ and the gas agitation speed was varied between 150 and $1400 \mathrm{rpm}$. Inlet gas flow rate was varied such that the outlet $\mathrm{SO}_{2}$ concentration remained near $1500 \mathrm{ppm}$. As expected, higher gas agitation speeds result in much higher gas film mass transfer coefficients (Figure E-4). A correlation for $k_{g}$ and gas agitation speed was developed from these measurements for use in calculating $k_{g}$ in later experiments:

$$
k_{g} A=1.86 \times 10^{-4}(r p m)^{0.50}
$$

The $k_{g} A$ does not appear to have a strong temperature dependence, especially at the higher agitation speeds.

Since disturbance of the gas/liquid surface was not approached with the 2.0-in diameter propeller at maximum gas agitation speed, the reactor could benefit from greater agitation. Tests were run with a 2.5 -in propeller under the same conditions as the 2.0-in diameter propeller. Results for tests run with this larger propeller at both $25^{\circ} \mathrm{C}$ and $55^{\circ} \mathrm{C}$ are shown in Figure E-5. Compared with data in 


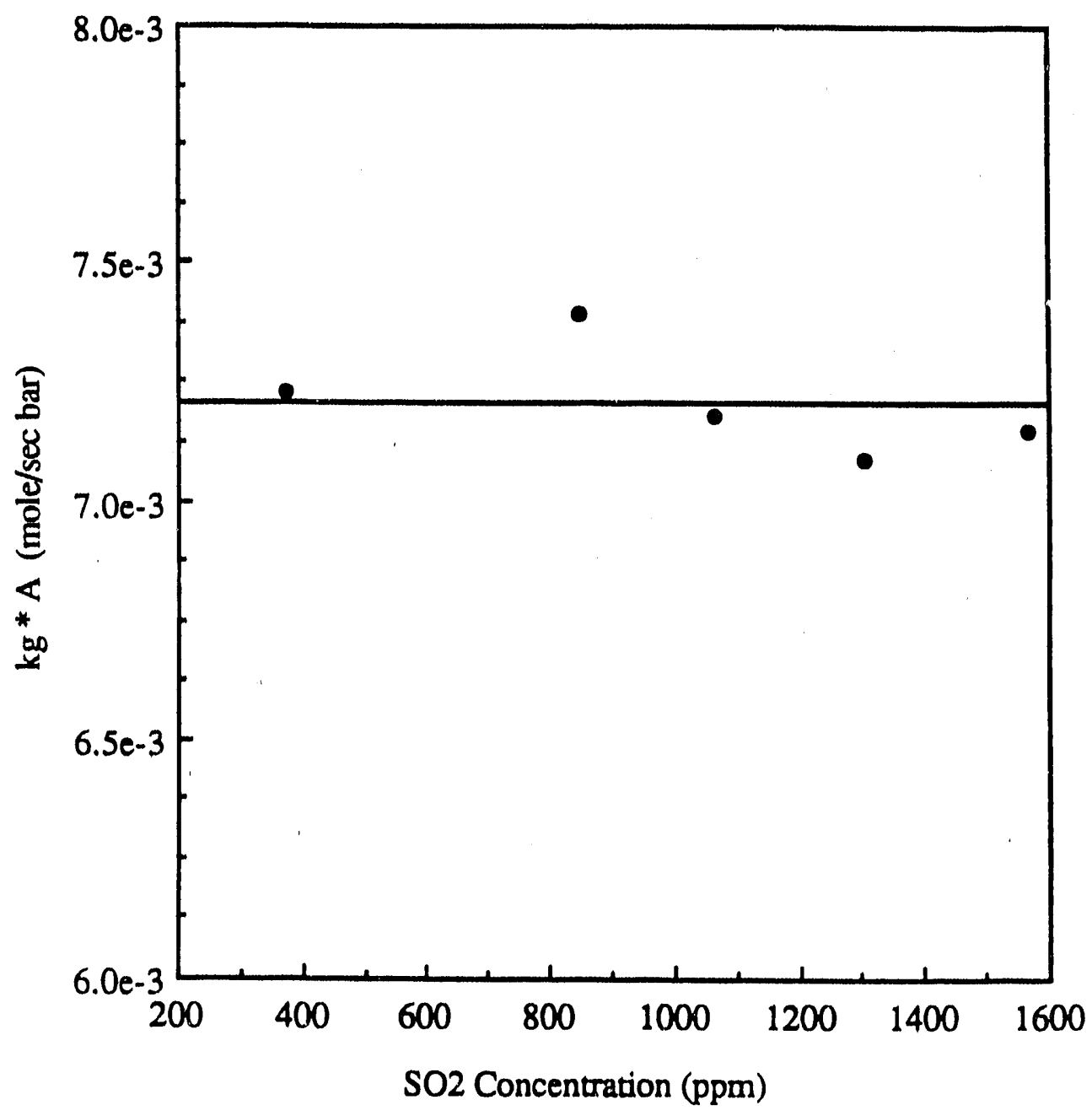

Figure E-3. Dependence of $\mathrm{k}_{g}$ on $\mathrm{SO}_{2}$ concentration. 


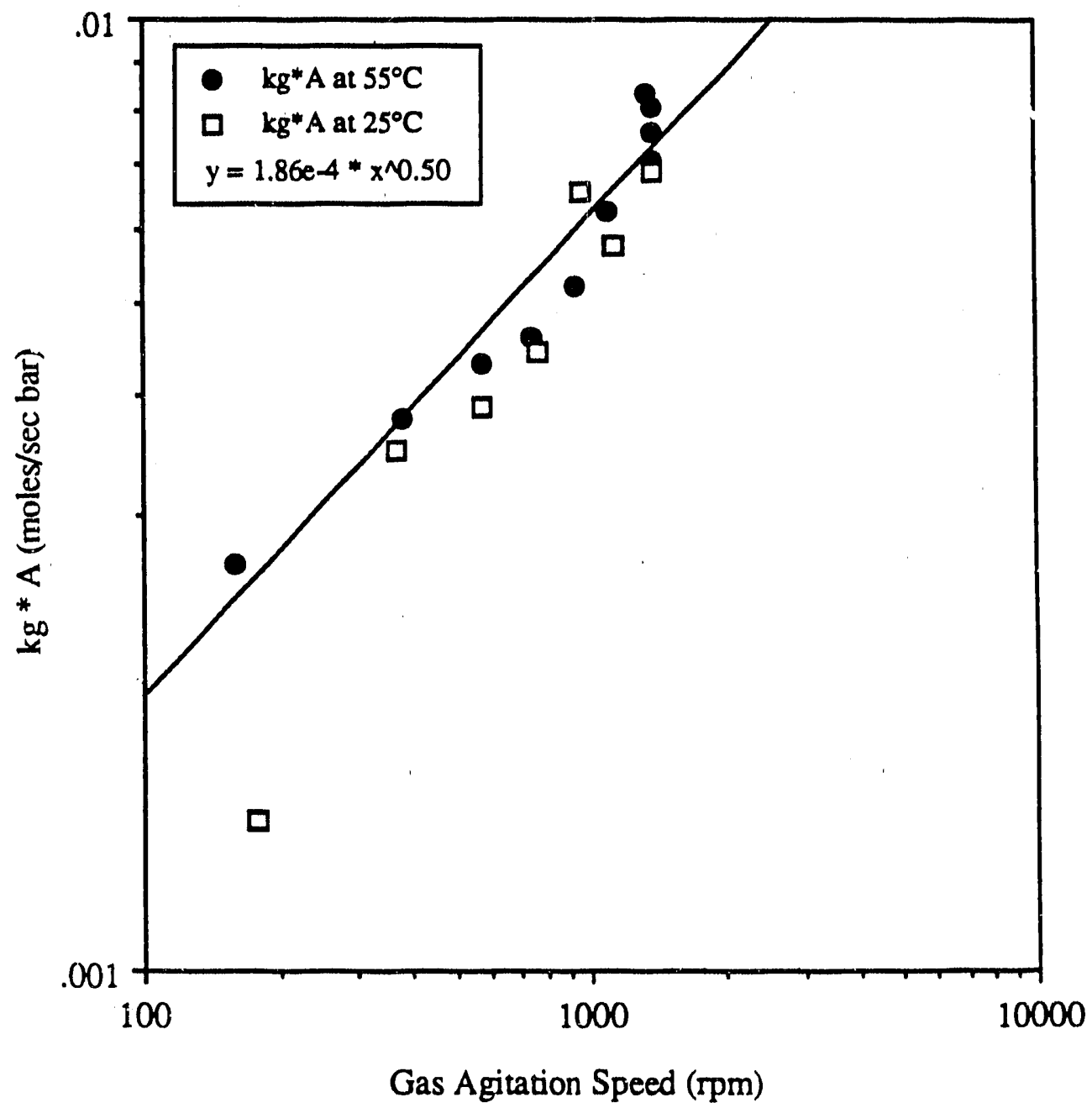

Figure E-4. Dependence of $k_{g}$ on gas agitation speed at $25^{\circ} \mathrm{C}$ and $55^{\circ} \mathrm{C}$ (2.0-in diameter propeller). 


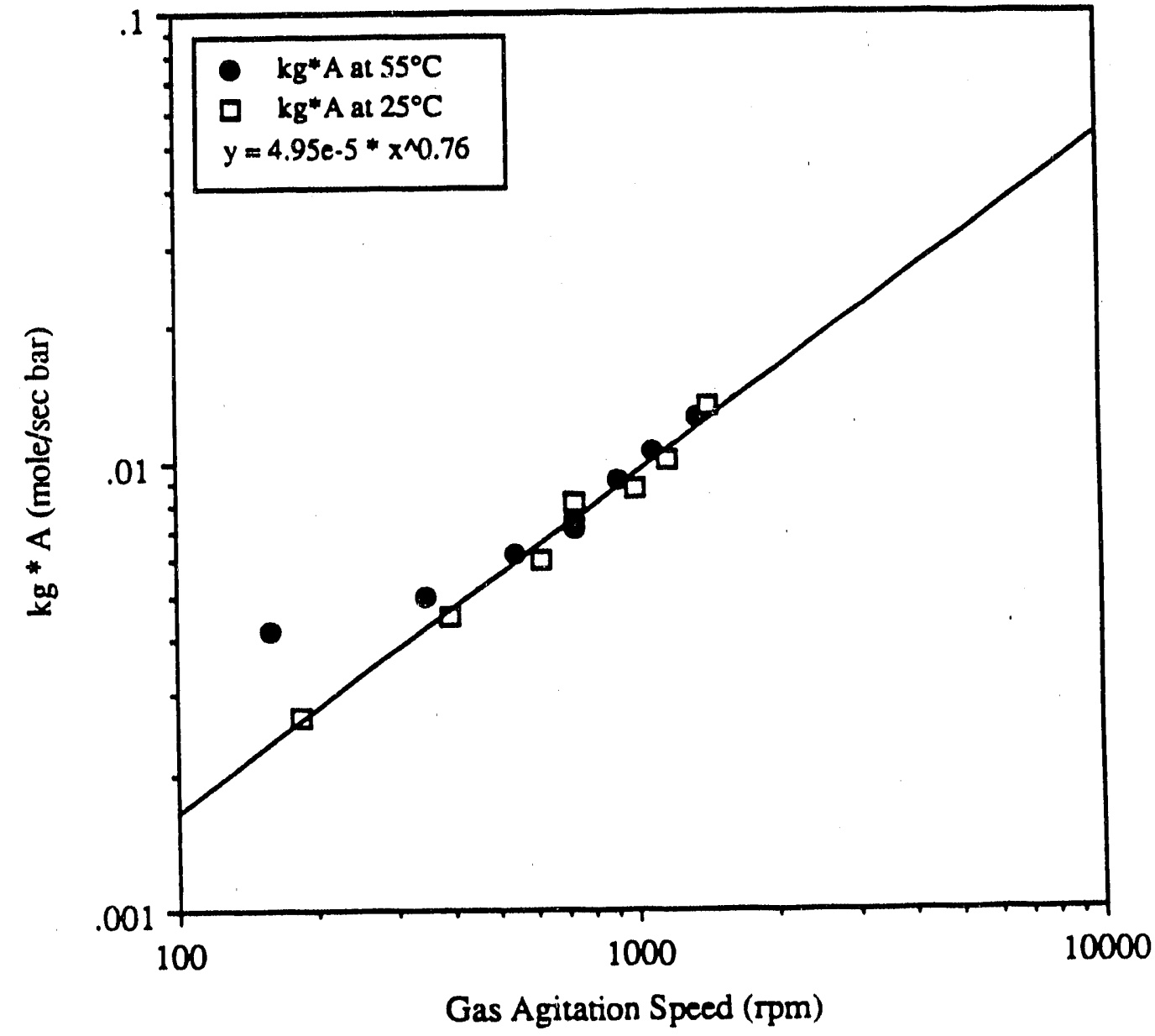

Figure $\mathrm{E}-5$. Dependence of $\mathrm{k}_{\mathrm{g}}$ on gas agitation speed at $25^{\circ} \mathrm{C}$ and $55^{\circ} \mathrm{C}$ (2.5-in diameter propeller). 
Figure E-4 for a 2-in diameter propeller, the 2.5-in diameter propeller resulted in about a 50 percent increase in $k_{g}$ at a corresponding $\mathrm{rpm}$. Because of the increased gas film mass transter, the 2.5-in diameter propeller was used for remaining experiments.

When studying gas film mass transfer, it is preferred that the reactor have a $k_{b}$ which approaches the range of values expected for slumy droplets. Values of $k_{g}$ for slumy droplets are estimated to be in the range of $10^{-2}$ to $10^{-3} \mathrm{~mole} / \mathrm{cm}^{2} \mathrm{~s}$ bar. The maximum $\mathrm{k}_{\mathrm{g}}$ measured for this study was on the order of $10^{-4}$ mole $/ \mathrm{cm}^{2} \mathrm{~s}$ bar. The results obtained in these experiments are comparable to gas film coefficients derived by other authors. The gas film mass transfer coefficients measured in this study are slightly greater than the values measured in other studies.

The values of $\mathrm{k}_{1}^{\circ}$ were measured as a function of temperature, agitation and $\mathrm{SO}_{2}$ concentration. The $k^{\circ}$, should only be a function of the properties of the liquid phase. The results shown in Figure E-6 confirm that $k_{1}^{\circ}$ is not a function of $\mathrm{SO}_{2}$ concentration. These results also indicate that $k_{1}^{\circ}$ can be measured repeatedly within about \pm 5 percent. The relationship between $k^{\circ}$, and liquid agitation speed was determined at $25^{\circ} \mathrm{C}$. During this set of tests, the $\mathrm{SO}_{2}$ concentration was allowed to vary between 1690 and $3070 \mathrm{ppm}$, and the liquid agitation speed was varied from 160 to $1350 \mathrm{rm}$. Figure E-7 shows the strong dependence of $k_{1}^{\circ}$ on liquid agitation speed. A correlation for $k^{\circ}$ as a function of liquid agitation speed was developed from this data for use in future experiments pertormed at $25^{\circ} \mathrm{C}$. Figure E-7 also presents the values of $k^{\circ}$, measured at $55^{\circ} \mathrm{C}$ as a function of liquid agitation speed. The increase in temperature from $25^{\circ} \mathrm{C}$ to $55^{\circ} \mathrm{C}$ results in a factor-of-2 increase in $\mathrm{k}^{\circ}$.

Values of $k^{\circ}$, measured by other researchers are of the same order-ot-magnitude. $k^{\circ}$, values vary from one study to the next, probably due to the differeni geometry of the reactors and diffusivities of the gases. Most of the previous experiments were run at lower liquid agitation speeds and, therefore, did not produce very high values for $k^{\circ}$. Since contact times on the order of $1 \mathrm{~s}$ were preferred in this research, higher values for $k^{\circ}$, were required, and liquid agitation speeds were greater. 


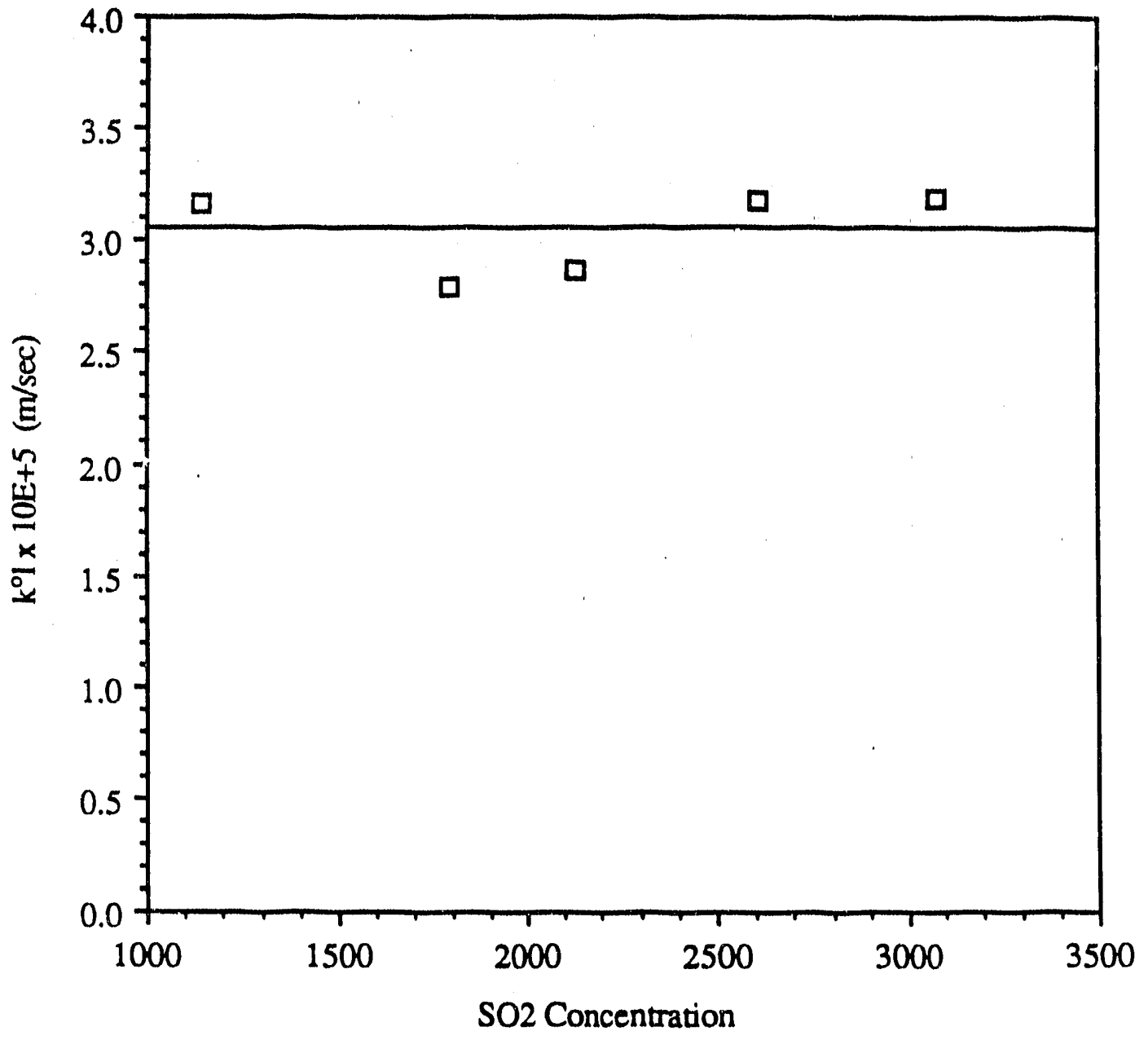

Figure E-6. Dependence of $\mathrm{k}_{1}^{\circ}$ on $\mathrm{SO}_{2}$ concentration at $25^{\circ} \mathrm{C}$. 


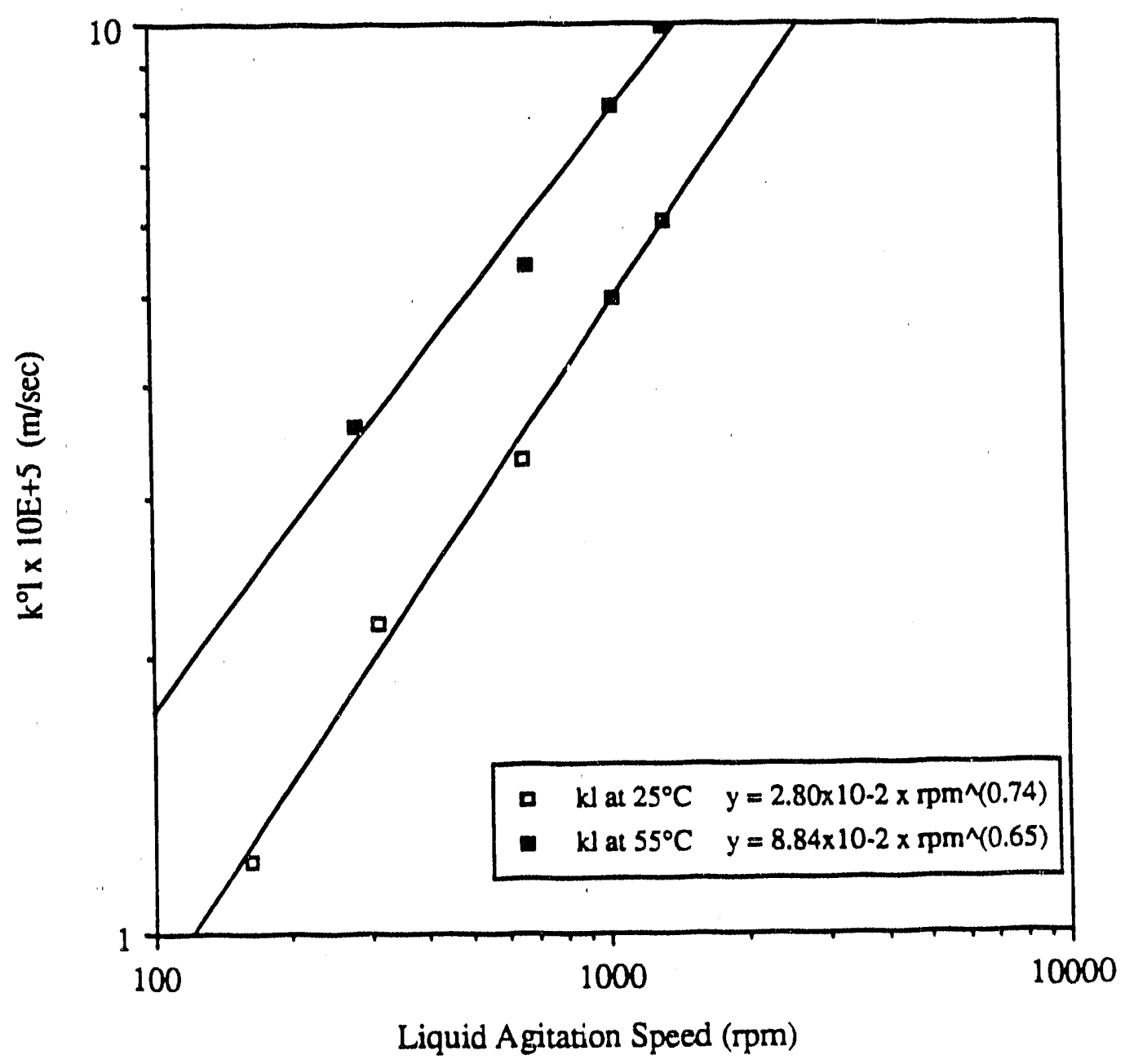

Figure E-7. Dependence of $k^{\circ}$, on agitation speed. 


\section{E.3.3 Comparison of Mass Transter Properties of The Stirred Tank to that in a Slurry Droplet}

The mass transter properties of the reactor determined in the tests discussed above can be compared to the properties of a slurry droplet to determine how olosely the reactor simulates the mass transfer properties of a droplet. Assuming the Shenwood number equals 2, a slurry drop of $10 \mu \mathrm{m}$ would have a corresponding $k_{g}$ of $1.1 \times 10^{-2}$ moles $/ \mathrm{cm}^{2} \mathrm{~s}$ bar. A 100- $\mu \mathrm{m}$ droplet would have a $\mathrm{k}_{\mathrm{g}}$ of $1.1 \times 10^{-3}$ moles $/ \mathrm{cm}^{2} \mathrm{~s}$ bar. The highest value of $k_{g}$ measured in the stirred tank was $1.5 \times 10^{-4}$ moles $/ \mathrm{cm}^{2} \mathrm{~s}$ bar. This corresponds to a slurry droplet diameter of approximately $800 \mu \mathrm{m}$, which is much larger than would be considered typical of droplets in commerclal use. It is easy to understand from this relationship why the design of the reactor included steps to minimize gas film resistance (i.e., increase $k_{g}$ ). Unfortunately, the attempts made to minimize gas film resistance did not produce the order-ot-magnitude increase in $\mathrm{k}_{\mathrm{g}}$ necessary to simulate a more reasonable droplet size (<100 $\left.\mu \mathrm{m}\right)$.

The liquid film mass transfer coefficient, $k_{1}^{\circ}$ is a function of the surface renewal time in the liquid. The amount of contact time in commercial slurry injection applications is determined by the slurry droplet drying time (usually on the order of $1 \mathrm{~s}$ ). A contact time of $1 \mathrm{~s}$ is equivalent to a $k^{\circ}$, of $7.0 \times 10^{-5} \mathrm{~m} / \mathrm{s}$. For comparison, the range of $k^{\circ}$, values measured in the stirred tank at $55^{\circ} \mathrm{C}$ was between $2.7 \times 10^{-5}$ and $8.6 \times 10^{-5} \mathrm{~m} / \mathrm{s}$. This is equivalent to a range of contact times of 0.65 to $6.6 \mathrm{~s}$.

These comparisons show that the stirred tank is capable of representing the mass transfer properties associated with a very large droplet with a drying time typical of a smaller droplet. The ratio of the degree of gas film mass transter to the liquid film mass transfer in the stirred tank is a useful quantity, which can also be used for comparison. Because of the low values of $\mathrm{k}_{\mathrm{g}}$ avallable in the reactor, the ratio of mass transfer coefficients will be about an order-of-magnitude lower than that expected for a slurry droplet.

\section{E.4 RESULTS OF EXPERIMENTS IN CLEAR SOLUTIONS}

\section{E.4.1 Experimental Conditions}

During these tests, $\mathrm{SO}_{2}$ was absorbed into several different solutions at $55^{\circ} \mathrm{C}$. The gas phase was mixed at the maximum agitation speed of approximately $1400 \mathrm{rpm}$, resulting in a gas phase mass 
transfer coefficient of $1.5 \times 10^{-4} \mathrm{~mole} / \mathrm{s}^{2}$ bar. Solution compositions and other variables are listed in Table E-2.

\section{E.4.2 Enhancement in Water}

Enhancement of $\mathrm{SO}_{2}$ absorption in water was measured over a narrow range of $\mathrm{SO}_{2}$ concentrations at varied liquid agitation speeds. The initial pH of the water was adjusted to 5.0 with a small amount of $\mathrm{HCl}$ so that absorption would not be blased by the presence of alkaline species in the water. The results show that for $\mathrm{SO}_{2}$ concentrations between 2,200 and 2,450 ppm, the reaction of $\mathrm{SO}_{2}$ with pure water enhanced $\mathrm{SO}_{2}$ absorption by a factor of 3 over absorption of $\mathrm{SO}_{2}$ into a non-reactive solution. The absorption of $\mathrm{SO}_{2}$ was primarily limited or controlled by the reaction occurring in the liquid phase (2-7 percent of gas film resistance).

The slurry ajsorption model was run with bulk solution concentrations and other conditions that simulated the absorption experiments in water. The enhancement measured in the stirred tank reactor experiments compared favorably with both the surface renewal prediction and the slurry absorption model.

\section{E.4.3 Enhancement in $0.1 \mathrm{M} \mathrm{CaCl}_{2}$ Solution}

The effect that calcium chloride has on $\mathrm{SO}_{2}$ absorption was studied first by absorbing $\mathrm{SO}_{2}$ into a solution containing $0.1 \mathrm{M} \mathrm{CaCl}_{2}$. The enhancement factor ranged between about 4 at the high $\mathrm{SO}_{2}$ TABLE E-2. CLEAR SOLUTION TEST CONDITIONS

\begin{tabular}{|l|c|c|c||}
\hline Liquid Makeup & $\mathrm{SO}_{2}$ Concentration (ppm) & Liquid Agitation $(\mathrm{pm})$ & $k_{1}^{\circ} \times 10^{5}(\mathrm{~m} / \mathrm{s})$ \\
\hline Water & $2,200-2,600$ & $110-1,360$ & $2.4-8.6$ \\
\hline $0.1 \mathrm{M} \mathrm{CaCl}_{2}$ & $1,000-4,970$ & $76-1,330$ & $2.2-8.4$ \\
\hline $\begin{array}{l}2.5 \mathrm{mM} \mathrm{Ca}(\mathrm{OH})_{2} \\
0.1 \mathrm{M} \mathrm{CaCl}\end{array}$ & $1,070-5,450$ & $200-1,330$ & $2.7-8.4$ \\
\hline $\begin{array}{l}17 \mathrm{mM} \mathrm{Ca}(\mathrm{OH})_{2} \\
0.1 \mathrm{M} \mathrm{CaCl}\end{array}$ & $580-3,790$ & $230-1,360$ & $2.9-8.6$ \\
\hline $17 \mathrm{mM} \mathrm{Ca}(\mathrm{OH})_{2}$ & $710-2,600$ & $706-1,190$ & $5.0-7.6$ \\
\hline $\begin{array}{l}17 \mathrm{mM} \mathrm{Ca}(\mathrm{OH})_{2} \\
0.1 \mathrm{M} \mathrm{NaCl}\end{array}$ & $710-2,690$ & $706-1,210$ & $5.0-7.7$ \\
\hline
\end{tabular}


concentrations near $4,400 \mathrm{ppm}$ and 6 at the low $\mathrm{SO}_{2}$ concentration of $1,000 \mathrm{ppm}$. At an $\mathrm{SO}_{2}$ concentration of $2,500 \mathrm{ppm}$, enhancement was improved about 30 percent over enhancement measured in water. Gas film resistance for the tests in $0.1 \mathrm{M} \mathrm{CaCl}_{2}$ solutions is slightly higher than for the tests in water. Absorption of $\mathrm{SO}_{2}$ in $\mathrm{CaCl}_{2}$ solutions differs from that in water only because $\mathrm{Cr}$ is present, allowing $\mathrm{HSO}_{3}{ }^{-}$and $\mathrm{H}^{+}$to diffuse independently, In other words, the reaction of $\mathrm{SO}_{2}$ in the $\mathrm{CaCl}_{2}$ solution is not inhibited by the lon-pairing effect.

Both the slurry absorption model and the surface renewal theory predict that enhancement is reduced when larger amounts of sulfur specles, mostly $\mathrm{SO}_{2}$ and $\mathrm{HSO}_{3}{ }^{\circ}$, are present in the liquid phase. The results measured in the stirred tank correlate best with the lower enhancement predicted by the slurry absorption model.

\section{E.4.4 Enhancement in $2.5 \mathrm{mM} \mathrm{Ca}(\mathrm{OH})_{2}$ Solution Containing $0.1 \mathrm{M} \mathrm{CaCl}_{2}$}

The olear $\mathrm{Ca}(\mathrm{OH})_{2}$ solutions containing $0.1 \mathrm{M} \mathrm{CaCl}_{2}$ were intended to simulate the liquid compesition and the chemical properties of slumy solutions. The first set of tests was run at a $\mathrm{Ca}(\mathrm{OH})_{2}$ level of $2.5 \mathrm{mM}$. These experiments were aimed at measuring the enhancement factor over a range of $\mathrm{SO}_{2}$ concentrations $(1,070-5,450 \mathrm{ppm})$. Enhancement factors measured during these tests ranged from just above 5, at high $\mathrm{SO}_{2}$ concentrations, up to 19 at the lowest concentrations. Gas film resistance increased considerably over levels measured with water and with $\mathrm{CaCl}_{2}$ solutions, ranging from about 10 percent at the highest $\mathrm{SO}_{2}$ concentrations to 30 percent at the lowest $\mathrm{SO}_{2}$ concentration.

The experimental data appear to be described relatively well by both the surface renewal theory and the slurry absorption model over the range of $\mathrm{SO}_{2}$ concentrations studied. Again, the two models differ slightly. The slurry absorption model predicts the experimentally measured enhancement more accurately at the lower $\mathrm{SO}_{2}$ concentrations.

\section{E.4.5 Enhancement in $17 \mathrm{mM} \mathrm{CalOH})_{2}$ Solution Containing $0.1 \mathrm{M} \mathrm{CaCl}_{2}$}

Another set of tests was nun with $\mathrm{Ca}(\mathrm{OH})_{2}$ at $17 \mathrm{mM}$, the level of saturation in $0.1 \mathrm{M} \mathrm{CaCl}_{2}$. This set of conditions is particularly interesting because it represents the same liquid conditions in the dissolved portion of a $\mathrm{Ca}(\mathrm{OH})_{2}$ slurry. The only difference between it and a slurry is the ability of the 
slurry to replenish the reacted $\mathrm{Ca}(\mathrm{OH})_{2}$ with the dissolution of solids lime. The $\mathrm{SO}_{2}$ concentrations studied during experiments with $17 \mathrm{mM} \mathrm{Ca}(\mathrm{OH})_{2}$ ranged from 580 to $3,790 \mathrm{ppm}$. The test conducted at the lowest $\mathrm{SO}_{2}$ concentration resulted in absorption that was too gas film controlled to accurately. determine the enhancement. Gas film resistance for the test runs varled from 12 percent to 83 percent. The enhancement factor measured during these tests ranged from about 13 , at the highest $\mathrm{SO}_{2}$ concentrations to 133 at the lowest $\mathrm{SO}_{2}$ concentration that could be evaluated.

The slurry absorption model was run with bulk solution concentrations and other conditions that simulated a $17 \mathrm{mM} \mathrm{Ca}(\mathrm{OH})_{2}$ in $0.1 \mathrm{M} \mathrm{CaCl}_{2}$ solution. The results of the slurry absorption model are plotted with enhancement estimated by the surface renewal theory, and enhancement measured in the stirred tank reactor in Figure E-8. The slurry absorption model predicted over twice the enhancement measured in the stirred tank. The surface renewal theory also predicted much greater enhancement than that measured in the stirred tank, and slightly greater enhancement than that predicted by the slurry absorption model. The rate of crystallization of $\mathrm{CaSO}_{3}$ had little effect on the $\mathrm{SO}_{2}$ absorption predicted by the model. Of all the properties considered, only the changes made to the diffusivity of $\mathrm{OH}^{-}$had a significant effect on the prediction of the $\mathrm{SO}_{2}$ absorption.

\section{E.4.6 Enhancement in Solutions of Varying lonio Strength}

To investigate the effect of the lonic strength in the bulk solution, $17 \mathrm{mM} \mathrm{Ca}(\mathrm{OH})_{2}$ solutions of varying lonic strength were tested. One test was run using $17 \mathrm{mM} \mathrm{Ca}(\mathrm{OH})_{2}$ solution containing no $\mathrm{CaCl}_{2}$. Another test was run with $0.1 \mathrm{M} \mathrm{NaCl}$ added, which is $1 / 3$ the lonic strength of $0.1 \mathrm{M} \mathrm{CaCl}_{2}$.

By changing the lonic strength of the bulk solution, actlvities of constituents can charge, which directly affects solution equilibria. Equilibrium constants and solubility constants as well as diffusivities of lonic species can be aftected.

The results of tests pertormed in $17 \mathrm{mM} \mathrm{Ca}(\mathrm{OH})_{2}$ solutions with varled lonic strength are compared in Figure E-9. Varying the lonic strength of the bulk solution had no significant effect on the enhancement of $\mathrm{SO}_{2}$ absorption. 


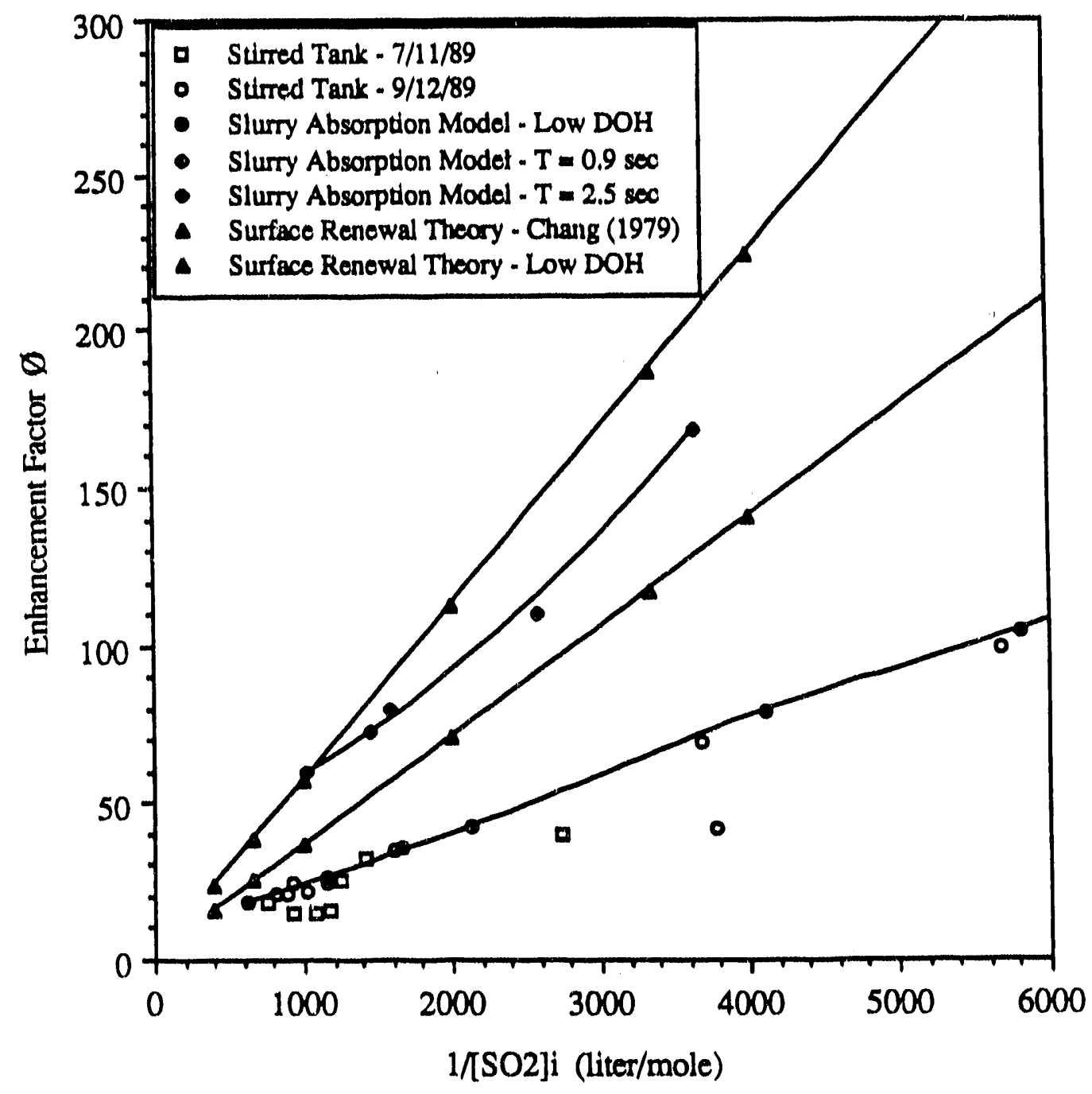

Figure E-8. Enhancement of $\mathrm{SO}_{2}$ absomption in $17 \mathrm{mM} \mathrm{Ca}(\mathrm{OH})_{2} / 0.1 \mathrm{M} \mathrm{CaCl}_{2}$ solution. 


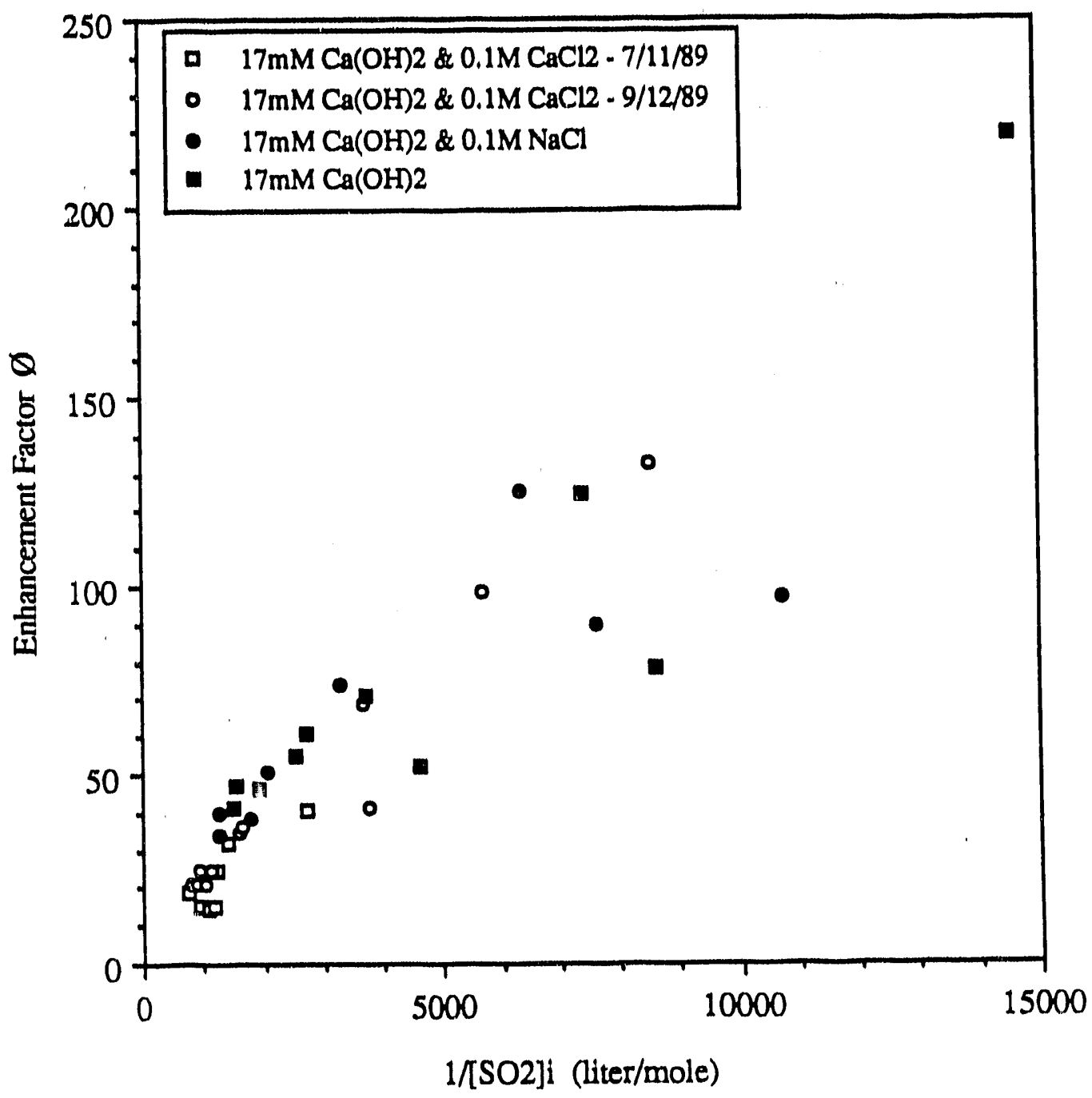

Figure E-9. Comparison of enhancement of $\mathrm{SO}_{2}$ absorption in $17 \mathrm{mM} \mathrm{Ca}(\mathrm{OH})_{2}$ solutions at various lonlo strengths. 
The olear solution experiments revealed a few important detalls about the absorption of $\mathrm{SO}_{2}$ in solutions containing $\mathrm{Ca}(\mathrm{OH})_{2}$. The relative $\mathrm{SO}_{2}$ absorption rate was measured in terms of the enhancement factor and in terms of the extent that gas fllm resistance controls the absorption. Also, the einhanoement of $\mathrm{SO}_{2}$ absorption measured in these solutions was used to validate the enhanoement predloted by the slurry absorption model.

\section{E.5 RESULTS OF EXPERIMENTS IN Ca(OH) $)_{2}$ SLURRIES}

The experiments performed in $\mathrm{Ca}(\mathrm{OH})_{2}$ sturries were designed to study two factors affecting absorption. The most important factor was the amount of sollds present in the slurry. $\mathrm{SO}_{2}$ absorption was measured in slurries with total $\mathrm{Ca}(\mathrm{OH})_{2}$ concentration ranging from $35 \mathrm{mM}$ to $1.0 \mathrm{M}$. Absorption of $\mathrm{SO}_{2}$ at concentrations of 500 to $5,000 \mathrm{ppm}$ into slurites containing $1.0 \mathrm{M}$ (7 wt percent) $\mathrm{Ca}(\mathrm{OH})_{2}$ or more solids was found to be controlled primarily by gas film resistance.

A second factor that was studied involved measuring $\mathrm{SO}_{2}$ absorption into slurries with varied $\mathrm{Ca}(\mathrm{OH})_{2}$ reactivity. Thus, slurries were prepared with $\mathrm{Ca}(\mathrm{OH})_{2}$ from different sources, and $\mathrm{SO}_{2}$ absorption rate was measured. Properties of the solid $\mathrm{Ca}(\mathrm{OH})_{2}$ particles, such as surface area and particle size, are known to affect reactivity toward $\mathrm{SO}_{2}$. These measurements were made to determine how much of an effect such properties could have on the enhancement factor and, hence, on their ability to control or limit the absorption of $\mathrm{SO}_{2}$.

The slurry experiments allowed for further verification of the slurry absorption model. Several important factors affecting the absorption of $\mathrm{SO}_{2}^{\prime}$ into a clear solutions of $\mathrm{Ca}(\mathrm{OH})_{2}$ were investigated. The slurry experiments also provide data to evaluate the effect of various properties of the $\mathrm{Ca}(\mathrm{OH})_{2}$ solids. This allows for valldation of the $\mathrm{Ca}(\mathrm{OH})_{2}$ dissolution portion of the slurry absorption model.

\section{E.5.1 Results of Slurry Experiments}

The first set of slurry experiments used reagent grade $\mathrm{Ca}(\mathrm{OH})_{2}$. Slurries containing three levels of total $\mathrm{Ca}(\mathrm{OH})_{2}$ concentration $(35 \mathrm{mM}, 0.1 \mathrm{M}$, and $1.0 \mathrm{M})$ were tested with these reagents. Intilal experiments at these concentrations showed that absorption was greatly improved with solids present. The second set of test runs with $35 \mathrm{mM} \mathrm{Ca}(\mathrm{OH})_{2}$ slurry, prepared with MCB Reagent 
$\mathrm{Ca}(\mathrm{OH})_{2}$, produced measurable values of $\varnothing$. Gas film resistance was moderately high. Contact times for these experiments were varied from about y to $2 \mathrm{~s}$. Enhancement faotors measured in the $35 \mathrm{mM}$ $\mathrm{Ca}(\mathrm{OH})_{2}$ slurry ranged from about 20 to 80 , whille gas film resistance ranged from 23 to 65 percent. Another set of tests were pertormed at the higher solids concentration of $0.1 \mathrm{M} \mathrm{Ca}(\mathrm{OH})_{2}$. The higher sollds level in the $0.1 \mathrm{M} \mathrm{Ca}(\mathrm{OH})_{2}$ slurry resulted in enhancement factors ranging from 35 to 185 and gas film resistance increased to the range of 34 to 81 percent. The highest enhancement factor arid gas film resistance is always achieved at lowest $\mathrm{SO}_{2}$ concentrations and short contact times.

Tests in slurries prepared with Mississippl $\mathrm{Ca}(\mathrm{OH})_{2}$ at three $\mathrm{Ca}(\mathrm{OH})_{2}$ concentrations were pertormed. The first had a $\mathrm{Ca}(\mathrm{OH})_{2}$ conoentration of $0.1 \mathrm{M}$ so that results could be compared to the test using $0.1 \mathrm{M}$ reagent grade $\mathrm{Ca}(\mathrm{OH})_{2}$. The other two tests used slurries prepared at higher $\mathrm{Ca}(\mathrm{OH})_{2}$ concentrations of $0.4 \mathrm{M}$ and $1.0 \mathrm{M}$. For the range of contact times of 1-2 s, enhancement factors ranged from about 50 to 250 . Gas film resistance varied from 42 to 85 percent.

The results of the test with Mississippl $\mathrm{Ca}(\mathrm{OH})_{2}$ slurry containing $0.4 \mathrm{M} \mathrm{Ca}(\mathrm{OH})_{2}$ are compared to the test results wh Mississippl $\mathrm{Ca}(\mathrm{OH})_{2}$ slurry containing $0.1 \mathrm{M} \mathrm{Ca}(\mathrm{OH})_{2}$ and those from tests with $35 \mathrm{mM}$ Reagent grade $\mathrm{Ca}(\mathrm{OH})_{2}$ in Figure $\mathrm{E}-10$. An increase in enhancement was measured, but this increase was only 20 to 25 percent for a 4 -told increase in solids concentration. Gas film resistance during these experiments was above 50 percent. Experiments were run with different types of $\mathrm{Ca}(\mathrm{OH})_{2}$ to determine If measurement of the enhancement in the stirred tank is sensitive enough to show significant differences from one type to another. One batch of Mississippl $\mathrm{CaO}$ was slaked at a concentration of $0.1 \mathrm{M} \mathrm{Ca}(\mathrm{OH})_{2}$ over a period of approximately $1 \mathrm{~h}$. Figure E-11 compares the test results of the three types of $\mathrm{Ca}(\mathrm{OH})_{2}$. No Significant differences in enhancement were measured among these three types of $\mathrm{Ca}(\mathrm{OH})_{2}$. An analysis of the surface area of the $\mathrm{Ca}(\mathrm{OH})_{2}$ particles in each slurry was not pertormed. These results indicate that either the three $\mathrm{Ca}(\mathrm{OH})_{2} \mathrm{~s}$ tested had similar reactivities toward $\mathrm{SO}_{2}$ or the stirred tank reactor is capable of measuring only large differences in absorption seen with changes in solids concentration. 


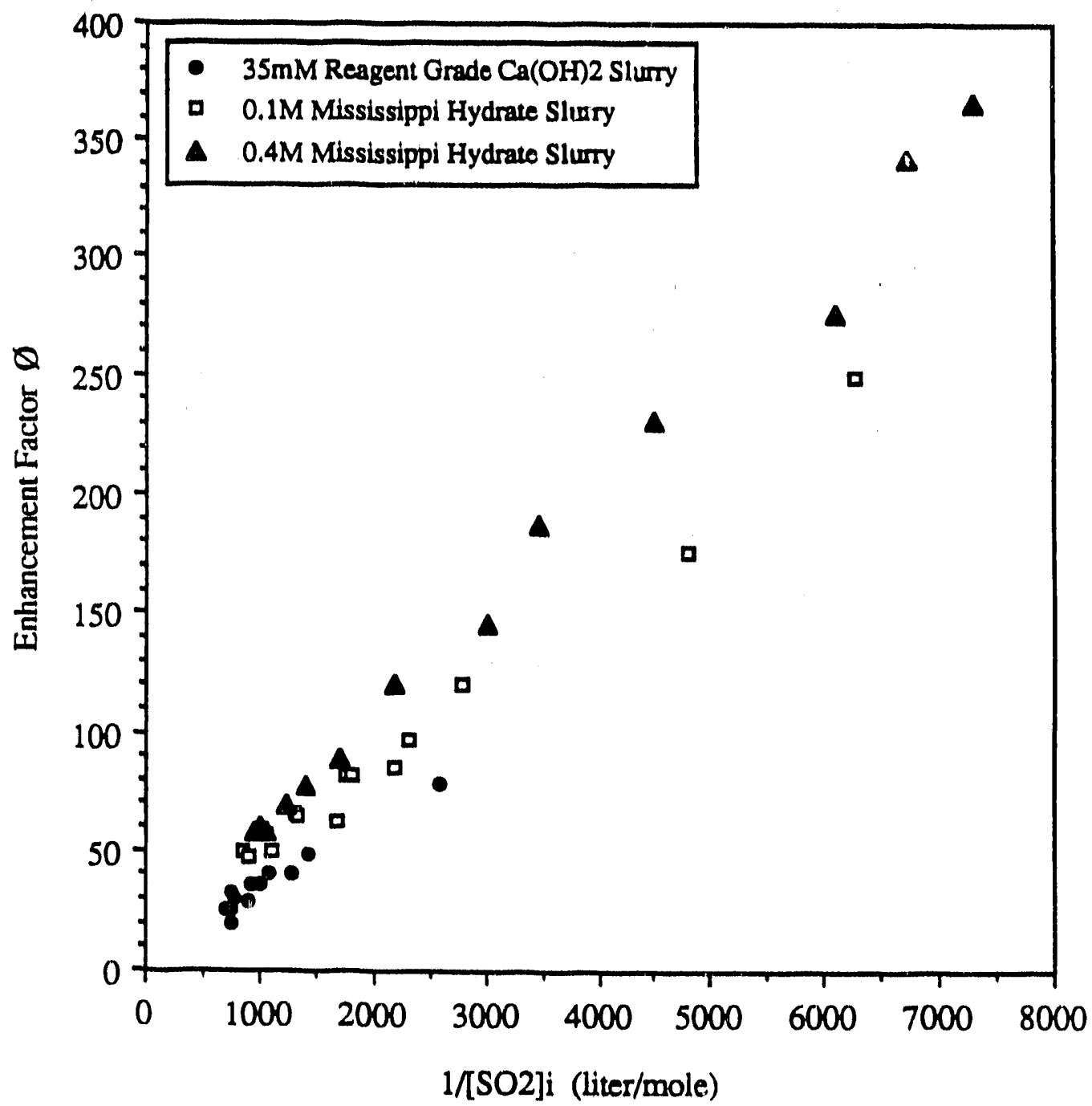

Figure E-10. Comparison of enhancement in Mississippi $\mathrm{Ca}(\mathrm{OH})_{2}$ slurry at higher $\mathrm{Ca}(\mathrm{OH})_{2}$ concentrations. 


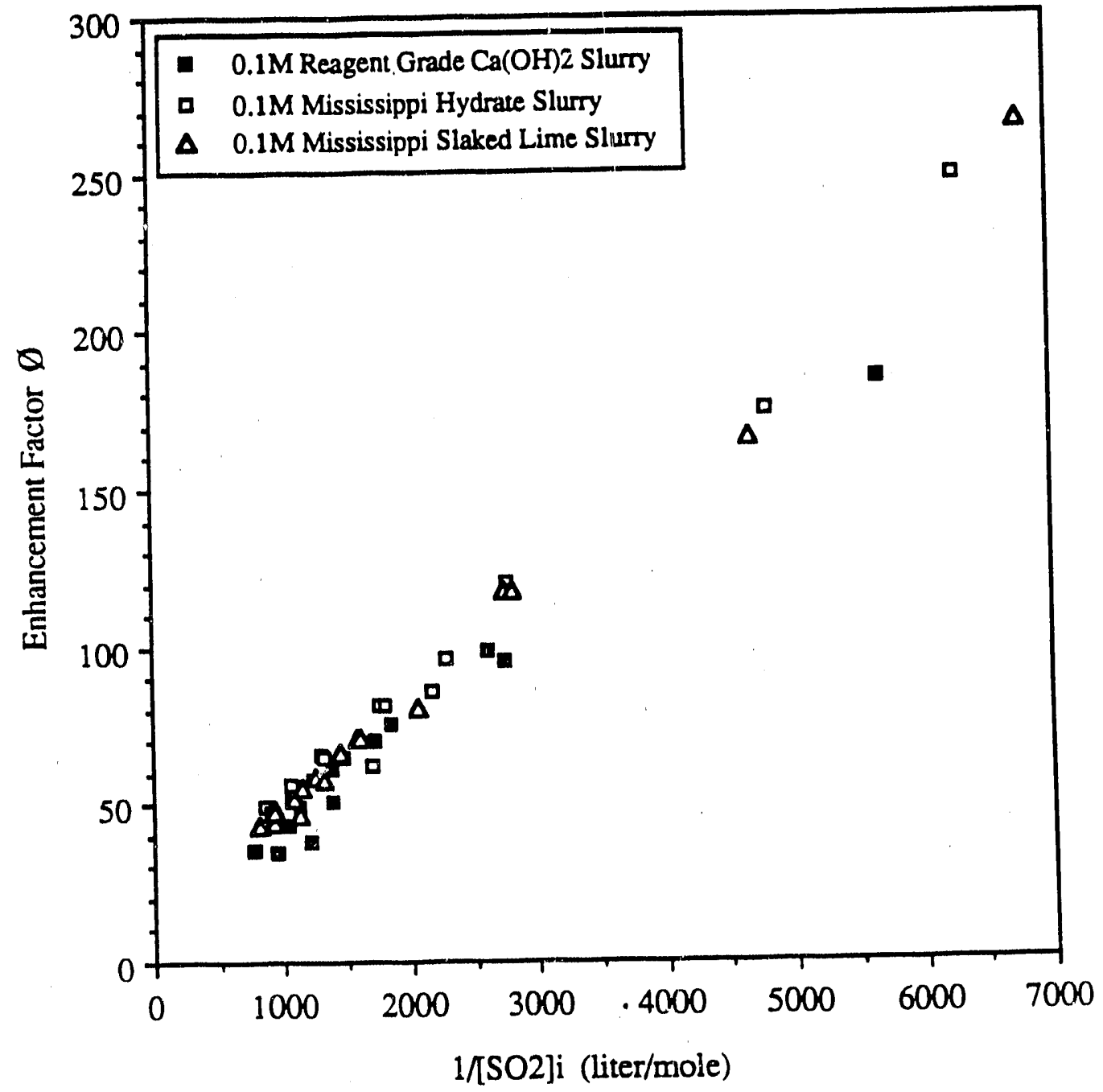

Figure E-11. Comparison of enhancement in slurry from three different sources of $\mathrm{Ca}(\mathrm{OH})_{2}$ at $0.1 \mathrm{M}$ $\mathrm{Ca}(\mathrm{OH})_{2}$. 


\section{E.5.2 Validation of Slurry Absorption Model For $\mathrm{Ca}(\mathrm{OH})_{2}$ Slurries}

The model was validated for the solution containing $17 \mathrm{mM} \mathrm{Ca}(\mathrm{OH})_{2}$ and $0.1 \mathrm{M} \mathrm{CaCl}_{2}$ by adjusting the diffusivity of hydroxide to 40 percent of the referenced value. The composition of the slurry was assumed to be the same as the $17 \mathrm{mM}$ (saturated) $\mathrm{Ca}(\mathrm{OH})_{2}$ solution with additional solid $\mathrm{Ca}(\mathrm{OH})_{2}$.

Solids concentration was specified as the same concentrations used in the stirred tank absorption experiments. The model was run for slurries containing total $\mathrm{Ca}(\mathrm{OH})_{2}$ at levels of $35 \mathrm{mM}$, $0.1 \mathrm{M}, 0.4 \mathrm{M}$ and $1.0 \mathrm{M}$ in $0.1 \mathrm{M} \mathrm{CaCl}_{2}$. The model was run at several particle sizes to determine which sizes represent the conditions of the slurry used in the stirred tank experiments. Particle sizes of $0.5,1,5$ and $10 \mu \mathrm{m}$ were used as input to the model.

A first step in predicting enhancement in slurries with the slurry absorption model was to validate that reducing the $\mathrm{D}_{\mathrm{OH}}$ to 40 percent improved the ability of the model to predict the experimental results obtained in the stirred tank. In the case of the $17 \mathrm{mM} \mathrm{Ca}(\mathrm{OH})_{2}$ solution, the model overpredicted enhancement by a factor of 2 without adjusting the $\mathrm{D}_{\mathrm{OH}_{-}}$to 40 percent of the referenced value. The model was then run with reduced $D_{\mathrm{OH}-}$ at two different particle sizes. By reducing $\mathrm{D}_{\mathrm{OH}-1}$ the slurry absorption model was able to predict the enhancement measured in the stirred tank experiments for the $35 \mathrm{mM}$ slurry. Increasing the particle size of the $\mathrm{Ca}(\mathrm{OH})_{2}$ solids from 1 to $5 \mu \mathrm{m}$ did not have a significant effect on the predicted enhancement.

A comparison was made between enhancement predicted at different contact times.

Figure E-12 shows model results generated at a particle size of $1.0 \mu \mathrm{m}$ at a $2.5 \mathrm{~s}$ contact time. The model verified that the enhancement factor in slurries is not a function of contact time over the range investigated by the experiments. The model predicts that no significant change in enhancement should result from reducing the particle size from $1.0 \mu \mathrm{m}$ to $0.5 \mu \mathrm{m}$. However, increasing the particle size to $5 \mu \mathrm{m}$ and further to $10 \mu \mathrm{m}$ results in measurably lower enhancement. The experimental results appear to be best described by a slurry with a particle size between 5 and $10 \mu \mathrm{m}$. 


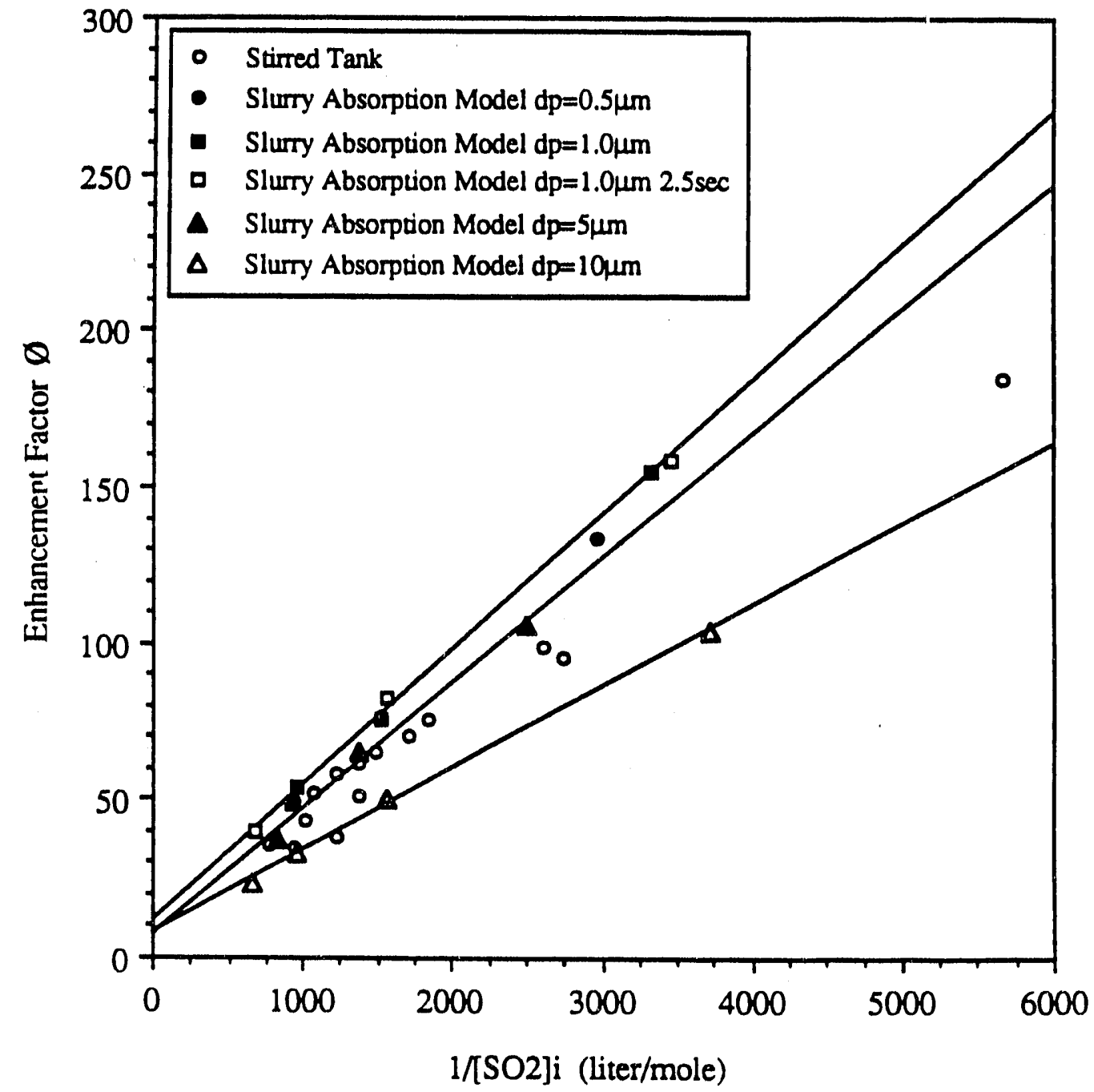

Figure E-12. Effect of particle size on enhancement predicted by slurry absorption model for $0.1 \mathrm{M}$ $\mathrm{Ca}(\mathrm{OH})_{2}$ slurry. 
There is a possible explanation for the difference in enhancement predicted by the model and measured in the stirred tank when solids content is increased. As is the case for all slumies, $\mathrm{Ca}(\mathrm{OH})_{2}$ particles will settle due to gravity if not well mixed. Although the bulk solution was well mixed in slurry experiments in the stirred tank, the boundary layer is inherently stagnant. Dissolved species remain present in the boundary layer for the defined contact time, but the solid particles may have settled out of the boundary layer sooner. Thus, the solld particles may not have enhanced the absorption of $\mathrm{SO}_{2}$ as much as the model would predict. The experiments showed that this effect was more pronounced at higher solids concentrations. Model results show that the penetration distance becomes much smaller as the slurry solids content is increased. Also, the penetration distance is smaller for larger slurry particles. Solids are more likely to settle out of the boundary layer if the penetration distance is smaller.

\section{E.5.3 Discussion of Slurry Absorption Experiments}

The slurry absorption experiments documented the effects that increased solids content and changes to reactivity of the slurry have on $\mathrm{SO}_{2}$ absorption. The effects were reported in terms of the enhancement factor and the extent that gas film resistance controlled the absorption. In some of these experiments, a completely gas film controlled absorption was achieved, thus enhancing the absorption to the highest degree. The results of the slurry absorption experiments were used to validate enhancement and degree of gas film resistance predicted by the slurry absorption model. Because solid $\mathrm{Ca}(\mathrm{OH})_{2}$ is present in the slurries, these experiments were used to validate the part of the model that governs solid $\mathrm{Ca}(\mathrm{OH})_{2}$ dissolution and reaction. Conclusions that were reached regarding the model's ability to predict the experimentally measured absorption of $\mathrm{SO}_{2}$ are also summarized below.

Enhancement factors predicted by the slurry absorption model for absorption in the $35 \mathrm{mM}, 0.1$ $\mathrm{M}, 0.4 \mathrm{M}$, and $1.0 \mathrm{M} \mathrm{Ca}(\mathrm{OH})_{2}$ slurries studied are summarized in Figure $\mathrm{E}-13$. Enhancement factors are presented as a function of $\mathrm{SO}_{2}$ concentration. The clear solution experiments pointed out that measurements of enhancement in slurries would not be possible with bulk gas $\mathrm{SO}_{2}$ concentrations less than $2,000 \mathrm{ppm}$ because these conditions would yield a gas film controlled absorption. Initial slurry tests were limited to the range of 2,000 to $5,000 \mathrm{ppm} \mathrm{SO}_{2}$, and tests with higher slurry solids content 


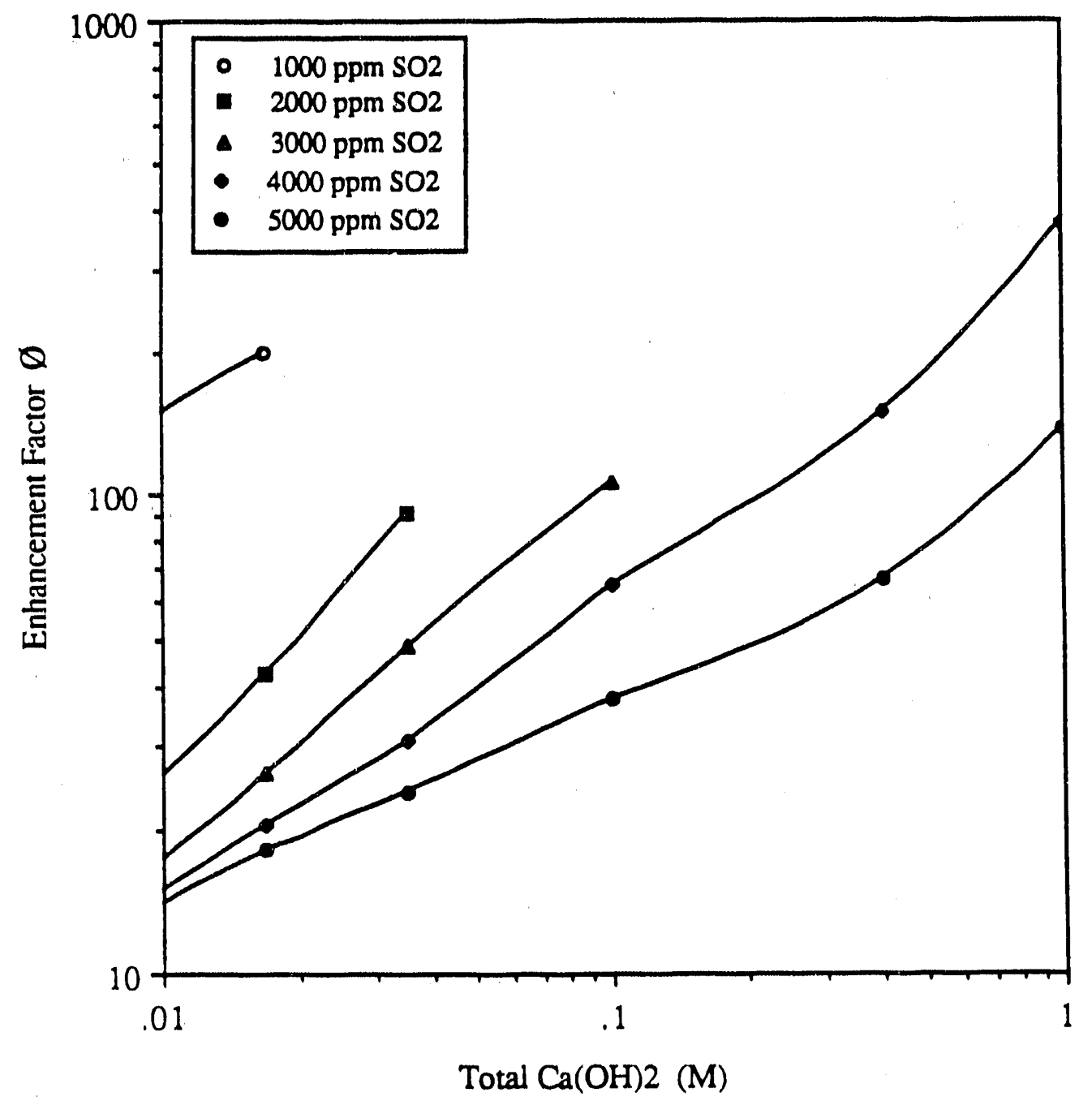

Figure E-13. Effect of slurry $\mathrm{Ca}(\mathrm{OH})_{2}$ concentration on enhancement predicted by slurry absorption model for tests pertormed in the stirred tank (corresponding $d_{d r o p l e t}=800 \mu \mathrm{m}, d_{p}=$ 5-10 $\mu \mathrm{m}, \theta=0.9 \mathrm{~s})$. 
required over $3,000 \mathrm{ppm} \mathrm{SO}_{2}$ to avoid an 80 percent or more gas fllm controlled condition. Finally, the tests with $1.0 \mathrm{M} \mathrm{Ca}(\mathrm{OH})_{2}$ required over $4,000 \mathrm{ppm} \mathrm{SO}_{2}$ to make accurate measurements of enhancement. The stirred tank and the model were not able to produce meaningful enhancement factors under these conditions because the absorption was too gas film controlled. These limitations due to gas film resistance are easily seen in Figure E-14. In order to predict the enhancement and gas film resistance in a slurry droplet for $\mathrm{SO}_{2}$ absomption of the in-duct injection process, the global mass transfer effects cannot be ignored. Thus, this analysis falls short of predicting the mass transfer that would be expected in a slurry droplet.

Figures E-15 and E-16 present the enhancement factors predicted by these slurry droplet model runs. Figure E-15 shows the predicted enhancement as a function of $\mathrm{SO}_{2}$ concentration. Figure E-16 shows the relationship of enhancement in a slurry droplet with increasing solids concentration. For a given $\mathrm{SO}_{2}$ concentration and total $\mathrm{Ca}(\mathrm{OH})_{2}$ concentration, the enhancement predicted for a slurry droplet in Figures E-15 and E-16 is less than the enhancement shown in Figure E-13 for the stirred tank.

Figure E-17 shows the relationship between gas film resistance and $\mathrm{Ca}(\mathrm{OH})_{2}$ utilization for several $\mathrm{SO}_{2}$ concentrations. The results show that the absorption of $\mathrm{SO}_{2}$ is primarily liquid film controlled at low to moderate leve!s of $\mathrm{Ca}(\mathrm{OH})_{2}$ utilization. This confirms the results determined by the slurry absorption model that were previously shown.

\section{E.6 COMPUTER MODELING}

\section{E.6.1 Model}

The model includes three kinetic phenomena which all depend on the solution composition:

- Dissolution of $\mathrm{Ca}(\mathrm{OH})_{2}$

- Crystallization of $\mathrm{CaSO}_{3}$

- Absorption of $\mathrm{SO}_{2}$

These kinetic rates are not independent from each other. To calculate the dissolution rate and the crystallization rate, the bulk solution composition is needed which depends on the amount of 


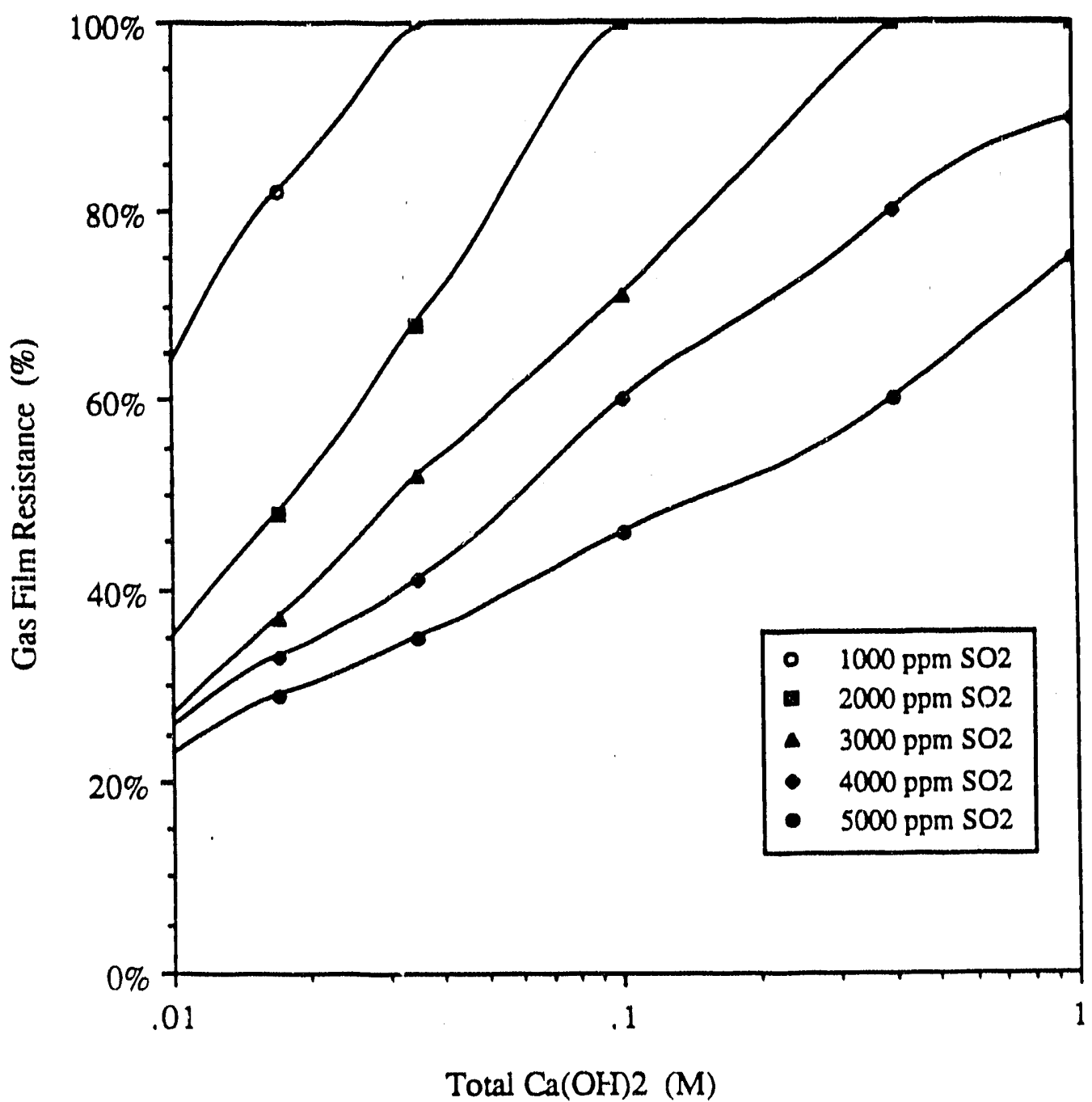

Figure E-14. Effect of slurry $\mathrm{Ca}(\mathrm{OH})_{2}$ concentration on gas film resistance predicted by slurry absomtion model for tests performed in the stirred tank (corresponding $d_{\text {droplet }}=800$ $\left.\mu \mathrm{m}, d_{p}=5-10 \mu \mathrm{m}, \theta=0.9 \mathrm{~s}\right)$. 


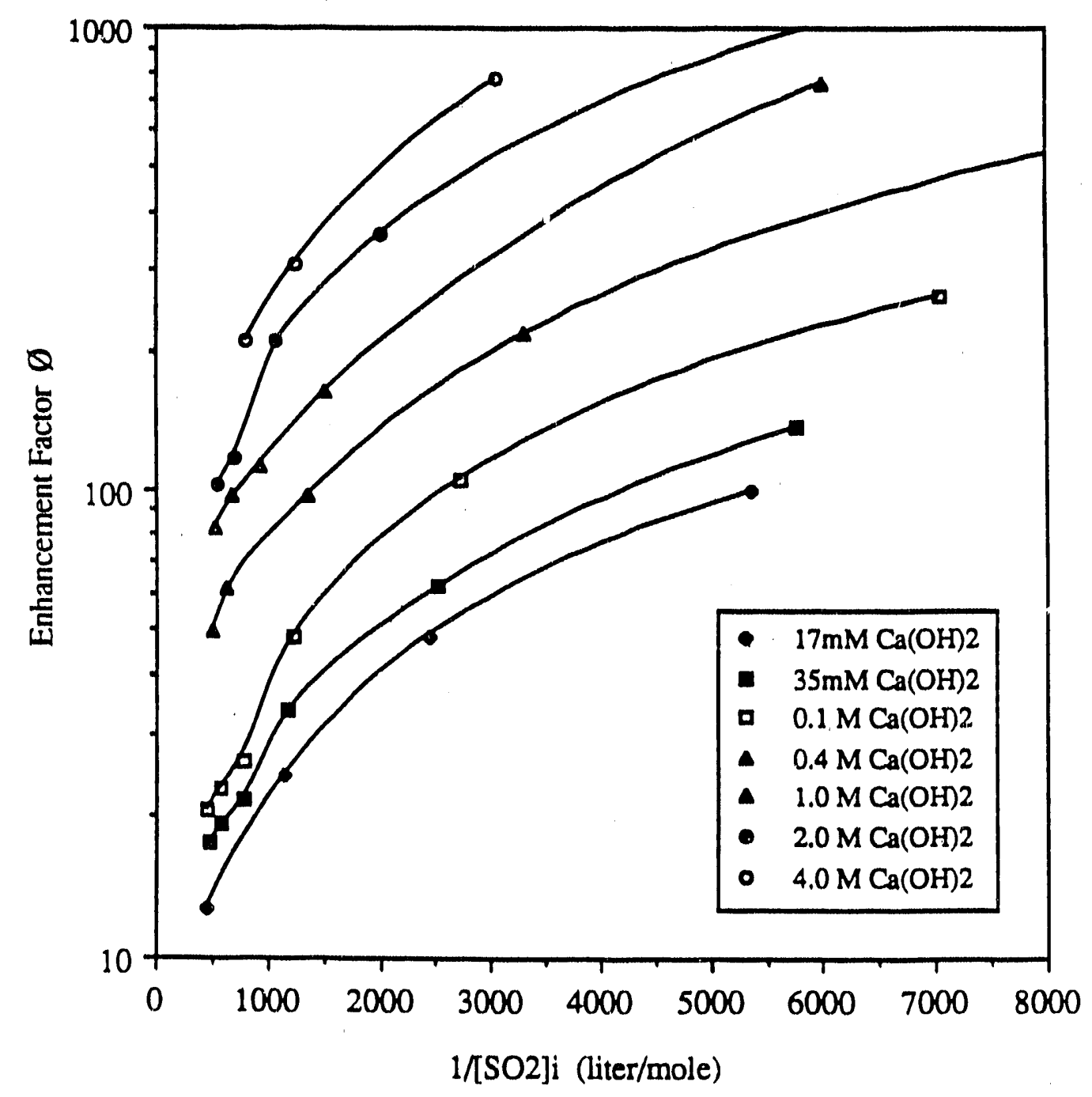

Figure E-15. Enhancement in a slurry droplet predicted by slurry absorption model ( $d_{\text {droplet }}=75 \mu \mathrm{m}$, $\left.d_{p}=5 \mu \mathrm{m}, \theta=0.9 \mathrm{~s}\right)$. 


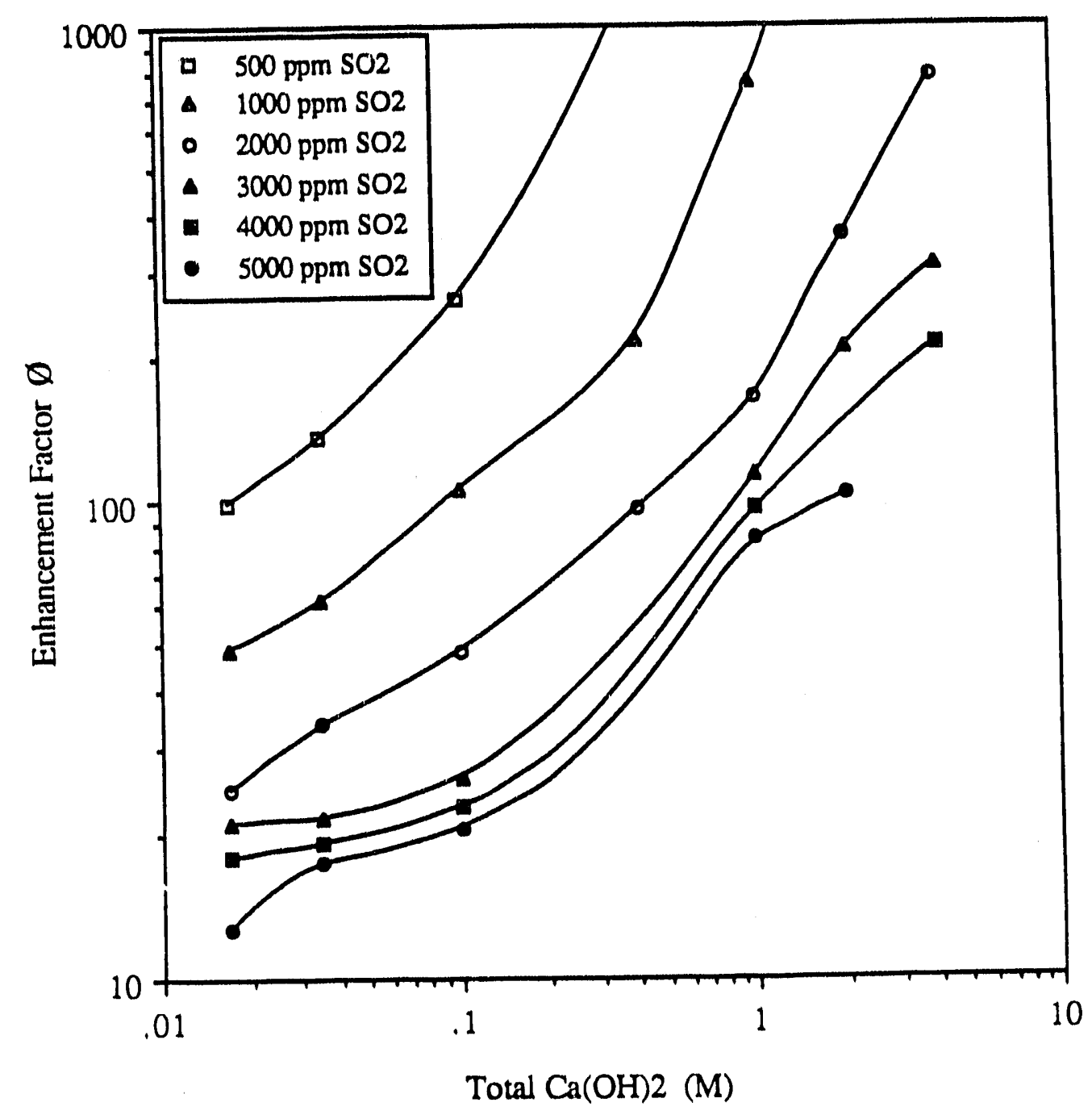

Figure E-16. Effect of $\mathrm{Ca}(\mathrm{OH})_{2}$ concentration in a slurry droplet on enhancement predicted by slurry absorption model (d droplet $=75 \mu \mathrm{m}, d_{p}=5 \mu \mathrm{m}, \theta=0.9 \mathrm{~s}$ ). 


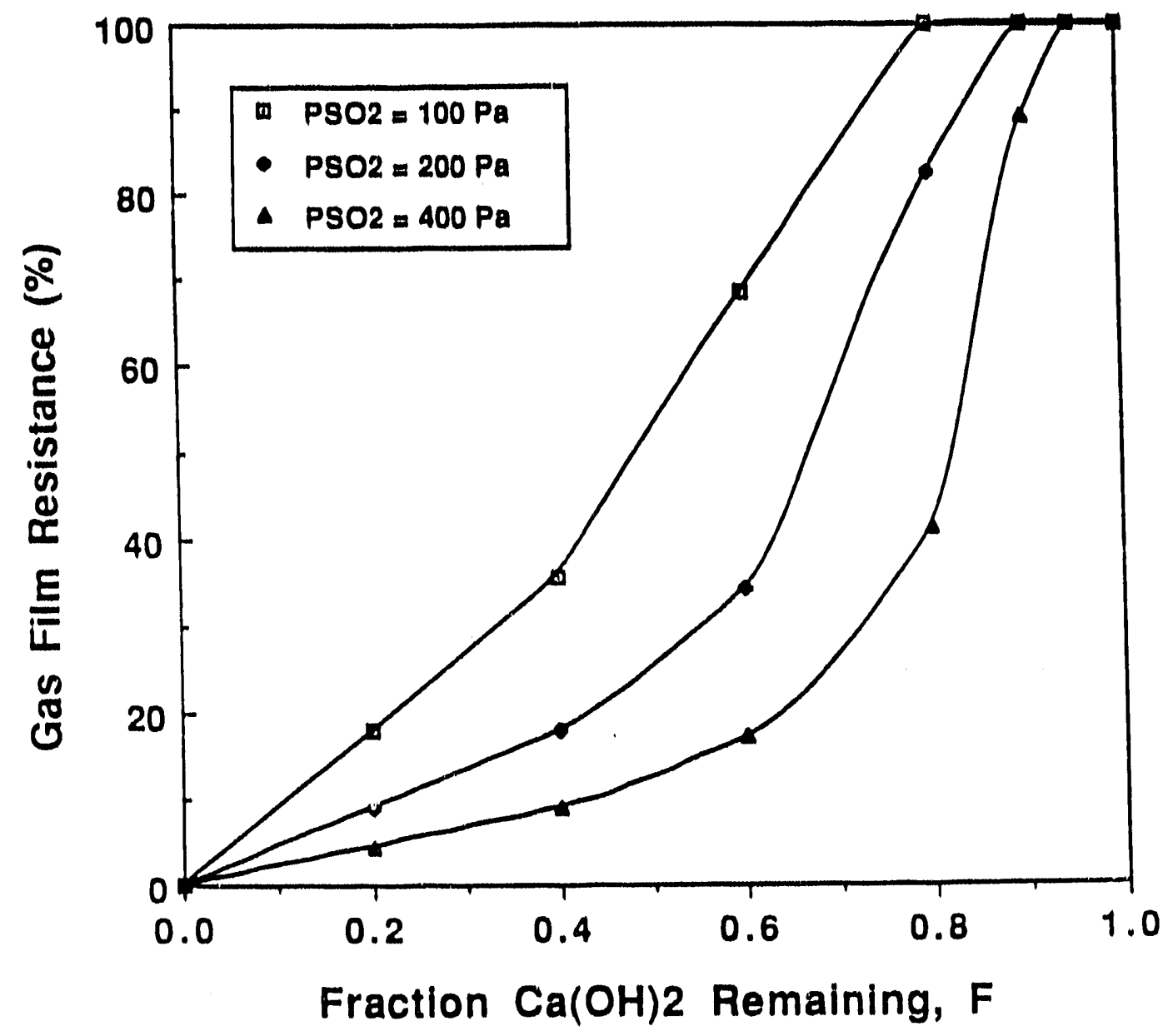

Figure E-17. Gas film resistance as a function of $\mathrm{Ca}(\mathrm{OH})_{2}$ utillization: using $\mathrm{DI} \Delta[\mathrm{S}(\mathrm{IV})]=7.0 \times 10^{-8}$ mole/m 8 . 
absorbed $\mathrm{SO}_{2}$ and vice versa. The model assumes instantaneous equillbrilum of the specles $\mathrm{H}^{+}, \mathrm{H}_{2} \mathrm{O}$, $\mathrm{OH}, \mathrm{SO}_{2}, \mathrm{HSO}_{3}{ }^{-}$and $\mathrm{SO}_{3}{ }^{2 n}$. The llquid is saturated with $\mathrm{SO}_{2}$ at the gas llquild interface. The solid $\mathrm{Ca}(\mathrm{OH})_{2}$ dissolution rate is caloulated by steady state mass transter theory. The solld $\mathrm{Ca}(\mathrm{OH})_{2}$ /s assumed to be spherioal partioles in an infinite stagnant solution. Electrioal potential gradient is assumed to be very small so the diffusivitles are constant throughout the llquld phase.

The differential material balances for total calolum, S(IV) specles and the oharge can easily be Integrated to the following expressions.

$$
\begin{aligned}
& D_{\mathrm{Ca}^{2}+} C_{\mathrm{Ca}^{2+}}+D_{\mathrm{CaOH}^{+}} C_{\mathrm{OaOH}^{+}}+D_{\mathrm{CaSO}_{3}^{0}} C_{\mathrm{CaSO}_{3}^{0}}=\alpha_{1}+\beta_{1} y \\
& D_{\mathrm{SO}_{2}} C_{\mathrm{SO}_{2}}+D_{\mathrm{HSO}_{3}^{-}} C_{\mathrm{HSO}_{3}^{-1}}+D_{\mathrm{SO}_{3}^{2-}} C_{\mathrm{SO}_{3}^{2-}}+D_{\mathrm{OASO}_{3}} C_{\mathrm{OaSO}_{3}}=\alpha_{2}+\beta_{2} y \\
& 2 D_{\mathrm{Ca}^{2+}} C_{\mathrm{Ca}^{2+}}+D_{\mathrm{CaOH}^{+}} C_{\mathrm{OaOH}^{+}}+D_{\mathrm{H}^{+}} C_{\mathrm{H}^{+}}-D_{\mathrm{OH}^{-}} C_{\mathrm{OH}^{-}} \\
& -D_{\mathrm{HSO}_{3}^{-}} C_{\mathrm{HSO}_{3}^{-}}-2 D_{\mathrm{SO}_{3}^{2-}} C_{\mathrm{SO}_{3}^{2-}}-D_{\mathrm{O1}_{1}}-C_{\mathrm{O}^{-}}=\alpha_{3}+\beta_{3} y
\end{aligned}
$$

where $\alpha_{1}$ and $\beta_{1}$ are integration constants.

Caloium sulfte will precipttate in the llquil film during the absorption. The supersaturation of $\mathrm{CaSO}_{31}$ $\mathrm{RS}_{\mathrm{CaSO},}$ is defined as:

$$
R S_{\mathrm{CaSO}_{3}}=\frac{a_{\mathrm{Ca}^{2+}} a_{S O_{3}^{2-}}}{K_{s p} \mathrm{CaSO}_{3}}
$$

The crystallization/dissolution rate, $R_{0}$ can be written as a function of the supersaturation of $\mathrm{CaSO}_{3}$ :

$$
\left.R_{c}=1.6210^{-1} \exp (-5153 / T)\left(R S_{\mathrm{CaSO}_{3}}-1\right)^{n} A / R S_{\text {Oa! }}\right)_{4} \quad\left(\mathrm{~mol} / \mathrm{m}^{3} \mathrm{~s}\right)
$$

where $A$ is the BET surface area of calclum sulfite per volume of slurry.

The crystallization rate, $R_{0}$ is in the same way as the dissolution rate of $\mathrm{Ca}(\mathrm{OH})_{2}$ a function of both time, $t$, and the distance, $x$, from the gas-llquid interface. 
The absorption of $\mathrm{SO}_{2}$ is modeled with the peneiration model. The unsteady state material balance for each specles is:

$$
\begin{gathered}
\frac{\partial C_{1}}{\partial t}-\nabla J_{1}+r_{1} \\
J_{1}=z_{1} D_{1} \frac{F}{R T} C_{1} \nabla \varnothing-D_{1} \nabla c_{1}
\end{gathered}
$$

All the material balanoes with S(IV) specles are combined to one dfferential equation and all the material balanoes involving calolum speoles are combined. This allows not having to use rate constants fixed at arbitrarily high values for the equillbrium reaotions.

$$
\begin{aligned}
& \frac{\partial C_{S Y M}}{\partial t}=\sum_{i=1}^{4}\left(D_{1} \nabla^{2} C_{1}-z_{1} D_{1} \frac{F}{R T} \nabla(C, \nabla \varnothing)\right)-R_{d}(x, D) \\
& l=S O_{2}, H_{S O}-S O_{3}^{2-}, C_{S S O} O^{\circ}
\end{aligned}
$$

$$
\begin{aligned}
& \frac{\partial C_{\text {Oa } 10 t}}{\partial t}=\sum_{i=1}^{3}\left(D_{1} \nabla^{2} C_{1}-z_{1} D_{1} \frac{F}{A_{T}} \nabla\left(C_{1} \nabla \theta\right)\right)-H_{d}\left(x_{1} t\right)+R_{d}\left(x_{1} t\right) \\
& 1=\mathrm{Ca}^{2+}, \mathrm{CaOH}^{+}, \mathrm{CaSO}_{3}^{0} \\
& \frac{\partial C_{O l}}{\partial t}=D_{C l} \nabla^{2} C_{O l}+D_{O l} \frac{F}{R T} \nabla\left(C_{O l} \nabla \varnothing\right)
\end{aligned}
$$

The absorption rate will vary with time. At the start when the llquid element is brought up to the surface, the absorption rate is large since the interfacial concentration of $\mathrm{SO}_{2}$ is small. As the absorption proceeds, the concentration of $\mathrm{SO}_{2}$ at the gas-llquid intertace increases, and the absorption rate decreases. The averag. absorption rate, measured from the stirred tank reactor experiments, is calculated from:

$$
\pi \mathrm{SO}_{2}=\frac{1}{\theta} \int_{0}^{\theta} N_{\mathrm{SO}_{2}} d t
$$


Where $\theta$ is the total contact time.

The computer code is written in FORTRAN 77 and is avallable both on a VAX computer and on a Cray computer. In order to solve the differentlal equations that describe the absorption process, the dissolution rate of $\mathrm{Ca}(\mathrm{OH})_{2}, R_{d 1}$ and the orystallization rate of $\mathrm{CaSO}_{3}, R_{0}$ need to be caloulated.

To solve the equations for the conoentrations at the $\mathrm{Ca}(\mathrm{OH})_{2}$ surtace, all the concentrations are expressed in the concentrations of hydrogen and sullte by using the equillibria equations. That reduces the number of equations to two nonlinear equations, $f_{1}=0$ and $f_{2}=0$.

$$
\begin{aligned}
& C_{H^{+}+1}\left(\frac{\partial f_{1}}{\partial C_{H^{+}}}\right)_{N}+C_{S O_{3}^{2-N+1}}\left(\frac{\partial f_{1}}{\partial C_{S O_{3}^{2-}}}\right)_{N}=-f_{1}\left(C_{H^{+} N^{\prime}} C_{S O_{3}^{2-N}}\right) \\
& +C_{H^{+} N}\left(\frac{\partial f_{1}}{\partial C_{H^{+}}}\right)_{N}+C_{{S O_{3}^{2-N}}^{2-}}\left(\frac{\partial f_{1}}{\partial C_{S O_{3}^{2-}}}\right)_{N} \\
& C_{H^{+}+1}\left(\frac{\partial f_{2}}{\partial C_{H^{+}}}\right)_{N}+C_{S_{3}^{2-} N+1}\left(\frac{\partial f_{2}}{\partial C_{S O_{3}^{2-}}}\right)_{N}=-f_{2}\left(C_{H^{+} N^{\prime}} C_{S O_{3}^{2-N}}\right) \\
& +C_{H^{+} N}\left(\frac{\partial f_{2}}{\partial C_{H^{+}}}\right)_{N}+C_{\mathrm{SO}_{3}^{2-N}}\left(\frac{\partial f_{2}}{\partial C_{\mathrm{SO}_{3}^{2-}}}\right)_{N}
\end{aligned}
$$

Orthogonal collocation transforms the partial differential equations in $t$ and $x$ into ordinary differential equations in t. The first and the second spatial derivative at any collocation points can be expressed in terms of the value of the function at the collocation points in that specific element. The gas film resistance is calculated as the average absorption rate divided by $\mathrm{k}_{\mathrm{g}}$ and $\mathrm{P}_{\mathrm{SO}_{2}}$. The gas fllm resistance is thus a normalized flux which makes it possible to compare results for cases with different $\mathrm{P}_{\mathrm{SO}_{2}}$ and different mass transfer coefficients. The gas film resistance is also a ratio between the average flux and the maximum flux for that specific case. If the absorption is totally gas film controlled, 
the gas film resistance is equal to one, and the absomtion rate can not further be increased by any chemical reaction in the absorbing liquid. If the gas fllm resistance is equal to 50 peroent, this condition Implles that up to this point the slurry has absorbed 50 percent of the amount that could have been absorbed if the process was totally gas film controlled. The modeling results are often presented as a function of contact time. The contact time is the time the liquid element stays at the gas-liquid intertace before it is transported back to the liquild bulk.

\section{E.6.2 Modeling Results}

The reactivity of $\mathrm{Ca}(\mathrm{OH})_{2}$ has been altered by changing the size of the $\mathrm{Ca}(\mathrm{OH})_{2}$ particles in the slurry. The particle size ranged from $0.2 \mu \mathrm{m}$ to $5 \mu \mathrm{m}$. Figures E-18 and E-19 show how the gas film resistance varies with contact time for alfferent $\mathrm{Ca}(\mathrm{OH})_{2}$ reactivities. In the modeling results shown in Figure E-18, $k_{g}$ was set at a value corresponding to a $100-\mu \mathrm{m}$ slurry droplet. The corresponding droplet size for the results in Figure E-19 is $10 \mu \mathrm{m}$.

Initially, all the resistance to mass transfer is concentrated in the gas film, since the concentration of $\mathrm{SO}_{2}$ in the liquid is approximately zero. During the absorption, hydrogen lons are produced and $\mathrm{Ca}(\mathrm{OH})_{2}$ dissolves to neutralize the formed hydrogen lons. If the dissolution of $\mathrm{Ca}(\mathrm{OH})_{2}$ is not fast enough or if the concentration of $\mathrm{Ca}(\mathrm{OH})_{2}$ approaches zero, the $\mathrm{pH}$ at the gas-liquid interface decreases and the gas film resistance decreases.

Figures E-20 and E-21 show the concentration proflles for an absorption case without any $\mathrm{Ca}(\mathrm{OH})_{2}(\mathrm{~s})$ in the llquild bulk. These profiles take $1.6 \mathrm{~s}$ to be formed, and they correspond to an instantaneous gas film resistance of 45 percent. The partial pressure of $\mathrm{SO}_{2}$ is $2,000 \mathrm{ppm}$, and $\mathrm{k}_{\mathrm{g}}$ is $1.1 \times 10^{-4} \mathrm{~mol} / \mathrm{m}^{2} \mathrm{~s} \mathrm{~Pa}$.

Figures E-22 and E-23 show the profiles for the same absorption case as above when the bulk concentration of $\mathrm{Ca}(\mathrm{OH})_{2}(\mathrm{~s})$ is $500 \mathrm{~mol} / \mathrm{m}^{3}$. These profiles also correspond to a gas film resistance of 45 percent, but since the presence of $\mathrm{Ca}(\mathrm{OH})_{2}(\mathrm{~s})$ maintains a high gas film resistance a longer time, it takes $8.1 \mathrm{~s}$ until these profiles are formed. Figure E-22 with the profiles of $\mathrm{H}^{+} / \mathrm{OH}^{-}$and $\mathrm{SO}_{2} / \mathrm{HSO}_{3}{ }^{-}$ $1 \mathrm{SO}_{3}{ }^{2-}$ looks approximately the same as Figure E-2O. 


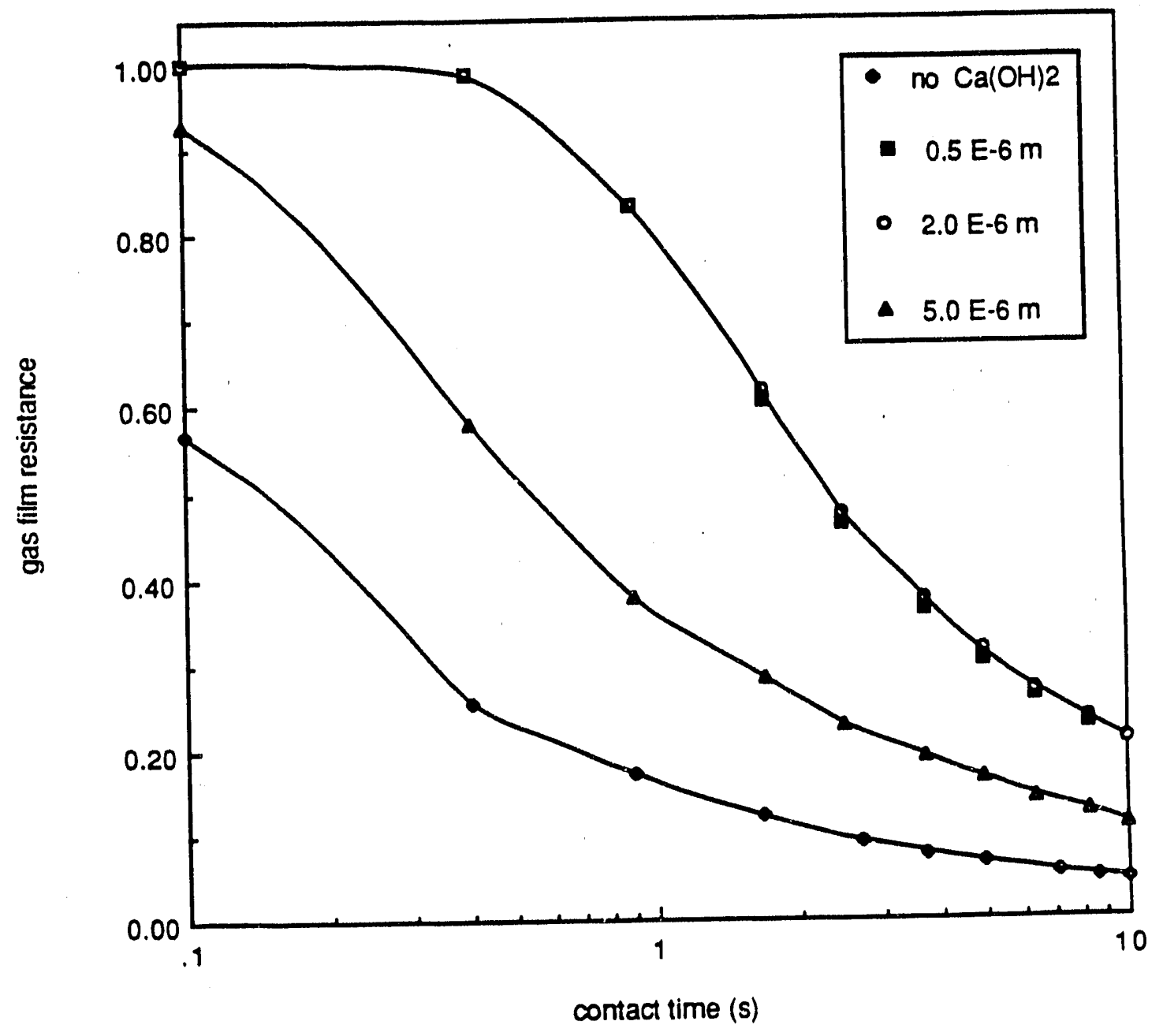

Figure E-18. The gas film resistance versus the contact time. The different curves correspond to different particle sizes of $\mathrm{Ca}(\mathrm{OH})_{2} .200 \mathrm{~Pa} \mathrm{SO}_{2}, 0$ and $200 \mathrm{~mol} / \mathrm{m}^{3} \mathrm{Ca}(\mathrm{OH})_{2}, 100 \mu \mathrm{m}$ droplet, $0.5-5.0 \mu \mathrm{m} \mathrm{Ca}(\mathrm{OH})_{2}, 0.1-10 \mathrm{~s}$ contact time. 


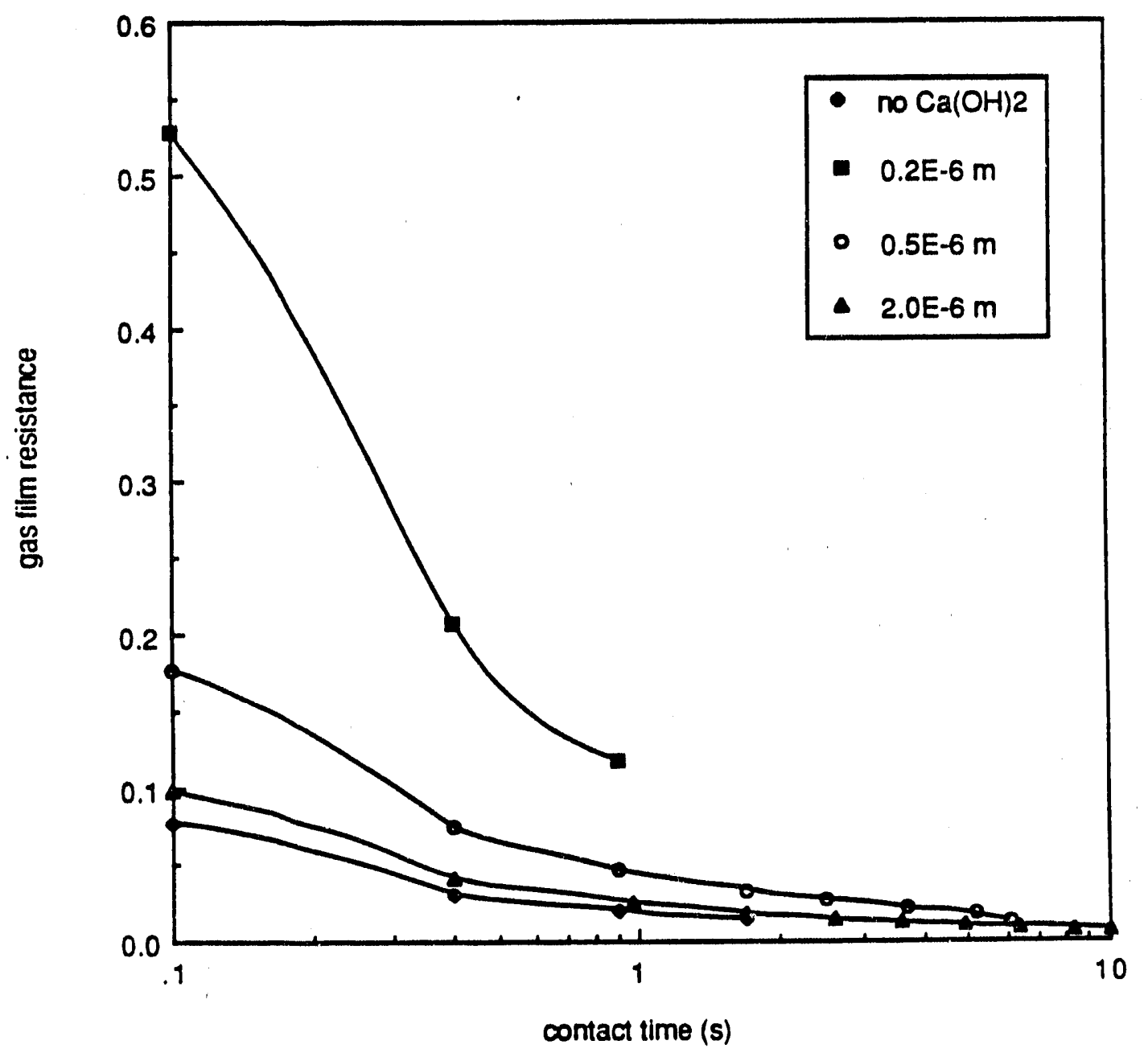

Figure E-19. The gas film resistance versus the contact time. The different curves correspond to different particle sizes of $\mathrm{Ca}(\mathrm{OH})_{2} .200 \mathrm{~Pa} \mathrm{SO}, 0$ and $200 \mathrm{~mol} / \mathrm{m}^{3} \mathrm{Ca}(\mathrm{OH})_{2}, 10 \mu \mathrm{m}$ droplet, $0.5-5.0 \mu \mathrm{m} \mathrm{Ca}(\mathrm{OH})_{2}, 0.1-10 \mathrm{~s}$ contact time. 


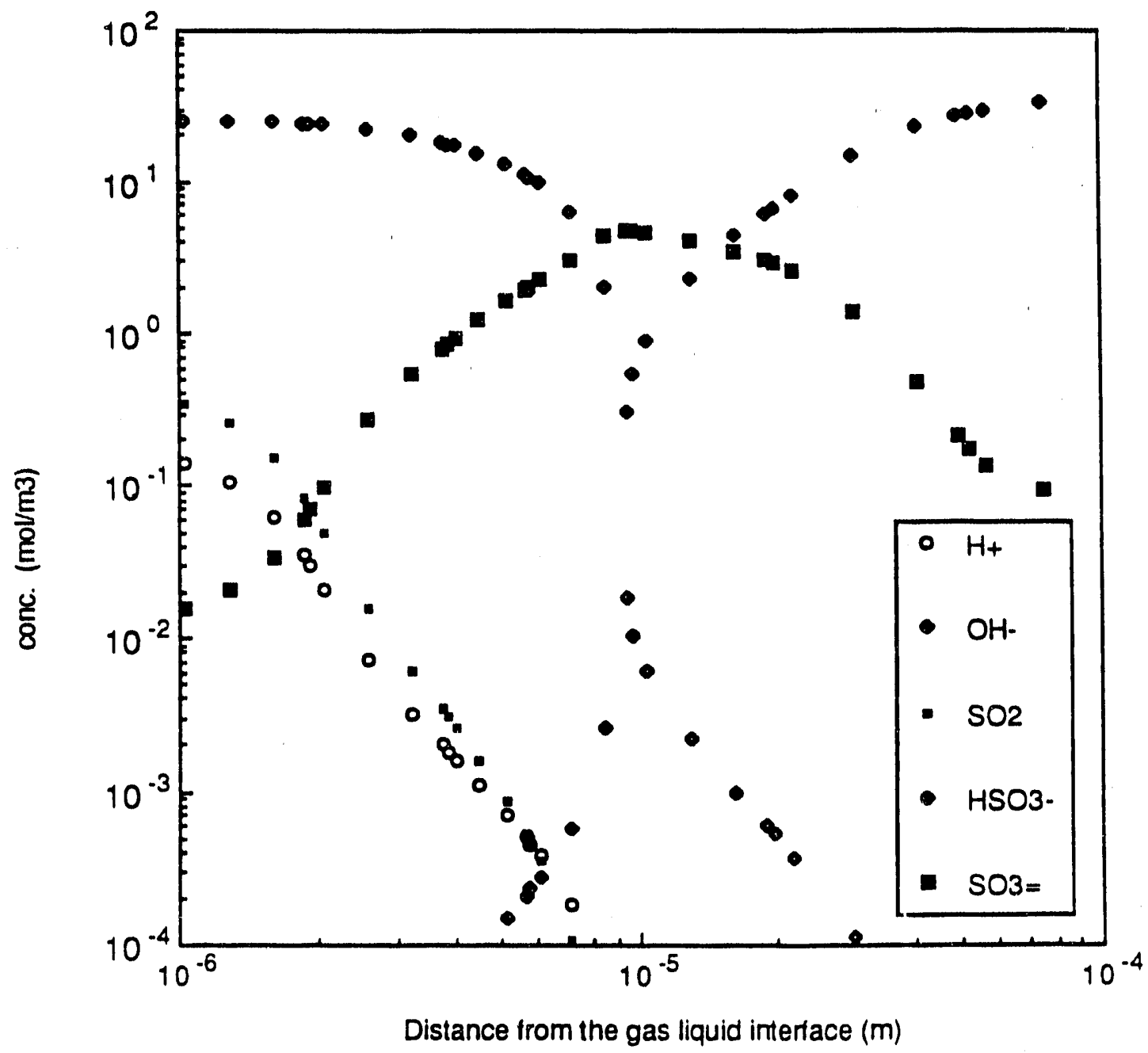

Figure E-20. Concentrations profiles corresponding to 45 percent gas film resistance. $\mathrm{No} \mathrm{Ca}(\mathrm{OH})_{2}$ (s) in the liquid bulk. $200 \mathrm{~Pa} \mathrm{SO}_{2}, 100 \mu \mathrm{m}$ droplet, $1.6 \mathrm{~s}$ contact time. 


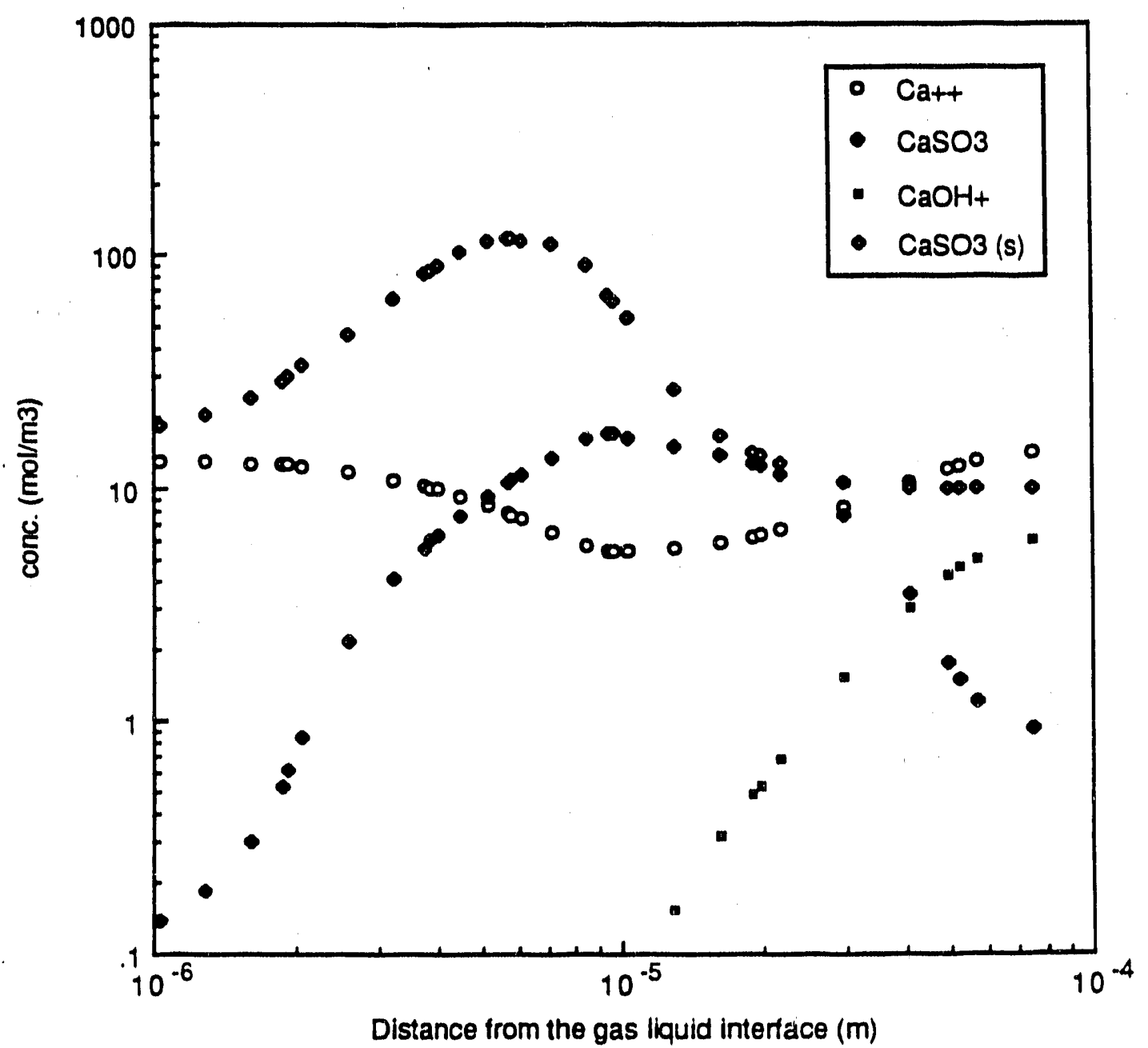

Figure E-21. Concentration profiles corresponding to a gas film resistance of 45 percent. No $\mathrm{Ca}(\mathrm{OH})_{2}(\mathrm{~s})$ in the liquid bulk. $200 \mathrm{~Pa} \mathrm{SO}_{2}, 100 \mu \mathrm{m}$ droplet, $1.6 \mathrm{~s}$ contact time. 


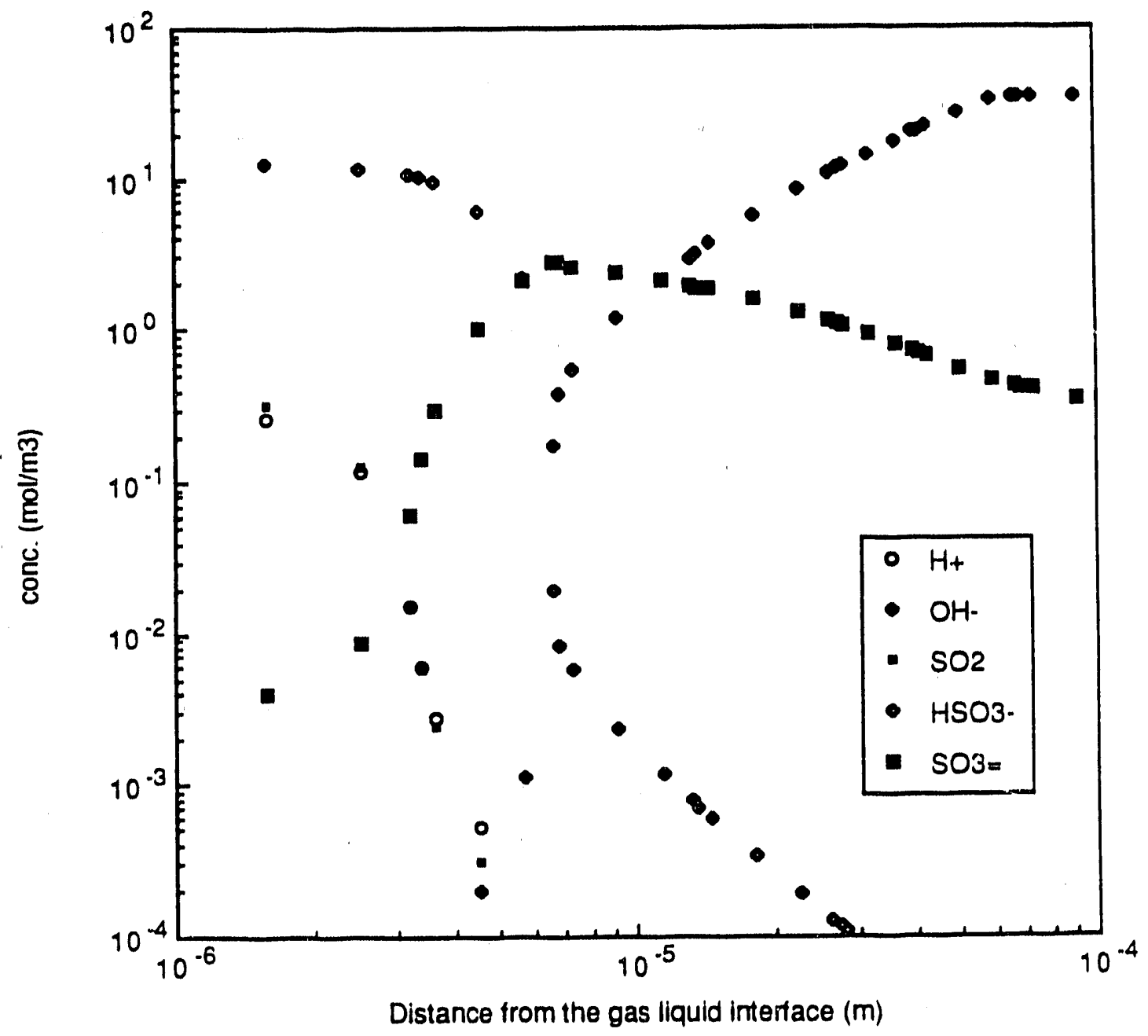

Figure E-22. Concentration profiles corresponding to 45 percent gas film resistance with $\mathrm{Ca}(\mathrm{OH})_{2}$ (s) in the liquid bulk. $200 \mathrm{~Pa} \mathrm{SO}_{2}, 500 \mathrm{molm}^{3} \mathrm{Ca}(\mathrm{OH})_{2}, 100 \mu \mathrm{m}$ droplet, $2.0 \mu \mathrm{m}$ $\mathrm{Ca}(\mathrm{OH})_{2}, 8.1 \mathrm{~s}$ contact time. 


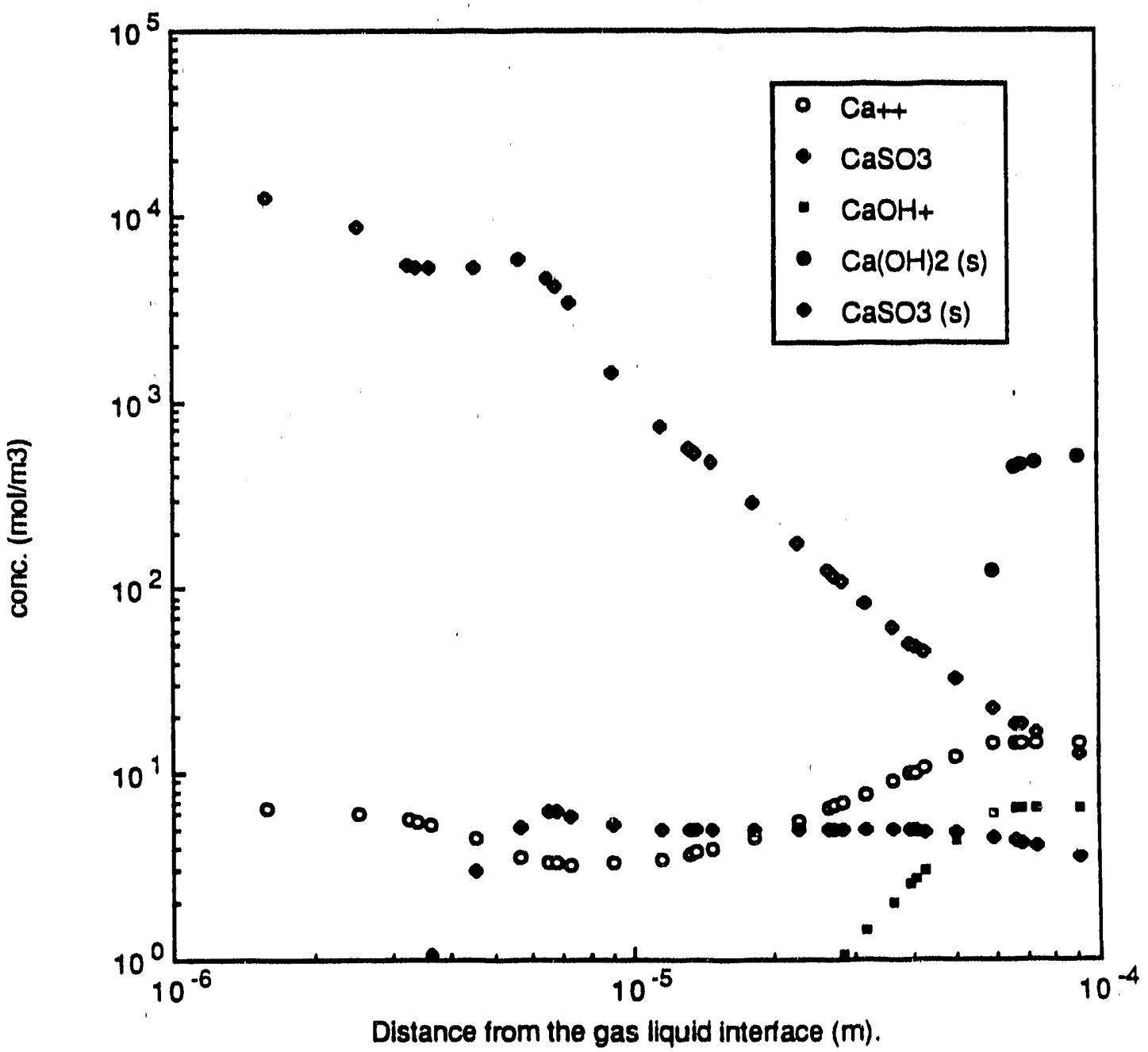

Figure E-23. Concentration profiles corresponding to 45 percent gas film resistance with $\mathrm{Ca}(\mathrm{OH})_{2}$ (s) in the liquid bulk. $200 \mathrm{~Pa} \mathrm{SO}_{2}, 500 \mathrm{~mol} / \mathrm{m}^{3} \mathrm{Ca}(\mathrm{OH})_{2}, 100 \mu \mathrm{m}$ droplet, $2.0 \mu \mathrm{m}$ $\mathrm{Ca}(\mathrm{OH})_{2}, 8.1 \mathrm{~s}$ contact time. 
During the absorption of $\mathrm{SO}_{2}$ into a slurry of calolum hydroxide the partial pressure of $\mathrm{SO}_{2}$ at the gas-liquid interface increases, causing the absorption rate to decrease. Figure E-23 shows how the $\mathrm{P}_{\mathrm{SO} 2}$ I varies with contact time for the same conditions as in Figure E-21 and E-22. Figure E-24 shows how the gas film resistance varies with different concentrations of $\mathrm{Ca}(\mathrm{OH})_{2}(\mathrm{~s})$. At higher concentrations of $\mathrm{Ca}(\mathrm{OH})_{2}(s)$ it takes a longer time for the $\mathrm{Ca}(\mathrm{OH})_{2}(\mathrm{~s})$ front to move away from the gas-liquid interface. When there is no $\mathrm{Ca}(\mathrm{OH})_{2}(\mathrm{~s})$ present in the liquid bulk the gas film resistance is only 60 percent after $0.1 \mathrm{~s}$, while for a $\mathrm{Ca}(\mathrm{OH})_{2}(\mathrm{~s})$ concentration of $1,000 \mathrm{moVm}^{3}$, the gas film resistance is larger than 60 percent up to a contact time of $6 \mathrm{~s}$.

Figures E-25 and E-26 show how the $\mathrm{Ca}(\mathrm{OH})_{2}(\mathrm{~s})$ reactivity affects the absorption rate of $\mathrm{SO}_{2}$. The gas film resistance is plotted versus the ratio between $k_{g}$ and $k_{l}$ for a $k_{g}$ corresponding to a $100 \mu m$ slurry droplet in Figure E-25, and for a $\mathrm{k}_{\mathrm{g}}$ corresponding to a $10 \mu \mathrm{m}$ slurry droplet in Figure E-26. Figures E-27 and E-28 shows how the gas film resistance varies with the penetration distance for different reactivities of $\mathrm{Ca}(\mathrm{OH})_{2}(s)$. The results in Figure $\mathrm{E}-27$ are modeled with a $\mathrm{k}_{\mathrm{g}}$ corresponding to a $100 \mu \mathrm{m}$ slurry droplet and the results in Figure E-28 correspond to a $10 \mu \mathrm{m}$ slurry droplet. The partial pressure of $\mathrm{SO}_{2}$ is $2,000 \mathrm{ppm}$ and the concentration of $\mathrm{Ca}(\mathrm{OH})_{2}(\mathrm{~s})$ is varied from 200 up to $1,000 \mathrm{~mol} / \mathrm{m}^{3}$.

\section{E.7 CONCLUSIONS AND RECOMMENDATIONS}

The theory, experiments and modeling activities of this research allowed for many conclusions to be made about absorption of $\mathrm{SO}_{2}$ into $\mathrm{Ca}(\mathrm{OH})_{2}$ slurries, and validation of the slurry absorption model. Below is a summary of the conclusions that are discussed througnout the preceding sections of this report.

Also during the course of this research, a number of areas which require additional study were identified. Some additional experiments are recommended to address assumptions made in this research. Recommendations are also made for modifying the slurry absorption model. 


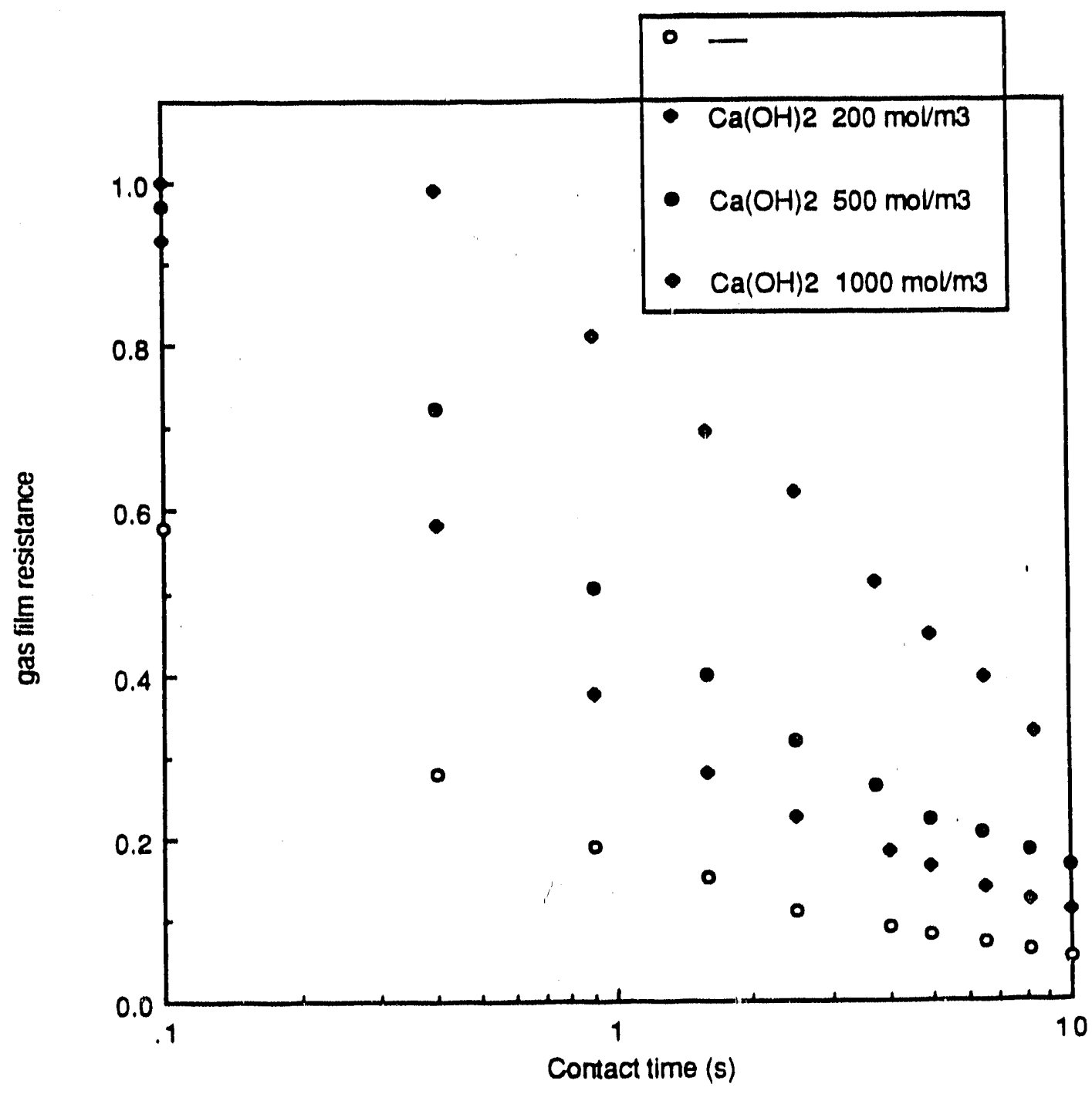

Figure E-24. Gas film resistance versus contact time for different concentrations of $\mathrm{Ca}(\mathrm{OH})_{2}(s)$. $200 \mathrm{~Pa} \mathrm{SO}_{2}, 100 \mu \mathrm{m}$ drop, $5 \mu \mathrm{m} \mathrm{Ca}(\mathrm{OH})_{2}$. 


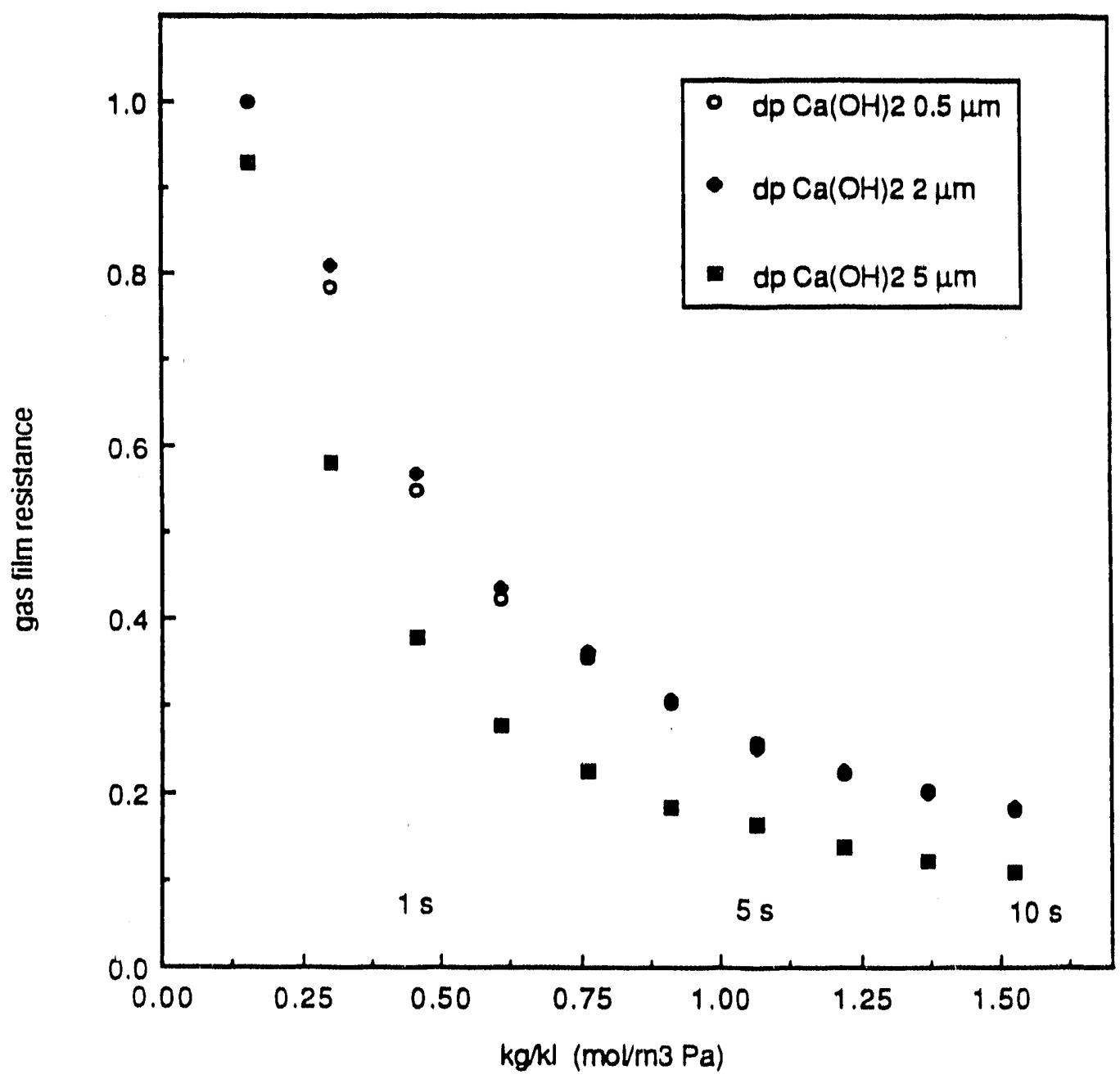

Figure E-25. Gas film resistance versus the ratio between $k_{g}$ and $k_{1}$ for different reactivities of $\mathrm{Ca}(\mathrm{OH})_{2}(\mathrm{~s})$. $\mathrm{k}_{\mathrm{g}}$ corresponds to a $100 \mu \mathrm{m}$ droplet. $200 \mathrm{~Pa} \mathrm{SO}_{2}, 200 \mathrm{~mol} / \mathrm{m}^{3} \mathrm{Ca}(\mathrm{OH})_{2}$ $100 \mu \mathrm{m}$ drop, 0.5-5 $\mu \mathrm{m} \mathrm{Ca}(\mathrm{OH})_{2}$. 


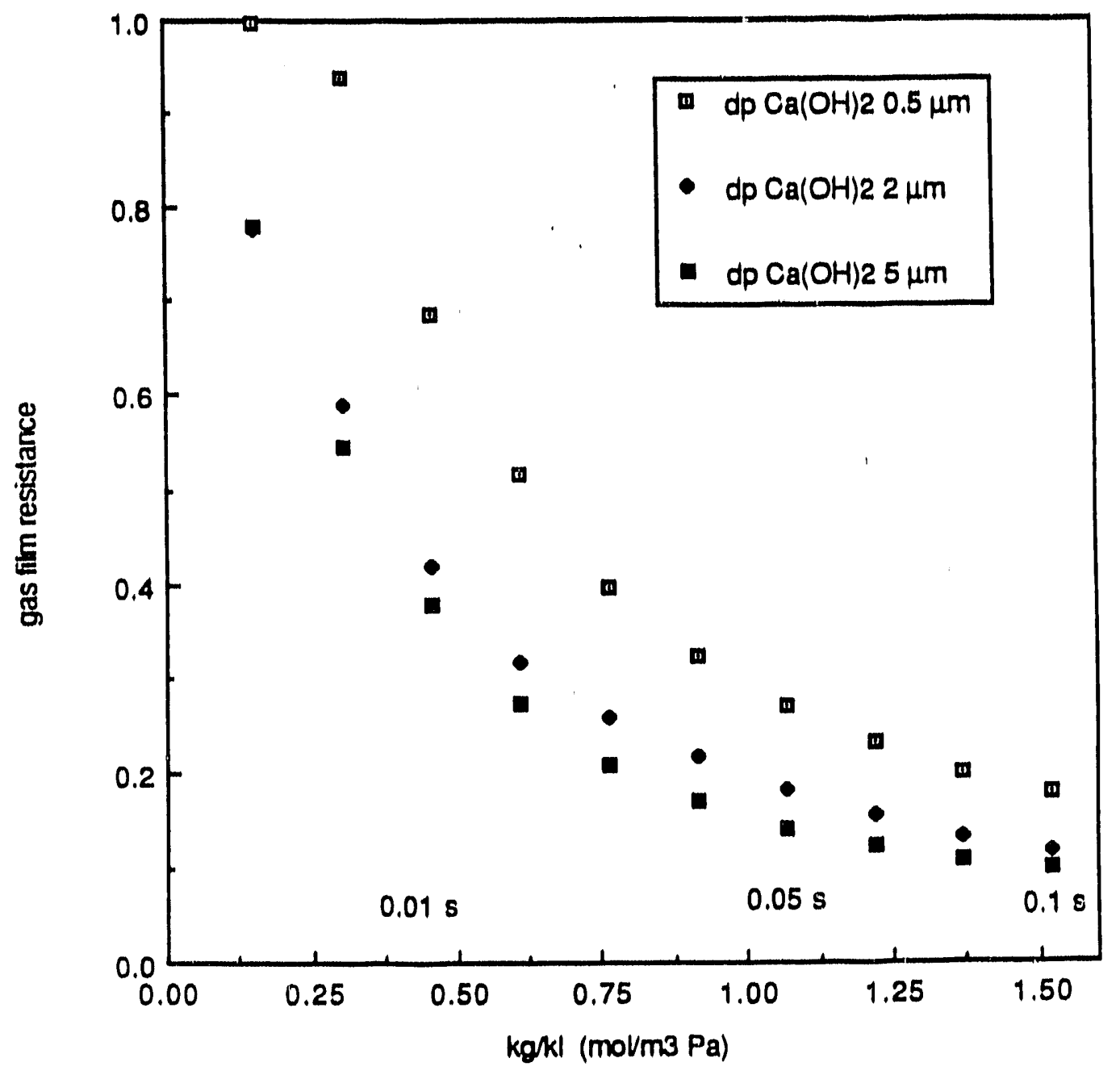

Figure E-26. Gas film resistance versus the ratio between $k_{g}$ and $k_{1}$ for different reactivities of $\mathrm{Ca}(\mathrm{OH})_{2} . \mathrm{k}_{\mathrm{g}}$ corresponds to a $10 \mu \mathrm{m}$ droplet. $200 \mathrm{~Pa} \mathrm{SO}_{2}, 200 \mathrm{~mol} / \mathrm{m}^{3} \mathrm{Ca}(\mathrm{OH})_{2}, 10$ $\mu \mathrm{m}$ droplot, $8.5-5 \mu \mathrm{m} \mathrm{Ca}(\mathrm{OH})_{2}$. 


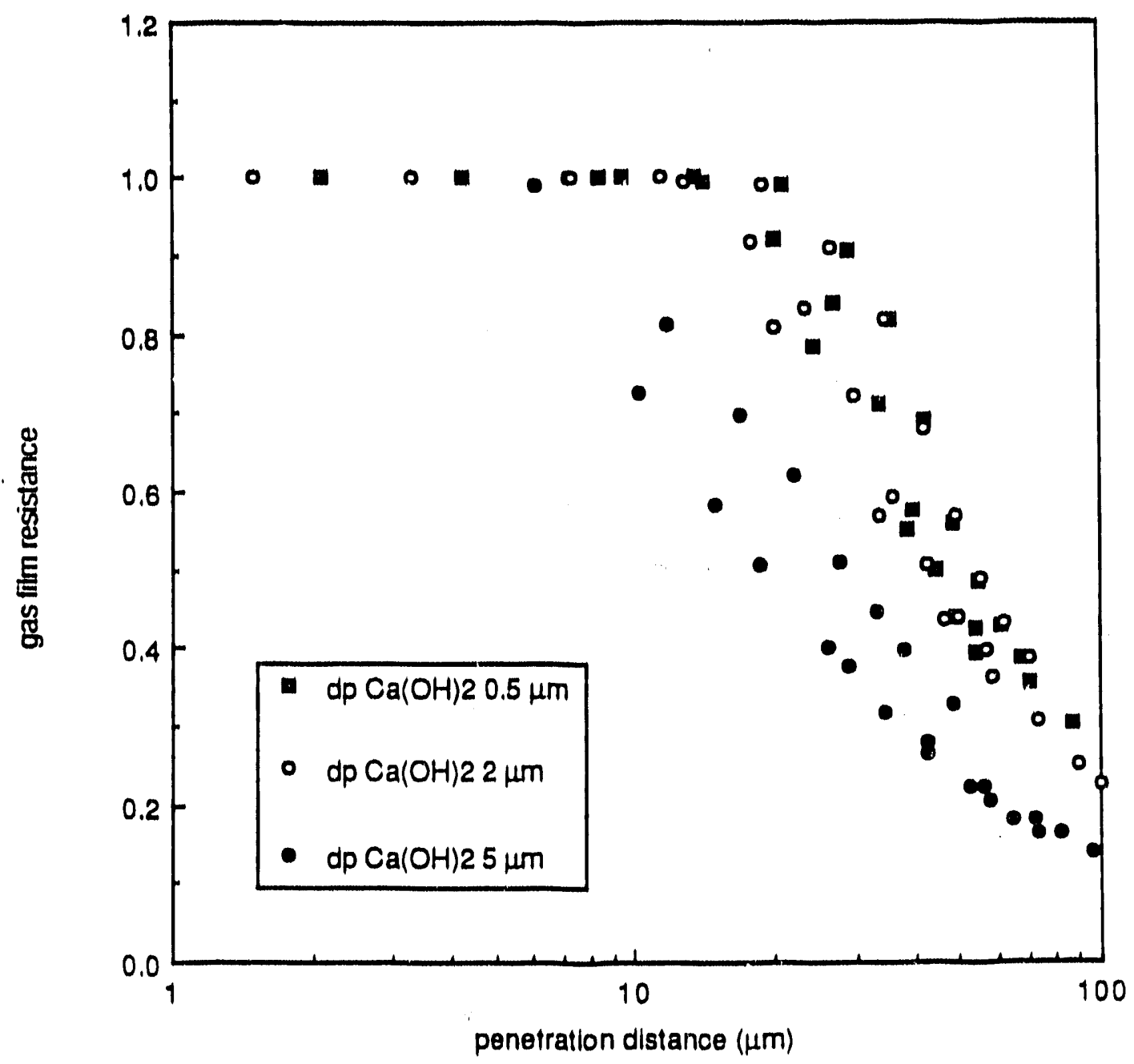

Figure E-27. Gas film resistance versus pentration distance, $200 \mathrm{~Pa} \mathrm{SO}, 200-1,000 \mathrm{~mol} / \mathrm{m}^{3}$ $\mathrm{Ca}(\mathrm{OH})_{2}, 100 \mu \mathrm{m}$ droplet. 


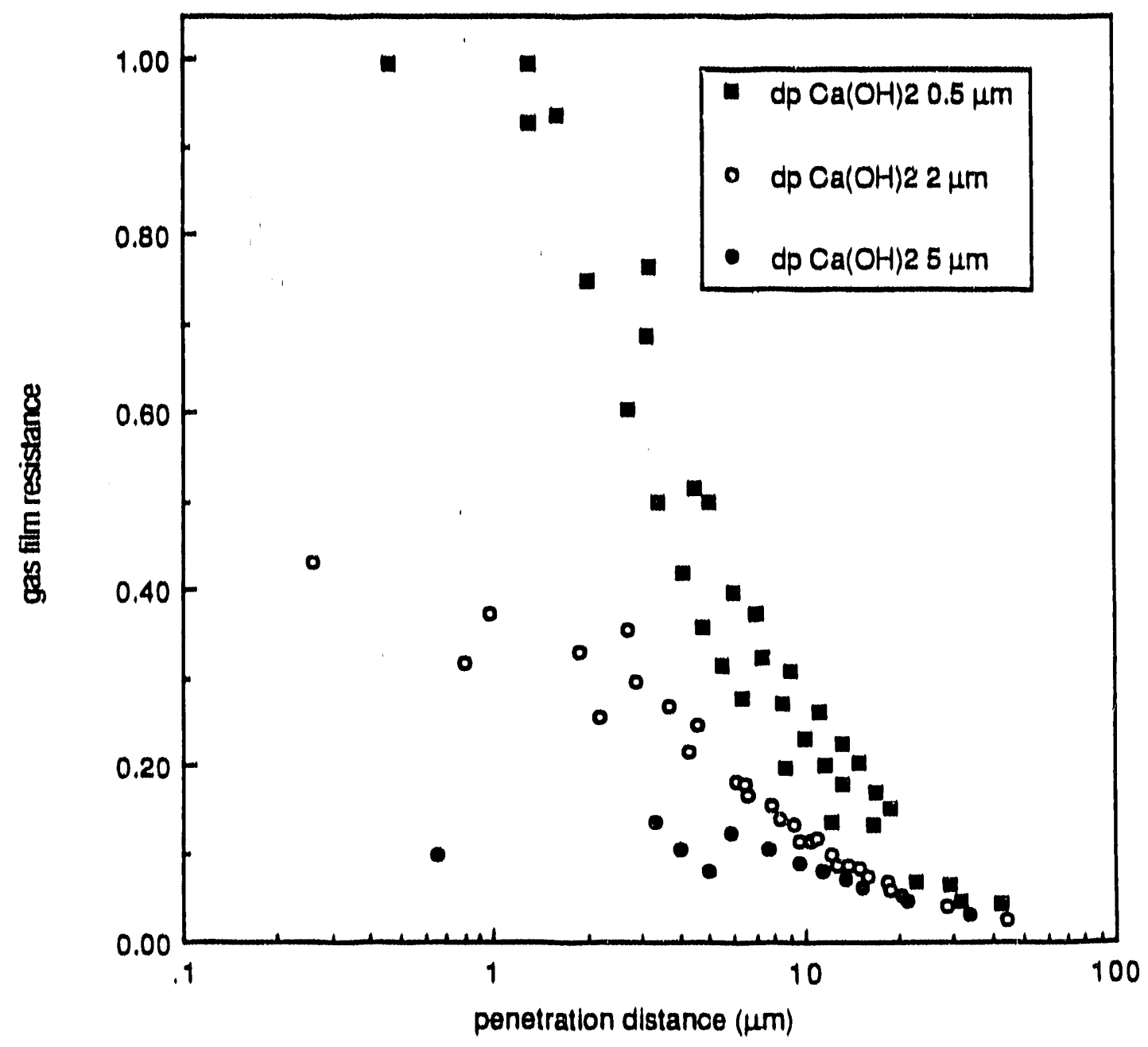

Figure E-28. Gas film resistance versus penetration distance. $200 \mathrm{~Pa} \mathrm{SO}, 200-1,000 \mathrm{~mol} / \mathrm{m}^{3}$ $\mathrm{Ca}(\mathrm{OH})_{2}, 10 \mu \mathrm{m}$ droplet. 


\section{E.7.1 Mass Transter Theory}

1. The surtace renewal theory is the best avallable mass transter model to use for desoribing the absorption of $\mathrm{SO}_{2}$ into $\mathrm{Ca}(\mathrm{OH})_{2}$ slurries. Applied as the penetration theory (assuming constant contact times for slurry elements) absorption of $\mathrm{SO}_{2}$ into slurries can be accurately predicted.

2. The enhancement faotor (normalized flux) is a valuable basis for comparison of absorption. It was proved to be independent of contact time (or $k^{0}$ ), but strongly dependent on $\mathrm{SO}_{2}$ concentration.

\section{E.7.2 Stirred Tank Reaotor Experiments}

1. The stirred tank was designed to maximize the gas film mass transfer coetflolent, $k_{g}$, so that mass transter would be similar to that of a slurry droplet and experiments would not be gas film controlled. However, $k_{g}$ was an order of magnitude less than expected for a typloal droplet and some experiments were gas film controlled.

2. The llquid fllm coefficient, $k^{\circ}$, measured in the stirred tank represented reasonable contact times between 0.7 and $6.6 \mathrm{~s}$. For the range of slurry concentrations studied, $k^{\circ}$ ald not vary due to increased sollds convient (l.e., greater viscosity). Corrections " $\supset k^{0}$, may need to be made to slurries with greater than $1.0 \mathrm{M} \mathrm{Ca}(\mathrm{OH})_{2}$ solids.

3. Gas fllm resistance began to control absorption of $\mathrm{SO}_{2}$ in the reactor when enough sollds were added to the $\mathrm{Ca}(\mathrm{OH})_{2} / \mathrm{CaCl}_{2}$ solution to form a slurry. Measurement of enhancement factors for $\mathrm{SO}_{2}$ absorption in slurries could not be made at low $\mathrm{SO}_{2}$ concentrations because gas fllm resistance was too high.

4. Addition of $\mathrm{Ca}(\mathrm{OH})_{2}$ solids greatly enhanced $\mathrm{SO}_{2}$ absorption, although the increment of enhanoement measured in the stirred tank diminished as the slurry solids concentration was increased.

5. Enhancement measured in slurries prepared with $\mathrm{Ca}(\mathrm{OH})_{2}$ from three different sources was virtually the same. 


\section{E.7.3 Model Valldation}

1. The slurry absorption model predioted enhancement factors that compared well with both the surface renewal theory solutions and with the measured enhanoement from clear solution experiments in the stirred tank. However, both the model and the surface renewal theory solutions overpredicted enhancement that was measured in the stirred tank for the case of a $17 \mathrm{mM} \mathrm{Ca}(\mathrm{OH})_{2}$ solution.

2. Adjusting the diffusivity of hydroxide, $\mathrm{D}_{\mathrm{OH}}$, to 40 percent of the referenced value allowed the model to more accurately predict enhancement in the $17 \mathrm{mM} \mathrm{Ca}(\mathrm{OH})_{2}$ solution and in slurries. Adjusting $D_{\mathrm{OH}^{*}}$ did not signiflcantly change the enhancement predicted by the model for dilute $\mathrm{Ca}(\mathrm{OH})_{2}$ solutions.

3. The model predloted the enhancement of $\mathrm{SO}_{2}$ absorption measured in the stirred tank for slurries of low solids content, but predicted higher enhancement than measured in the stirred tank for slumies of high sollds content. Experimental data might be influenced by solids settling in the boundary layer, but it is unclear whether this occurs in droplets.

4. The model predicted Itttle difference in enhancement for changes in particle size (reactivity) of $\mathrm{Ca}(\mathrm{OH})_{2}$ unless the particle size is changed by an order of magnitude. This supports that enhancement is not sensitive to changes in the reactivity of the solids unless the reactivity is grossly different, as found also in stirred tank experiments.

\section{E.7.4 Computer Modeling}

Athough this is not a model of a slurry droplet it seems probable that the absorption of $\mathrm{SO}_{2}$ into a slurry of $\mathrm{Ca}(\mathrm{OH})_{2}$ is in most cases gas film controlled. The contact time when the liquid film resistance becomes important is often too long to be practical. For example, in a spray dryer, the drying of the droplet is so fast that the absorption process, as long as the droplet is wet, will be gas fllm controlled. When the water has evaporated, other processes determine the absorption rate. The only time the liquid film resistance can be of importance is when very unreactive lime is used in small droplets. 


\section{SECTION 1 \\ INTRODUCTION}

Emission control technologies for power plants fall into three categories, depending on where they are applied: before, during or after combustion. Post-combustion, flue gas desulfurization (FGD) processes using calcium-based sorbents have gained interest as promising iechniques. Such processes applied to older power plants must be inexpensive and must be able to retrofit the existing power plant equipment. Several initial studies (Babu, 1988; Bechtel Inc., 1988; Samuel, 1989; Giovanni, 1988; Yoon, 1985) showed that injection of calcium-based sorbents into the existing ductwork of a power plant might be a low cost option worthy of further research. Thus, the DOE-PETC has initiated a comprehensive effort aimed at developing in-duct injection technology to a point of commercial readiness for use by power plants requiring $\mathrm{SO}_{2}$ control in the near future.

A schematic of a typical in-duct injection process is shown in Figure 1-1. Sorbent, typically calcium hydroxide $\left[\mathrm{Ca}(\mathrm{OH})_{2}\right]$, is injected into flue gas which is typically at $130-180^{\circ} \mathrm{C}$ downstream of the air preheater and upstream of the particulate collection device. The dry, reacted sorbent is collected in the existing particulate collector, commonly an electrostatic precipitator, and forms a non-hazardous, dry solid product. Since water is required for the reaction of $\mathrm{SO}_{2}$ and sorbent, the flue gas must either be humidified or the sorbent must be mixed with water and injected as a slurry. In either case, the water that is injected reduces the temperature to about $50-70^{\circ} \mathrm{C}$. Figure $1-1 \mathrm{~A}$ presents the schematic of dry sorbent injection (DSI). In this process, $\mathrm{Ca}(\mathrm{OH})_{2}$ is typically injected into a duct upstream of the water humidification point, but may alternatively be injected downstream of water 


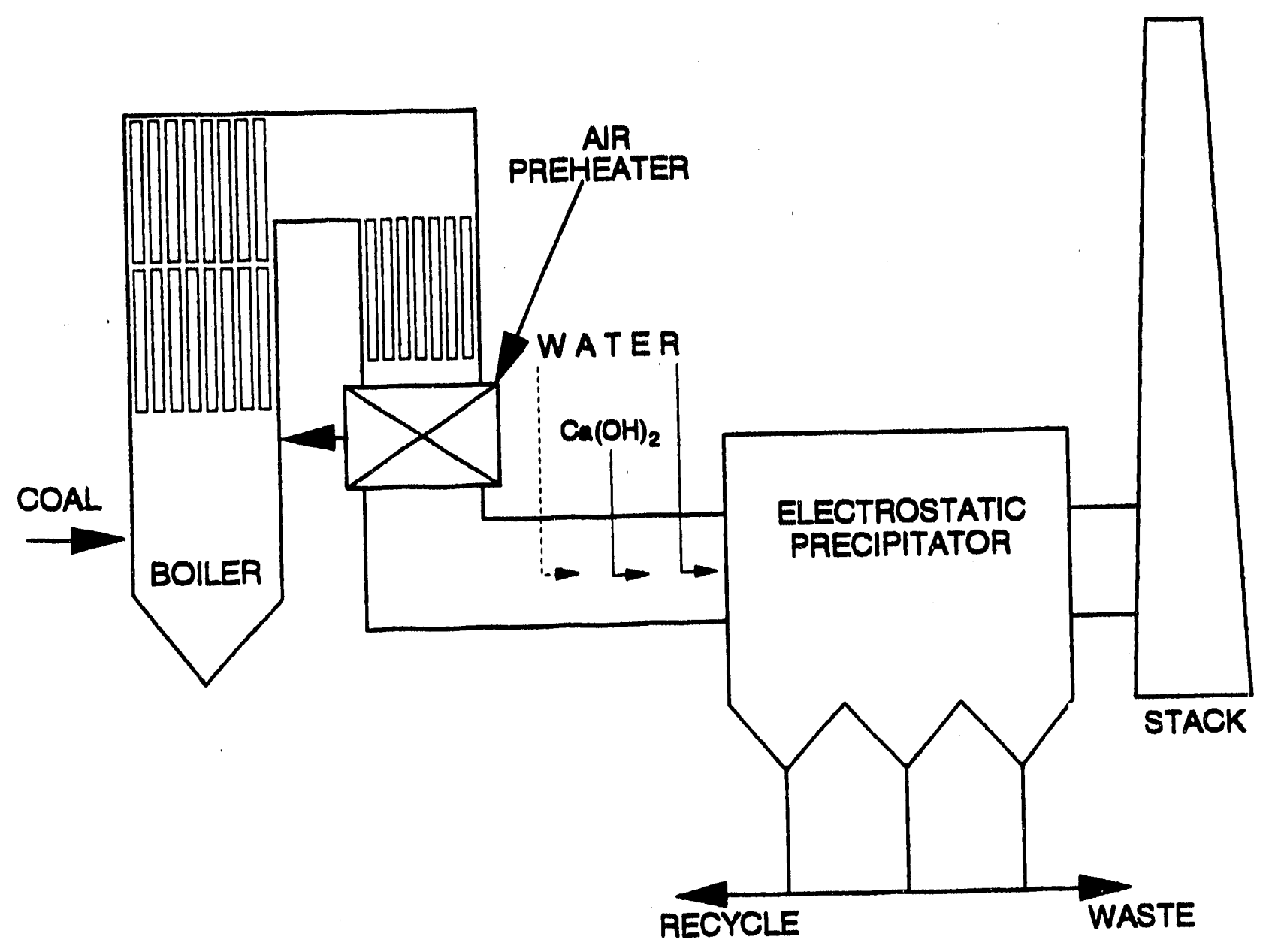

Figure 1-1A. Schematic of the dry sorbent injection (DSI) process. 


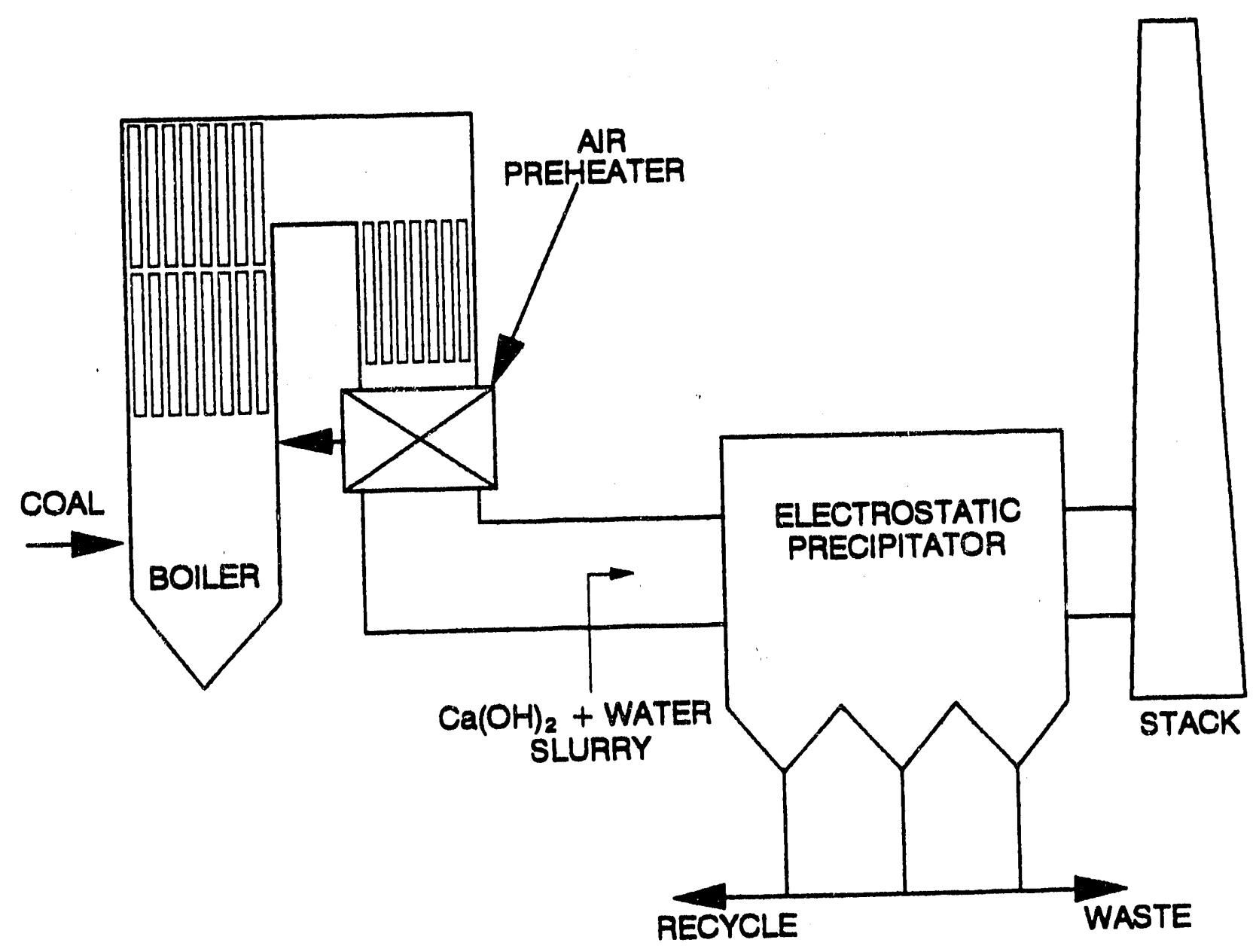

Figure 1-1B. Schematic of the duct spray drying (DSD) process. 
humidification. Figure 1-1B presents the schematic of duct spray drying (DSD) in which $\mathrm{Ca}(\mathrm{OH})_{2}$ slurry is injected into a duct upstream of the existing particulate control device.

Although this in-duct injection technology may be simple to apply and has low capital costs compared to commercially avallable wet scrubbing processes, the economics of this process can be improved substantially by enhancing sorbent utilization. The studies noted above found that the In-ductinjection process is capable of removing about 40 to 60 percent of the $\mathrm{SO}_{2}$ present in the flue gas at a $\mathrm{Ca}$ to $\mathrm{S}$ ratio of 1.5 to 2.0. Therefore, only 20 to 40 percent of the sorbent is typically utllized, depending upon how much sorbent is injected. Techniques which enhance the absorption of $\mathrm{SO}_{2}$ and promote utilization of the sorbent could make the in-duct injection process much more commercially attractive.

In order to improve absorption of $\mathrm{SO}_{2}$ in the in-duct injection process, the overall mechanisms which govern the absorption must be understood. Some basic understanding of these mechanisms has been gained by Energy and Environmental Research (1989), under the same DOE Duct Injection Program. More has been gained through previous studies such as those conducted by Lee (1988), and Harriot (1988). However, the in-duct injection process, although simple in concept, is a very complicated process to describe fully in a theoretical sense, and additional study will be necessary to produce a comprehensive model.

For instance, different mechanisms occur when $\mathrm{Ca}(\mathrm{OH})_{2}$ is injected as a dry powder and mixed with water inside the duct, as opposed to being injected as a slurry. In the first case, the sorbent must impact or "scavenge" the water droplets to form a reactive siurry. Some of the sorbent particles may only become partially wet and never reach a full slurry state. When sorbent is injected as a slurry, mechanisms which become important are the atomization of the droplet (which determines its size) and the droplet drying time. To describe or model these processes involves coupling fluid dynamics and simultaneous heat transier and mass transfer.

Although the general physical or "global" mechanisms are important for predicting the $\mathrm{SO}_{2}$ removal potential of the two types of in-duct injection processes, these mechanisms are not the focus of 
this research. Equally important for prediction of $\mathrm{SO}_{2}$ absorption in these processes is understanding and modeling the absorption of $\mathrm{SO}_{2}$ into a single droplet in the absence of the more complicated global effects. Once the basic mass transfer principles which control $\mathrm{SO}_{2}$ absorption and reaction are understood and described, these principles can serve as a basis upon which to couple the theory describing the global mechanisms. This study focuses on describing $\mathrm{SO}_{2}$ absorption into a single droplet in order to learn more about how the absorption might be enhanced. The experimental work performed in the stirred tank and the other analyses that comprise this section were intended to simulate absorption of $\mathrm{SO}_{2}$ into a slurry droplet.

In addition, the DOE program called for a computer model of $\mathrm{SO}_{2}$ absorption into $\mathrm{Ca}(\mathrm{OH})_{2}$ slurries based on mass transter theories and engineering principles. This computer model was developed and will be used to predict the relative contribution of gas and liquid mass transfer, solid dissolution, and other chemical processes which control $\mathrm{SO}_{2}$ absorption into a slurry droplet under a variety of conditions. The experimental work described in this section supports this effort by providing measurements of the $\mathrm{SO}_{2}$ absorption rate which are used to valldate the rnodel.

It should be noted that this research, atthough funded in support of in-duct injection technology, may be equally as useful in understanding and describing $\mathrm{SO}_{2}$ absorption in $\mathrm{Ca}(\mathrm{OH})_{2}$ slurries used in spray drying applications. Since the results of experiments and the model describe absorption into slurry droplets, the in-duct injection and spray drying processes are essentially the same at this fundamental level. For application of these results to spray dryers, however, slightly longer contact times of 2 to $10 \mathrm{~s}$ would be of more interest.

Three theories have prevailed to describe the type of mass transfer associated with $\mathrm{SO}_{2}$ absomtion into liquid solutions. The oldest and simplest, which serves as a basis for most mass transfer theories, is the film theory proposed by Whitman (1923). In this theory, a concentration gradient from the interface to the bulk solution over a thin film thickness is assumed. In the penetration theory developed by Higbie (1935), mass transfer is determined by how much contact time a fluid element spends at the gas/liquid interface. The third theory for description of gas absorption is the 
surface renewal theory proposed by Danckwerts (1955), which is a generalized version of the penetration theory. This theory, as applied by Chang and Rochelle (1980), is used to predict the mass transfer that governs $\mathrm{SO}_{2}$ absorption in the stirred tank. Chang and Rochelle added the important chemical reactions of $\mathrm{SO}_{2}$ in several solutions and produced equations that were relled on to predict $\mathrm{SO}_{2}$ absorption for this study.

Results of some studies which described and measured gas absorption in slurries and alkaline solutions are discussed in this report and compared to the measured absorption in the stirred tank. Of these studies, only those by Uchida $(1977,1978)$, Sada $(1977,1979)$, and Vivian (1973) specifically reported measurements of absorption of $\mathrm{SO}_{2}$ into $\mathrm{Ca}(\mathrm{OH})_{2}$ slurries. More extensive and valuable information is available regarding absorption of $\mathrm{SO}_{2}$ into alkaline solutions and water. This program also relied heavily on the experimental work of Chang and Rochelle $(1979,1980,1981,1982)$ and Weems and Rochelle (1981) who studied $\mathrm{SO}_{2}$ absorption in several alkaline solutions with emphasis on enhancing the absorption with butfer additives. Others who have reported useful measurements of $\mathrm{SO}_{2}$ absorption in alkaline solutions and water include Sada, et al., (1978) and Hikita et al., $(1977,1978)$. Several researchers reported useful results of gas absorption into slurries other than $\mathrm{Ca}(\mathrm{OH})_{2}$ slurries. Many of the slurries studied were alkaline and involved instantaneous reaction such as that of $\mathrm{SO}_{2}$ in $\mathrm{Ca}(\mathrm{OH})_{2}$ slurries [Uchida $(1975,1977)$, Sada (1981) and Ramachandran (1969)]. Other studies, such as those by Quicker, Alper and Deckwer (1989), Sada and Kumazawa (1982), Holstvoogd, et al. (1986) and Mlyachi, et al. (1981), were useful in determining the effect of increased slurry solids content on mass transfer properties.

Most of the current models of $\mathrm{SO}_{2}$ absorption in slurry droplets have not treated the absorption and reaction of $\mathrm{SO}_{2}$ in a rigorous fashion. Some, such as the model of Jozewicz and Rochelle (1984) began with the assumption that the absorption is controlled by gas film resistance and therefore, do not fully address liquid film resistances based on the complex chemical reactions, or dissolution of $\mathrm{Ca}(\mathrm{OH})_{2}$. Damle (1985) and Karlsson and Klingspor (1987) determined that liquid phase resistances would be minor and constructed models of $\mathrm{SO}_{2}$ absorption controlled by gas film resistances and the 
dissolution of $\mathrm{Ca}(\mathrm{OH})_{2}$. Another model by Maibodi (1986) considered both the gas and liquid film resistances and $\mathrm{Ca}(\mathrm{OH})_{2}$ dissolution and concluded that the absorption of $\mathrm{SO}_{2}$ is controlled primarily by $\mathrm{Ca}(\mathrm{OH})_{2}$ dissolution.

Some of the models allow only a monosized droplet distribution, whereas other more developed models, such as those by Jozewicz and Rochelle and by Kinsey and Harriot $(1986,1988)$, have shown the importance of accounting for the size distribution of droplets in a typical spray. The model of Kinsey and Harriot includes both gas and liquid phase resistances but does not consider $\mathrm{Ca}(\mathrm{OH})_{2}$ dissolution as a controlling process. There are some considerable difterences in the conclusions reached as a result of these modeling efforts. Those that attempt to describe the complex global mechanisms of the absorption in detall typically simplify the calculation of absorption and reaction of $\mathrm{SO}_{2}$ by making assumptions that may not be sufficient. Thus, under this DOE sponsored program, Energy and Environmental Research (1989) has developed a model that focuses on the global mechanisms that affect mass transfer and used a rigorous treatment of the absorption and reaction of $\mathrm{SO}_{2}$ in a slurry droplet.

The objective of this program was to conduct measurements designed to discover the mass transfer processes that limt absorption of $\mathrm{SO}_{2}$, the chemical and physical processes that might affect $\mathrm{SO}_{2}$ absomption and the role of sorbent reactivity. As discussed in Section 1, the experimental data was used to validate the concurrently developed slurry absorption model. Section 2 introduces the mass transfer theory which governs the $\mathrm{SO}_{2}$ absorption process. The stirred tank reactor that was used to pertorm the absorption experiments is described in Section 3 along with a discussion of the methods used to measure absorption of $\mathrm{SO}_{2}$ into the solutions and slurries. Results of $\mathrm{SO}_{2}$ absorption experiments are presented in Sections 4 and 5. The clear solution experiments of Section 4 allow for validation of the model with experimental measurements and theory. The results of slurry experiments described in Section 5 further validate the model. Also, the slurry absorption model was extrapolated to predict $\mathrm{SO}_{2}$ absorption into slurry droplets, and the results are summarized in Section 5. Conclusions reached during the course of this research are discussed throughout the report. Section 6 gives 
detalled discussions of the computer model developed. Section 7 provides a summary of conolusions and recommendations that address the speciflo objectives outlined above. 


\section{SECTION 2 \\ THEORY OF $\mathrm{SO}_{2}$ ABSORPTION IN Ca(OH $)_{2}$ SLURRIES}

This research is focused on describing and measuring the absorption of $\mathrm{SO}_{2}$ from a dilute gas into several solutions and, ultimately, into $\mathrm{Ca}(\mathrm{OH})_{2}$ slurries. Since $\mathrm{SO}_{2}$ reaots instantaneously in the solutions studied, the absorption and reaction of $\mathrm{SO}_{2}$ is controlled, or linited, by mass transfer principles.

The reaction of $\mathrm{SO}_{2}$ with alkaline species occurs in the dissolved or aqueous state. Therefore a number of experiments were designed to measure and describe absorption into the aqueous clear solution. Chang and Rochelle $(1979,1981)$ investigated the absorption of $\mathrm{SO}_{2}$ into aqueous clear solutions and developed equations io predict the absorption rate into solutions undergoing instantaneous reversible reaction.

The absorption and reaction of $\mathrm{SO}_{2}$ becomes more complicated in the presence of an excess of solids. In a $\mathrm{Ca}(\mathrm{OH})_{2}$ slurry, there is an aqueous solution saturated with $\mathrm{Ca}(\mathrm{OH})_{2}$ and containing the remaining excess solids. Reaction with $\mathrm{SO}_{2}$ consumes dissolved $\mathrm{Ca}(\mathrm{OH})_{2}$, which must be replenished. The dissolution rate of $\mathrm{Ca}(\mathrm{OH})_{2}$ is fast but may not be fast enough to maintain a completely saturated bulk solution. Another factor that may be important in influencing the absorption rate of $\mathrm{SO}_{2}$ into slurries is the rate at which $\mathrm{CaSO}_{3}$ crystallizes. As the slurry absorbs and reacts with $\mathrm{SO}_{2}$, the amount of $\mathrm{CaSO}_{3}$ increases in solution and eventually precipitates when the point of $\mathrm{CaSO}_{3}$ saturation is achieved. The crystallization of $\mathrm{CaSO}_{3}$ and its affects on $\mathrm{SO}_{2}$ absorption must also be considered.

A medel was developed to predict the absorption of $\mathrm{SO}_{2}$ into $\mathrm{Ca}(\mathrm{OH})_{2}$ slurries with all of these factors considered. The model combines equations describing the absorption and reaction of $\mathrm{SO}_{2}$, the 
dissolution rate of solid $\mathrm{Ca}(\mathrm{OH})_{2}$, and the crystallization of $\mathrm{CaSO}_{3}$. Experimental results were used to valldate the model.

\subsection{BASIC MASS TRANSFER PRINCIPLES}

For the experiments pertormed for this research, we are interested in describing the absorption of $\mathrm{SO}_{2}$ across a gas/liquid interface into a liquild phase where it is avallable for reaction. Because the reaction of $\mathrm{SO}_{2}$ with the slurry influences the absonption rate, the liquid phase reactions must be considered when describing the mass transfer of $\mathrm{SO}_{2}$.

\subsubsection{Mass Transfer Coetflioients}

Absorption proceeds in two steps. First, $\mathrm{SO}_{2}$ in the gas phase must diffuse from the bulk gas mixture to the intertace. The absorption rate of $\mathrm{SO}_{2}$ to the intertace is described frequently, as in Treybal (1980), in terms of a gas film mass transfer coefficient, $k_{g}$ and the concentration driving force:

$$
N_{\mathrm{SO}_{2}}=k_{g} A\left(P_{\mathrm{SO}_{20}}-P_{\mathrm{SO}_{2}}\right)
$$

Next the $\mathrm{SO}_{2}$ must diffuse from the interface into the bulk llquid. At the interface, the flux of $\mathrm{SO}_{2}$ from the gas must equal the flux of $\mathrm{SO}_{2}$ in the liquild. The absomtion rate of $\mathrm{SO}_{2}$ from the intertace into the bulk liquid is described in terms of a liquid film mass transfer coefficient, $k_{1}$, and the concentration driving force (in mole $/ \mathrm{m}^{3}$ ):

$$
N_{\mathrm{SO}_{2}}=k_{1} A\left(\left[\mathrm{SO}_{2}\right]_{1}-\left[S \mathrm{~S}_{2}\right]_{0}\right)
$$

Reaction of $\mathrm{SO}_{2}$ in the liquid phase can therefore enhance absorption by reducing $\left[\mathrm{SO}_{2}\right]_{0}$ and increasing the liquid fllm mass transfer coefficient, $k_{4}$. A key objective of this research is to determine the degree to which the gas phase and liquil phase driving forces are limiting or controlling the absomtion. The absorption is frequently referred to as "gas film controlled" or "liquid film controlled" for this reason. 


\subsubsection{Enhancement of Absorption With Reactlon}

The following reactions occur when $\mathrm{SO}_{2}$ is absorbed into the solutions and slurrles studled in this research:

$$
\begin{gathered}
\mathrm{SO}_{2}(\mathrm{aq})+\mathrm{H}_{2} \mathrm{O} \Leftrightarrow \mathrm{H}^{+}+\mathrm{HSO}_{3}^{-} \\
\mathrm{HSO}_{3}^{-} \Leftrightarrow \mathrm{H}^{+}+\mathrm{SO}_{3}^{-2} \\
\mathrm{H}^{+}+\mathrm{OH}^{-} \Leftrightarrow \mathrm{H}_{2} \mathrm{O}
\end{gathered}
$$

As previously mentioned, the $\mathrm{Ca}(\mathrm{OH})_{2}$ dissolution and $\mathrm{CaSO}_{3}$ orystallization reactions which follow are also important for absorption of $\mathrm{SO}_{2}$ into slurries:

$$
\begin{gathered}
\mathrm{Ca}\left(\mathrm{OH}_{2}(\mathrm{~s}) \rightarrow \mathrm{Ca}^{2+}+2 \mathrm{OH}^{-}\right. \\
\mathrm{Ca}^{2+}+\mathrm{SO}_{3}^{-2} \Leftrightarrow \mathrm{CaSO}_{3}(\mathrm{~s})
\end{gathered}
$$

As aqueous $\mathrm{SO}_{2}$ is consumed by this series of reactions, the absorption of $\mathrm{SO}_{2}$ is enhanced by increasing the driving force for absorption defined in equation (2-2). The degree to which liquid phase mass transfer is enhanced is quantified by Sherwood, et al. (1975) in terms of the enhancement factor, $\oslash$. The enhancement factor is the ratio of the measured liquid phase mass transfer coefficient, $k_{1}$, and $k_{1}^{\circ}$, the characteristic liquid phase mass transfer coefficient for the conditions that no chemical reactions occur. The $k^{\circ}$ for different experimental conditions is known based on the correlations developed later in Section 3. The value of $\varnothing$ can be deterrinined experimentally from the following relationship:

$$
\mathrm{NSO}_{2}=\varnothing k_{1}^{\circ} A\left(\left[\mathrm{SO}_{2}\right]_{i}-\left[\mathrm{SO}_{2}\right]_{0}\right)
$$


where concentratiory of $\mathrm{SO}_{2}$ in the bulk llquid phase, $\left[\mathrm{SO}_{2}\right]_{0}$ is usually negligible. The absorption rate is known directly trom gas phase material balanoe measurements, and $\left[\mathrm{SO}_{2}\right]_{1}$ is known by applying the following expression of Henry's law to the known gas concentrations:

$$
\left.\left[\mathrm{SO}_{2}\right] /=\mathrm{H} \times \mathrm{PSO}_{2}\right]
$$

\subsubsection{Gas Film Resistanoe}

The percent of gas film resistance reflects the degree to which gas film mass transfer dominates the absorption of $\mathrm{SO}_{2}$. When gas film mass transter dominates the absorption, changes to the liquid phase composition resulting from the previously listed reactions cannot enhance mass transfer further. The transfer of $\mathrm{SO}_{2}$ from the bulk gas phase to the surface of the liquld is the limiting or controlling mechanism. Experiments in very alkaline solutions, such as the experiments in $1.0 \mathrm{M}$ $\mathrm{NaOH}$ described in Section 3, are 100 percent gas film controlled. Experiments in $\mathrm{Ca}(\mathrm{OH})_{2}$ slurries approach 100 percent gas film controlled absorption as the solids content of the slurry is increased. Gas film resistance is defined as:

$$
\text { Gas FilmResistance (\%) }=\frac{p_{\mathrm{SO}_{2 \mathrm{o}}}-p_{\mathrm{SO}_{2}}}{P_{\mathrm{SO}_{2} \mathrm{O}}} \times 100
$$

As gas film resistance approaches 100 percent, the intertace concentration of $\mathrm{SO}_{2}$ becomes Insignificant. In other words, the liquid phase is so reactive towards $\mathrm{SO}_{2}$ that as soon as it is absorbed, It reacts immediately. Enhancement of the liquid phase absorption is thus infinite, and a liquid phase enhancement factor cannot be defined for a gas film controlled absorption. A totally gas film controlled absorption in $\mathrm{Ca}(\mathrm{OH})_{2}$ slurries represents a condition where no properties of the liquid, such as liquid phase mass transfer reactions, $\mathrm{Ca}(\mathrm{OH})_{2}$ dissolution, or $\mathrm{CaSO}_{3}$ crystallization are affecting absorption. Ultimately, this would be the most desirable condition because the absorption rate is maximized.

Below is another way to define gas film resistance that shows its relationship to other important mass transter properties: 


$$
\text { GasFilmRosistanoo }(\%)=\frac{1}{\left(\frac{k_{g}}{H k^{\circ}, \varnothing}\right)+1} \times 100
$$

In many cases, absorption of $\mathrm{SO}_{2}$ into slurries can become gas film controlled. In these Instances, no additives or improvements to the properties of the $\mathrm{Ca}(\mathrm{OH})_{2}$ can improve absorption. The research focuses on determining conditions where the mass transfer is not gas film controlled, so that enhancernent of absorption under these conditions might be improved by altering liquid phase oharacteristios. It was important, therefore, to monitor the degree of gas film resistance encountered during the slurry experiments.

\subsection{ENHANCEMENT PAEDICTED BY SURFACE RENEWAL THEORY}

As found by Chang (1979), predicting the absorption rate of $\mathrm{SO}_{2}$ is complicated by the faot that the absorption is an unsteady state process. Therefore a series of unsteady state material and charge balances must be solved to determine the concentration of constituents that influence absorption. Solutions to the unsteady state equations are made based on assumed boundary conditions. Boundary conditions for the equations are developed from one of a number of theories, as discussed in Section 1 , which have been proposed to describe mass transfer across a fluid surface.

Chang (1979) applled the surface renewal theory to $\mathrm{SO}_{2}$ absomtion into different solutions which represented four different types of equilibrium reactions. Solutions of the unsteady state equations were made for these 4 cases and compared to fllm theory solutions for the same cases given by Olander (1960). By this comparison, Chang and Rochelle found that the surtace renewal theories could be closely approximated by solving the simpler film theory and replacing the speoles diffusivitles by their square roots.

A review of proposed mass transfer models for absorption in stirred tanks by Versteeg, et al. (1987) arrived at a similar conclusion. This study points out that most mass transfer models for gas/liquid absorption, such as those described above, are the same except for the dependence of the mass transfer coefficient on the diffusivity of the absorbed species. Additional review of llquid film mass 
transter coefflolents by Bin (1984) supports this conclusion and goes further to study differences in the geometry of the stirred tank reactor designs and how these differences influence the liquid film mass transfer coettiolent. Since the design of the stirred tank reactor used for this research is similar to that used by Chang, the mass transter coettlolent should be represented well by assuming a deperidence on the square-root of the diffusivity of $\mathrm{SO}_{2}$,

Solutions to the unsteady state surtace renewal theory equations were developed by Chang and Rochelle and reported in terms of the enhancement factor for the absorption. The solutions were verified by several experiments $(1980,1981,1982)$. However, the solutions were not used to predict absorption in $\mathrm{Ca}(\mathrm{OH})_{2}$ slurrles. Clear solution experiments were performed for this research to support experiments performed in slurries. The results of the clear solution experiments are compared in Section 4 to the enharicement factors which result from applying the equations developed by Chang and Rochelle that follow. The enhancement factors are then compared to enhancement predicted by the slurry absorption model, which is described funther below, for model validation.

\subsubsection{Enhancement in Water}

The surface renewal theory solution for $\mathrm{SO}_{2}$ absorption in water is based on the reaction represented by equation (2-3). The solution assumes that in an excess of water, $\mathrm{H}_{2} \mathrm{O}$. is not included in the species balance and the blsulfite and hydrogen lons diffuse at the same rate. Thus, the reaction takes the form of $A \Leftrightarrow 2 B$ and the approximate solution to the unsteady state equations takes the form:

$$
\varnothing=1+\frac{\sqrt{D_{H_{S O}^{-}}}}{\sqrt{D_{\mathrm{SO}_{2}}}} \frac{\sqrt{K_{\mathrm{c}} / 4}}{\sqrt{\left[S O_{2}\right]_{1}}-\sqrt{\left[S O_{2}\right]_{0}}}
$$

This relationship shows a linear dependence of $\varnothing$ on $1 / \sqrt{\left[\mathrm{SO}_{2}\right]_{1}}$ when $\left[\mathrm{SO}_{2}\right]_{0}$ can be neglected. The proportionality constant is a function of the diffusivities of $\mathrm{SO}_{2}$ and bisulfite, and the $\mathrm{K}_{\mathrm{o}}$ is the concentration-based equilibrium constant of the reaction represented by equation (2-3). 
In a solution of pure water, $\mathrm{HSO}_{3}{ }^{-}$formed by absorption and reaction of $\mathrm{SO}_{2}$ must diffuse at the same rate as the $\mathrm{H}^{+}$ions that are formed by the reaction. This effect is referred to as ion-pairing and is a result of the condition of electrical neutrality that must exist within the solution. The diffusivities of $\mathrm{HSO}_{3}^{-}$and $\mathrm{H}^{+}$must therefore be equal to an effective diffusivity as follows:

$$
\frac{2}{D_{\text {eff }}}=\frac{1}{D_{\mathrm{HSO}_{3}^{-}}}+\frac{1}{D_{H^{+}}}
$$

Diffusivities of $\mathrm{HSO}_{3}{ }^{-}$and $\mathrm{H}^{+}$at $55^{\circ} \mathrm{C}$ are calculated to be $2.54 \times 10^{-5}$ and $1.78 \times 10^{-4} \mathrm{~cm}^{2} / \mathrm{s}$, respectively, from values reported at $25^{\circ} \mathrm{C}$ by Chan and Rochelle (1981). The diffusivities were corrected for viscosity and temperature differences at $55^{\circ} \mathrm{C}$ using the Stokes-Einstein Equation. The resulting effective diffusivity, $D_{\text {eff }}$, for both species is $4.45 \times 10^{-5} \mathrm{~cm}^{2} / \mathrm{s}$ based on equation (2-13). This effective diffusivity was used instead of $D_{H S O 3}$. in equation (2-12).

\subsubsection{Enhancement in $\mathrm{CaCl}_{2}$ Solution}

For $\mathrm{SO}_{2}$ absorption into a solution containing $\mathrm{CaCl}_{2}$, the bisulfite and hydrogen ions diffuse independently. Thus, the reaction takes the form of $A \Leftrightarrow B+C$ and the approximate solution to the unsteady state equations gives this relationship:

$$
\varnothing=1+\frac{\sqrt{D_{\mathrm{HSO}_{3}^{-}}}}{\sqrt{D_{\mathrm{SO}_{2}}}} \frac{\left[\mathrm{HSO}_{3}^{-}\right]_{i}-\left[\mathrm{HSO}_{3}^{-}\right]_{0}}{\left[\mathrm{SO}_{2}\right]_{i}-\left[\mathrm{SO}_{2}\right]_{0}}
$$

The bulk concentrations of aqueous $\mathrm{SO}_{2}$ and bisulfite can be neglected in most cases. The interfacial bisulfite concentration, $\left[\mathrm{HSO}_{3}\right]_{7}$, is determined from the equilibrium relationship of equation (2-3) as follows:

$$
\left[\mathrm{HSO}_{3}^{-}\right]_{i}=\frac{K_{c 1}\left[\mathrm{SO}_{2}\right]_{i}}{\left[\mathrm{H}^{+}\right]_{i}}
$$


The hydrogen ion concentration is determined by material and charge balances at the interface. Chang (1979) solved these expressions to arrive at:

$$
\begin{gathered}
{\left[\mathrm{HSO}_{3}^{-}\right]_{l}=\frac{\left[\mathrm{HSO}_{3}^{-}\right]_{0}-R\left[\mathrm{H}^{+}\right]_{0}+\sqrt{\left(\left[\mathrm{HSO}_{3}^{-}\right]_{0}-R\left[\mathrm{H}^{+}\right]_{0}\right)^{2}+4 \mathrm{gN}_{01}\left[\mathrm{SO}_{2}\right]_{i}}}{2}} \\
\text { where } R=\frac{\sqrt{D_{H^{+}}}}{\sqrt{D_{\mathrm{HSO}_{3}^{-}}}}
\end{gathered}
$$

Because $\left[\mathrm{HSO}_{3}\right]_{1}$ depends on the square root of $\left[\mathrm{SO}_{2}\right]_{1}$, this theory again shows a dependence of $\varnothing$ on $1 / \sqrt{\left[\mathrm{SO}_{2}\right]_{i}}$.

This differs from the expression for enhancement in water, equation (2-12), only because diffusion of $\mathrm{HSO}_{3}{ }^{-}$and $\mathrm{H}^{+}$are considered independently. Therefore, the additional enhancement observed in the experiments in $\mathrm{CaCl}_{2}$ solutions is a result of $\mathrm{Cr}$ being present, allowing $\mathrm{HSO}_{3}{ }^{-}$and $\mathrm{H}^{+}$ to diffuse independently. In other words, the reaction of $\mathrm{SO}_{2}$ in the $\mathrm{CaCl}_{2}$ solution is not inhibited by the ion-pairing effect.

\subsubsection{Enhancement in Dilute $\mathrm{Ca}(\mathrm{OH})_{2}$ Solutions}

Chang (1979) were also able to apply the surface renewal theory to absorption in solutions containing dissolved $\mathrm{Ca}(\mathrm{OH})_{2}$. Formation of sulfite is significant in $\mathrm{Ca}(\mathrm{OH})_{2}$ solutions. Therefore, the solution of the unsteady state equations has to be stated in its most general form for the reaction of $A$ $+B \Leftrightarrow C+D$. This analysis showed that enhancement in $\mathrm{Ca}(\mathrm{OH})_{2}$ solutions can be expressed by the following relationship:

$$
\begin{aligned}
\varnothing=1 & +\frac{\sqrt{D_{\mathrm{HSO}_{3}^{-}}}}{\sqrt{D_{\mathrm{SO}_{2}}}}\left(\frac{\left[\mathrm{HSO}_{3}^{-}\right]_{i}-\left[\mathrm{HSO}_{3}^{-}\right]_{0}}{\left[S \mathrm{~S}_{2}\right]_{i}-\left[S \mathrm{SO}_{2}\right]_{0}}\right) \\
& +\frac{\sqrt{\left.D_{\mathrm{SO}_{3}^{2-}}\right]_{i}}}{\sqrt{D_{\mathrm{SO}}}}\left(\frac{\left[S \mathrm{SO}_{3}^{2-}\right]_{i}-\left[S \mathrm{SO}_{3}^{2-}\right]_{0}}{\left[S \mathrm{SO}_{2}\right]_{i}-\left[S \mathrm{SO}_{2}\right]_{0}}\right)
\end{aligned}
$$


The alkaline solution reacts with aqueous $\mathrm{SO}_{2}$ very quickly. Thus, reactions represented by equations (2-3) and (2-4) dominate the liquid phase. In all solutions containing $\mathrm{Ca}(\mathrm{OH})_{2}$ that were tested, $\left[\mathrm{SO}_{2}\right]_{0}$ and $\left[\mathrm{HSO}_{3}{ }^{-}\right]_{0}$ were found to be insignificant. Virtually all of the sulfur species present in the bulk liquid phase were completely converted to sulfite.

The interfacial concentrations of sulfite and bisulfite are not known but are related to $\left[\mathrm{H}^{+}\right]_{1}$ and $\left[\mathrm{SO}_{2}\right]_{1}$ by the equilibrium relations for the reactions of equations (2-4) and (2-5). The expression for $\left[\mathrm{HSO}_{3}\right]_{1}$ was shown in equation (2-15). The equilibrium expressions for $\left[\mathrm{SO}_{3}{ }^{2}\right]_{1}$ and $[\mathrm{OH}]_{1}$ are defined as follows:

$$
\begin{gathered}
{\left[S O_{3}^{2-}\right]_{i}=\frac{K_{c 1} K_{c 2}\left[S O_{2}\right]_{i}}{\left[H^{+}\right]_{i}^{2}}} \\
{\left[\mathrm{OH}^{-}\right]_{i}=\frac{K_{w}}{\left[H^{+}\right]_{i}}}
\end{gathered}
$$

When the appropriate bulk concentrations are neglected and the two equilibrium expressions are applied to equation (2-17), the equation for the enhancement factor becomes:

$$
\varnothing=\frac{\sqrt{D_{\mathrm{HSO}_{3}^{-}}}}{\sqrt{D_{\mathrm{SO}_{2}}}} \frac{K_{c 1}}{\left[H^{+}\right]_{i}}+\frac{\sqrt{D_{\mathrm{SO}_{3}^{2-}}}}{\sqrt{D_{\mathrm{SO}_{2}}}}\left(\frac{K_{c 1} K_{\mathrm{c2}}}{\left[\mathrm{H}^{+}\right]_{i}^{2}}+\left[\mathrm{SO}_{3}^{2-}\right]_{0}\right)
$$

$\left[\mathrm{H}^{+}\right]_{i}$ can be found by solving the following equation, which was derived by Chang and Rochelle from solution of surface renewal theory material balances for $\mathrm{SO}_{2}$ and acidity:

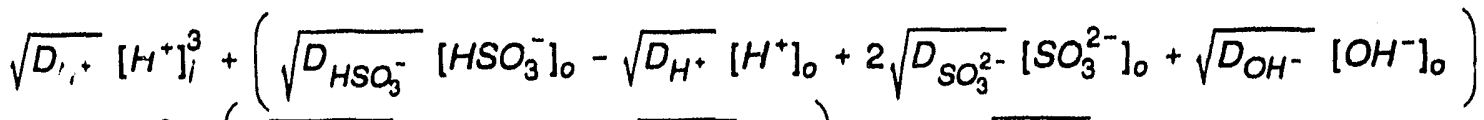

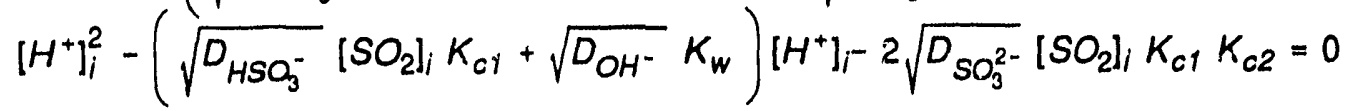

It was found that the last term in this expression was small relative to the other terms, so that $\left[\mathrm{H}^{+}\right]_{1}$ could be solved directly by reducing the expression to quadratic form. 


\subsection{SLURAY ABSORPTION MODEL}

The slurry absorption model was developed by Stromblad and Rochelle (1989) as part of this program. Experiments pertormed for this research are intended to verify the model and draw conclusions about factors which affect $\mathrm{SO}_{2}$ absorption in $\mathrm{Ca}(\mathrm{OH})_{2}$ solutions and slurries. The results of experiments and the model are compared to predictions from the approximate solution of the surface renewal theory equations that were outlined above.

The slurry absorption model consists of 3 parts. The first part simulates absorption of $\mathrm{SO}_{2}$ into the solution, which is enhanced by chemical reaction. The $\mathrm{SO}_{2}$ absomtion calculation is based on the penetration theory. The second part of the model includes dissolution of $\mathrm{Ca}(\mathrm{OH})_{2}$ solids in the solution based on the film theory. The third part consists of $\mathrm{CaSO}_{3}$ crystallization calculated from a rate expression deveioped experimentally by Gleason and Rochelle (1987). The expressions developed in each of these 3 parts are coupled nonlinear differentlal equations which are solved numerically on the Cray X-MP at the University of Texas Center for High Performance Computing.

The approximate solutions to the surface renewal theory developed by Chang and Rochelle differ from the slurry absorption model in a few ways. First, the approximate solutions to the surface renewal theory calculate a time-averaged flux of $\mathrm{SO}_{2}$ and do not solve the unsteady-state equations directly. The slurry absorption model provides a rigorous solution to the unsteady-state equations. Thus, in the approximate solutions developed by Chang and Rochelle, $\mathrm{p}_{\mathrm{SO}_{2 i}}$ is assumed to be constant. The slurry absorption model allows for $p_{S O 2 \mid}$ to vary with time.

Secondly, the approach used by Chang and Rochelle does not allow for the presence of a potential gradient to exist in the boundary layer of the solution. Although such a gradient might be small if it exists, the slurry absorption model allows for the presence of a small potential gradient due to the relative diffusion of charged species.

Lastly, there is a fundamental difference in the theories supporting the model and those in the approximate solutions of Chang and Rochelle. The slurry absorption model is based on the penetration theory, whereas the solutions of Chang and Rochelle are actually film theory solitions that approximate 
the surface renewal theory. Chang and Rochelle documented that their modifled film theory solutions approximated the surface renewal theory well in most cases. However, some conditions might exist in which differences in the theories might cause dispartiy in predicted $\mathrm{SO}_{2}$ absorption.

The slurry absorption model has been run successfully to simulate the clear solution experiments pertormed in the reactor to verify the first part of the model. The model was also run for conditions which simulate the experiments performed in slurry solutions to verify the second part of the model. No experiments were run specifically to verify the third part of the model. Although the effects of $\mathrm{CaSO}_{3}$ crystallization may be relatively less significant than the first two parts of the model, some experimental work should be done in the future to fine tune the model with respect to $\mathrm{CaSO}_{3}$ crystallization.

\subsubsection{Absorption With Reaction}

The model uses the penetration theory to develop the boundary conditions necessary to solve the unsteady state differential mass balance equations for the absorption of $\mathrm{SO}_{2}$. Each element of llquid at the surface is exposed to the gas for the same length of time, which is defined as $\theta$, the contact time. During its time at the surface, the liquid element is assumed to be stagnant.

The unsteady state material balances are included for total S(IV) species, calcium species, and chloride. A charge balance at the interface is made equal to zero by adjusting the level of chloride in the solution. Also, the fluxes of calcium and chloride are set equal to zero at the interface. Solution of the equations proceeds by recognizing that the absorption rate of $\mathrm{SO}_{2}$ is equal to the sum of the S(IV) fluxes at the interface. This treatment of the unsteady-state equations allows for a small potential gradient to exist in the solution due to the relative differences in diffusion of charged species.

\subsection{2 $\mathrm{Ca}(\mathrm{OH})_{2}$ Solids Dissolution}

The unsteady state material balance for calcium requires that the rate of dissolution of $\mathrm{Ca}(\mathrm{OH})_{2}$ be known. To calculate the dissolution rate, the $\mathrm{Ca}(\mathrm{OH})_{2}$ particles are assumed to be spherical particles in an infinite stagnant solution. Also, the solution is assumed to be saturated with $\mathrm{Ca}(\mathrm{OH})_{2}$ at the surface of the particle. Simple differential mass balances are made for calcium, S(IV) species, and 
for the charge balance. Although solution of these equations is straightionward, the rate of dissolution is complicated by the fact that the size of the particle decreases with time as it dissolves. Also, the .. dissolution rate depends upon the concentration of hydroxide lons in the solution, which is not untiorm. Therefore, the ditssoliston rate of $\mathrm{Ca}(\mathrm{OH})_{2}$ varies with time and distance from the gas/liquid intertace.

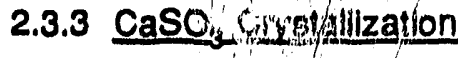

At some point during the absorption, the concentration of $\mathrm{CaSO}_{3}$ reaches a point of supersaturation where solid $\mathrm{CaSO}_{3}$ begins to preciptate. Based on the perork done by Gleason and Rochelle (1987), the rate of orystalization, $R_{c}$, was found to be represented by the following third order expression:

$$
R_{c}=-k_{0}\left(R S_{\mathrm{CaSO}_{3}}-1\right)^{3}
$$

The constant, $k_{c}$, includes both a rate constant and the BET surface area per volume of the $\mathrm{CaSO}_{3}$ crystals. This expression is also a furction of both time and distance from the gas/liquid Interface because $\mathrm{RS}_{\mathrm{CaSO}}$, the relative saturation, depends upon the concentration of $\mathrm{CaSO}_{3}$ in solution which is nonuniform and time dependent.

\subsubsection{Inputs to the Model}

The operating conditions and solution compositions used in the stirred tank experiments had to be specified as inputs to the model. Table 2-1 lists the input variables for the clear solution experiments.

The temperature, contact time, and gas film coefficient, $k_{g}$, remained the same throughout most of the clear solution and slurry model runs. Contact time was varied on a few occasions to verify that it

TABLE 2-1. INPUT VARIABLES FOR THE SLUAAPY ABSORPTION MODEL USED IN CLEAR SOLUT ON TESTS

\begin{tabular}{|l|c|}
\hline Operating Conditions & $\mathrm{PsO}_{2}, \mathrm{~K}_{\mathrm{g}}$, contact time, temperature, $\mathrm{pH}$ \\
\hline Solution Composition & $\mathrm{Ca}^{2+}, \mathrm{Mg}^{2+}, \mathrm{Na}^{+}, \mathrm{K}^{+}, \mathrm{SO}_{3}{ }^{2-}, \mathrm{SO}_{4}{ }^{2-}, \mathrm{CO}_{3}{ }^{2-}, \mathrm{Cl}^{-}, \mathrm{H}_{2} \mathrm{O}$ \\
\hline
\end{tabular}


does not have an appreciable effect on the absorption rate. Model runs for each solution composition were performed with the bulk gas phase $\mathrm{SO}_{2}$ concentration, $\mathrm{P}_{\mathrm{SO} 2}$, set at $500,1,000,2,000,3,000,4,000$ and $5,000 \mathrm{ppm}$. The $\mathrm{pH}$ and ion concentrations were set to values which represented the liquid phase at steady state in the stirred tank reac:a?.

The first step of the model calculation is to determine the concentrations and activity coefficients of important species, concentration based equilibrium constants, and the Henry's law constant. This is done by using the Bechtel Modified Radian Equilibrium Program, BMREQ (Epstein, 1975), with the specifled solution composition, $\mathrm{pH}$ and temperature. Estimated diffusivities of important species used by the model are listed in Table 2-2. In general, values were obtained at $25^{\circ} \mathrm{C}$ from Chan and Rochelle (1981) and corrected for the change in viscosity and temperature at $55^{\circ} \mathrm{C}$ using the Stokes-Einstein relationship. Together, this information provides all the necessary input for the main program to pertorm the absorption calculations.

TABLE 2-2. ESTIMATED DIFFUSIVITIES OF IMPORTANT SPECIES USED BY THE SLURRY ABSORPTION MODEL $\left(\mathrm{cm}^{2} / \mathrm{s} \times 10^{5}\right)$

\begin{tabular}{|l|c|c||}
\hline Species & $25^{\circ} \mathrm{C}$ & $55^{\circ} \mathrm{C}$ \\
\hline $\mathrm{H}^{+}$ & 9.31 & 17.8 \\
\hline $\mathrm{OH}^{-}$ & 5.24 & 10.0 \\
\hline $\mathrm{SO}_{2}$ & 2.00 & 3.83 \\
\hline $\mathrm{HSO}_{3}{ }^{-}$ & 1.33 & 2.54 \\
\hline $\mathrm{SO}_{3}^{-2}$ & 0.96 & 1.84 \\
\hline $\mathrm{Ca}^{+2}$ & 0.79 & 1.51 \\
\hline $\mathrm{CaSO}_{3}{ }^{\circ}$ & 0.53 & 1.01 \\
\hline $\mathrm{CaOH}^{+}$ & 0.79 & 1.51 \\
\hline $\mathrm{Cl}^{-}$ & 2.03 & 3.88 \\
\hline
\end{tabular}




\subsubsection{Model Output}

The model provides several forms of output. Since the absorption rate is generally a function of the contact time, $\theta$, the model lists the output for 10 periods of time over a specified range of $\theta$. Therefore, each time the model is run, information is available for 10 incremental contact times. The most useful model output for the purposes of this study was the average absorption rate of $\mathrm{SO}_{2}, \mathrm{~N}_{\mathrm{SO}_{2}}$. The model calculates an average absorption rate (as opposed to an instantaneous absorption rate) from the following equation, and reports the average $\mathrm{N}_{\mathrm{SO} 2}$ at 10 contact times:

$$
\overline{S_{O_{2}}}=\frac{1}{\theta} \int_{0}^{\theta} N_{S O_{2}} d t
$$

The average absorption rate at a specified contact time was measured in the stirred tank and reported in terms of the enhancement factor, $\varnothing$. To compare the results from the stirred tank experiments to the absorption rate predicted by the model, the average $\mathrm{N}_{\mathrm{SO} 2}$ computed as above by the model is also expressed in terms of the enhancement factor. To arrive at the value of the enhancement factor, the expression for liquid phase absorption, equation (2-8) is solved for $\emptyset$ using the average $\mathrm{SO}_{2}$ absomtion rate given by the model at the contact time of interest.

Also available are concentration profiles of the species lisied in Table 2-2 as a function of distance from the interface as well as a function of the 10 incremental fractions of contact time. Because concentration profiles in the boundary layer could not be measured in the stirred tank, this information was not used directly for comparison to experimental data. .Concentration profiles for several cases were generated by Stromblad and Rochelle (1989). The profiles were screened for their ability to represent expected behavior of chemical species concentrations in the boundary layer. The

model also lists the gas phase concentration of $\mathrm{SO}_{2}$ at the interface, $\mathrm{Y}_{\mathrm{SO}_{2} \text {, }}$ at a series of contact times.

Other useful output of the model is the penetration distance, which defines the liquid film thickness. The model specifies this as the distance from the gas/liquid interface to the point where the concentration of soild $\mathrm{Ca}(\mathrm{OH})_{2}$ particles is half of the concentration in the bulk liquid. The penetration 
distance is also a measure of the amount of solld $\mathrm{Ca}(\mathrm{OH})_{2}$ that has been consumed. Therefore, this definition only applies to slurries. The penetration distance is reported by the model for slurries at each - of the 10 incremental contact times. 


\section{SECTION 3}

\section{EXPERIMENTAL.}

The purpose of the stirred tank reactor experiments is to simulate absorption of $\mathrm{SO}_{2}$ across the gas/liquid interface of a droplet, into slurries of $\mathrm{Ca}(\mathrm{OH})_{2}$ with varied solution compositions. The reactor system is designed to provide a bulk gas phase with a known $\mathrm{SO}_{2}$ concentration in contact with liquild solutions. The area of gas/liquid contact at the interface is known by maintaining a flat, undisturbed surface.

The reactor was designed to approximate the mass transfer properties that are common to slurry droplets. Measurements of the range of gas and liquid film mass transter coefficients in the reactor were made. Mass transfer coefficlents can be varied in the reactor by changing gas and liquid agitator speeds. The reactor is capable of providing a range of liquid film mass transfer coefficients corresponding to contact times from 0.7 to $6.6 \mathrm{~s}$ at $55^{\circ} \mathrm{C}$. The maximum gas film mass transter coefficient available in the reactor was estimated to be one order of magnitude smaller than would be typical for a slurry droplet in the duct.

\subsection{DESIGN OF REACTOR AND SUPPORTING E?ZUIPMENT}

The stirred tank reactor and supporting equipment used to measure the absorption rate of $\mathrm{SO}_{2}$ are pictured in Figure 3-1. This design was based on similar gas/liquid contact devices for which mass transfer properties have been determined by several previous investigators, including Chang and Rochelle (1979), Versteeg (1987), Sada (1981), Huasheng (1988) and Uchida (1978). 


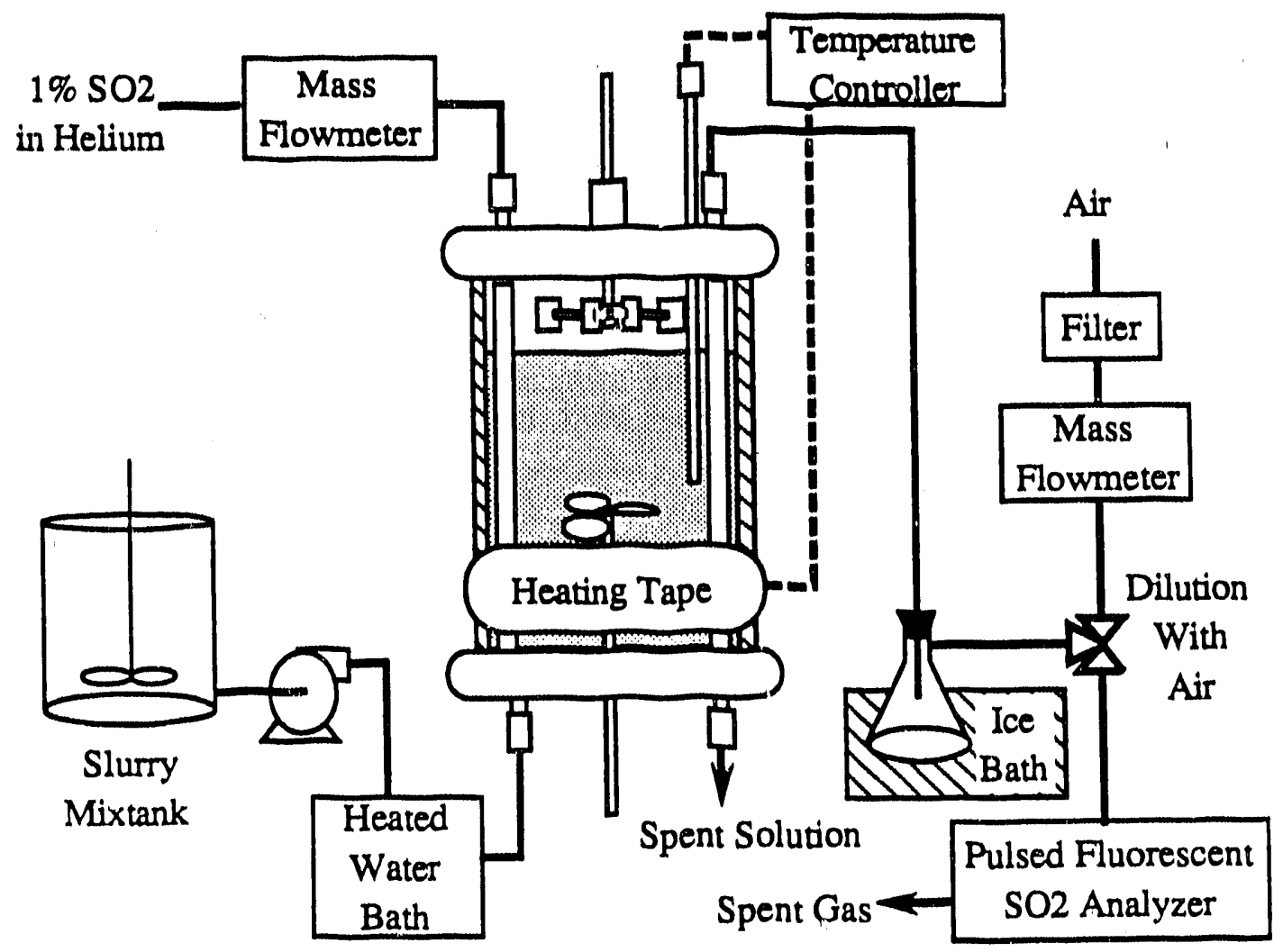

Figure 3-1. Stirred tank reactor and supporting equipment. 
The reactor has a $4-\ln$ diameter and $61 / 2-\ln$ height. The total volume of the reactor is $1.275 \mathrm{~L}$, of which $1.10 \mathrm{~L}$ is the maximum liquild volume. The gas/liquid contaot area is $81 \mathrm{~cm}^{2}$. The reactor vessel is a thick glass oylinder with 316 stainless steel metal plates sealed to the top and bottom by thick gasket clamps. Four $3 / 8-$-In wide, equally-spaced battles of 316 stainless steel are welded to the base plate. The base plate also contains swagelock-fitted ports for liquid inlet and outlet. The top plate contains swagelook-fitted ports for the gas Inlet and outlet and the thermocouple.

Heating tape was wrapped around the reactor anci used with a temperature controller to maintain a constant temperature. Experiments were run at both $25^{\circ} \mathrm{C}$ and $55^{\circ} \mathrm{C}$.

Gas was supplied to the reactor from a standard oylinder containing 1 percent $\mathrm{SO}_{2}$ with a balance of hellum. The flow rate of gas was measured using mass flow meters manufactured by Brooks Instrument Dlvision of Emerson Eleotric Company. The models used were series $5850 \mathrm{E}$ and C. Three sizes of mass flow meters were used, depending upon the range of flow rate of gas that was required for the experiment. These included flow meters with capactties of $1 \mathrm{~L} / \mathrm{min}, 5 \mathrm{~L} / \mathrm{min}$, and 100 $\mathrm{mL} / \mathrm{min}$. The output of the mass flow meters was displayed in percent of full capacity on a Brooks model $\mathbf{5 8 7 8}$ dightal readout device. This device had multiple channels, allowing selection of the readout for up to 4 mass flow meters.

Gas was continuously removed from the reactor for $\mathrm{SO}_{2}$ analysis using a Thermo Electron Model 40 source-level pulsed-fluorescent $\mathrm{SO}_{2}$ analyzer. The range of the analyzer was typically set at the 0 to $1,000 \mathrm{ppm}$, or 0 to $5,000 \mathrm{ppm}$ scale. The $\mathrm{SO}_{2}$ concentration was read from a digital readout device on the PID controller, which accepted the analyzer signal as an input. Prior to entering the analyzer, water vapor was condensed in a chilled flask.

It was determined that dilution of the sample stream with air was necessary for 2 reasons. First, because the sample stream contained mostly hellum, the analyzer pump had diftlculty providing adequate sample flow because of the difference in density of the gas. Secondly, the amount of sample drawn from the reactor was less than the $2 \mathrm{~L} / \mathrm{min}$ required by the analyzer. Although the analyzer was plumbed with a recirculation loop, the analyzer required a larger amount of sample than the reactor 
provided. Dilution alr was added at a 10:1 ratlo to sample and was measured with mass flow meters of $20 \mathrm{~L} / \mathrm{min}$ or $5 \mathrm{~L} / \mathrm{min}$ capaolty.

Liquild was generally fed continuously to the reactor, although some experiments were pertormed with liquid introduced in batch mode. The continuous flow system required a feed tank, a peristaltic pump and a waste collection bucket. A $10 \mathrm{gal} \mathrm{mix}$ tank with mounted aghtator was added to the system for testing with slurries.

The pump had a capacity to dellver $205 \mathrm{~mL} / \mathrm{min}$. Two heads were installed on the pump to dellver and whthdraw llquid at the same rate. This provided a relatively stable llquid level in the tank, although the level tended to drop a few millimeters over the course of a minute. A mark was made on the wall of the reactor $3 / 4$ in below the top of the glass reactor vessel to indicate the level where experiments would be performed. The liquid level was monitored constantly and adjusted manually by pinohing the liquid extt stream tubing. This maintained the level to within $1 / 8$ in of the mark throughout the tests.

\subsubsection{Agltation}

An important feature of the reactor design is that the gas and liquid phases are stirred Independently. Both liquid and gas phases had dedicated agitators with separate speed control mechanisms. Agitators were each set at the desired speed setting, and the speed was measured using a hand-held tachometer. This allowed for higher speed agitation of the gas phase relative to the llquid phase. The liquid phase agltation was strong enough, at speeds of approximately $1,100 \mathrm{rpm}$, to disturb the interface. Thus, experimental conditions were limited to liquid agltation speeds of less than $1,100 \mathrm{rpm}$

Experiments required that gas agttation be maximized to maintain a high gas film mass transfer coefficient. Most experiments were performed at the maximum gas agitation speed of approximately $1,400 \mathrm{rpm}$. Another advantage of Independent agitation was that the amount of agitation In the liquid could be changed while maintaining a constant gas agitation speed. Therefore, the liquid and gas film mass transfer coefficients could be varled independently in the reactor. 
At the maximum agitation speed of $1450 \mathrm{rpm}$, the gas phase agitation was not strong enough to disturb the interface. Additional propeller designs were tested to dlscover if turbulence could be increased at the maximum speed. A 2.0-In dlameter turbine-type propeller was chosen to improve turbulence. This propeller was designed to produce high shear and moderate numping aotion. To improve gas fill'n mass transter further, the propeller was modifled, Inoreasing the blade lengths to 2.5In dlameter. A comparison of gas film mass transfer coefficients measured with each propeller is made later in this section. The varlous propellers used are shown in Figure 3-2.

Both the top and bottom plates of the reactor were originally fitted with Teflon O-ring seals for. the agitator shafts. The llquid phase agitator was typloally operated between 200 and $1100 \mathrm{rpm}$ without disturbing the liquid surface. At these lower speeds, the O-ring seal was sufficient. O-rings required replacement after approximately 50 to $100 \mathrm{~h}$ of operation, depending upon agitation speeds of the tests performed. However, these seals were found to be inadequate for constant operation at higher speeds of 1,300 to $1,450 \mathrm{rpm}$ required by the gas phase agitator. The upper plate of the reactor was redesigned with a mechanical (vacuum pump) shat! seal. Although more diffloult to allgn, this shaft seal pertormed well throughout testing.

\subsubsection{System Irnprovements}

As experiments were pertormed, some changes to the original design were made to improve accuracy and functionality. Original design allowed only for manual control of the gas flow rate. One of the first improvements was the addition of a PID controller to monitor the analyzer $\mathrm{SO}_{2}$ concentration output and automatically adjust the rate of gas flow to the reactor, a very useful adaption for the sets of experiments performed at a constant $\mathrm{SO}_{2}$ level.

In Initial measurements of the gas film mass transfer coefficient, there was suspicion that incomplete gas mixing was occurring as the gas entered the reactor, especially at high flow rates. Gas entered the reactor vertically, from the top plate and may have been impinging directly on the surface of the liquid without mixing with the bulk gas. This area of impingement would experience a higher gas 


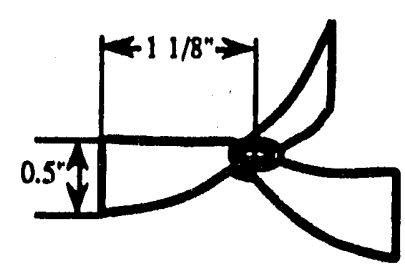

Original Gas

Phase Propeller

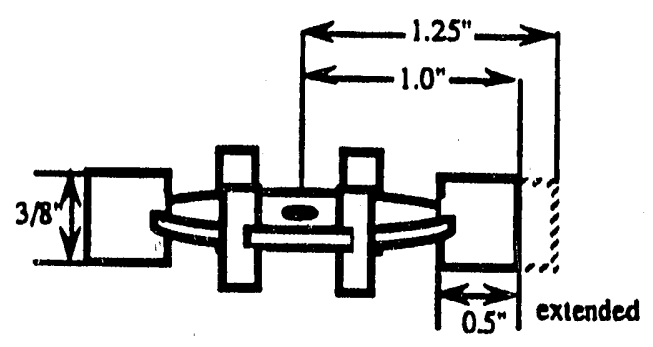

New Gas Phase

Propeller

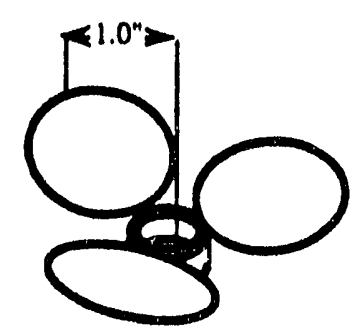

Liquid Phase

Propeller

Figure 3-2. Propeller designs used in stirred tank reactor. 
concentration and, therefore, enhanced mass transfer. In order to avoid such localized enhancement, a steel elbow was fth into the gas inlet to direct tine incoming gas horizontally into the reactor.

The initial gas film coefficient tests wisre performed with continuous gas flow and liquid phase in batch mode. Changing from a batch system to a continuous flow system for the remainder of the experiments required a few more improvements. When running liquid through the system at the maximum flow rate of $205 \mathrm{~mL} / \mathrm{min}$, the heating tape alone could not maintain the $55^{\circ} \mathrm{C}$ specified for most of the experiments. Therefore, a pre-heated water bath was also added to the liquid inlet line and provided adequate heating to the continuous liquid stream. The heating tape was then used only to fine tune the temperature and help insulate the glass walls.

\subsubsection{Gas Phase Analysis and Ma:erial Balance}

The $\mathrm{SO}_{2}$ absorption rate was determined primarily by gas phase material balance. The material balance was based on supplying a known concentration of $\mathrm{SO}_{2}$ to the reactor and measuring the reactor outlet (bulk) gas concentration. The bulk gas concentration was varied from $\mathbf{5 0 0}$ to $5,000 \mathrm{ppm} \mathrm{SO} \mathrm{O}_{2}$ for experiments by varying the inlet gas flow rate. The inlet gas flow rate was measured and adjusted using a mass flow meter. Since inlet and outlet flow rates were approximately equivalent, the absorption rate was determined by the following relationship:

$$
N_{\mathrm{SO}_{2}}=\left(C_{\mathrm{SO}_{2} \text { in }}-C_{\mathrm{SO}_{2} \text { out }}\right) q_{\text {out }}
$$

Several steps were taken to ensure that the gas phase material balance provided accurate measurement of $\mathrm{N}_{\mathrm{SO} 2}$. First, the system was checked frequently for leaks. This could be done easily at the beginning of tests because the reactor and tubing were always under a slight positive pressure during experiments and responded to testing with a soap solution. Also, the analyzer was calibrated each day before testing using the same flow meters, tubing, dilution system and ice bath set up but with just the reactor bypassed. Any leaks or contamination of the system were usually identified at this stage of the test. 
Also, a cross-check of the accuracy of the gas phase material balance was made by directly analyzing the absorbed total S(IV) in the liquid. Thus, the amount of absorbed S(IV) calculated from the gas phase material balance and compared to the liquid phase sample analysis. Methods of liquid phase analysis are discussed further, later in this section.

The gas supply used in most experiments was a purchased, certified mixture of 1 mole percent $\mathrm{SO}_{2}$ in helium. Helium was chosen as the balance of the gas mixture as a means of minimizing the gas film resistance because of its higher diffusivity. Using a theoretical equation to predict diffusivities in a binary gas mixture reported by Hirschfelder, Curtiss and Bird (1964), and the method prescribed by Sherwood (1975), the diffusivities of $\mathrm{SO}_{2}$ in $\mathrm{N}_{2}$, and $\mathrm{SO}_{2}$ in He were predicted. The value of $\mathrm{D}_{\mathrm{SO}-\mathrm{He}}$ is $2.07 \mathrm{~cm}^{2} / \mathrm{s}$ and of $D_{\text {SO2-N2 }}$ is $0.60 \mathrm{~cm}^{2} / \mathrm{s}$.

Experiments performed by Versteeg (1987) verified that the dependence of the gas film coefficient, $k_{g}$, on the diffusivity of the absorbed species is proportional to $\sqrt{D}$ for a similar stirred vessel. This relationship shows that using helium should increase the mass transfer coefficient for $\mathrm{SO}_{2}$ by a factor of 2 over using nitrogen. The experiments performed by Versteeg also indicate that the use of helium may allow operation at higher agitation speeds. In experiments where $\mathrm{NH}_{3}$ in a balance of $\mathrm{N}_{2}$ was used, rippling of the surface was noted at $600 \mathrm{~mm}$. With $\mathrm{NH}_{3}$ in a balance if $\mathrm{He}$, no surface disturbance was noticed at stirrer speeds of over $1,200 \mathrm{~mm}$. Operation at the higher agitation speeds could also increase $\mathrm{k}_{\mathrm{g}}$.

Use of helium caused some initial problems with gas analysis, however. Because the analyzer could read from 0 to $5,000 \mathrm{ppm} \mathrm{SO}_{2}$, a dilution system did not appear necessary. Initial measurements of the $\mathrm{He} / \mathrm{SO}_{2}$ reactor outlet mixture were analyzed directly, without a dilution system.

Helium had 2 observable effects on the analyzer. First, since it has a lower density than air, the pumping capacity was much less. In order to operate the analyzer at the recommended pressure, the sample flow rate was greaily reduced. This increased the amount of time required for the analyzer to make a steady state measurement. Secondly, helium caused the analyzer to be much less sensitive to $\mathrm{SO}_{\mathrm{i}}$. Span and zero adjustments were far from settings for air. Readings were being made in a 
non-linear range, which made interpretation of the results more complicated. In addition, sensitivity toward $\mathrm{SO}_{2}$ appeared to deteriorate over time. After several weeks of operation, problems with this system indicated that dilution system was necessary.

A dilution system was installed so that the analyzed sample would be mainly $\mathrm{SO}_{2}$ in air. In experiments following this modification, the reactor outlet gas was diluted 10:1 to eliminate the effects of helium. Calibration was then made with mixtures of $\mathrm{SO}_{2}$ in nitrogen. Calibration of the analyzer was performed before each test run. Generally, at least a 3-point check was made to ensure that the analyzer was linear and was not drifting, as had been noted in the earlier experiments using the undiluted helium $/ \mathrm{SO}_{2}$ mixture. These changes resolved the analyzer drift problem and produced reliable $\mathrm{SO}_{2}$ concentration data. Typically, $\mathrm{SO}_{2}$ concentration could be read to $\pm 5 \mathrm{ppm}$.

Later, experiments were performed to verity that use of helium instead of nitrogen was actually increasing gas film mass transfer. The results of these experiments showed that no significant improvement in gas film mass transfer resulted from using helium. Although the diffusivity of $\mathrm{SO}_{2}$ was increased due the lower molecular weight of helium, the lower density also caused less mixing action for a given agitation speed. This apparently had an equally important effect on the mass transfer coefficient.

\subsubsection{Liquid Phase Analysis}

During some of the tests, it was important to krow the concentration of sulfur species in the liquid phase. Knowing these concentrations also provided a means of checking the accuracy of the gas phase material balance. Two types of liquid phase analyses were performed and direct titration with iodine and ion chromatography were used to determine total sulfur of liquid samples.

Samples of liquid taken from tests which measured liquid film coefficients contained $\mathrm{SO}_{2}$ absorbed in $\mathrm{HCl}$. These samples had to be analyzed immediately by direct lodine titration because of the tendency for $\mathrm{SO}_{2}$ to be desorbed from the collected sample. A known concentration of lodine was placed in a beaker with starch solution and weighed. When the experiment reached a steady state, a 
sample of the reactor effluent was pumped into the beaker until the clear endpoint was reached, and the net weight of reactor solution was recorded.

Samples collected during slurry tests were analyzed for total sulfur, mainly in the form of the bisulfite ion, $\mathrm{HSO}_{3}{ }^{-}$. These samples were oxidized using a 30 percent hydrogen peroxide solution to form sulfate, $\mathrm{SO}_{4}^{2-}$. A 1-mL portion of each sample was withdrawn and diluted 100:1 for analysis by lon chromatography. The lon chromatograph used was a Dionex Corporation model 2000VSP. A Hewlett-Packard 3390A integrator was used to report the output peak heights and areas. The peak heights reported for samples were compared to peak heights of standards of known concentration to determine the sample concentration. The relationship of peak height to concentration was linear for the range used. Standards were made from $\mathrm{NaSO}_{4}$ to provide $\mathrm{SO}_{4}{ }^{2-}$ concentrations of $0.01 \mathrm{mM}, 0.005$ $\mathrm{mM}$, and $0.001 \mathrm{mM}$. The standards and diluted samples were analyzed in random order to account for potential drift of the chromatograph.

\subsection{MASS TRANSFER PROPERTIES OF THE STIRRED TANK REACTOR}

The reactor has a characterist:c gas film mass transfer coefficient, $k_{g}$, and liquid film mass transfer coefficient, $k_{1}^{\circ}$, which depend upon specific operating conditions. A series of initial experiments were performed to determine these mass transfer properties of the reactor, and relate them to variable operating conditions such as agitation speeds. The gas film mass transfer coefticient was determined by $\mathrm{SO}_{2}$ absorption in $1 \mathrm{M} \mathrm{NaOH}$. The liquid film mass transfer coefficient was determined by $\mathrm{SO}_{2}$ absorption in $0.3 \mathrm{M} \mathrm{Hcl}$.

\subsubsection{Gas Film Mass Transter Properties}

The amount of $\mathrm{SO}_{2}$ absorbed by the hquid, $\mathrm{N}_{\mathrm{SO}}$, depends on a driving force for mass transfer between the bulk gas and liquid interface as described in equation (2-1). The $k_{g}$ can be easily determined by measuring the absorption rate of $\mathrm{SO}_{2}$ irito a strong alkali solution that causes immediate

removal of $\mathrm{SO}_{2}$ at the interface. In strong alkaline solutions, $\mathrm{SO}_{2}$ reacts instantaneously, causing PSO2I to be insignificant. 
In tests run to determine the gas film coefficient, the reactor was filled with $1.1 \mathrm{~L}$ of $1.0 \mathrm{M}$ $\mathrm{NaOH}$ for reaction in batch mode. Batch mode was chosen simply for ease of operation. At this concentration, there was sufficient $\mathrm{OH}^{-}$avallable to maintain a high enough $\mathrm{pH}$ to support the reactions listed as equations (2-3) through (2-5) to allow for several hours of operation. The key assumption in these experiments is that $\mathrm{SO}_{2}$ reacts immediately with $\mathrm{NaOH}$, resulting in a negligible $\mathrm{SO}_{2}$ concentration at the interface.

Initial experiments used a continuous flow of helium containing 1 mole percent $\mathrm{SO}_{2}$. The gas phase was stirred first with the 2.0-in diameter propeller blade. Experiments were performed at room temperature, varying first the gas and liquid agitation speeds and then the $\mathrm{SO}_{2}$ concentration. The $\mathrm{k}_{\mathrm{g}}$ was then measured at the elevated temperature of $55^{\circ} \mathrm{C}$ and also with a larger diameter propeller blade. Final measurements of $\mathrm{k}_{g}$ were made using nitrogen containing 1 percent $\mathrm{SO}_{2}$ as a gas source but were not significantly different from initial measurements made with 1 percent $\mathrm{SO}_{2}$ in helium.

\subsubsection{Experimental Results}

The following presents the values of $k_{g}$ measured as a function of temperature, agitation and $\mathrm{SO}_{2}$ concentration. Results showed that $\mathrm{k}_{\mathrm{g}}$ was not a function of $\mathrm{SO}_{2}$ concentration. It also did not vary measurably when changing the temperature from $25^{\circ} \mathrm{C}$ to $55^{\circ} \mathrm{C}$. It was, however, strongly dependent on gas agitation speed. Atthough the $\mathrm{k}_{\mathrm{g}}$ could also be affected by changes in the liquid level in the reactor (i.e., changes in gas volume), the liquid level/gas volume was maintained constant throughout all experiments.

Holding the inlet gas flow rate constant at approximately $1500 \mathrm{~mL} / \mathrm{min}$ and the upper agitator speed at the maximum, the liquid phase agitation speed was varied between 200 and $1100 \mathrm{rmm}$. No change to the outlet $\mathrm{SO}_{2}$ concentration resulted. As expected, varying the liquid agitation speed had no effect on the gas phase mass transfer coefficient.

Holding the liquid agitation speed constant at approximately $500 \mathrm{rpm}$ and gas agitation at maximum, the $\mathrm{k}_{\mathrm{g}}$ was measured at various outlet $\mathrm{SO}_{2}$ concentrations. Under these conditions, theoretically, the gas phase mass transier coefficient should not vary. However, the first 8 
measurements taken indicated that $k_{g}$ increased with each reading. This was caused by the analyzer drift problems previously discussed. Once this problem was solved and the air dilution system was adopted, new measurements of $k_{g}$ were made. The results of these tests are shown in Figure 3-3. In these tests, the value of $\mathrm{K}_{\mathrm{g}} \mathrm{A}$ was not dependent on $\mathrm{SO}_{2}$ concentration, as also witnessed by Chang and Rochelle $(1979,1981)$ and Versteeg (1987). These results also show that $k_{g}$ can be repeatedly measured to within \pm 2.5 percent.

Next, the liquid agitator was held constant at approximately $500 \mathrm{~mm}$ and the gas agitation speed was varied between 150 and $1400 \mathrm{rmm}$. Inlet gas flow rate was varied such that the outlet $\mathrm{SO}_{2}$ concentration remained near 1,500 ppm.

Values of $k_{g} A$ calculated from these tests are plotted in Figure 3-4. As expected, higher agitation speeds result in much higher gas film mass transfer coefficients. A correlation for $k_{g}$ and gas agitation speed was developed from these measurements for use in calculating $k_{g}$ in later experiments. The correlation for the $k_{g} A$ using the 2.0-in diameter propeller was:

$$
k_{g} A=1.86 \times 10^{-4}(r p m)^{0.50}
$$

The dependence of $k_{g}$ on gas agitation speed is similar to that found by Versteeg (1987), who determined that $k_{g}$ is proportional to $(r p m)^{0.63}$.

Also plotted in Figure 3-4 are values of $k_{g} A$ determined under the same conditions described above, except that the reactor was heated to $55^{\circ} \mathrm{C}$. The $\mathrm{k}_{\mathrm{g}} \mathrm{A}$ does not appear to have a strong temperature dependence, especially at the higher agitation speeds. Chang and Rochelle $(1979,1981)$ also found this to be the case in experiments performed between 15 and $30^{\circ} \mathrm{C}$.

The fact that $k_{g}$ exhiblts little dependence on temperature can be explained by examining the properties it depends on. As determined by Versteeg (1987), $k_{g}$ can be expressed empirically in dimensionless form in terms of the Reynolds number as:

$$
S h=\frac{k_{g} d_{s t}}{D}=c_{1} R e^{c_{2}}
$$




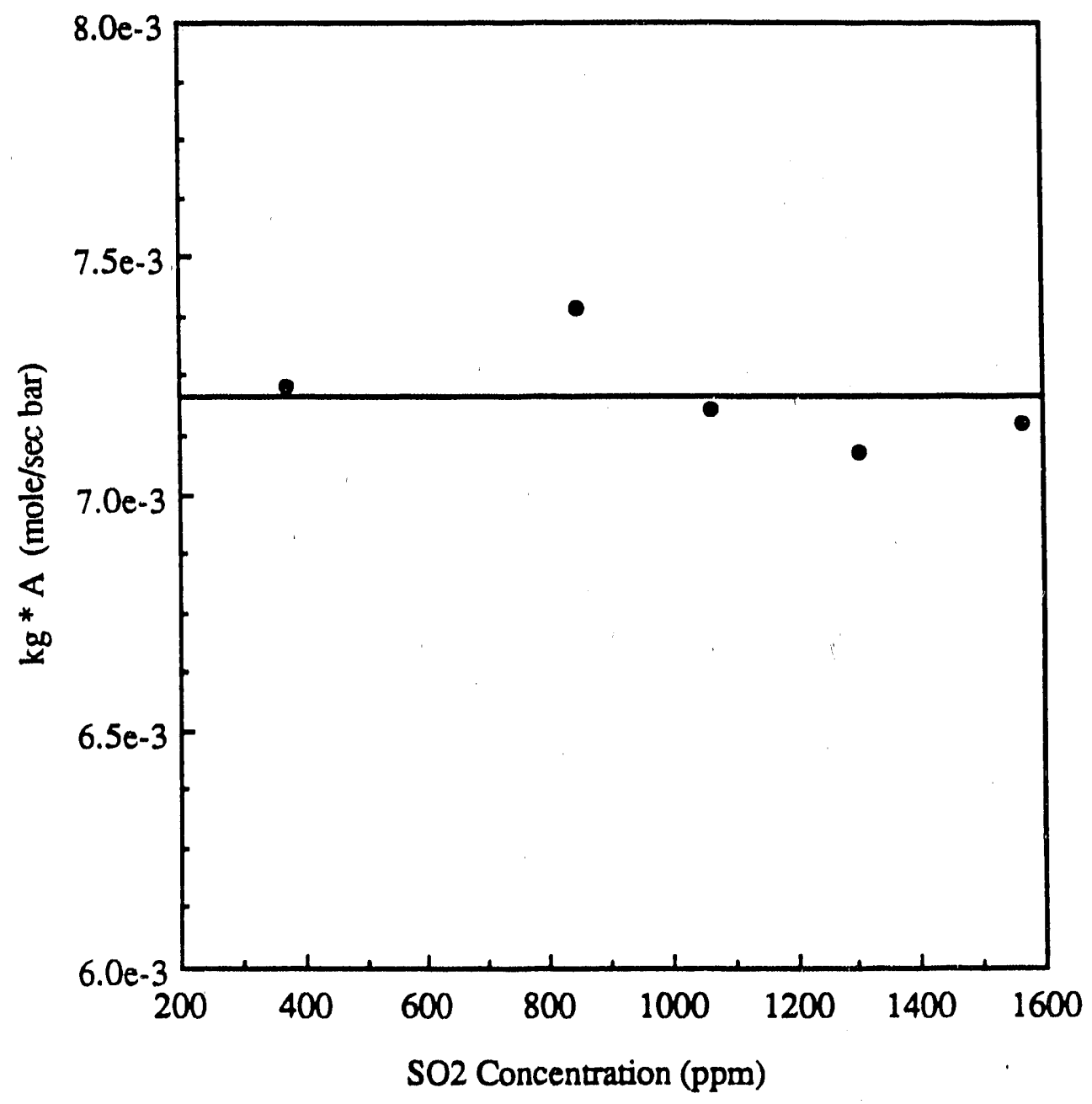

Figure 3-3. Dependence of $\mathrm{k}_{\mathrm{g}}$ on $\mathrm{SO}_{2}$ concentration. 


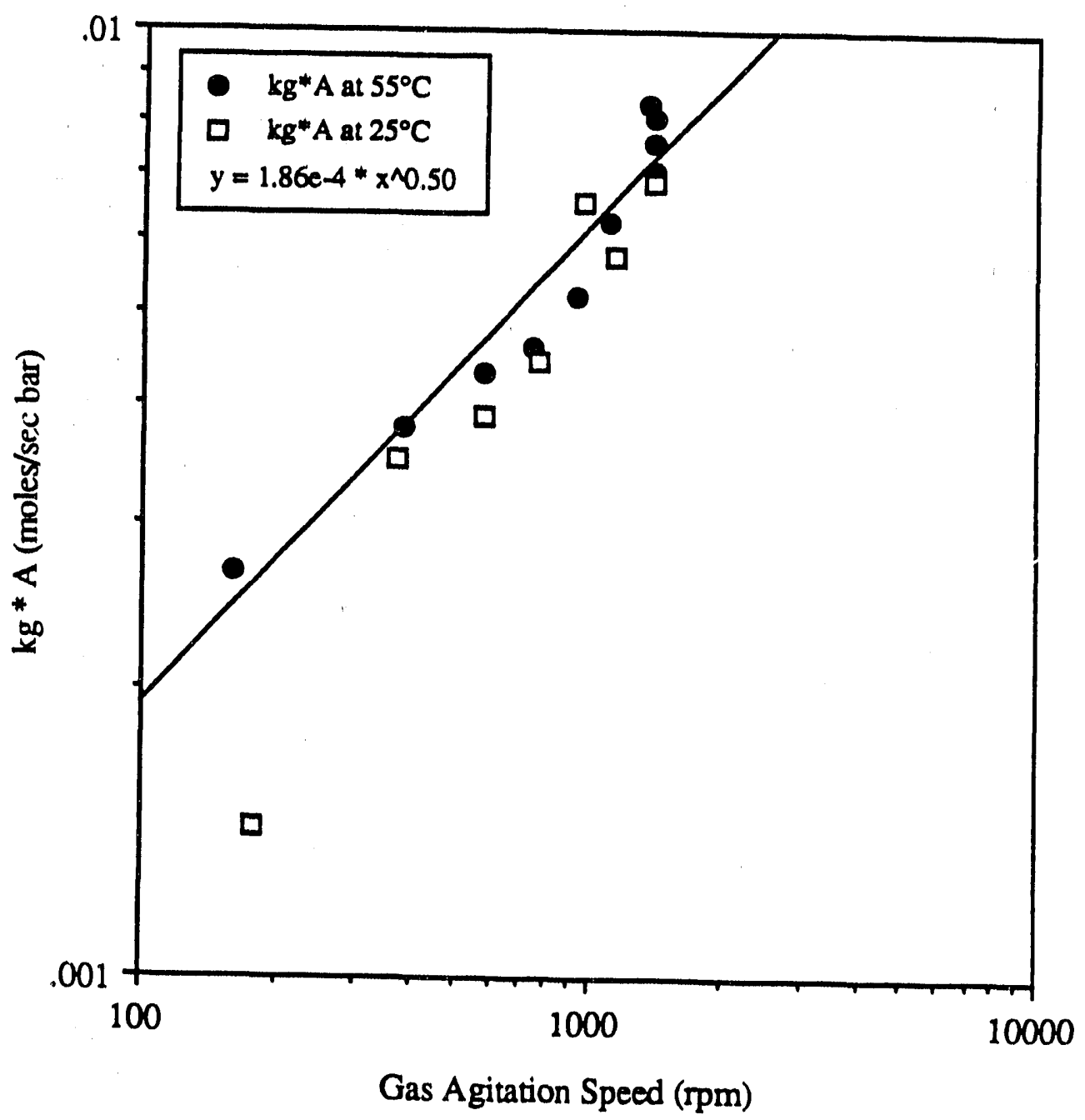

Figure 3-4. Dependence of $k_{g}$ on gas agitation speed at $25^{\circ} \mathrm{C}$ and $55^{\circ} \mathrm{C}$ (2.0-in diameter propeller). 
where $c_{1}$ and $c_{2}$ are constants. In Versteeg's work, $c_{2}$ generally ranged from 0.61 to 0.74 for systems of different gases using different stirrers. Using this correlation (assuming a constant stirrer diameter), $k_{g}$ can be approximated by:

$$
k_{0}=c_{3} D R e^{2 / 3}
$$

where:

$$
R \theta=\frac{d_{s t}^{2} N \rho}{\mu}
$$

The parameters that depend on temperature are $, ?, \rho$, and $\mu$. Empirical equations that predict the temperature dependence of these parameters have been developed by several researchers and are compiled in the Chemical Engineer's Handbook (Perry and Chilton, 1973). For the diffusivity of gases, $D \propto T^{2 / 3}$. For ideal gases, $\rho \propto 1 / T$. The viscosity of gases has a more complicated temperature dependence. This is given in Perry and Chiton (1973) as:

$$
\mu=\frac{T^{2 / 3}}{T+1.47 T_{b}}
$$

Thus, the temperature dependence of the gas film coefficient becomes:

$$
k_{g} \propto t^{2 / 3}\left(\frac{1}{T}\right)^{2 / 3}\left(\frac{T^{2 / 3}}{T+1.47 T_{b}}\right)^{2 / 3}
$$

The temperature dependence due to diffusivity and viscosity cancel each other, and the temperature dependence due to viscosity is weak. Thus, experiments showed no influence of temperature on $\mathrm{k}_{\mathrm{g}}$ for a difference of $30^{\circ} \mathrm{C}$.

Since disturbance of the gas/liquid surface was not observed with the 2.0-in diameter propeller at maximum gas agitation speed, the reactor could benefit from greater agitation. This suggested the 
attempt to increase agitation by increasing the diameter of the propeller to $2.5 \mathrm{in}$, the maximum which would it in the reactor. Athough the 2.5-in diameter impeller increased agitation and increased $k_{0}$, the point of surface disiurbance was still not attained. Tests were run with this propeller under the same conditions as the 2.0-in diameter propeller. Results for tests run with this propeller at both $25^{\circ} \mathrm{C}$ and $55^{\circ} \mathrm{C}$ are shown in Flgure 3-5. The correlation for $k_{g} A$ for the 2.5-in diameter propeller was:

$$
k_{g} A=4.95 \times 10^{-4}(r p m)^{0.76}
$$

Comparison of $k_{g} A$ measured with each propeller at $55^{\circ} \mathrm{C}$ is shown in Figure 3-6. Because of the increased gas film mass transfer, the 2.5-in diameter propeller was used for the remaining experiments.

\subsubsection{Discussion}

A goal of this research was to design the reactor such that $k_{g}$ is maximized, an important factor for several reasons. Most importantly, a low value of $k_{g}$ results in absorption which becomes limited by gas film mass transfer. When gas film mass transfer is the limiting mechanism of absorption, changes to the liquid phase do not have an effect on absorption. This limiting condition represents 1 Jo percent gas film resistance. The objective of these experiments was to study the behavior of $\mathrm{SO}_{2}$ absorption due to changes to clear solution and slurry solution compositions. When the absorption is gas film controlled, study of these effects is not possibie.

Also, it is preferred that the reactor have a $k_{g}$ which approaches the range of values expected for slurry droplets. Values of $k_{g}$ for slurry droplels are estimated to be in the range of $10^{-2}$ to $10^{-3}$ mole $/ \mathrm{cm}^{2} \mathrm{~s}$ bar. The maximum $k_{g}$ measured l'or this study was on the order of $10^{-4} \mathrm{~mole} / \mathrm{cm}^{2} \mathrm{~s}$ bar. The results obtained in these experiments are comparable to gas film coefficients derived by other authors, as shown in Table 3-1. The gas film mass transfer coefficients measured in this study are slightly greater than the values measured in other studies. 


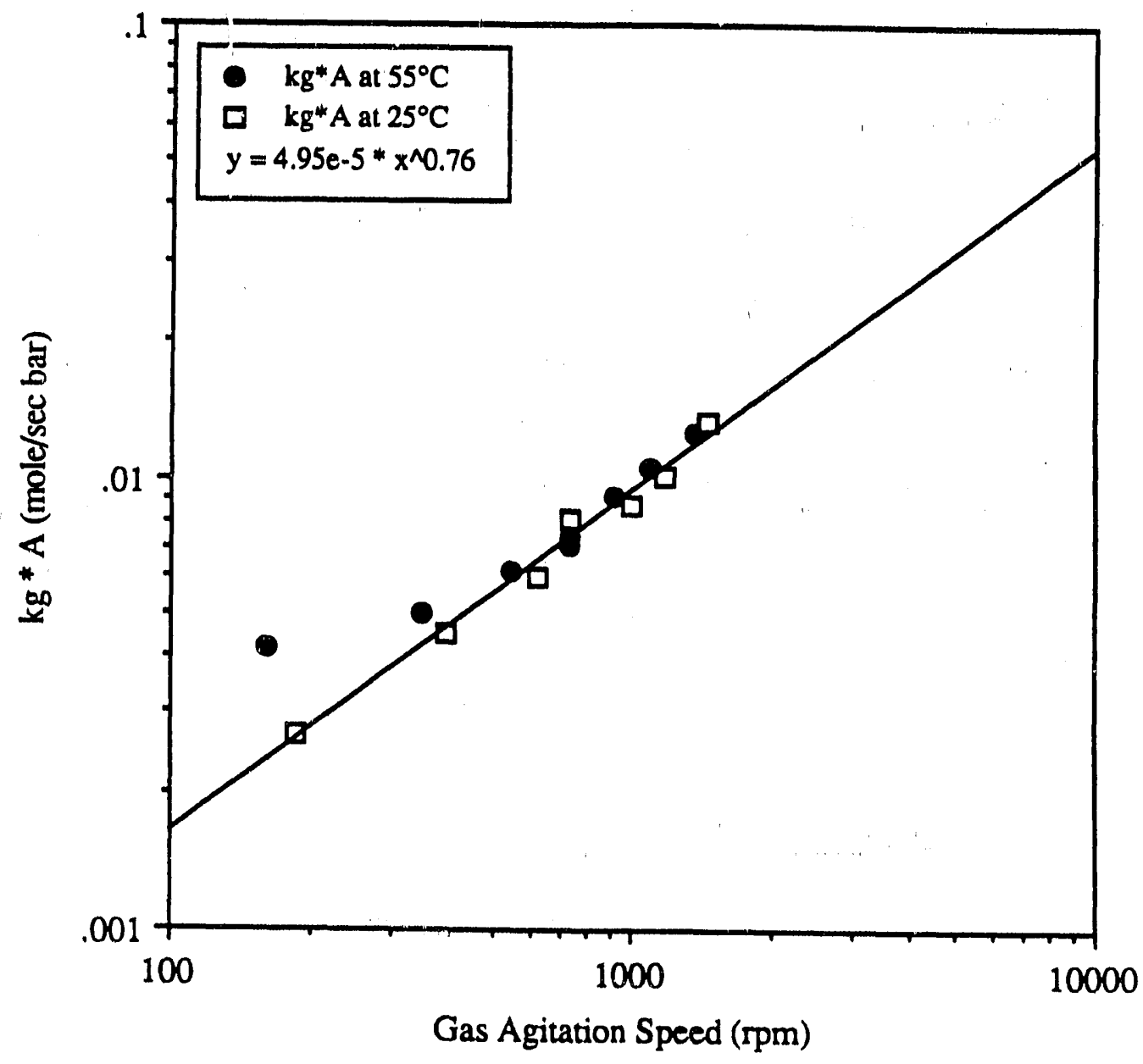

Figure 3-5. Dependence of $k_{g}$ on gas agitation speed at $25^{\circ} \mathrm{C}$ and $55^{\circ} \mathrm{C}$ (2.5-in diameter propeller). 


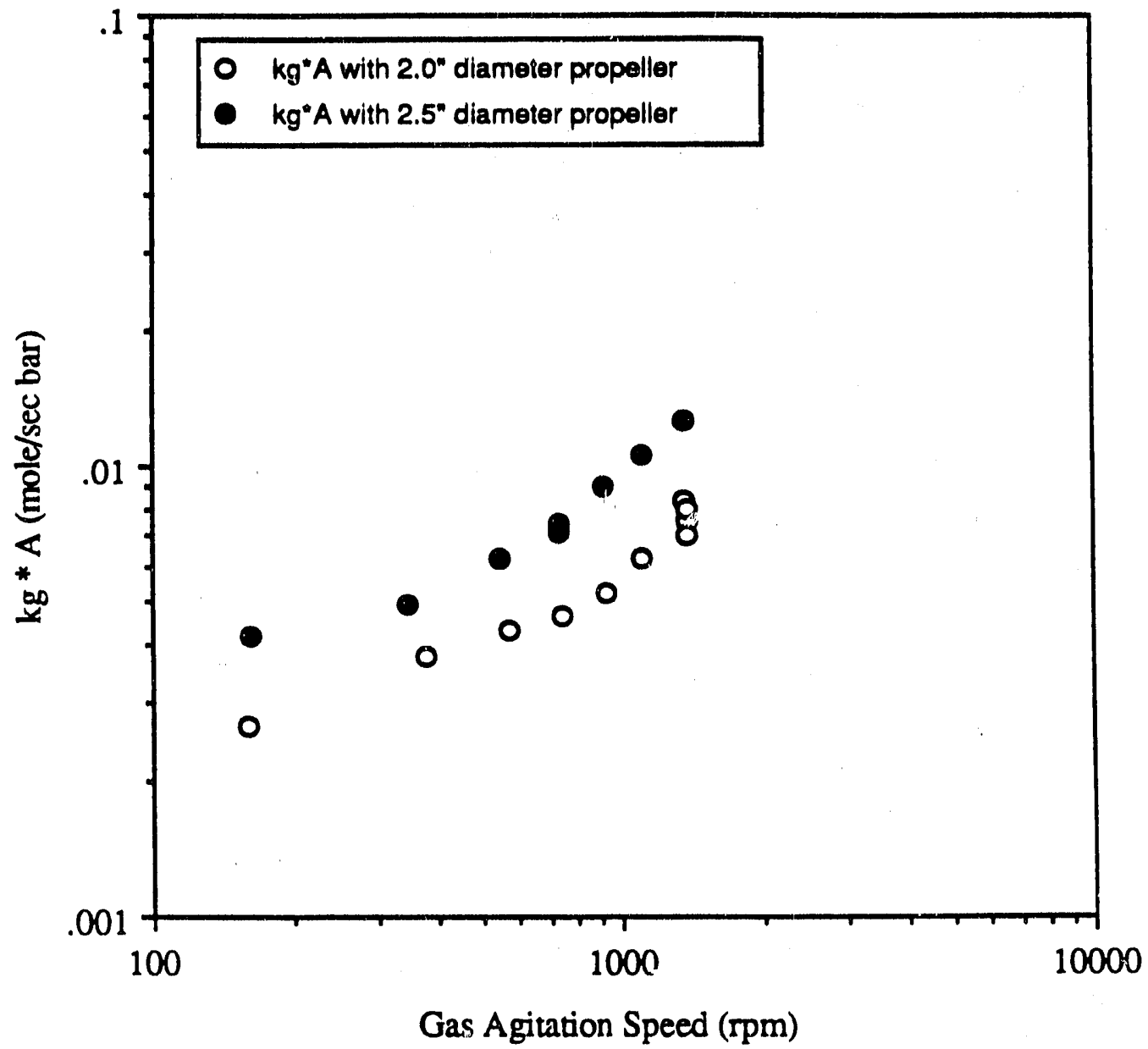

Figure 3-6. Comparison of $\mathrm{k}_{\mathrm{g}}$ at $55^{\circ} \mathrm{C}$ with two propeller sizes. 
TABLE 3-1. COMPARISON OF EXPERIMENTALLY DETERMINED

GAS FILM MASS TRANSFER COEFFICIENTS

\begin{tabular}{|c|c|c|c|c|}
\hline $\begin{array}{l}\text { Previous } \\
\text { Study }\end{array}$ & Temp $\left({ }^{\circ} \mathrm{C}\right)$ & $\begin{array}{c}\text { Gas } \\
\text { Composition }\end{array}$ & Max rpm & $\begin{array}{c}k_{\mathrm{g}} \times 10^{4} \\
\text { (mole/cm } \\
\text { bar) }\end{array}$ \\
\hline Sada (1978) & 25 & $\begin{array}{l}4 \text { percent } \mathrm{SO}_{2} \\
\text { in } \mathrm{N}_{2}\end{array}$ & 600 & 0.76 \\
\hline $\begin{array}{l}\text { Chang \& } \\
\text { Rochelle } \\
(1979)\end{array}$ & $.15-30$ & pure $\mathrm{SO}_{2}$ in $\mathrm{N}_{2}$ & 350 & 0.99 \\
\hline $\begin{array}{l}\text { Weems \& } \\
\text { Rochelle } \\
\text { (1981) }\end{array}$ & 55 & pure $\mathrm{SO}_{2}$ in $\mathrm{N}_{2}$ & 540 & 0.32 \\
\hline This study & 25 & $\begin{array}{l}1 \text { percent } \mathrm{SO}_{2} \\
\text { in } \mathrm{He}\end{array}$ & 1365 & 1.55 \\
\hline This study & 55 & $\begin{array}{l}1 \text { percent } \mathrm{SO}_{2} \\
\text { in } \mathrm{He}\end{array}$ & 1440 & 1.66 \\
\hline
\end{tabular}

The higher $k_{g}$ measured in this study was due primarily to the ability to stir the liquid and gas phases separately. Some improvement in $\mathrm{k}_{\mathrm{g}}$ was also due to optimizing propeller design. Also, helium was used as the balance of the $\mathrm{SO}_{2}$ gas mixture because of its lower density. This was originally expected to improve $\mathrm{k}_{\mathrm{g}}$ as well, however measurement of $\mathrm{k}_{\mathrm{g}}$ in a gas containing $\mathrm{SO}_{2}$ in nitrogen showed no benefit of using helium instead of nitrogen. Overall, the design improvernents resulted in an increase of about a factor of 2 in $\mathrm{k}_{\mathrm{g}}$. An order-of-magnitude increase in $\mathrm{k}_{\mathrm{g}}$ was not feasible with this apparatus.

\subsubsection{Liquid Film Mass Transfer Properties}

$A$ characteristic value of the liquid film mass transfer coefficient, $k_{1}^{\circ}$, was determined at specific operating conditions in the reactor. Reactions, such as those listed as equations (2-3) through (2-5), greatly enhance liquid film mass transfer. To study the degree of enhancement due to reaction, the reactor's characteristic $k_{1}^{\circ}$, measured in the absence of chemical reaction, must be known for the range of conditions studied. This $k_{1}^{\circ}$ can then be compared to $k_{1}$ measured in solutions where reaction of $\mathrm{SO}_{2}$ occurs to compute the enhancement factor. The value of $k_{1}^{\circ}$ is determined from equation (2-2). 
Experimental conditions necessary for determining $\mathrm{k}_{1}^{\circ}$ require that $\mathrm{SO}_{2}$ be absorbed in a solution where negligible reaction in the liquid occurs. According to equations (2-3) through (2-5), a strongly acidic solution inhibits reaction. Weems and Rochelle (1981) found that a concentration of 0.3 $\mathrm{M} \mathrm{HCl}$ or greater was sufficient to inhiblt reaction. Therefore, experiments were perfurmed in a solution of $0.3 \mathrm{M} \mathrm{HCl}$ to determine $\mathrm{k}^{\circ}$.

To calculate $\mathrm{k}_{1}^{\circ}$ from equation (2-2), the concentrations of $\mathrm{SO}_{2}$ at the interface, $\left[\mathrm{SO}_{2}\right]_{1}$, and in the bulk phase, ! $\left.\mathrm{SO}_{2}\right]_{0}$, must be known. The interface concentration was calculated sing equation (2-1), Henry's law and the measured value of $\mathrm{k}_{\mathrm{g}}$. The bulk phase $\mathrm{SO}_{2}$ concentration was maintained at a level low enough to be insignificant when compared to the interface concentration. Thus, a continuous flow of $\mathrm{HCl}$ solution through the reactor was necessary to prevent accumulation of $\mathrm{SO}_{2}$ in the liquid phase.

This also helped to provide a large driving force for absorption. A liquid flow rate of 205 $\mathrm{mL} / \mathrm{min}$ was found to be sufficient. Typically, the absorbed $\mathrm{SO}_{2}$ concentration was $0.2 \mathrm{mM}$ or less. The absorbed $\mathrm{SO}_{2}$ concentration in the liquid was estimated using the gas phase material balance and liquid flow rate and then confirmed by the direct lodine titration method previously described.

\subsubsection{Experimental Results}

The following presents the values of $k^{\circ}$, measured as a function of temperature, agitation and $\mathrm{SO}_{2}$ concentration. The $\mathrm{k}_{1}^{\circ}$ should only be a function of the properties of the liquid phase. It should be completely independent of the properties of the gas phase, such as $\mathrm{k}_{\mathrm{g}}$ and the $\mathrm{SO}_{2}$ concentration. As a quality control check on the measurement of $k_{1}^{\circ}$, a set of experiments were performed holding the liquid agitation speed constant at about 670 to $690 \mathrm{rm}$ and varying the $\mathrm{SO}_{2}$ concentration between 1150 and $3070 \mathrm{ppm}$. The results shown in Figure $3-7$ confirm that $\mathrm{k}_{1}^{\circ}$ is not a function of $\mathrm{SO}_{2}$ concentration. These results also indicate that $k^{\circ}$, can be measured repeatedly to within about \pm 5 percent. 


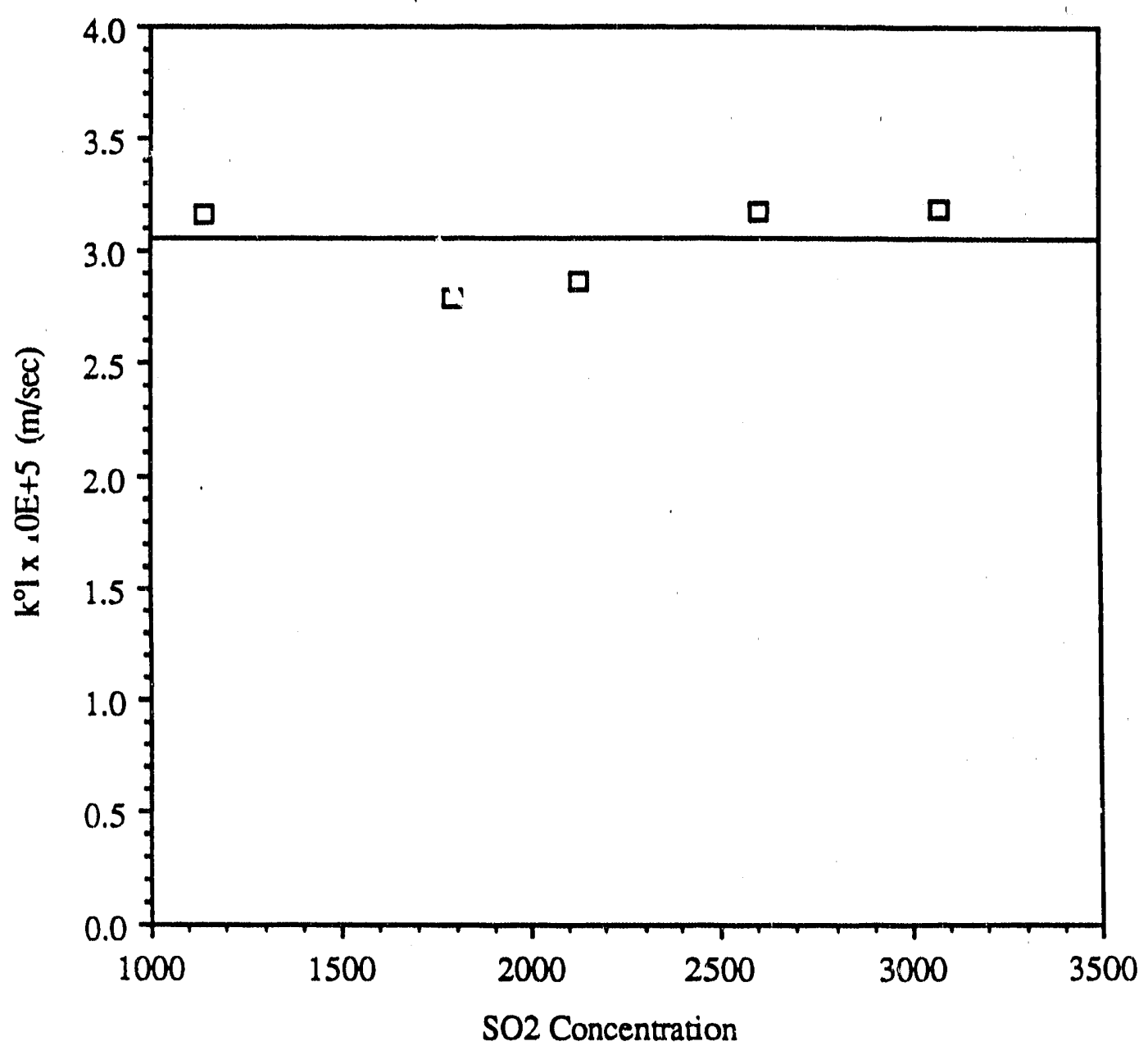

Figure 3-7. Dependence of $\mathrm{k}_{1}^{\circ}$ on $\mathrm{SO}_{2}$ concentration at $25^{\circ} \mathrm{C}$. 
Next, the relationship between $\mathrm{k}^{\circ}$ and llquid agitation speed was determined at $25^{\circ} \mathrm{C}$. During this set of tests, the $\mathrm{SO}_{2}$ concentration was allowed to vary between 1690 and $3070 \mathrm{ppm}$, and the liquid agitation speed was vatied from 160 to $1350 \mathrm{rmm}$. Figure 3-8 shows the strong dependence of $k^{\circ}$, on liquid agitation speed. A correlation for $k^{\circ}$ as a function of liquid agitation speed was developed from this data for use in future experiments performed at $25^{\circ} \mathrm{C}$.

As found in the study by Chang (1979), the liquid film coefficient depends on temperature so it was measured at both $25^{\circ} \mathrm{C}$ and $55^{\circ} \mathrm{C}$. Figure $3-8$ also presents the values of $\mathrm{k}^{\circ}$, measured at $55^{\circ} \mathrm{C}$ as a function of liquid agitation speed. The increase in temperature from $25^{\circ} \mathrm{C}$ to $55^{\circ} \mathrm{C}$ results in a factor of 2 increase in $k_{\%}^{\circ}$. Another correlation for $k_{j}^{\circ}$ as a function of liquid agitation speed was developed from this data for use in future experiments performed at $55^{\circ} \mathrm{C}$. Results obtained by Versteeg (1987) showed roughly the same uopendence of $k^{\circ}$, on agitation speed. In experiments performed at $20^{\circ} \mathrm{C}$ and $30^{\circ} \mathrm{C}$, he reports that $k_{1}^{\circ}$ is proportional to $(\mathrm{mpm})^{0.72}$.

According to the penetration theory, the value of $k^{\circ}$, determines the contact time, $\theta_{\text {, }}$ (or surface renewal time) achieved in the vessel by the relationship (Treybal, 1980):

$$
\theta=\frac{4 D_{\mathrm{SO}_{2}}}{\pi k^{\circ}}
$$

Contact times determined from $k^{\circ}$, data are plotted in Figure 3-9. The value of $D_{\mathrm{SO} 2}$ at $30^{\circ} \mathrm{C}$ was taken from Peaceman (1951). To arrive at a value of $D_{\mathrm{SO} 2}$ at $55^{\circ} \mathrm{C}$, corrections for temperature and change in viscosity were made using the Stokes-Einstein relationship shown below (Bird, Stewart and Lightfoot, 1960):

$$
D=\frac{k_{B} T}{6 \pi r_{0} \mu}
$$




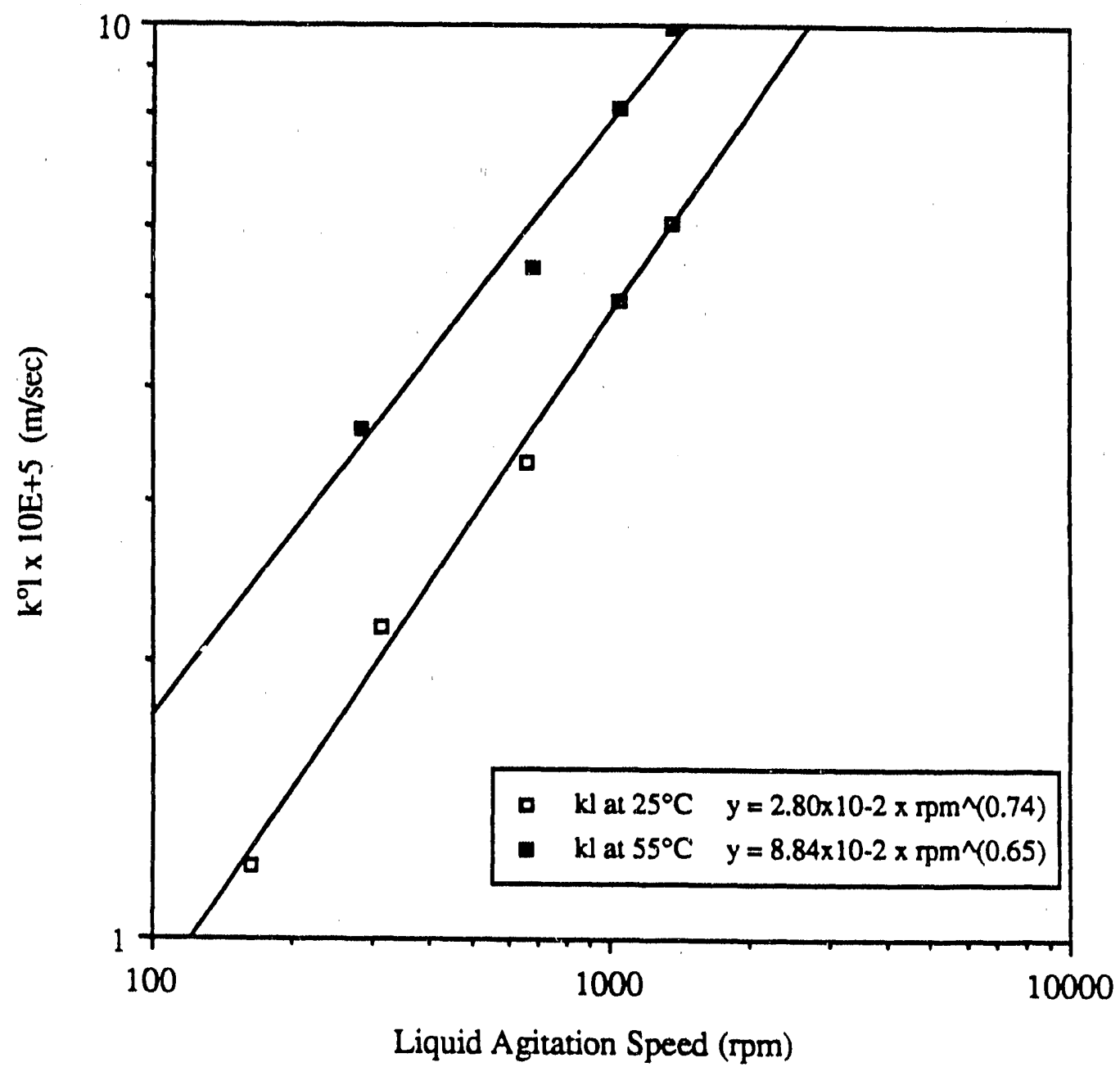

Figure 3-8. Dependence of $\mathrm{k}^{\circ}$, on liquid agitation speed at $25^{\circ} \mathrm{C}$ and $55^{\circ} \mathrm{C}$. 


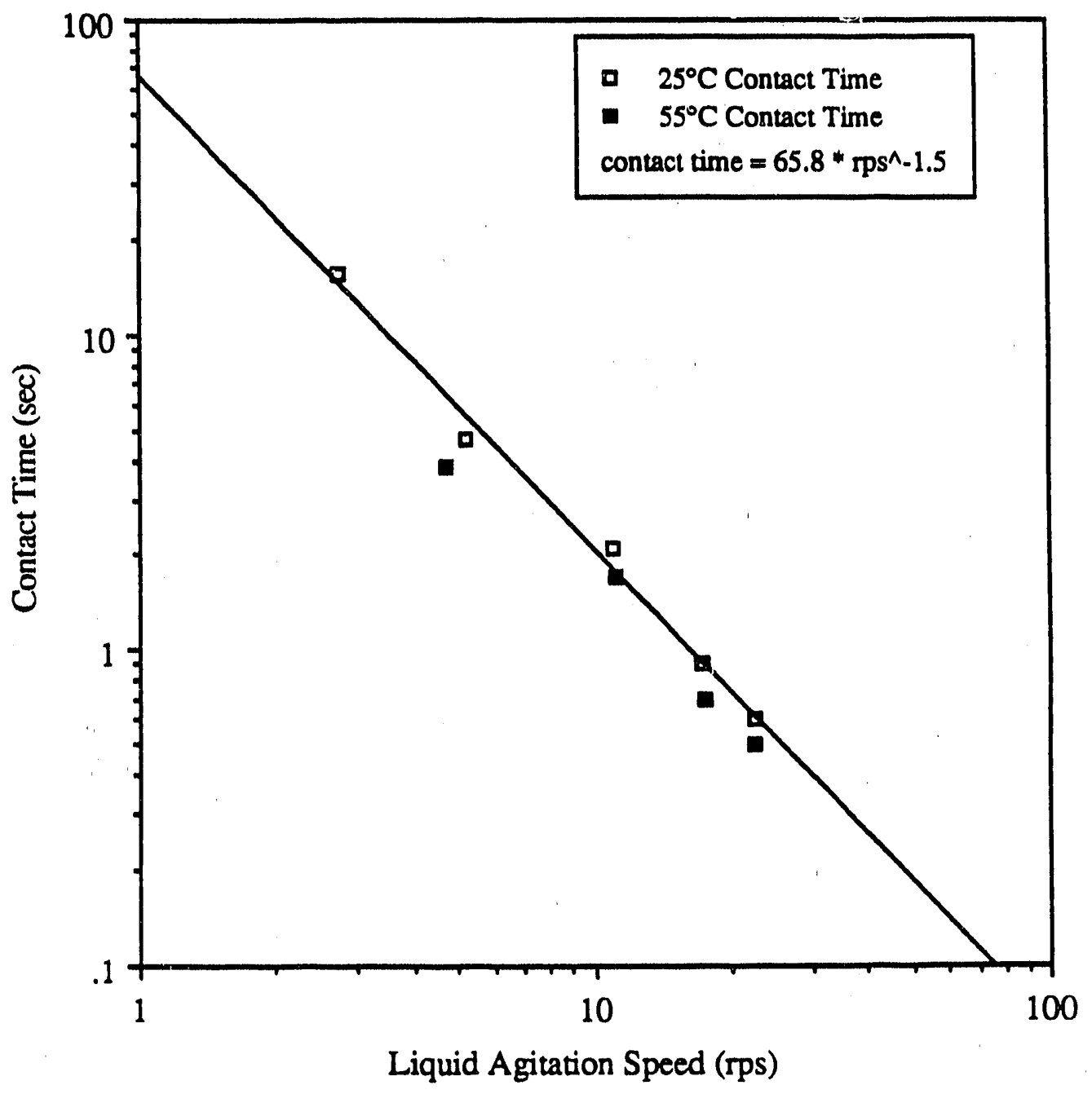

Figure 3-9. Contact time as a function of liquid agitation spe日d. 
When used to correct for temperature and viscosity, the relationship becomes:

$$
\frac{D}{D_{25^{\circ} \mathrm{C}}}=\frac{T \mu_{298}}{298 \mu}
$$

Although lower mass transfer coefficients were found at $55^{\circ} \mathrm{C}$, contact time is not affected by a change in temperature. Since time and temperature are not intensive properties of the fluld, they are unrelated. Temperature dependence in $k^{\circ}$ is mainly a function of the dependency of $D_{\mathrm{SO} 2}$ on temperature. As can be seen by the values reported above, $D_{\mathrm{SO} 2}$ is strongly dependent on temperature.

Preliminary tests were run with chemically inert solids present in the $0.3 \mathrm{M} \mathrm{HCl}$ solution to determine if there would be any significant physical effect on the liquid film mass transfer coefficient (i.e., changing fluid viscosity, surface renewal ability). The original test plan called for use of $\mathrm{CaSO}_{4}$ solids, but a purified mixture of kaolinite and bentonite clay powder was used instead. These chemically inert solids were felt to be closer to the particle size and shape of $\mathrm{Ca}(\mathrm{OH})_{2}$ than $\mathrm{CaSO}_{4}$ solids, which are large, round particles.

The tests with inert solids were performed at $55^{\circ} \mathrm{C}$, approximately $700 \mathrm{rpm}$ liquid agitator speed and maximum gas agitation. Under these conditions, the correlation given in Figure 3-8 shows that $k^{\circ}$, was $4.7 \times 10^{-5} \mathrm{~m} / \mathrm{s}$ with no solids in the solution. The test run under the same conditions with $3.0 \mathrm{wt}$ percent solids in the solution measured a value of $k^{\circ}$, that was not significantly different. For this test, $k_{1}$ was $4.5 \times 10^{-5} \mathrm{~m} / \mathrm{s}$. However, another test run under the same conditions with $8.0 \mathrm{wt}$ percent solids in the solution measured a significantly lower value of $k_{1}$. In this case, $k_{1}$ was $1.1 \times 10^{-5} \mathrm{~m} / \mathrm{s}$.

Similar experiments were performed by Sada et al. (1977), where $\mathrm{NO}_{2}$ was absorbed into $\mathrm{Ca}(\mathrm{OH})_{2}$ slurries at $25^{\circ} \mathrm{C}$. Concentrations of $0,3,5,10$ and 20 weight percent solids were prepared. The $k^{\circ}$, was measured with liquid agitation speeds from 60 to $220 \mathrm{rpm}$ and found to be unaffected by solids concentration at all levels. These results are also verified by the work performed by Quicker, et al., (1989). Their experiments involved absorption of $\mathrm{CO}_{2}$ into slurries of inert particles. The absorption 
rate was found to drop dramatically at concentrations of solids greater than 10 weight percent due to increase in viscosity and blockage of the interface.

The $\mathrm{Ca}(\mathrm{OH})_{2}$ concentrations studied in this work ranged up to only 3 weight percent. One test was attempted at 7.3 weight percent, but enhancement could not be measured due to high gas film resistance. Based on the measurements made with the inert solids and Sada's previous findings, the correlations developed for $k_{1}^{\circ}$ are considered valid for use with the slurry solutions studied.

\subsubsection{Discussion}

Values of $k^{\circ}$, measured by other researchers with the conditions of their experiments and are listed in Table 3-2. In order to compare these values on an equivalent basis, the timensionless quantities of the Sherwood number, Sh, and the Reynolds number, Re, are compared in Figure 3-10. The Reynolds number for the reactor was defined in equation (3-5). The Shenwood number is defined in terms of the liquid film properties of the reactor as follows:

$$
S h=\frac{k^{\circ}, d_{s t}}{D}
$$

TABLE 3-2. COMPARISON OF EXPERIMENTALLY DETERMINED LIQUID FILM MASS TRANSFER COEFFICIENTS

\begin{tabular}{|c|c|c|c|c|}
\hline Previous Study & Temp $\left({ }^{\circ} \mathrm{C}\right)$ & $\begin{array}{c}\text { Gas \& Liquid } \\
\text { Phases }\end{array}$ & Max rpm & $k^{0} \times 10^{5}\left(\begin{array}{l}\mathrm{m} / \mathrm{s}) \\
\mathrm{n}\end{array}\right.$ \\
\hline $\begin{array}{l}\text { Chang \& Rochelle } \\
(1979)\end{array}$ & 25 & $\begin{array}{l}\text { pure } \mathrm{SO}_{2}- \\
\mathrm{HCl}\end{array}$ & 300 & 1.62 \\
\hline $\begin{array}{l}\text { Quicker, et al. } \\
(1989)\end{array}$ & 25 & $\mathrm{CO}_{2}-\mathrm{H}_{2} \mathrm{O}$ & 120 & 0.47 \\
\hline $\begin{array}{l}\text { Versteeg, et al. } \\
(1987)\end{array}$ & 20 & $\mathrm{CO}_{2}-\mathrm{H}_{2} \mathrm{O}$ & 68 & 2.5 \\
\hline $\begin{array}{l}\text { Versteeg, et al. } \\
(1987)\end{array}$ & 30 & $\mathrm{CO}_{2}-\mathrm{H}_{2}$ & 72 & 3.2 \\
\hline This study & 25 & 1 percent $\mathrm{SO}_{2}$ & 1350 & 6.0 \\
\hline This study & 55 & $\begin{array}{c}1 \text { percent } \mathrm{SO}_{2} \\
-\mathrm{HCl}\end{array}$ & 1350 & 9.9 \\
\hline
\end{tabular}




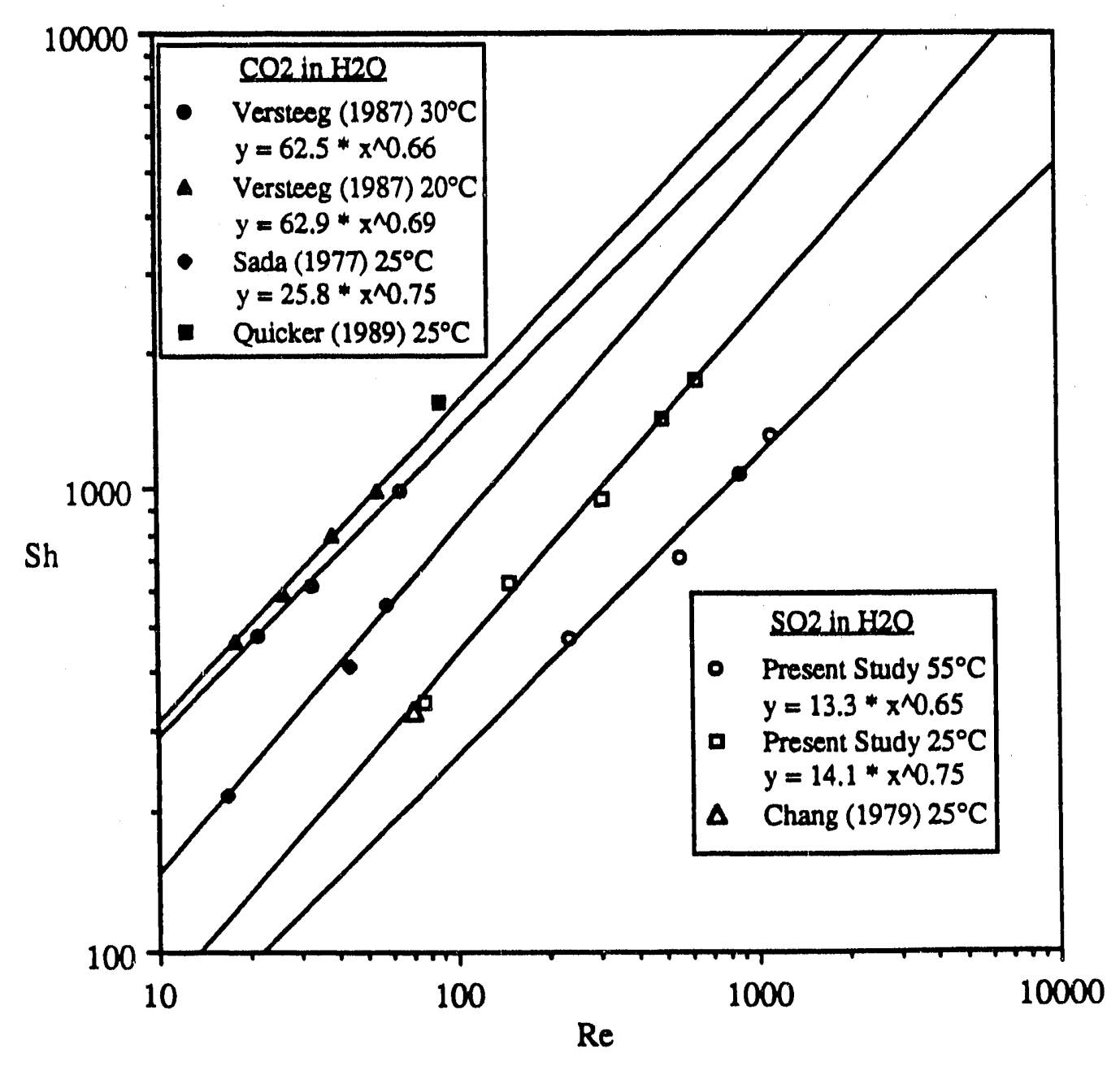

Figure 3-10. Companison of $k^{\circ}$, measured in several studies as a function of liquid agitation speed. 
Although the measured $k^{\circ}$, values are of the same order-ot-magnitude, they vary from one study to the next, probably due to the different geometry of the reactors and diffustvities of the gases. Most of the previous experiments were run at lower liquid agitation speeds and therefore did not produce very high values for $k_{\%}^{\circ}$. Since contact timies on the order of $1 \mathrm{~s}$ were preterred in this research, higher values for $k^{\circ}$, were required, and liquil agitation speeds were greater.

\subsection{COMPARISON OF MASS TRANSFER PROPERTIES OF THI: STIRRED TANK TO THAT IN A}

\section{SLURRY DROPLET}

The mass transfer properties of the reactor determined in the tests discussed above cari be compared to the properties of a slumy droplet to determine how closely the reactor simulates the mass transfer propertles of a droplet.

The gas film mass transfer coefficlent, $k_{g}$, can be defined in units of $m / s$ as a function of the diameter of the droplet and the diffusivity of the species winich is diffusing from the surrounding gas. The relationship was developed first by Harriot (1962) who applied the Ranz and Marshall Equation, below, to describe mass transfer into a droplet travelling at ths terminal velocity, assuming this is equivalent to its slip velocity:

$$
S h=\frac{k_{g} d_{d r o p l e t}}{D}=2+0.6 R e^{0.5} S c^{0.33}
$$

Based on studies by Jozewicz and Rochelle (1984) even very large droplets over $100 \mu \mathrm{m}$ decelerate quickly to the gas velocity. Thus, according to the analysis made by Chan and Rochelle (1981), the droplet is assumed to be stagnant relative to the gas and $\mathrm{Sh}=2$ is a valid approximation.

Using this relationship, a slurry droplet of $10 \mu \mathrm{m}$ would have a corresponding $k_{g}$ of $1.1 \times 10^{-2}$ moles $/ \mathrm{cm}^{2} \mathrm{~s}$ bar. A $100 \mu \mathrm{m}$ droplet would have a $\mathrm{k}_{\mathrm{g}}$ of $1.1 \times 10^{-3} \mathrm{moles} / \mathrm{cm}^{2} \mathrm{~s}$ bar. This covers the range of droplet sizes that would be found in common commercial sprays in dry scrubbing applications, based on the measurements made by Kinsey and Harriot (1988). The highest value of $k_{g}$ measured in the stirred tank was $1.5 \times 10^{-4} \mathrm{moles} / \mathrm{cm}^{2} \mathrm{~s}$ bar. This corresponds to a slurry droplet diameter of 
approximately $800 \mu \mathrm{m}$, which is much larger than would be considered typical of droplets in commerclal use.

It is easy to understand from this relationship why the design of the reactor included steps to minimize gas film resistance ( $\left(. \theta_{1}\right.$, maximize $k_{g}$ ). Unfortunately, the attempts made to minimize gas film resistance did not produce the order-of-magnitude inorease in $\mathrm{k}_{\mathrm{g}}$ necessary to simulate a more reasonable droplet size $(<100 \mu \mathrm{m})$.

The liquid i!lm mass transfer coefficient, $k_{1}^{\circ}$ is a funotion of the surface renewal time in the liquid. The penetration theory gives a relationship for the dependence of $k^{\circ}$, on the surface renewal or contact time as defined in equation (3-9). The amount of contact time in commercial slurry scrubbing applications is determined by the slurry droplet drying time. This is usually on the order of $1 \mathrm{~s}$ and depends on the operating temperature and humidity, droplet size, gas flow characteristics and size distribution of other droplets in the spray (Kinsey and Harriot, 1988). A contact time of $1 \mathrm{~s}$ is equivalent to a $\mathrm{k}^{\circ}$ of $7.0 \times 10^{-5} \mathrm{~m} / \mathrm{s}$. For comparison, the range of $\mathrm{k}^{\circ}$, values measured in the stirred tank at $55^{\circ} \mathrm{C}$ was between $2.7 \times 10^{-5}$ and $8.6 \times 10^{-5} \mathrm{~m} / \mathrm{s}$. This is equivalent to a range of contact times of 6.6 to $0.65 \mathrm{~s}$.

These comparisons show that the stirred tank is capable of representing the gas film mass transfer properties associated with a very large dreplet with a drying time typical of a smaller droplet. The ratio of the gas film mass transfer to the liquid film mass transfer in the stirred tank is a useful quantity and can also be used for comparison. $A k_{g} / k^{\circ}$, of up to 0.17 to $0.50 \mathrm{~mole} / \mathrm{m}^{3} \mathrm{~Pa}$ can be obtained in the stirred tank. Slurry droplets within the range of 10 to $100 \mu \mathrm{m}$ with a 1 to $2 \mathrm{~s}$ drying time would give a range of $\mathrm{k}_{\mathrm{g}} / \mathrm{k}^{\circ}$, from 1.6 to $22.3 \mathrm{~mole} / \mathrm{m}^{3} \mathrm{~Pa}$, based on the preceding analysis. Because of the low values of $k_{g}$ avallable in the reactor, the ratio of mass transfer coefficient! will be about an order-of-magnitude lower than expected for a slurry droplet. 


\section{SECTION 4}

\section{RESULTS OF EXPERIMENTS IN CLEAR SOLUTIONS}

The slurry can be considered to be comprised of two parts: an aqueous, clear solution of $\mathrm{Ca}(\mathrm{OH})_{2}$ including any added dissolved species and a uniformly dispersed phase of suspended solid $\mathrm{Ca}(\mathrm{OH})_{2}$ particles. Reaction with absorbed $\mathrm{SO}_{2}$ occurs entirely in the clear solution phase. It follows, then, that the conditions that will enhance $\mathrm{SO}_{2}$ absorption in slurries can be determined, in part, by studying the effects they will have on the absorption of $\mathrm{SO}_{2}$ into clear solutions.

Studying the clear solutions is also beneficial because mass transfer effects can be studied without some of the complications introduced by the addition of solids, such as $\mathrm{Ca}(\mathrm{OH})_{2}$. In addtion, physical effects, such as increased viscosity, need not be considered. Eliminating effects of solid particles also allowed a clearer look at those effects occurring entirely as a result of changes to solution composttion, such as the effect of lonic strength.

Experiments were designed to validate the first part of the slurry absorption model. For comparison, the slurry absorption model was run under conditions similar to those run in the stirred lank experiments. The surface renewal theory equations developed by Chang \& Rochelle (1979) were solved for the same conditions as an additional basis of comparison. It was assumed that if the slurry absorption model adequately predicts measured absorption rate under the conditions in the stirred tank, that it is capable of predicting absorption under the conditions expected in a slurry droplet.

Initial clear solution tests establish a baseline for absorption of $\mathrm{SO}_{2}$ into solutions containing no $\mathrm{Ca}(\mathrm{OH})_{2}$ at all. Additional clear solution tests then measure the increase in $\mathrm{SO}_{2}$ absorption due to increasing the amount of dissolved $\mathrm{Ca}(\mathrm{OH})_{2}$. Results of these tests are later compared to the 
increased $\mathrm{SO}_{2}$ absorption measured in the slumy tests of Section 5 , where $\mathrm{Ca}(\mathrm{OH})_{2}$ solids are added. The slurry absorption model was run for each of these condtions.

\subsection{EXPERIMENTAL CONDITIONS}

During these tests $\mathrm{SO}_{2}$ was absorbed into several different solutions at $55^{\circ} \mathrm{C}$. The gas phase was mixed at the maximum agitation speed of approximately $1,400 \mathrm{~mm}$, resulting in a gas phase mass transfer coefficient of $1.5 \times 10^{-4} \mathrm{~mole} / \mathrm{s} \mathrm{cm}^{2}$ bar. Solution compositions and other variables are listed in Table 4-1.

TABLE 4-1. CLEAR SOLUTION TEST CONDITIONS

\begin{tabular}{|l|c|c|c||}
\hline Liquid Makeup & $S_{2}$ Concentration $(\mathrm{ppm})$ & Liquid Agitation $(\mathrm{pm})$ & $k_{1}^{0} \times 10^{5}(\mathrm{~m} / \mathrm{s})$ \\
\hline Water & $2,200-2,600$ & $110-1,360$ & $2.4-8.6$ \\
\hline $0.1 \mathrm{M} \mathrm{CaCl}_{2}$ & $1,000-4,970$ & $76-1,330$ & $2.2 \cdot 8.4$ \\
\hline $\begin{array}{l}2.5 \mathrm{mM} \mathrm{Ca}(\mathrm{OH})_{2} \\
0.1 \mathrm{M} \mathrm{CaCl}\end{array}$ & $1,070-5,450$ & $200-1,330$ & $2.7-8.4$ \\
\hline $\begin{array}{l}17 \mathrm{mM} \mathrm{Ca}(\mathrm{OH})_{2} \\
0.1 \mathrm{M} \mathrm{CaCl}\end{array}$ & $580-3,790$ & $230-1,360$ & $2.9 \cdot 8.6$ \\
\hline $17 \mathrm{mM} \mathrm{Ca}(\mathrm{OH})_{2}$ & $710-2,600$ & $706-1,190$ & $5.0-7.6$ \\
\hline $\begin{array}{l}17 \mathrm{mM} \mathrm{Ca}(\mathrm{OH})_{2} \\
0.1 \mathrm{M} \mathrm{NaCl}\end{array}$ & $710-2,690$ & $706-1,210$ & $5.0 \cdot 7.7$ \\
\hline
\end{tabular}

Reagents were prepared in a large $20 \mathrm{~L}$ plastic carboy which was stirred from the top manually until the reagents dissolved. An anhydrous laboratory grade 4-20 mesh $\mathrm{CaCl}_{2}$ produced by Fisher Reagents was used. The $\mathrm{Ca}(\mathrm{OH})_{2}$ was a fresh supply of MCB Reagents stock, opened on $7 / 11 / 89$ for testing. The $\mathrm{NaCl}$ was a laboratory grade salt made by Fisher Reagents. Solutions were prepared by first dissolving the $\mathrm{CaCl}_{2}$ or $\mathrm{NaCl}$ salt and then adding the specified amount of $\mathrm{Ca}(\mathrm{OH})_{2}$.

Solutions containing $17 \mathrm{mM} \mathrm{Ca}(\mathrm{OH})_{2}$ are assumed to be saturated with respect to $\mathrm{Ca}(\mathrm{OH})_{2}$. The concentration of $\mathrm{Ca}(\mathrm{OH})_{2}$ required to produce a saturated solution in $0.1 \mathrm{M} \mathrm{CaCl}_{2}$ was measured by making a solution containing $0.1 \mathrm{M} \mathrm{CaCl}_{2}$ in a $500 \mathrm{~mL}$ beaker, stirred, and heated to $55^{\circ} \mathrm{C}$. Excess $\mathrm{Ca}(\mathrm{OH})_{2}$, corresponding to at least $30 \mathrm{mM}$, was added to the solution. The solution was then filtered, 
and three $50 \mathrm{~mL}$ samples were titrated with $0.1 \mathrm{~N}$ standard $\mathrm{HCl}$. The resulting concentrations of the saturated solutions were $16.9,17.0$ and $17.2 \mathrm{mM} \mathrm{Ca}(\mathrm{OH})_{2}$.

Measurements of $\mathrm{Ca}(\mathrm{OH})_{2}$ solubility in water and salt solutions including $\mathrm{CaCl}_{2}$ by Larsson (1931), Blix (1928) and Markarov (1954) show that addition of chloride salts increases the solubility of $\mathrm{Ca}(\mathrm{OH})_{2}$ in water. However, adding a $0.1 \mathrm{M}$ of these salts only results in approximately 1 percent increase in $\mathrm{Ca}(\mathrm{OH})_{2}$ solubility. Therefore, the solutions containing $17 \mathrm{mM} \mathrm{Ca}(\mathrm{OH})_{2}$ with no $\mathrm{CaCl}_{2}$ and $0.1 \mathrm{M} \mathrm{NaCl}$ are essentially saturated to $\mathrm{Ca}(\mathrm{OH})_{2}$ as well.

In the clear solution experiments, absorption of $\mathrm{SO}_{2}$ is affected by the properties of the liquid phase constituents. Liquid phase mass transfer is enhanced by choosing constituents that favor the reaction of $\mathrm{SO}_{2}$ as outlined in equations (2-3) through (2-5). The amount that liquid phase inass transfer is enhanced is quantified in terms of the enhancement factor, $\varnothing$, which is the ratio of the measured liquid phase mass transfer coefficient, $k_{1}$, and $k_{1}^{\circ}$, the characteristic liquid phase mass transfer coefficient in the absence of chemical reactions for the conditions of the experiment. The $\mathrm{k}^{\circ}$, for different conditions is known based on the correlations developed in Section 3.

The value of $\varnothing$ can be determined from the following relationship:

$$
\varnothing=\frac{\mathrm{N}_{\mathrm{SO}_{2}}}{k_{1}{ }_{1} A\left(\left[\mathrm{SO}_{2}\right]_{i}-\left[\mathrm{SO}_{2}\right]_{0}\right)}
$$

This equation shows that $\varnothing$ is a normalized absorption rate or flux is equivalent to the absorption rate divided by the liquid film mass transfer coefficient and the driving force. The enhancement factor is important because it allows comparison of data obtained in the stirred tank reactor independent of the value of $\mathrm{k}_{1}$ (or contact time) and the level of $\mathrm{SO}_{2}$ maintained in the liquid phase reactor. Because the driving force and the contact time are constantly changed within the reactor, the absorption rate, $\mathrm{N}_{\mathrm{SO} 2}$, cannot usually be compared directly from one test run to another.

Calculating $\oslash$ from equation (4-1) is simplified by knowing that in solutions containing $\mathrm{Ca}(\mathrm{OH})_{2}$, the concentration of $\mathrm{SO}_{2}$ in the bulk phase, $\left[\mathrm{SO}_{2}\right]_{0}$, is negligible due to the instantaneous reaction of 
$\mathrm{SO}_{2}$ forming sulfite and bisulfite. In clear solutions such as water and $\mathrm{CaCl}_{2}$, the bulk concentration of $\mathrm{SO}_{2}$ is significant. It is estimated by material balance and backed by direct measurement of total absorbed sulfur by lon chromatography, as described in Section 3.

The absorption rate, $\mathrm{N}_{\mathrm{SO}}$, was measured directly by gas phase material balance. The interface concentration, $\left[\mathrm{SO}_{2}\right]$, was calculated using the Henry's law relationship given in equation (2-10). The gas phase concentration of $\mathrm{SO}_{2}$ at the interface, $\mathrm{PSO}_{2}$, was determined by equation (2-1) and the relationship for $k_{g}$ given in equation (3-8).

Buildup of sulfur species, especially the bisulfite ion. can affect the equilibrium of the reaction of $\mathrm{SO}_{2}$ and water, equation (2-3). It was important to maintain a low concentration of sulfur species in the bulk liquid phase. A continuous "' $2 \mathrm{w}$ of $205 \mathrm{~mL} / \mathrm{min}$ solution through the reactor was maintained to prevent accumulation of bisulfite and other reacted sulfur species. This helped provide a large driving force for absorption. Results of the gas phase material balance and ion chromatography verifled that the total sulfur concentration was typically $2 \mathrm{mM}$ or less. This was adequate to allow the reaction of $\mathrm{SO}_{2}$ to proceed without being inhibited greatly by buildup of sulfur species.

\subsection{ENHANCEMENT IN WATER}

Enhancement of $\mathrm{SO}_{2}$ absontion in water was measured over a narrow range of $\mathrm{SO}_{2}$ concentrations at varied liquid agitation speeds. The initial pH of the water was adjusted to 5.0 with a small amount of $\mathrm{HCl}$ so that absorption would not be biased by the presence of alkatine species in the water. These tests were designed to confirm that varying the liquid agitation, (i.e., $k^{\circ}$, or contact time) does not have a significant effect on enhancement. The results are summarized in Table 4-2. The results confirmed that $\varnothing$ is independent of liquid agitation speed and, therefore, $k_{1}^{\circ}$, and contact time. $\varnothing$ can be measured in these solutions to approximately \pm 5 percent.

The results show that for $\mathrm{SO}_{2}$ concentrations between 2,200 and $2,450 \mathrm{ppm}$, the reaction of $\mathrm{SO}_{2}$ with pure water enhanced $\mathrm{SO}_{2}$ absomtion by a factor of 3 over absorption of $\mathrm{SO}_{2}$ into a non-reactive solution, such as the $\mathrm{HCl}$ solution used in experiments described in Section 3. Although the $\mathrm{SO}_{2}$ absorption was enhanced, the gas film resistance associated with these experiments ranged 
from only 2 to 7 percent. Referring to equation $(2-10)$, this means that the interfacial concentration of $\mathrm{SO}_{2}$ was quite high during these experiments. In other words, the absorption of $\mathrm{SO}_{2}$ was primarily limited or controlled by the reaction occurring in the liquid phase.

TABLE 4-2. ENHANCEMENT OF $\mathrm{SO}_{2}$ ABSORPTION IN WATER AT VARIOUS LIQUID AGITATION SPEEDS $\left(K_{g}=1.51 \times 10^{-5} \mathrm{Mole} / \mathrm{m}^{2} \mathrm{~Pa} \mathrm{~s}\right)$

\begin{tabular}{|c|c|c|c|c|c|c||}
\hline Test \# & $\begin{array}{c}\mathrm{SO}_{2} \text { Conc. } \\
(\mathrm{ppm})\end{array}$ & $\begin{array}{c}\text { Liq. Agitator } \\
\text { Spe日d }(\mathrm{pm})\end{array}$ & $\mathrm{k}_{1}^{\circ} \times 10^{5}(\mathrm{~m} / \mathrm{s})$ & $\begin{array}{c}\text { Contact Time } \\
(\mathrm{s})\end{array}$ & $\varnothing$ & $\begin{array}{c}\text { Gas Film } \\
\text { Res. (\%) }\end{array}$ \\
\hline CW1 & 2429 & 1363 & 8.5 & 0.66 & 3.2 & 7 \\
\hline CW2 & 2264 & 1042 & 6.8 & 1.1 & 3.2 & 6 \\
\hline CW3 & 2223 & 715 & 5.1 & 1.9 & 3.5 & 5 \\
\hline CW4 & 2431 & 332 & 3.3 & 4.5 & 3.4 & 3 \\
\hline CW5 & 2640 & 113 & 2.4 & 8.6 & 2.9 & 2 \\
\hline
\end{tabular}

Enhancement of $\mathrm{SO}_{2}$ absorption in water can be estimated by the surface renewal theory as proposed by Chang and Rochelle (1979): As found in Section 2, equation (2-12), the theory predicts a linear dependence of $\oslash$ on $1 / \sqrt{\left[\mathrm{SO}_{2}\right]_{1}}$. The proportionality constant is a function of the diffusivities of $\mathrm{SO}_{2}$ and $\mathrm{HSO}_{3}{ }^{-1}$ and the concentration-based equilibrium constant, $\mathrm{K}_{\mathrm{c}}$, of the reaction shown in equation (2-3).

In a solution of pure water, the diffusivity of $\mathrm{HSO}_{3}{ }^{-}$is altered by the lon-pairing effect described in Section 2. The $\mathrm{HSO}_{3}^{-}$and $\mathrm{H}^{+}$ions formed by the reaction in equation (2-3) must diffuse within the boundary layer at the same rate to maintain electrical neutrality of the solution. Diffusivities of $\mathrm{HSO}_{3}{ }^{-}$ and $\mathrm{H}^{+}$at $55^{\circ} \mathrm{C}$ are $2.54 \times 10^{-5}$ and $1.78 \times 10^{-4} \mathrm{~cm}^{2} / \mathrm{s}$, respectively. These diffusivities are based on values reported at $25^{\circ} \mathrm{C}$ by Chan and Rochelle (1981) and corrected for viscosity and temperature changes at $55^{\circ} \mathrm{C}$ using the Stokes-Einstein relationship in equation (3-11). The effective diffusivity for both species calculated using equation (2-13) is $4.45 \times 10^{-5} \mathrm{~cm}^{2} / \mathrm{s}$.

The slurry absorption model was run with bulk solution concentrations and other conditions that simulated the absorption experiments in water. The amount of total sulfur in the reactor liquid was 
calculated to average about $0.5 \mathrm{mM}$ by material balance. Tire bulk solution $\mathrm{pH}$ was determined initially by knowing that the $\mathrm{H}^{+}$concentration must be approximately equal to the $\mathrm{HSO}_{3}{ }^{-}$concentration as per equation (2-3). A charge balance pertormed by the slurry absorption model was checked to assure the correct solution composition.

The remainder of the component concentrations were determined by the Bechtel Modified Radian Equilibrium Program, BMREQ, Epstein (1975), which is used by the slurry absorption model. Table 4-3 summarizes the conditions and compositions used to simulate the solution in the stirred tank. Of the concentrations that are listed, only $\mathrm{H}^{+}, \mathrm{HSO}_{3}^{-}$and $\mathrm{SO}_{2}$ are appreciable. These are the same species which are included in the surface renewal theory solution in equation (2-12) (noting that the concentrations and diffusivities of $\mathrm{H}^{+}$and $\mathrm{HSO}_{3}{ }^{-}$are equivalent based on the ion-pairing assumption). The results from this model, the surface renewal theory prediction, and the measured results in the stirred tank reactor are shown together in Figure 4-1.

TABLE 4-3. CONDITIONS FOR SLURRY ABSORPTION MODEL FOR ABSORPTION OF $\mathrm{SO}_{2}$ IN WATER

\begin{tabular}{|c|c|}
\hline \multicolumn{2}{|c|}{ Concentrations of Important Species (mM) } \\
\hline $\mathrm{H}^{+}$ & 0.515 \\
\hline $\mathrm{OH}^{-}$ & $1.4 \times 10^{-7}$ \\
\hline $\mathrm{SO}_{2}$ & $3.13 \times 10^{-2}$ \\
\hline $\mathrm{HSO}_{3}^{-}$ & 0.469 \\
\hline $\mathrm{SO}_{3}^{-2}$ & $4.1 \times 10^{-5}$ \\
\hline $\mathrm{Cl}^{-}$ & 0.046 \\
\hline \multicolumn{2}{|l|}{ Other Conditions } \\
\hline Temperature & $55^{\circ} \mathrm{C}$ \\
\hline $\mathrm{pH}$ & 3.3 \\
\hline $\mathrm{k}_{\mathrm{g}}$ & $1.44 \times 10^{-5} \mathrm{~mole} / \mathrm{Pa} \mathrm{m} \mathrm{m}^{2} \mathrm{sec}$ \\
\hline Contact Time & 0.0075 to $7.53 \mathrm{~s}$ \\
\hline $\mathrm{PSO}_{\mathrm{SO}}$ & 500 to $4,000 \mathrm{ppm}$ \\
\hline
\end{tabular}




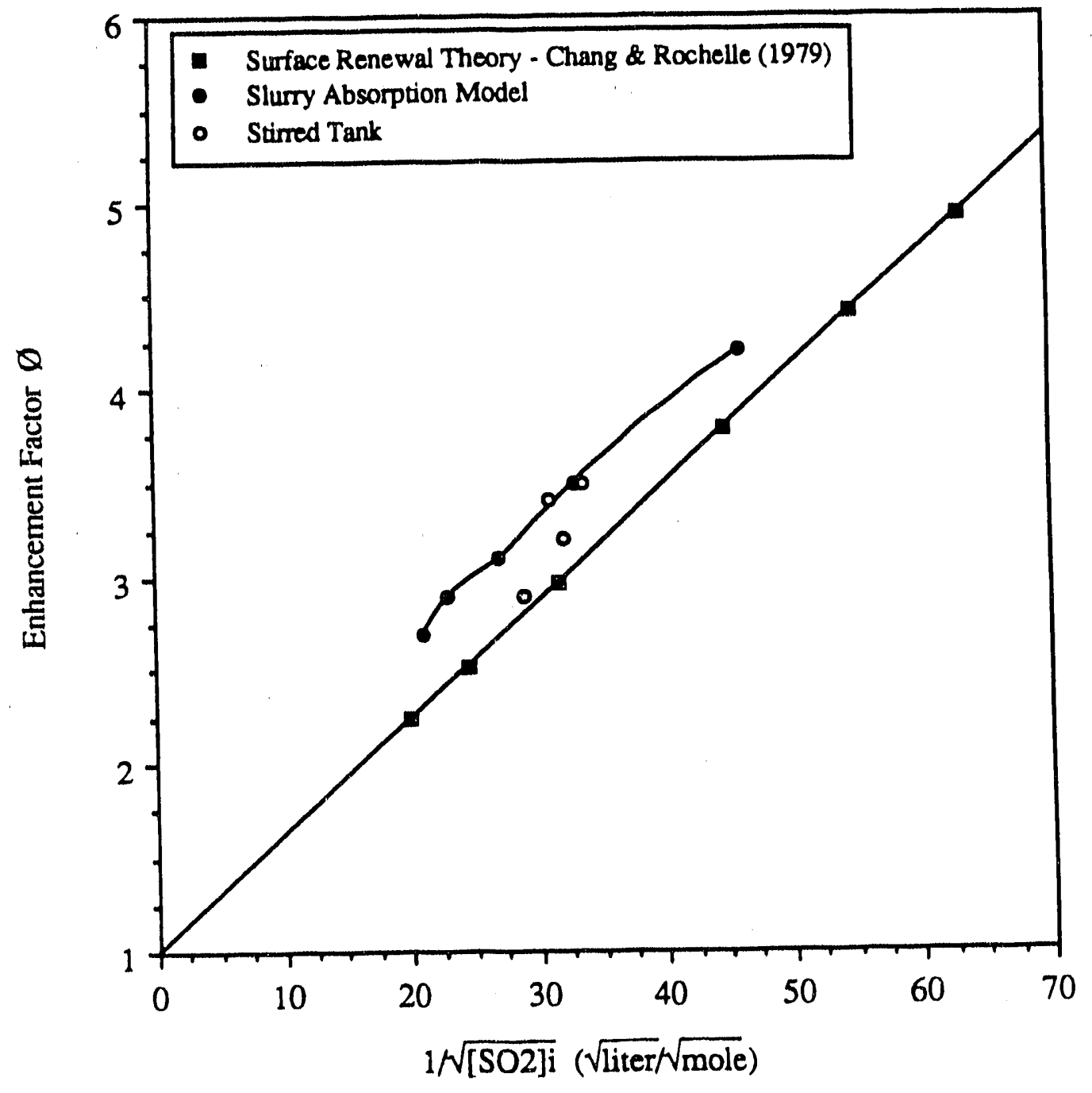

Figure 4-1. Enhancement of $\mathrm{SO}_{2}$ absorption in water. 
The slurry absorption model predicts enhancement that is greater than the enhancement predicted by the surface renewal theory by about 0.5 for the range of $\mathrm{SO}_{2}$ concentrations studied. The enhancement measured in the stirred tank reactor experiments falls in between the predictions of the surface renewal and the slurry absorption models. The measured values do not distinguish which of the two models best predicts the observed absorption because of the degree of inaccuracy associated with the measurements.

\subsection{ENHANCEMENT IN $0.1 \mathrm{M} \mathrm{CaCl}_{2}$ SOLUTION}

Chloride is a common constituent found in slurry solutions used in commercial scrubbing. Calcium chloride was added to some of the clear solutions described later in this chapter, and to all slurries studied in experiments described in Section $5 . \mathrm{CaCl}_{2}$ does not have an active role in the $\mathrm{SO}_{2}$ absomtion reactions shown in equations (2-3) through (2-5). However, adding an excess amount of this electrolyte causes the solution to maintain a constant ionic strength that might otherwise be changing as reaction of $\mathrm{Ca}(\mathrm{OH})_{2}$ with $\mathrm{SO}_{2}$ takes place.

The effect that calcium chloride has on $\mathrm{SO}_{2}$ absorption was studied first by absorbing $\mathrm{SO}_{2}$ into a solution containing $0.1 \mathrm{M} \mathrm{CaCl}_{2}$. Absorption in this solution differs from absorption in water because the ionic strength is altered. By adding $\mathrm{CaCl}_{2}$, the ion-pairing effect is no longer a requirement for electrical neutrality, so $\mathrm{H}^{+}$and $\mathrm{HSO}_{3}{ }^{-}$species can diffuse independently.

Experiments in $0.1 \mathrm{M} \mathrm{CaCl}_{2}$ solutions were designed to measure enhancement at several $\mathrm{SO}_{2}$ concentrations. Also, experiments were run at similar $\mathrm{SO}_{2}$ concentrations with varied liquid agitation speeds to confirm that changing speeds has a negligible effect on absorption of $\mathrm{SO}_{2}$. Again, the initial $\mathrm{pH}$ was adjusted to 5.0 with a small amount of $\mathrm{HCl}$.

Table 4-4 shows the results of tests run at similar $\mathrm{SO}_{2}$ concentrations of around $4400 \mathrm{ppm}$. The results of the first 4 tests show that enhancement can be measured repeatedly to within \pm 5 percent. The $\mathrm{SO}_{2}$ concentration was a bit higher during the following 2 tests, which was significant enough to cause a drop in enhancement. 
TABLE 4-4. ENHANCEMENT OF $\mathrm{SO}_{2}$ ABSORPTION IN $0.1 \mathrm{M} \mathrm{CaCl}_{2}$ AT VARIOUS LIQUID AGITATION SPEEDS

$\left(k_{\mathrm{g}}=1.45 \times 10^{-5} \mathrm{~mole} / \mathrm{m}^{2} \mathrm{~Pa} \mathrm{~s}\right)$

\begin{tabular}{|c|c|c|c|c|c|c|}
\hline $\begin{array}{c}\text { Test } \\
\#\end{array}$ & $\begin{array}{l}\mathrm{SO}_{2} \\
\text { Conc. } \\
\text { (ppm) }\end{array}$ & $\begin{array}{l}\text { Llq. Agitator } \\
\text { Speed (mm) }\end{array}$ & $\begin{array}{c}k^{0}, \times 10^{5} \\
(\mathrm{~m} / \mathrm{s})\end{array}$ & $\begin{array}{c}\text { Contact Time } \\
\text { (s) }\end{array}$ & $\varnothing$ & Gas Film Res. (\%) \\
\hline $\mathrm{CC}_{1}$ & 4460 & 1330 & 8.4 & 4.5 & 3.7 & 9 \\
\hline $\mathrm{CC2}$ & 4300 & 1019 & 6.7 & 7.2 & 3.9 & 7 \\
\hline $\mathrm{CC} 3$ & 4440 & 679 & 4.9 & 13.2 & 3.9 & 6 \\
\hline $\mathrm{CC} 4$ & 4620 & 412 & 3.7 & 23.8 & 3.6 & 4 \\
\hline 005 & 4880 & 236 & 2.9 & 38.1 & 3.2 & 3 \\
\hline CC6 & 4970 & 76 & 2.2 & 64.0 & 2.9 & 2 \\
\hline
\end{tabular}

TABLE 4-5. ENHANCEMENT OF $\mathrm{SO}_{2}$ ABSORPTION IN $0.1 \mathrm{M} \mathrm{CaCl}_{2}$ AT VARIOUS $\mathrm{SO}_{2}$ CONCENTRATIONS

$\left(k_{g}=1.45 \times 10^{-5} \mathrm{~mole} / \mathrm{m}^{2} \mathrm{~Pa} \mathrm{~s}, \mathrm{k}_{1}=4.9 \times 10^{-5} \mathrm{~m} / \mathrm{s}\right)$

\begin{tabular}{|c|c|c|c|c|}
\hline Test \# & SO $_{2}$ Conc. (ppm) & $\begin{array}{c}\text { Liq. Agitator Speed } \\
\text { (rpm) }\end{array}$ & $\emptyset$ & Gas Film Resistance (\%) \\
\hline CC3 & 4,440 & 679 & 3.9 & 6 \\
\hline CC7 & 2,490 & 674 & 4.2 & 6 \\
\hline CC8 & 1,000 & 674 & 6.0 & 8 \\
\hline CC9 & 1,990 & 674 & 4.8 & 7 \\
\hline
\end{tabular}

Table 4-5 reports the effect of $\mathrm{SO}_{2}$ concentration on enhancement. The enhancement factor ranged between about 4 at the high $\mathrm{SO}_{2}$ concentrations near $4,400 \mathrm{ppm}$, to 6 at the low $\mathrm{SO}_{2}$ concentration of $1,000 \mathrm{ppm}$. At an $\mathrm{SO}_{2}$ concentration of $2,500 \mathrm{ppm}$, enhancement was improved about 30 percent over enhancement measured in water.

The gas film resistance is reported in both Tables 4-4 and 4-5. Gas film resistance for the tests in $0.1 \mathrm{M} \mathrm{CaCl}_{2}$ solutions is slightly higher than for the tests in water. As indicated by equation (2-11) gas film resistance increases as either $k_{1}^{\circ}$ and/or $\varnothing$ increases.

The enhancement factor in $\mathrm{CaCl}_{2}$ solutions can be estimated by the surface renewal theory developed by Chang and Rochelle (1979). The solution for the enhancement factor shown in equations 
absorption in water, absorption depends on the concentrations and diffusivities of $\mathrm{SO}_{2}, \mathrm{HSO}_{3} ; \mathrm{H}^{+}$and the equillbrium constant, $K_{0}$ of the reaction shown in equation (2-3).

Absorption of $\mathrm{SO}_{2}$ in $\mathrm{CaCl}_{2}$ solutions differs from that in water only because $\mathrm{Cr}$ is present, allowing $\mathrm{HSO}_{3}{ }^{-}$and $\mathrm{H}^{+}$to diffuse independently. In other words, the reaction of $\mathrm{SO}_{2}$ in the $\mathrm{CaCl}_{2}$ solution is not inhibited by the ion-pairing effect.

The slurry absorption model was run with bulk solution concentrations and other conditions that simulated the absorption experiments in $0.1 \mathrm{M} \mathrm{CaCl}_{2}$ under steady state conditions. Again, the bulk solution $\mathrm{pH}$ was estimated by knowing that the $\mathrm{H}^{+}$concentration must be approximately equal to the $\mathrm{HSO}_{3}{ }^{-}$concentration as per equation (2-3). The $\mathrm{pH}$ was then adjusted until the charge balance of lonic species was satisfied. The remaining component concentrations were determined by BMREQ.

The amount of total sulfur in the bulk liquid during experiments was calculated to range between 0.4 and $2.0 \mathrm{mM}$ by material balance. Two solution compositions were determined for running the slurry absorption model. The first has a low value of $0.5 \mathrm{mM} \mathrm{S}(\mathrm{IV})_{0}$. The second has a value of $0.8 \mathrm{mM} \mathrm{S}(\mathrm{IV})_{0}$, which was the average for the conditions in the stirred tank. Table 4-6 summarizes the conditions and compositions that were used in the slurry absorption model to simulate the solution in the stirred tank.

Two solutions for the surface renewal theory were calculated as well, based on the equilibrium concentrations calculated by BMREQ for these 2 cases. Enhancement predicted by ine slurry absorption model, the surface renewal theory, and the measured results in the stirred tank reactor are shown together in Figure 4-2. 
TABLE 4-6. CONDITIONS FOR SLURRY ABSORPTION MODEL FOR ABSORPTION OF $\mathrm{SO}_{2}$ IN $0.1 \mathrm{M} \mathrm{CaCl}_{2}$

\begin{tabular}{|c|c|c|}
\hline \multicolumn{3}{|c|}{ Concentrations of Important Species (mM) } \\
\hline & Case 1 & Case 2 \\
\hline $\mathrm{H}^{+}$ & 0.843 & 0.497 \\
\hline $\mathrm{OH}^{-}$ & $1.35 \times 10^{-7}$ & $2.28 \times 10^{-7}$ \\
\hline $\mathrm{SO}_{2}$ & $4.75 \times 10^{-2}$ & $1.79 \times 10^{-2}$ \\
\hline $\mathrm{HSO}_{3}^{-}$ & 0.750 & 0.479 \\
\hline $\mathrm{SO}_{3}^{-2}$ & $1.32 \times 10^{-4}$ & $1.43 \times 10^{-4}$ \\
\hline $\mathrm{Ca}^{+2}$ & 100 & 100 \\
\hline $\mathrm{CaSO}_{3}{ }^{\circ}$ & $2.56 \times 10^{-3}$ & $2.78 \times 10^{-3}$ \\
\hline $\mathrm{CaOH}^{+}$ & $9.97 \times 10^{-8}$ & $1.69 \times 10^{-7}$ \\
\hline $\mathrm{Cl}^{-}$ & 200 & 200 \\
\hline \multicolumn{3}{|c|}{ Other Conditions } \\
\hline & Case 1 & Case 2 \\
\hline Temperature $\left({ }^{\circ} \mathrm{C}\right)$ & 55 & 55 \\
\hline $\mathrm{pH}$ & 3.15 & 3.38 \\
\hline$k_{\mathrm{g}}\left(\mathrm{mole} / \mathrm{Pa} \mathrm{m} \mathrm{m}^{2} \mathrm{~s}\right)$ & $1.44 \times 10^{-6}$ & $1.44 \times 10^{-6}$ \\
\hline Contact Time (s) & .0075 to 7.53 & .0075 to 7.53 \\
\hline $\mathrm{P}_{\mathrm{SO} 2}$ (ppm) & 500 to 5,000 & 500 to 2,000 \\
\hline
\end{tabular}

Both the slurry absorption model and the surface renewal theory using the BMREQ concentrations and diffusivities predict that enhancement is reduced when larger amounts of sulfur species, mostly $\mathrm{SO}_{2}$ and $\mathrm{HSO}_{3}{ }^{\circ}$, are present in the liquid phase. The reduction in enhancement is more pronounced at the lower $\mathrm{SO}_{2}$ concentrations (i.e., higher values of $1 / \sqrt{\left[\mathrm{SO}_{2}\right]_{1}}$ ). The slurry absorption model predicts a greater reduction in entiancement due to the increase in absorbed sulfur species than does the surface renewal theory. At high $\mathrm{SO}_{2}$ concentrations, the models compare relatively well to one another, and the amount of absorbed sulfur species has little effect on enhancement. 


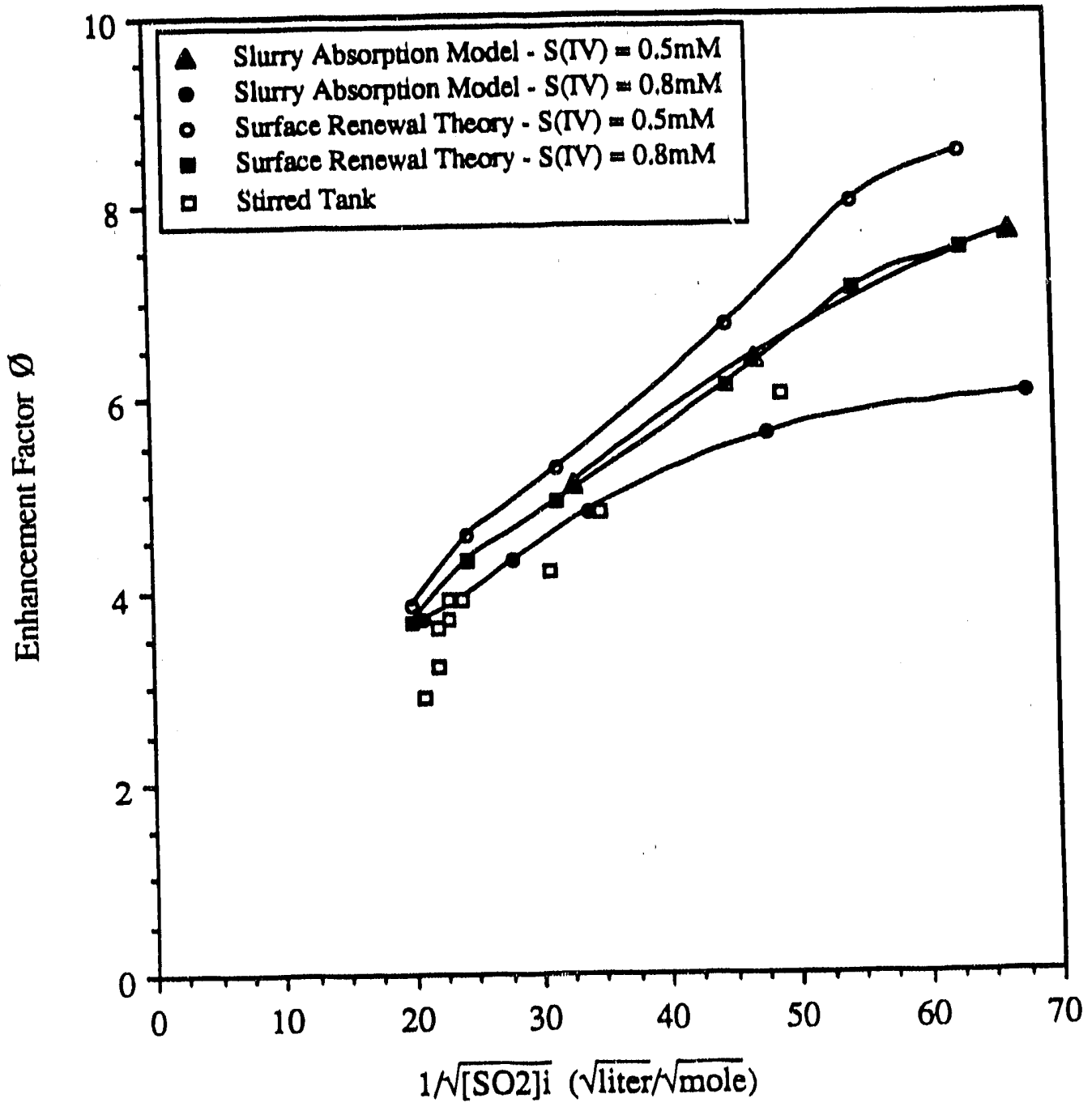

Figure 4-2. Enhancement of $\mathrm{SO}_{2}$ absorption in $0.1 \mathrm{M} \mathrm{CaCl}_{2}$ solution. 
The results measured in the stirred tank correlate best with the lower enhancement predioted by the slurry absorption model. During the stirred tank experiments, the $S(I V)_{0}$ conoentrations varied depending upon the degree of absorption ocourring. Table 4-7 lists results of experiments at varlous $\mathrm{SO}_{2}$ concentrations including the estimated amount of absorbed sulfur species in the llquid. Generally, within the stirred tank, as $\mathrm{SO}_{2}$ concentration increases the amount of sulfur speoles in the bulk liquid Increases as well.

4.4 ENHANCEMENT IN $2.5 \mathrm{mM} \mathrm{Ca(OH)_{2 }}$ SOLUTION CONTAINING $0.1 \mathrm{M} \mathrm{CaCl}_{2}$

The olear $\mathrm{Ca}(\mathrm{OH})_{2}$ solutions containing $0.1 \mathrm{M} \mathrm{CaCl}_{2}$ is more representative of the liquid composition and the chemical properties of slumy solutions than water. The first set of tests was run at a $\mathrm{Ca}(\mathrm{OH})_{2}$ level of $2.5 \mathrm{mM}$. These experiments were almed at measuring the enhancement factor over a range of $\mathrm{SO}_{2}$ concentrations.

Two sets of experiments were pertormed with $2.5 \mathrm{mM} \mathrm{Ca}(\mathrm{OH})_{2} / 0.1 \mathrm{M} \mathrm{CaCl}_{2}$ solutions. The first set of experiments was performed on $7 / 11 / 89$. Another set of experiments was performed several months later, 9/12/89, after some minor replumbing and recalibration of flow meters during slurry testing. The objective of the second set of tests was to check the reproduclbility of the results and obtain measurements over a wider range of $\left[\mathrm{SO}_{2}\right]_{1}$ levels. The results of these 2 sets of experiments are summarized in Table 4-8. The reported total sulfur content of the liquid, [S(IV) $]_{0}$, was calculated by material balanoe.

TABLE 4-7. PRESENCE OF ABSORBED SULFUR SPECIES IN $0.1 \mathrm{M} \mathrm{CaCl}_{2}$ SOLUTIONS AT VARIOUS $\mathrm{SO}_{2}$ CONCENTRATIONS

\begin{tabular}{||l|l|l|l||}
\hline Test \# & Bulk Gas SO ${ }_{2}$ Conc. (ppm) & {$\left[\mathrm{SO}_{2}\right]_{1}(\mathrm{mM})$} & $\mathrm{S}(\mathrm{IV})_{0}$ Cono. (mM) \\
\hline CC3 & 4,440 & 2.06 & 1.23 \\
\hline CC7 & 2,490 & 1.15 & 0.72 \\
\hline CC8 & 1,000 & 0.45 & 0.41 \\
\hline$C C 9$ & 1,990 & 0.92 & 0.66 \\
\hline
\end{tabular}


TABLE 4-8. ENHANCEMENT OF $\mathrm{SO}_{2}$ ABSORPTION IN $2.5 \mathrm{mM} \mathrm{Ca}(\mathrm{OH})_{2}$ WITH $0.1 \mathrm{M} \mathrm{CaCl}$

$\left(k_{\mathrm{g}}=1,44 \times 10^{-6} \mathrm{~mole} / \mathrm{m}^{2} \mathrm{~Pa} \mathrm{~s}\right)$

\begin{tabular}{|c|c|c|c|c|c|c|}
\hline Test \# & $\begin{array}{c}\mathrm{SO}_{2} \text { Conc. } \\
(\mathrm{ppm})\end{array}$ & $k^{0} \times 10^{5}$ & $\begin{array}{l}\text { Contact } \\
\text { Time }(8)\end{array}$ & $\varnothing$ & $\begin{array}{c}{[S(I V)]_{0}} \\
(m M)\end{array}$ & Gas Film Res. (\%) \\
\hline \multicolumn{7}{|c|}{$7 / 11 / 89 \quad\left(k_{g}=1.44 \times 10^{-5} \mathrm{~mole} / \mathrm{m}^{2} \mathrm{~Pa} \mathrm{~s}\right)$} \\
\hline CD1 & 4,000 & 8.4 & 0.70 & 5.9 & 1.8 & 13 \\
\hline CD2 & 3,850 & 6.5 & 1.1 & 8.6 & 2.0 & 15 \\
\hline CDB & 4270 & 4.9 & 2.0 & 8.5 & 1.7 & 11 \\
\hline CD4 & 4,680 & 3.6 & 3.7 & 5.4 & 0.9 & 6 \\
\hline CD5 & 2,760 & 3.6 & 3.7 & 7.1 & 0.7 & 7 \\
\hline CD6 & 1,490 & 3.6 & 3.7 & 10.0 & 0.5 & 10 \\
\hline CD7 & 2,260 & 2.7 & 6.6 & 11.6 & 0.7 & 9 \\
\hline \multicolumn{7}{|c|}{$9 / 12 / 89 \quad\left(k_{g}=1.42 \times 10^{-6} \mathrm{~mole} / \mathrm{m}^{2} \mathrm{~Pa} \mathrm{~s}\right)$} \\
\hline CD8 & 3,600 & 7.4 & 0.90 & 9.7 & 2.2 & 13 \\
\hline $\operatorname{CDg}$ & 2,890 & 7.4 & 0.90 & 10.2 & 1.9 & 19 \\
\hline CD10 & 2,111 & 7.4 & 0.90 & 10.4 & 1.4 & 19 \\
\hline CD11 & 1,070 & 7.4 & 0.90 & 18.9 & 1.1 & 30 \\
\hline CD12 & 1,210 & 6.5 & 1.2 & 17.7 & 1.1 & 26 \\
\hline CD13 & 2,170 & 6.5 & 1.2 & 11.3 & 1.4 & 19 \\
\hline CD14 & 3,110 & 6.5 & 1.2 & 10.2 & 1.8 & 17 \\
\hline CD15 & 5,450 & 6.5 & 1.2 & 5.9 & 2.0 & 11 \\
\hline CD16 & 3,730 & 4.9 & 2.0 & 9.7 & 1.7 & 13 \\
\hline CD17 & 3,140 & 4.9 & 2.0 & 8.3 & 1.2 & 11 \\
\hline
\end{tabular}

Overall, the $\mathrm{SO}_{2}$ concentrations studied ranged from 1,070 to $5,450 \mathrm{ppm}$. Enhancement factors measured during these tests ranged from about 5 , at high $\mathrm{SO}_{2}$ concentrations, to 19 at the lowest $\mathrm{SO}_{2}$ concentrations. Gas film resistance inoreased considerably over levels measured in water and $\mathrm{CaCl}_{2}$ solutions, ranging from about 10 percent at the high $\mathrm{SO}_{2}$ concentrations to 30 percent at the lowest $\mathrm{SO}_{2}$ concentration.

Chang and Rochelle (1970) were also able to apply the surtace renewal theory to absorption in solutions containing dissolved $\mathrm{Ca}(\mathrm{OH})_{2}$. Enhancement, as given by equations $(2-20)$ and $(2-21)$, is a 
funotion of additional species, Of course, the absorption depends heavily on the bulk concentration of OH. Also, at the higher $\mathrm{pH}_{1} \mathrm{HSO}_{3}{ }^{-1}$ reacts to form $\mathrm{SO}_{3}{ }^{-2}$, which reaches signitloant levels.

The slurry absorption model was run with bulk solution concentrations and other conditions that simulated the absorption experiments with the $2.5 \mathrm{mM} \mathrm{Ca}(\mathrm{OH})_{2} / 0.1 \mathrm{M} \mathrm{CaCl}_{2}$ solution. Since the addition of $\mathrm{Ca}(\mathrm{OH})_{2}$ made the solution very alkaline, the bulk solution pH was determined by estimating the $\mathrm{OH}^{-}$concentration. The initial amount of $\mathrm{OH}^{-}$added to the feed was $5.0 \mathrm{mM}$. However, the net result of equations (2-3) through (2-5) requires that for every mole of $\mathrm{SO}_{3}{ }^{-2}$ formed, two moles of $\mathrm{OH}^{-}$ are consumed.

The amount of total sulfur in the reactor liquid was calculated to range between 0.5 and $2.2 \mathrm{mM}$ by material balance. A typlcal value of $0.85 \mathrm{mM}$ was chosen as the total $\mathrm{S}$ (IV) concentration for modeling pumoses. Under these alkaline conditions, almost all of the absorbed S(IV) is reacted to $\mathrm{SO}_{3}{ }^{-2}$. Therefore under steady state conditions, the $\mathrm{OH}^{-}$concentration is $3.3 \mathrm{mM}$. As a first approximation, the $\mathrm{pH}$ was chosen such that the $\mathrm{OH}^{-}$and $\mathrm{CaOH}^{+}$concentrations summed olose to 3.3 $\mathrm{mM}$. The $\mathrm{pH}$ was then fine-tuned to ensure a proper charge balance.

The remainder of the component concentrations were determined by BMREQ, which is called by the slurry absorption model. Table 4-9 summarizes the conditions and compositions used to simulate the solution in the stirred tank. As shown in the table, bulk concentrations of $\mathrm{H}^{+}, \mathrm{HSO}_{3}{ }^{-}$and $\mathrm{SO}_{2}$ are no longer important species as they were in the solutions with lower pH previously studied. Instead, Important bulk species are $\mathrm{OH}^{-}, \mathrm{SO}_{3}{ }^{-2}, \mathrm{CaSO}_{3}{ }^{\circ}$ and $\mathrm{CaOH}^{+}$. Note that the surface renewal theory solution does not consider the presence of the $\mathrm{CaOH}^{+}$and $\mathrm{CaSO}_{3}{ }^{\circ}$ lon pairs.

The results of the slurry absorption model are plotted along with enhancement estimated by the surface renewal theory, and enhancement measured in the stirred tank reactor in Figure 4-3. The experimental data appear to be described relatively well by both the surface renewal theory and the slurry absorption model over the range of $\mathrm{SO}_{2}$ concentrations studied. Again, the two models differ slightly. The slurry absorption model predicts the experimentally measured enhancement more accurately at the lower $\mathrm{SO}_{2}$ concentrations (l.e., the higher values of $\left.1 /\left[\mathrm{SO}_{2}\right]_{1}\right)$. 
TABLE 4-9. CONDITIONS FOR SLURRY ABSORPTION MODEL FOR ABSORPTION OF $\mathrm{SO}_{2}$ IN $2.5 \mathrm{mM} \mathrm{Ca}(\mathrm{OH})_{2}$ WITH $0.1 \mathrm{M} \mathrm{CaCl}_{2}$

\begin{tabular}{|c|c|}
\hline \multicolumn{2}{|c|}{ Concentrations of Important Species (mM) } \\
\hline $\mathrm{H}^{+}$ & $5.97 \times 10^{-8}$ \\
\hline $\mathrm{OH}^{-}$ & 1.90 \\
\hline $\mathrm{SO}_{2}$ & negligible \\
\hline $\mathrm{HSO}_{3}^{-}$ & $1.72 \times 10^{-5}$ \\
\hline $\mathrm{SO}_{3}^{-2}$ & $4.3 \times 10^{-2}$ \\
\hline $\mathrm{Ca}^{+2}$ & 100.3 \\
\hline $\mathrm{CaSO}_{3}{ }^{\circ}$ & 0.83 \\
\hline $\mathrm{CaOH}^{+}$ & 1.41 \\
\hline $\mathrm{Cl}^{-}$ & 199.9 \\
\hline \multicolumn{2}{|c|}{ Other Conditions } \\
\hline Temperature & $55^{\circ} \mathrm{C}$ \\
\hline $\mathrm{pH}$ & 10.30 \\
\hline$k_{g}$ & $1.44 \times 10^{-5} \mathrm{~mole} / \mathrm{Pa} \mathrm{m} \mathrm{m}^{2} \mathrm{~s}$ \\
\hline Contact Time & 0.01 to $10 \mathrm{~s}$ \\
\hline $\mathrm{PSO}_{\mathrm{SO}}$ & 500 to $5,000 \mathrm{ppm}$ \\
\hline
\end{tabular}

One unknown factor which could have influenced absorption measured in the stirred tank was how much of the $\mathrm{CaSO}_{3}{ }^{\circ}$ precipltated during the individual runs. The slurry absorption model was run under the assumption that the solution was saturated to $\mathrm{CaSO}_{3}$. According to the BMREQ data from the slurry absorption model conditions, of the $1.0 \mathrm{mM} \mathrm{S}(\mathrm{IV})_{0}$ assumed to be present, $0.95 \mathrm{mM}$ was present as $\mathrm{CaSO}_{3}{ }^{\circ}$ under saturated conditions. This means that the model assumed that a small amount of $\mathrm{CaSO}_{3}$ had precipitated.

Of the solutions studied, most had S(IV) concentrations estimated to be above $1.0 \mathrm{mM}$. The few measurements taken during the first set of tests which measured low absorption also had low absorbed $\mathrm{S}(\mathrm{IV})_{0}$ concentrations. These solutions were probably not saturated with $\mathrm{CaSO}_{3}$, which may account for the poor agreement with the absorption predicted by the model. The amount of total absorbed sulfur determined by material balance, $S(I V)_{0}$, was given in Table 4-8. 


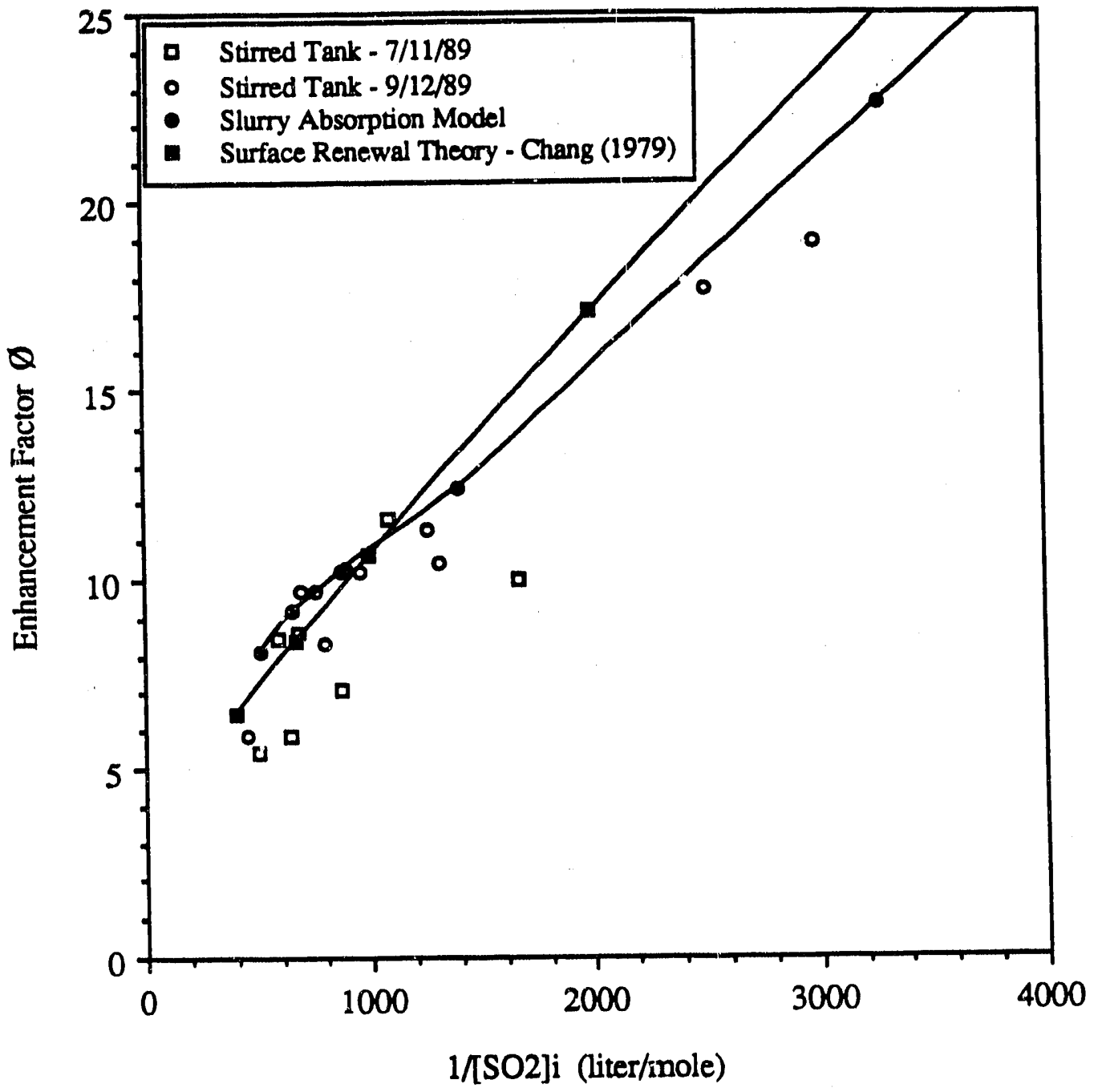

Figure 4-3. Enhancement of $\mathrm{SO}_{2}$ absorption in $2.5 \mathrm{mM} \mathrm{Ca}(\mathrm{OH})_{2} / 0.1 \mathrm{M} \mathrm{CaCl}_{2}$ solution. 
Solutions with greater than $1.0 \mathrm{mM} \mathrm{S}(I V)_{0}$ either reached a supersaturated concentration of $\mathrm{CaSO}_{3}{ }^{\circ}$ at steady state or had precipitated $\mathrm{CaSO}_{3}$ solids during the experiment. During some of the experiments, it was noted that the bulk solution became cloudy, and during experiments where the absorption rate was greatest (i.e., high bulk gas $\mathrm{SO}_{2}$ concentrations) some small, round platelets were found in the bulk solution. The bulk solutions of most of the experiments run were therefore known to be merely saturated with $\mathrm{CaSO}_{3}$ and not supersaturated.

It was expected that conditions of saturation versus supersaturation of $\mathrm{CaSO}_{3}$ in the boundary layer of the solution could have influenced absorption of $\mathrm{SO}_{2}$. Since it was not possible to monitor such conditions, the actual condition of $\mathrm{CaSO}_{3}$ in the boundary layer is not known. Because the absorption of $\mathrm{SO}_{2}$ measured in the stirred tank agreed well with the model and theory, whatever influence these conditions may have had was not significant enough to affect the measured absorption. Such behavior should only be of concern in describing the absorption of $\mathrm{SO}_{2}$ in dilute solutions of $\mathrm{Ca}(\mathrm{OH})_{2}$. In slurries and solutions saturated with $\mathrm{Ca}(\mathrm{OH})_{2}$, precipitation of $\mathrm{CaSO}_{3}$ will surely occur. The bulk liquid (and probably the boundary layer as well) will always be saturated with $\mathrm{CaSO}_{3}$ in $\mathrm{Ca}(\mathrm{OH})_{2}$ slurries studied.

\subsection{ENHANCEMENT IN $17 \mathrm{mM} \mathrm{Ca}(\mathrm{OH})_{2}$ SOLUTION CONTAINING $0.1 \mathrm{M} \mathrm{CaCl}_{2}$}

Another set of tests was run with $\mathrm{Ca}(\mathrm{OH})_{2}$ at $17 \mathrm{mM}$, the saturation level in $0.1 \mathrm{M} \mathrm{CaCl}_{2}$. This set of conditions is particularly interesting because it represents the same conditions as those in the dissolved portion of a $\mathrm{Ca}(\mathrm{OH})_{2}$ slurry. The only difference between it and a $\mathrm{Ca}(\mathrm{OH})_{2}$ slurry is the ability of the slurry to regenerate the reacted $\mathrm{Ca}(\mathrm{OH})_{2}$ with dissolution of solid lime. Again, experiments were run on two occasions. A summary of results are presented in Table 4-10.

The $\mathrm{SO}_{2}$ concentrations studied during experiments with the $17 \mathrm{mM} \mathrm{Ca}(\mathrm{OH})_{2}$ solution ranged from 580 to $3,790 \mathrm{ppm}$. The test conducted at the lowest $\mathrm{SO}_{2}$ concentration resulted in absorption that was too gas film controlled to accurately determine the enhancement. Gas film resistance for the test runs varied from 12 percent to 83 percent. The enhancement factor measured during these tests 
TABLE 4-10. ENHANCEMENT OF $\mathrm{SO}_{2}$ ABSORPTION IN $17 \mathrm{mM} \mathrm{Ca}(\mathrm{OH})_{2}$ WITH $0.1 \mathrm{M} \mathrm{CaCl}$

\begin{tabular}{|c|c|c|c|c|c|c|}
\hline Test \# & $\begin{array}{c}\mathrm{SO}_{2} \text { Conc. } \\
\text { (ppm) }\end{array}$ & $\begin{array}{c}k^{0} \times 10^{5}(\mathrm{~m} / \mathrm{s}) \\
\text { Contact Time } \\
(\mathrm{s})\end{array}$ & $\begin{array}{c}{[S(I V)]_{0}} \\
(\mathrm{mM})\end{array}$ & $\varnothing$ & \multicolumn{2}{|c|}{ Gas Film Res. (\%) } \\
\hline \multicolumn{7}{|c|}{$7 / 11 / 89 \quad\left(\mathrm{k}_{\mathrm{g}}=1.44 \times 10^{-6} \mathrm{~mole} / \mathrm{m}^{2} \mathrm{~Pa} \mathrm{~s}\right)$} \\
\hline CS1 & 2895 & 8.6 & 0.66 & 15 & 2.8 & 28 \\
\hline CS2 & 3181 & 7.0 & 1.00 & 15 & 2.7 & 24 \\
\hline CS3 & 2359 & 5.0 & 1.92 & 32 & 2.7 & 33 \\
\hline CS4 & 2287 & 3.6 & 3.77 & 25 & 1.7 & 22 \\
\hline CS5 & 1179 & 3.6 & 3.77 & 40 & 1.3 & 31 \\
\hline CS6 & 3570 & 3.6 & 3.77 & 19 & 2.1 & 17 \\
\hline CS7 & 2172 & 2.9 & 5.88 & 15 & 0.9 & 12 \\
\hline \multicolumn{7}{|c|}{$9 / 19 / 89 \quad\left(k_{g}=1.42 \times 10^{-5} \mathrm{~mole} / \mathrm{m}^{2} \mathrm{~Pa} \mathrm{~s}\right)$} \\
\hline CS8 & 2496 & 7.3 & 0.92 & 35 & 3.8 & 44 \\
\hline CS9 & 1271 & 7.3 & 0.92 & 99 & 3.0 & 69 \\
\hline CS10 & 582 & 7.3 & 0.92 & -- & 1.6 & 83 \\
\hline CS11 & 952 & 6.4 & 1.19 & 133 & 2.4 & 72 \\
\hline CS12 & 2301 & 6.4 & 1.19 & 36 & 3.3 & 42 \\
\hline CS13 & 2841 & 6.0 & 1.35 & 25 & 3.1 & 31 \\
\hline CS14 & 3521 & 6.0 & 1.35 & 24 & 3.8 & 31 \\
\hline CS15 & 3044 & 6.0 & 1.35 & 21 & 3.0 & 29 \\
\hline CS16 & 3793 & 6.0 & 1.35 & 21 & 3.6 & 28 \\
\hline CS17 & 1051 & 6.0 & 1.35 & 42 & 1.6 & 44. \\
\hline CS18 & 1274 & 5.1 & 1.88 & 69 & 2.3 & 52 \\
\hline CS19 & 3342 & 5.1 & 1.88 & 21 & 2.8 & 25 \\
\hline
\end{tabular}

ranged from about 13 at the high $\mathrm{SO}_{2}$ concentrations to 133 at the lowest $\mathrm{SO}_{2}$ concentration that could be evaluated.

The slurry absorption model was run with bulk solution concentrations and other conditions that simulated a solution containing $17 \mathrm{mM} \mathrm{Ca}(\mathrm{OH})_{2}$ in $0.1 \mathrm{M} \mathrm{CaCl}_{2}$. The bulk solution $\mathrm{pH}$ was determined by estimating the $\mathrm{OH}^{-}$concentration as described previously for the dilute $\mathrm{Ca}(\mathrm{OH})_{2}$ solution. An initial 
$\mathrm{pH}$ of 11.3 was chosen such that the $\mathrm{OH}^{-}$and $\mathrm{CaOH}^{+}$concentrations summed close to $34 \mathrm{mM}$. The $\mathrm{pH}$ was then fine tuned to achieve the proper charge balance. The amount of total sulfur in the reactor liquid was calculated to range between 0.9 and $3.8 \mathrm{mM}$ by material balance. A typical value of $2.0 \mathrm{mM}$ was chosen as the total S(IV) concentration for modeling purposes.

The remainder of the component concentrations were determined by BMREQ. The solution was assumed to be saturated with $\mathrm{CaSO}_{3}$ since the calcium sulfite precipitated during all of the experiments. Again, important bulk species are $\mathrm{OH}^{-}, \mathrm{SO}_{3}^{-2}, \mathrm{CaSO}_{3}{ }^{\circ}$ and $\mathrm{CaOH}^{+}$. Table 4-11 summarizes the conditions and compositions used to simulate the $17 \mathrm{mM} \mathrm{Ca}(\mathrm{OH})_{2}$ solution in the stirred tank. Because of our error in computer input, the calculations were done for $18 \mathrm{mM} \mathrm{Ca}(\mathrm{OH})_{2}$.

TABLE 4-11. CONDITIONS FOR SLURRY ABSORPTION MODEL FOR ABSORPTION OF $\mathrm{SO}_{2}$ IN $18 \mathrm{mM} \mathrm{Ca}(\mathrm{OH})_{2}$ WITH $0.1 \mathrm{M} \mathrm{CaCl}_{2}$

\begin{tabular}{|c|c|}
\hline \multicolumn{2}{|c|}{ Concentrations of Important Species (mM) } \\
\hline $\mathrm{H}^{+}$ & $5.76 \times 10^{-8}$ \\
\hline $\mathrm{OH}^{-}$ & 19.6 \\
\hline $\mathrm{SO}_{2}$ & negligibis \\
\hline $\mathrm{HSO}_{3}^{-}$ & $1.67 \times 10^{-5}$ \\
\hline $\mathrm{SO}_{3}^{-2}$ & $4.34 \times 10^{-2}$ \\
\hline $\mathrm{Ca}^{+2}$ & 102.5 \\
\hline $\mathrm{CaSO}_{3}{ }^{\circ}$ & 0.82 \\
\hline $\mathrm{CaOH}^{+}$ & 14.7 \\
\hline $\mathrm{Cl}^{-}$ & 200.0 \\
\hline \multicolumn{2}{|c|}{ Other Conditions } \\
\hline Temperature & $55^{\circ} \mathrm{C}$ \\
\hline $\mathrm{pH}$ & 11.313 \\
\hline$k_{g}$ & $1.44 \times 10^{-5} \mathrm{~mole} / \mathrm{Pa} \mathrm{m} \mathrm{m}^{2} \mathrm{~s}$ \\
\hline Contact Time & 0.01 to $10.0 \mathrm{~s}$ \\
\hline $\mathrm{p}_{\mathrm{SO} 2}$ & 1,000 to $4,000 \mathrm{ppm}$ \\
\hline
\end{tabular}


As previously mentioned, Chang and Rochelle (1979) used the surface renewal theory to predict the enhancement factor in $\mathrm{Ca}(\mathrm{OH})_{2}$ solutions. Using equations $(2-20)$ and $(2-21)$ with bulk species concentrations given by BMREQ, enhancement for $\mathrm{SO}_{2}$ absorption in $17 \mathrm{mM} \mathrm{Ca}(\mathrm{OH})_{2}$ solution was estimated. The results of the slurry absorption model are plotted with enhancement estimated by the surface renewal theory, and enhancement measured in the stirred tank reactor shown in Figure 4-4.

The predicted enhancement at contact times of 0.9 and $2.5 \mathrm{~s}$ is shown in Figure 4-4. Notice that enhancement does not appear to be a function of contact time for the conditions studied. However, the slurry absorption model predicted over twice the enhancement measured in the stirred tank. The surface renewal theory also predicted much greater enhancement than that measured in the stirred tank, and slightly greater those predicted by the slurry absorption model.

The species which influence absorption most are $\mathrm{OH}^{-}$and $\mathrm{SO}_{3}{ }^{-2}$. Properties of these species were changed, and the model was run to test whether the absorption rate of $\mathrm{SO}_{2}$ predicted by the model would be affected. Initially, equilibrium conditions for formation of the $\mathrm{CaOH}^{+}$and $\mathrm{CaSO}_{3}{ }^{\circ}$ lon pairs were changed but did not result in a significant effect on the predicted $\mathrm{SO}_{2}$ absorption.

The rate of crystallization of $\mathrm{CaSO}_{3}$ was also changed but had little effect on the resulting $\mathrm{SO}_{2}$ absorption predicted by the model. Of all the properties, only the changes made to the diffusivity of $\mathrm{OH}^{-}$had a significant effect on predicted absorption of $\mathrm{SO}_{2}$.

In fact, there may be some physical explanation for why the diffusivity of $\mathrm{OH}^{-}$in the $17 \mathrm{mM}$ $\mathrm{Ca}(\mathrm{OH})_{2}$ solution may be altered. For example, the diffusivities of $\mathrm{Ca}^{2+}$ and $\mathrm{OH}^{-}$used by the model assume diffusion occurs in an infinitely dilute solution. Perhaps as the concentration of $\mathrm{Ca}(\mathrm{OH})_{2}$ is increased, the assumption of an infinitely dilute solution no longer holds, and the diffusivities of one or both of these species are affected. This was not documented by any experiments performed for this type of research.

The slurry absorption model was run initially using a value of $1.00 \times 10^{-4} \mathrm{~cm}^{2} / \mathrm{s}$ for the diffusivity of the hydroxide ion. This value was taken from $\mathrm{D}_{\mathrm{OH}-2}$ reported at $25^{\circ} \mathrm{C}$ by Chan and Rochelle (1981) 


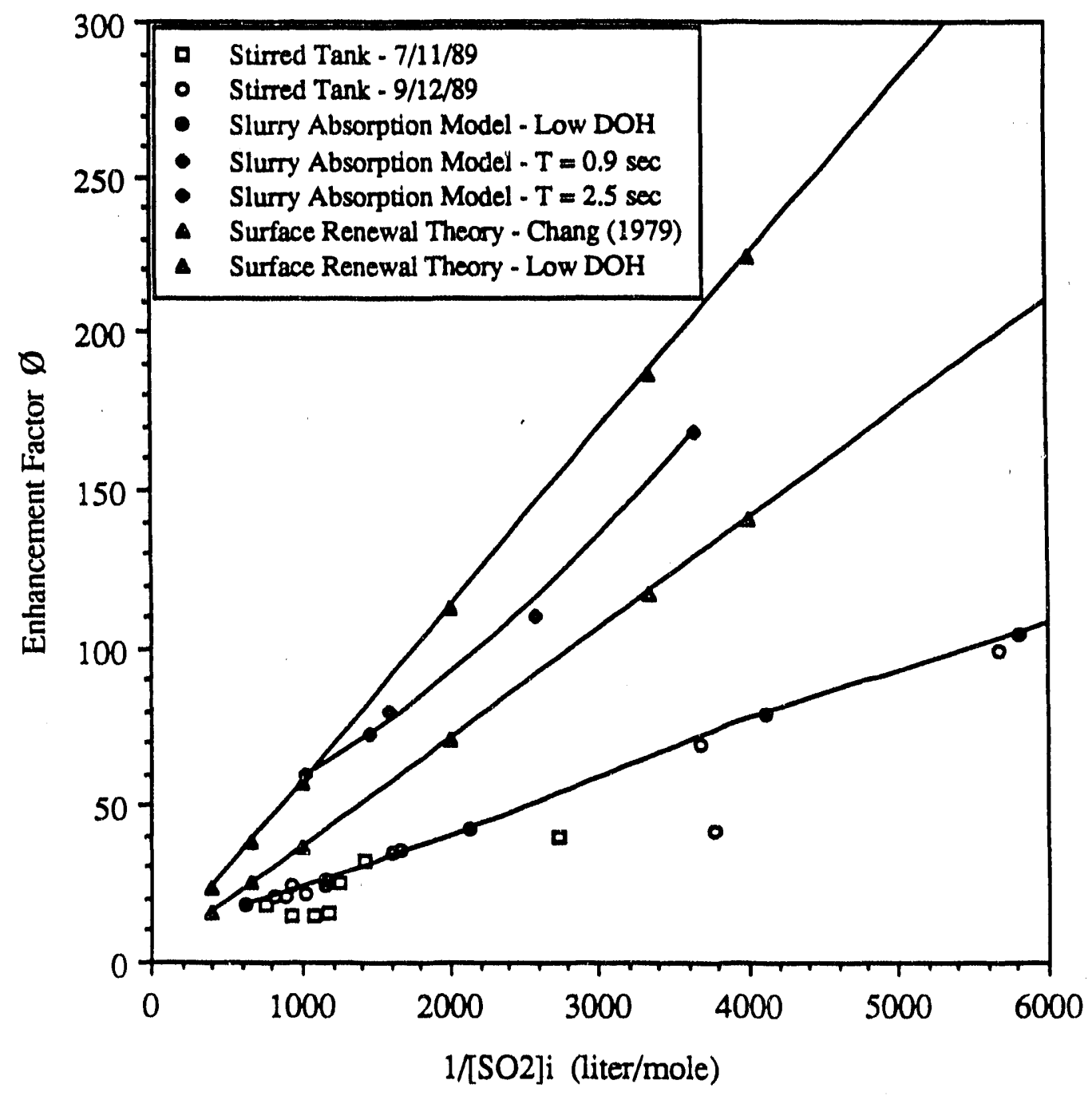

Figure 4-4. Enhancement of $\mathrm{SO}_{2}$ absorption in $17 \mathrm{mM} \mathrm{Ca}(\mathrm{OH})_{2} / 0.1 \mathrm{M} \mathrm{CaCl}_{2}$ solution (calculations done at $18 \mathrm{mM} \mathrm{Ca}(\mathrm{OH})_{2}$ ). 
and corrected for the change in viscosity and temperature at $55^{\circ} \mathrm{C}$ using equation $(3-11)$, based on the Stokes-Einstein relationship.

An adjusted diffusivity of $\mathrm{OH}^{-}$was chosen such that the model predictions would match the absorption of $\mathrm{SO}_{2}$ measured in the stirred tank. The resulting diffusivity was $3.83 \times 10^{-5} \mathrm{~cm}^{2} / 8$. The results of the slurry absorption model and the surface renewal theory based on this lower $\mathrm{D}_{\mathrm{OH}}$ - are shown in Figuie 4-4 for comparison. Under these conditions the surtace renewal theory no longer predicts to the same degree of enhancement as does the slurry absorption model.

Since the lower value for $\mathrm{D}_{\mathrm{OH} \text { - }}$ will be used to model absorption in solutions and slumies containing $\mathrm{Ca}(\mathrm{OH})_{2}$, it is important to model the absorption in the $2.5 \mathrm{mM} \mathrm{Ca}(\mathrm{OH})_{2}$ solution with the low $\mathrm{D}_{\mathrm{OH}}$ - as well. Figure 4-5 contains the same results plotted in Figure 4-3 with the addition of the enhancement predicted by the slurry absorption model for this solution assuming the low $\mathrm{D}_{\mathrm{OH}_{-}}$of $3.83 \times 10^{-5} \mathrm{~cm}^{2} / \mathrm{s}$. Under these conditions, enhancement is nearly the same as that predicted using the higher $\mathrm{D}_{\mathrm{OH}_{-}}$at values of $1 /\left[\mathrm{SO}_{2}\right]_{1}$ near $1400 \mathrm{~L} /$ mole. However, the model predicted unexplainably lower enhancement at both higher and iower values of $1 /\left[\mathrm{SO}_{2}\right]$. The enhancement measured in the stirred tank could be described by using either value of $\mathrm{D}_{\mathrm{OH}}$ - with about the same degree of accuracy, however.

\subsection{ENHANCEMENT IN SOLUTIONS OF VARYING IONIC STRENGTH}

All tests previously run in $\mathrm{Ca}(\mathrm{OH})_{2}$ solutions and slurries have contained $0.1 \mathrm{M} \mathrm{CaCl}_{2}$. To investigate the effect of the lonic strength in the bulk solution, $17 \mathrm{mM} \mathrm{Ca}(\mathrm{OH})_{2}$ solutions of varying lonic strength were tested. One test was run using $17 \mathrm{mM} \mathrm{Ca}(\mathrm{OH})_{2}$ solution containing no $\mathrm{CaCl}_{2}$. Another test was run with $0.1 \mathrm{M} \mathrm{NaCl}$ added, which is $1 / 3$ the ionic strength of $0.1 \mathrm{M} \mathrm{CaCl}_{2}$.

By changing the lonic strength of the bulk solution, a number of properties can be affected. Without $\mathrm{CaCl}_{2}$ or some other electrolyte present, a constant lonic strength would not be ensured throughout the solution. Activities of constituents can change, which directly affects solution equilibria. 


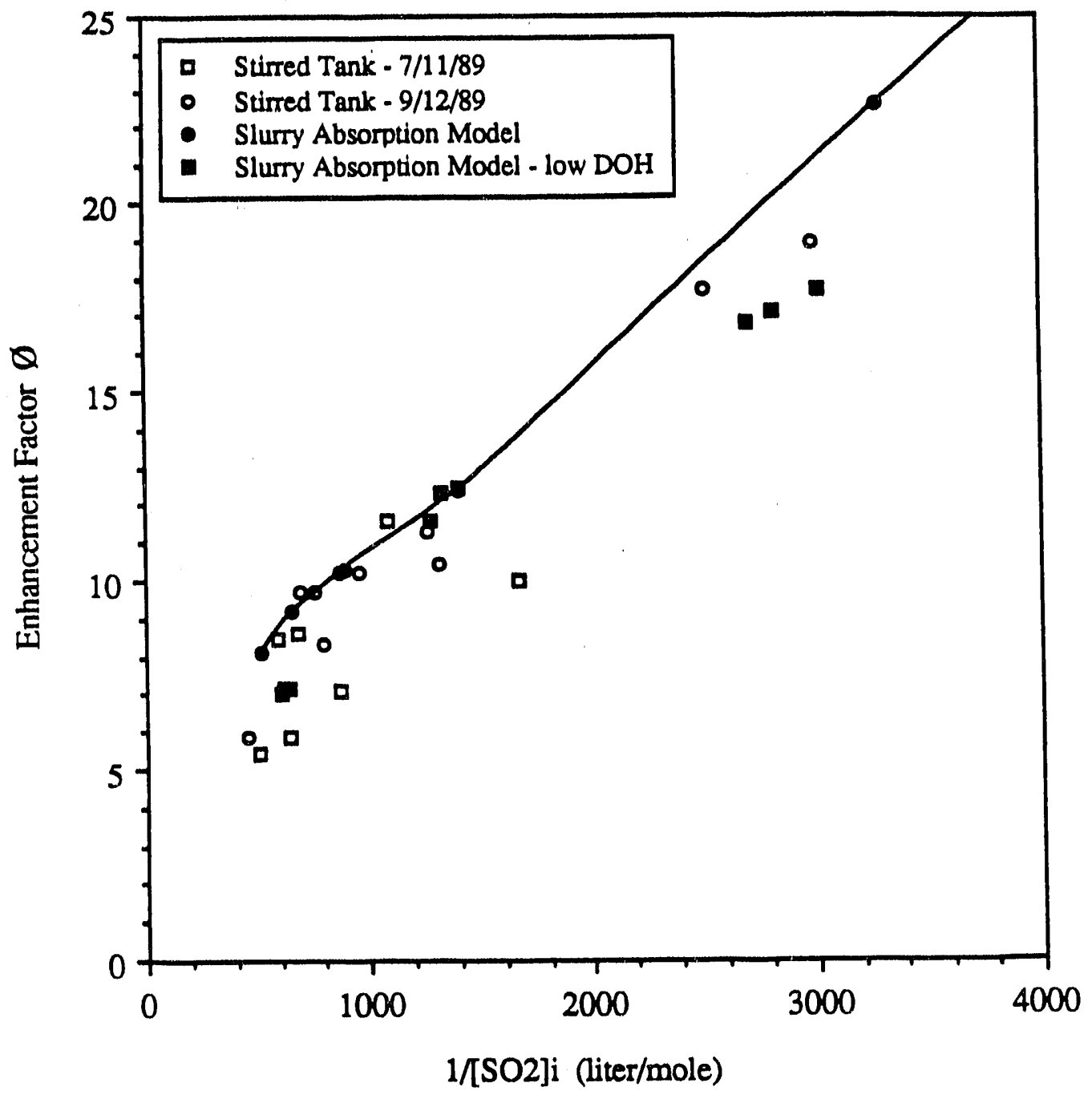

Figure 4-5. Effect of low $\mathrm{D}_{\mathrm{OH}}$ on enhancement of $\mathrm{SO}_{2}$ absorption in $2.5 \mathrm{mM} \mathrm{Ca}(\mathrm{OH})_{2} / 0.1 \mathrm{M} \mathrm{CaCl}$ solution. 
Equilibrium constants and solubility constants can be affected. Also, diffusivitles of lonio species can be affected. Of course, absorption and reaction of $\mathrm{SO}_{2}$ occurs within the boundary layer at the surface of the gas/liquild interface, and absorption and reaction depend upon the lonio strength of the boundary layer solution. These experiments will show whether there is significant change to the conditions within the boundary layer when lonic strength in the bulk solution is altered.

Shown in Tables 4-12 and 4-13 are summaries of results for tests performed in solutions of $17 \mathrm{mM} \mathrm{Ca}(\mathrm{OH})_{2}$ containing no $\mathrm{CaCl}_{2}$ and containing $0.1 \mathrm{M} \mathrm{NaCl}$, respectively. The range of $\mathrm{SO}_{2}$ concentrations tested was 600 to $2,700 \mathrm{ppm}$. Under these condttions, enhancement and gas film resistance were high. In fact, two tests at low $\mathrm{SO}_{2}$ concentrations resulted in absorption that was too gas film controlled to yield a measurable enhancement factor.

The results of tests performed in $17 \mathrm{mM} \mathrm{Ca}(\mathrm{OH})_{2}$ solutions with varied ionic strength are compared in Figure 4-6. Varying the lonic strength of the bulk solution had no significant effect on enhancement of $\mathrm{SO}_{2}$ absorption.

Inputs which simulate the composttion of the solutions used in these tests were developed for running the slurry absorption model. However, the model had trouble converging and would not run at all for solutions containing $\mathrm{NaCl}$. It would be interesting to note whether the model predicts any significant effect of changes in loric strength in the bulk solution. The model should be modifled in the future to allow for such a comparison.

\subsection{SUMMARY OF EXPERIMENTS IN CLEAR SOLUTIONS}

The clear solution experiments revealed a tew important detalls about the absorption of $\mathrm{SO}_{2}$ in solutions containing $\mathrm{Ca}(\mathrm{OH})_{2}$. The degree of absorption of $\mathrm{SO}_{2}$ was measured in terms of the enhancement factor and in terms of the degree that gas film resistance controls the absorption. The results are compared and summarized below. Also, the enhancement of $\mathrm{SO}_{2}$ absomption measured in these solutions was used to validate enhancement predicted by the slurry absorption model. Conclusions reached from comparing the experimentally measured absorption of $\mathrm{SO}_{2}$ to the absorption predicted by this model are also summarized below. 
TABLE 4-12. ENHANCEMENT OF $\mathrm{SO}_{2}$ ABSORPTION IN $17 \mathrm{mM} \mathrm{Ca}(\mathrm{OH})_{2}$ CONTAINING NO CaCl $\left(K_{\mathrm{g}}=1.49 \times 10^{-5} \mathrm{~mole} / \mathrm{m}^{2} \mathrm{~Pa} 8\right)$

\begin{tabular}{||c|c|c|c|c|c|c||}
\hline Test \# & $\begin{array}{c}\mathrm{SO}_{2} \text { Conc. } \\
(\mathrm{ppm})\end{array}$ & $\begin{array}{c}\text { Liq. Agitator } \\
\text { Speed }(\mathrm{mm})\end{array}$ & $\begin{array}{c}k^{0} \times 10^{5} \\
(\mathrm{~m} / \mathrm{s})\end{array}$ & $\begin{array}{c}\text { Contaot } \\
\text { Time }(\mathrm{s})\end{array}$ & $\varnothing$ & Gas Fllm Res. (\%) \\
\hline CNo1 & 1942 & 1193 & 7.6 & 0.8 & 61 & 58 \\
\hline CNo2 & 1145 & 1193 & 7.6 & 0.8 & 124 & 74 \\
\hline CNo3 & 710 & 1193 & 7.6 & 0.8 & 78 & 64 \\
\hline CNo4 & 817 & 1028 & 6.7 & 1.1 & 219 & 81 \\
\hline CNo5 & 1836 & 1028 & 6.7 & 1.1 & 55 & 52 \\
\hline CNo6 & 2.074 & 891 & 6.0 & 1.4 & 46 & 45 \\
\hline CNo7 & 2601 & 891 & 6.0 & 1.4 & 47 & 46 \\
\hline CNo8 & 921 & 891 & 6.0 & 1.4 & 52 & 48 \\
\hline CNo9 & 1232 & 706 & 5.0 & 1.9 & 71 & 52 \\
\hline CNo10 & 2358 & 706 & 5.0 & 1.9 & 41 & 38 \\
\hline
\end{tabular}

TABLE 4-13. ENHANCEMENT OF $\mathrm{SO}_{2}$ ABSORPTION IN $17 \mathrm{mM} \mathrm{Ca}(\mathrm{OH})_{2}$ CONTAINING $0.1 \mathrm{M} \mathrm{NaCl}$

$\left(k_{\mathrm{g}}=1.49 \times 10^{-6} \mathrm{~mole} / \mathrm{m}^{2} \mathrm{~Pa} \mathrm{~s}\right)$

\begin{tabular}{|c|c|c|c|c|c|c||}
\hline Test \# & $\begin{array}{c}\mathrm{SO}_{2} \text { Conc. } \\
(\mathrm{ppm})\end{array}$ & $\begin{array}{c}\text { Liq. Agltator } \\
\text { Speed }(\mathrm{mm})\end{array}$ & $\begin{array}{c}\mathrm{k}^{\circ} \times 10^{5} \\
(\mathrm{~m} / \mathrm{s})\end{array}$ & $\begin{array}{c}\text { Contact } \\
\text { Time (s) }\end{array}$ & $\varnothing$ & Gas Film Res. (\%) \\
\hline CNa1 & 1745 & 1212 & 7.7 & 0.8 & 74 & 66 \\
\hline CNa2 & 899 & 1212 & 7.7 & 0.8 & $\cdots$ & 97 \\
\hline CNa3 & 643 & 1212 & 7.7 & 0.8 & 97 & 72 \\
\hline CNa4 & 734 & 1035 & 6.7 & 1.1 & $\cdots$ & 91 \\
\hline CNa5 & 2023 & 1035 & 6.7 & 1.1 & 38 & 47 \\
\hline CNa6 & 1903 & 863 & 5.8 & 1.4 & 51 & 50 \\
\hline CNa7 & 2692 & 863 & 5.8 & 1.4 & 40 & 44 \\
\hline CNa8 & 711 & 863 & 5.8 & 1.4 & 90 & 64 \\
\hline CNa9 & 968 & 706 & 5.0 & 1.9 & 125 & 68 \\
\hline CNa10 & 2421 & 706 & 5.0 & 1.9 & 34 & 37 \\
\hline
\end{tabular}




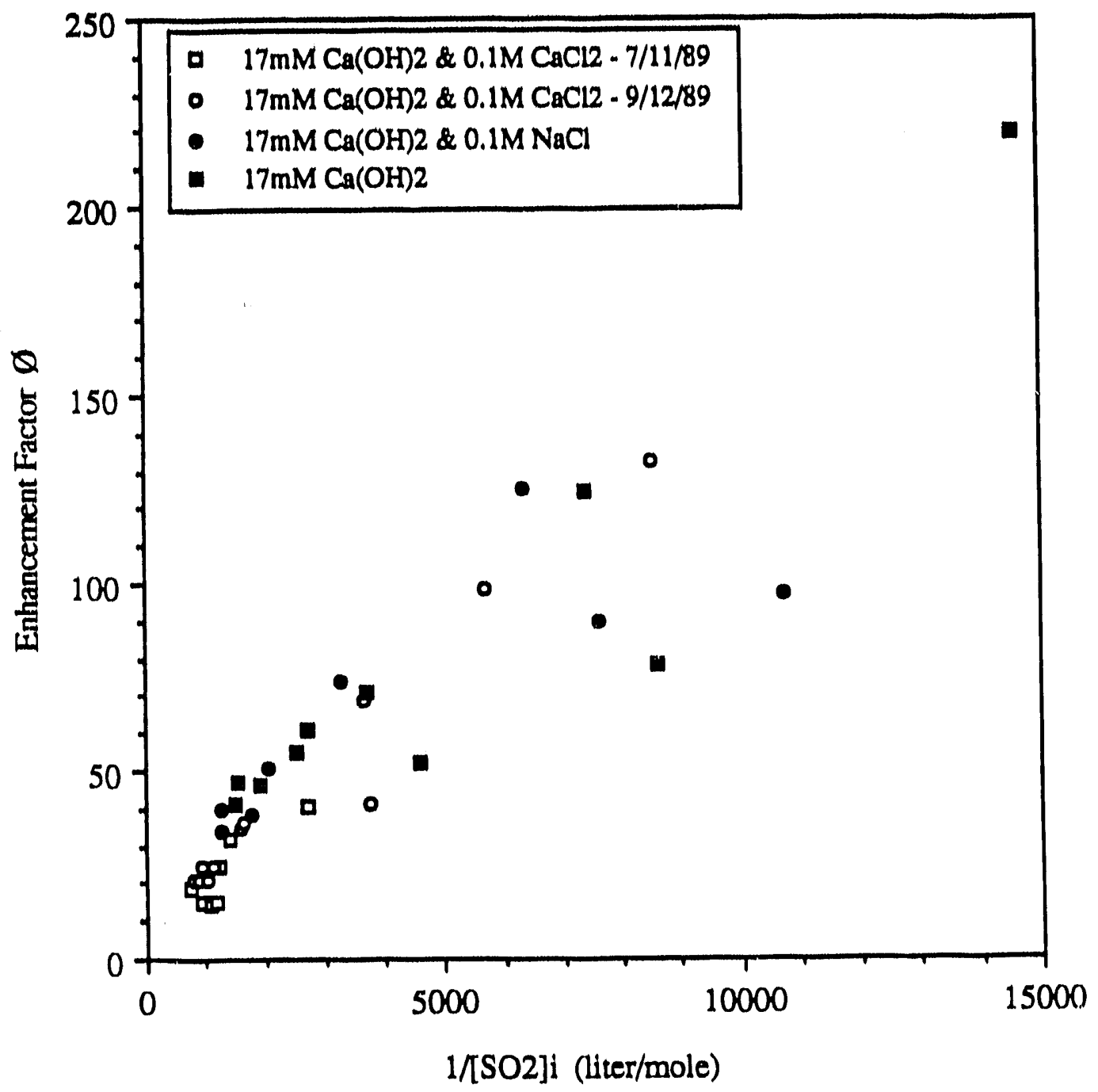

Figure 4-6. Comparison of enhancement of $\mathrm{SO}_{2}$ absorption in $17 \mathrm{mM} \mathrm{Ca}(\mathrm{OH})_{2}$ solutions at various lonio strengths. 


\subsubsection{Enhanoement and Gas Film Resistance}

The enhancement faotor has proven to be a valuable parameter for comparing the degree of $\mathrm{SO}_{2}$ absorption measured in the stirred tank reactor. Because it represents a normalized flux of $\mathrm{SO}_{2}$ it Was possible to vary the bulk gas $\mathrm{SO}_{2}$ concentration and the contaot time in the reactor and still have a constant basis for comparison of absorption. The enthanoement factor was shown to be independent of contaot time, or $k_{1}^{\circ}$, determined by the liquid agttation rate in the reactor. Measurement of enhanoement in water and $\mathrm{CaCl}_{2}$ solutions was found to be repeatable to within about 5 percent.

The enhancement factor was found to be a strong function of the $\mathrm{SO}_{2}$ concentration of the bulk gas. The enhancement factor Inoreased about 30 percent when $\mathrm{CaCl}_{2}$ was added to water. Even more dramatio inoreases in enhanoement were measured when inoreasing amounts of dissolved $\mathrm{Ca}(\mathrm{OH})_{2}$ were tested. Changes to the bulk lonio strength did not influence the enhancement measured In $17 \mathrm{mM} \mathrm{Ca}(\mathrm{OH})_{2}$ solutions, however. Flgure 4-7 summarizes the enhancement factors presented in this section, with the enhancement predicted by the slurry absomption model to lllustrate the influence of the bulk gas $\mathrm{SO}_{2}$ concentration. The model for the $17 \mathrm{mM} \mathrm{Ca}(\mathrm{OH})_{2}$ solution was run assuming the low value of $D_{\mathrm{OH}-1}$

Generally, as the enhancement factor increased, the degree of gas fllm resistance for the absorption of $\mathrm{SO}_{2}$ also increased in the stirred tank experiments. The percentage of gas film resistance was an important parameter to monitor because It defined the operating limits for the stirred tank reactor. The degree of gas film resistance increased for conditions of low bulk $\mathrm{SO}_{2}$ concentration and short contact times. As a solution nears 100 percent gas film resistance, enhancement can no longer be measured. The absorption is dominated by the gas flim properties. Some olear solution tests resulted in absorption that was c jer 90 percent gas fllm controlled, and enhancement could not be measured accurately.

Gas film resistance increased as the solutions in the stirred tank were made more reactive towards $\mathrm{SO}_{2}$. The highest degree of gas film resistance was measured in $17 \mathrm{mM} \mathrm{Ca}(\mathrm{OH})_{2}$ at low bulk. $\mathrm{SO}_{2}$ concentrations. Figure $4-8$ shows the degree of gas fllm resistanoe measured in the stirred tank 


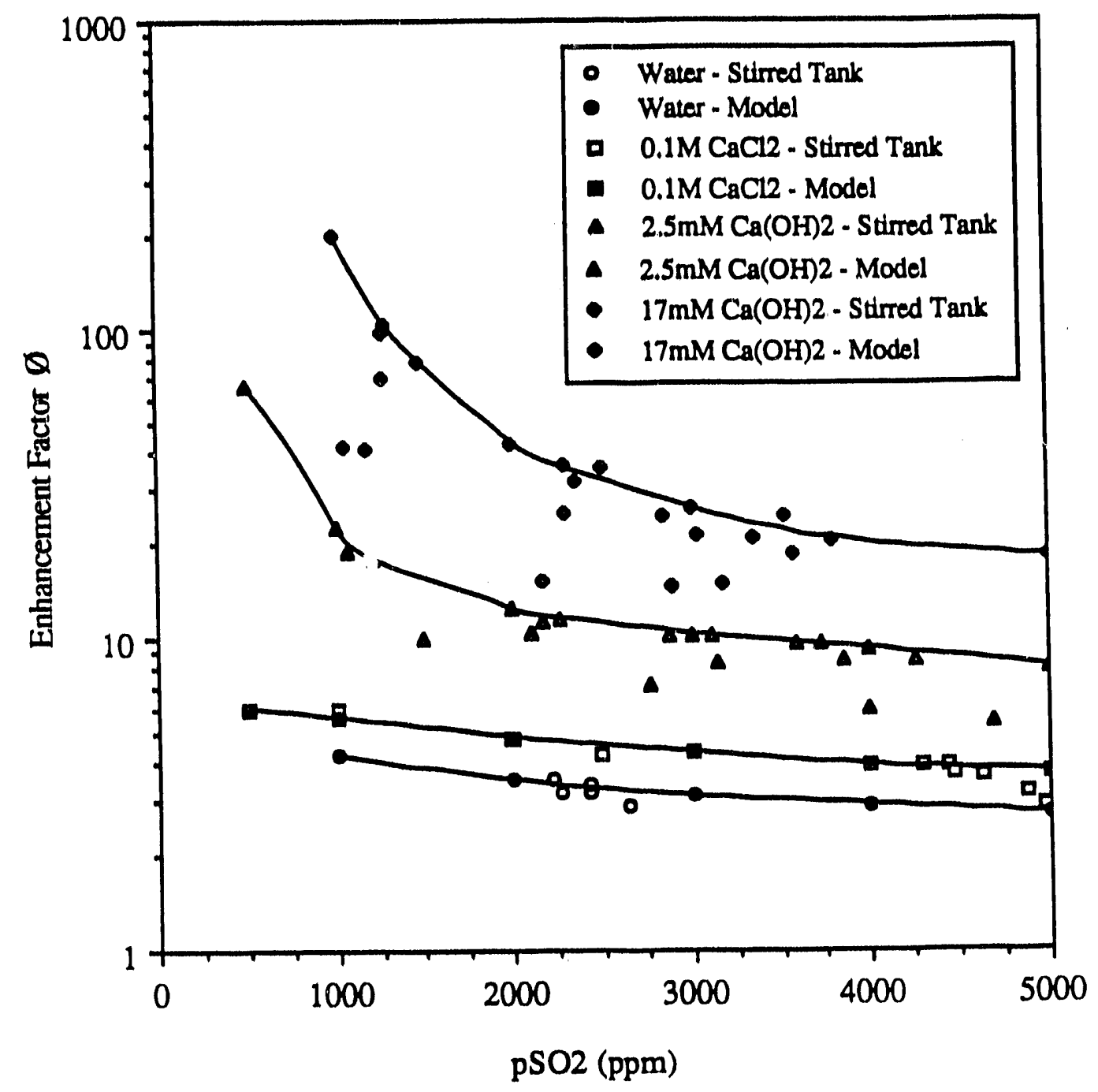

Figure 4-7. Enhancement of $\mathrm{SO}_{2}$ absorption in clear solutions as a function of bulk $\mathrm{SO}_{2}$ concentration (model: $\theta=0.9 \mathrm{~s}$, data: $\theta=0.9-2.5 \mathrm{~s}$ ). 


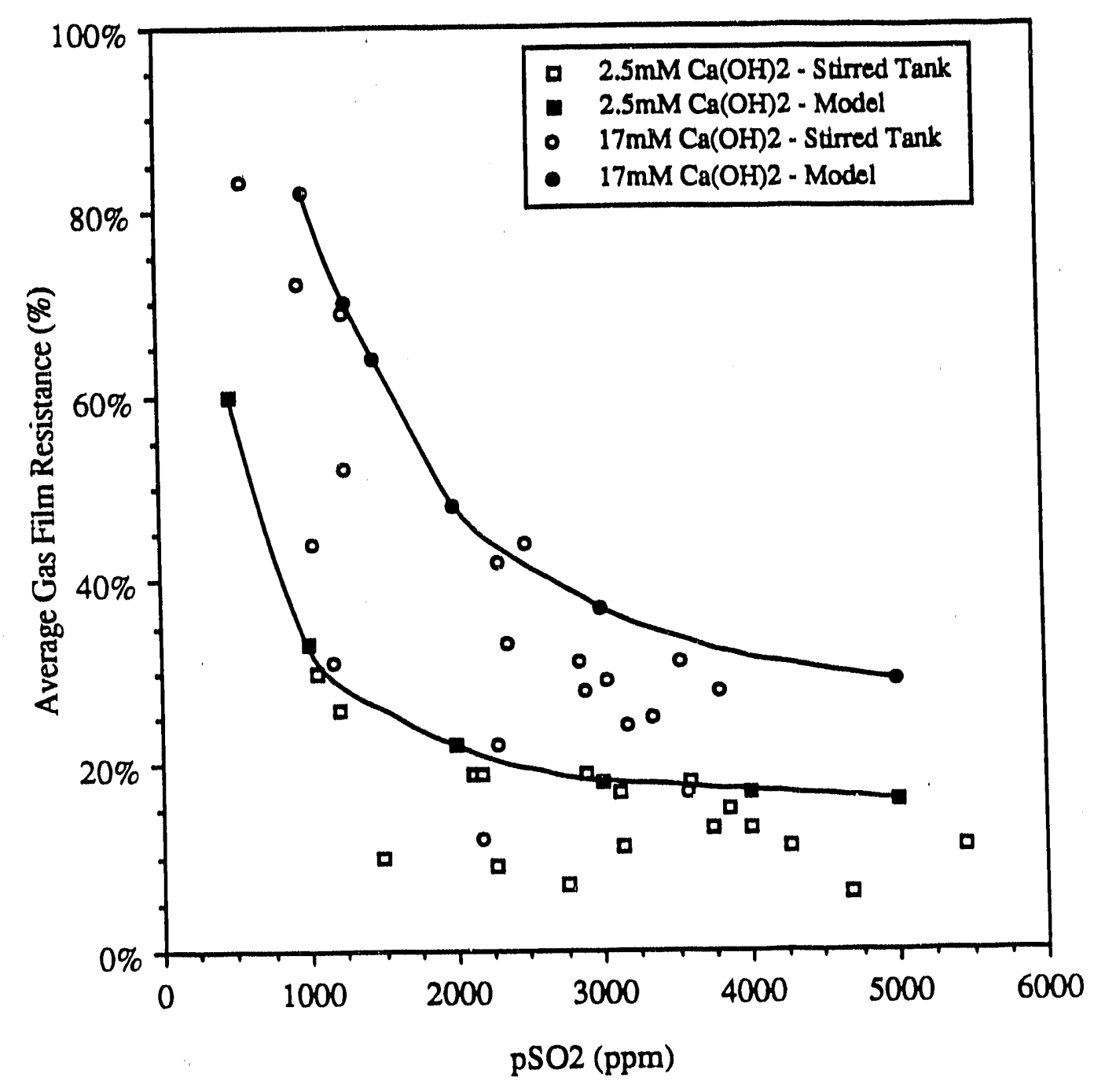

Figure 4-8. Gas film resistance in clear solutions of $\mathrm{Ca}(\mathrm{OH})_{2}$ as a function of bulk $\mathrm{SO}_{2}$ concentration (model: $\theta=0.9 \mathrm{~s}$, data: $\theta=0.9-2.5 \mathrm{~s}$ ). 
and predicted by the slurry absorption model for the $2.5 \mathrm{mM}$ and $17 \mathrm{mM} \mathrm{Ca}(\mathrm{OH})_{2}$ solutions. The model was run for a contact time of $0.9 \mathrm{~s}$. Note that the experimental data spans contact times of 0.9 to $2.5 \mathrm{~s}$, which is why most of the data is below the model curves. Again, the model for the $17 \mathrm{mM} \mathrm{Ca}(\mathrm{OH})_{2}$ solution was run assuming the low value of $\mathrm{D}_{\mathrm{OH} \text { - }}$.

This flgure shows that when the clear solution containing $17 \mathrm{ml} / \mathrm{Ca}(\mathrm{OH})_{2}$ was exposed to $\mathrm{SO}_{2}$ concentrations of less than $2,000 \mathrm{ppm}$, the absorption was over 50 percent gas film controlled. As determined in the slurry experiments discussed in Section 5, it was difficult to measure enhancement in $\mathrm{Ca}(\mathrm{OH})_{2}$ slurries subjected to $\mathrm{SO}_{2}$ concentrations of less than $2,000 \mathrm{ppm}$ because gas film resistance increased to over 90 percent.

As previously mentioned, the absorption tended to be more gas film controlled at the shorter contact times. The range of contact times available in the stirred tank was about 0.9 to $2.5 \mathrm{~s}$. In Figure 4-8, the model was run at a contact time of $0.9 \mathrm{~s}$, thus some of the data obtained in the stirred tank at higher contact times lies below the curve predicted by the model. The slurry absorption model clearly illustrates the dependence of gas film resistance on contact time. Figure 4-9 shows gas film resistance predicted in $17 \mathrm{mM} \mathrm{Ca}(\mathrm{OH})_{2}$ over a range of contact times from 0.1 to $10 \mathrm{~s}$ for three $\mathrm{SO}_{2}$ concentrations.

\subsubsection{Slurry Absorption Model and Theory}

The measurements of the absorption of $\mathrm{SO}_{2}$ in clear solutions were useful in validating the slurry absorption model. The surface renewal theory solutions for the enhancement of $\mathrm{SO}_{2}$ absorption developed by Chang and Rochelle (1979) were used as a reference for comparison. The predictions made by Chang and Rochelle, based on the surface renewal theory, had been experimentally proven in their work $(1980,1981,1982)$ and in experiments performed by Weems (1981). The clear solution experiments in water, $0.1 \mathrm{M} \mathrm{CaCl}_{2}$ and $2.5 \mathrm{mM} \mathrm{Ca}(\mathrm{OH})_{2}$ performed for this research produced enhancement factors which compared well with those predicted by the surface renewal theory solutions. Also, the slurry absorption model predicted enhancement factors for $\mathrm{SO}_{2}$ absorption in these solutions 


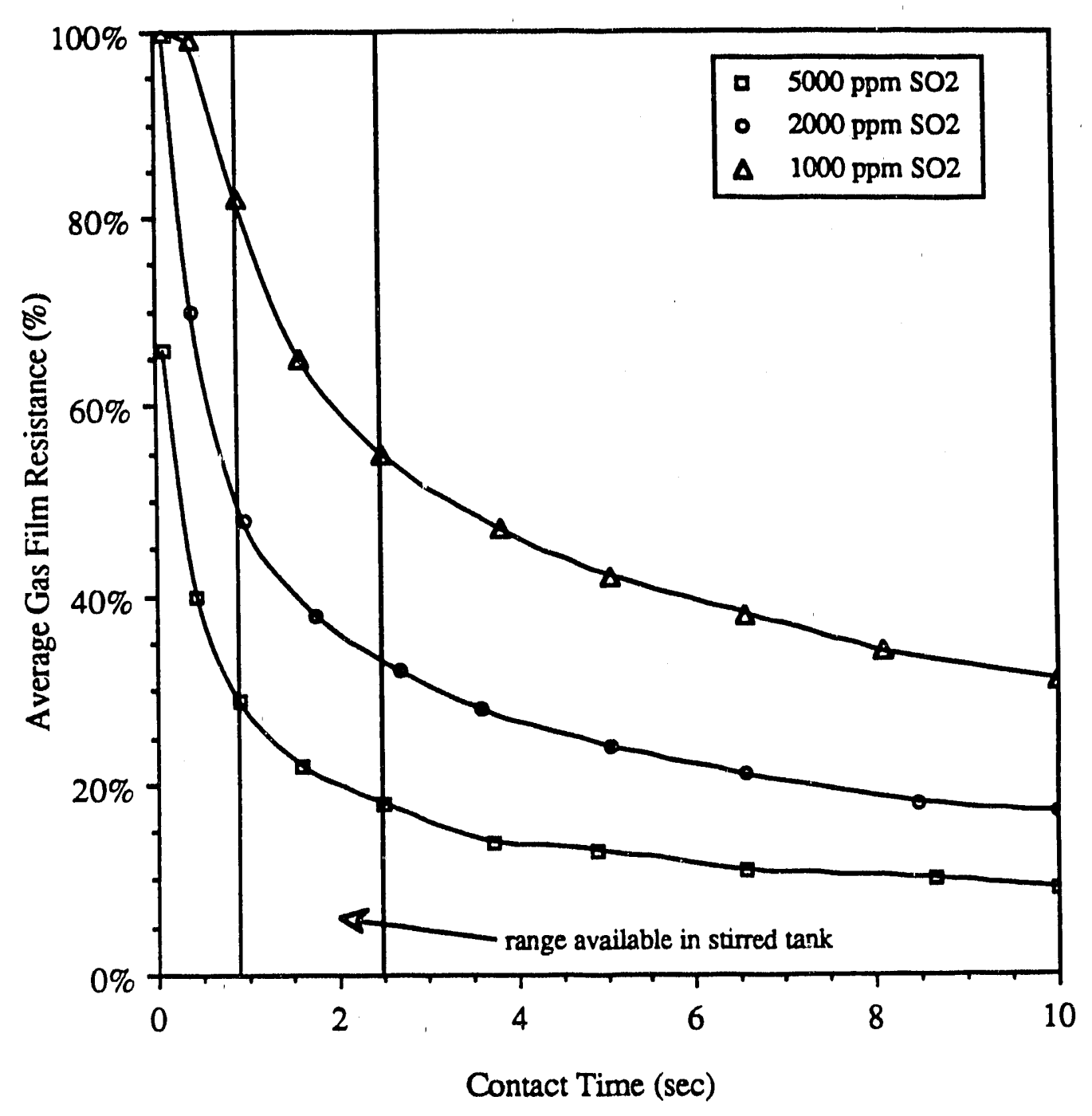

Figure 4-9. Gas film resistance in $17 \mathrm{mM} \mathrm{Ca}(\mathrm{OH})_{2}$ as a function contact time. 
that compared well with the measured enhancement factors and generally followed the surface renewal theory solutions.

However, both the surface renewal theory solutions and the slumy absorption model were not initially capable of predicting measured enhancement of $\mathrm{SO}_{2}$ absorption in the $17 \mathrm{mM} \mathrm{Ca}(\mathrm{OH})_{2}$ solution. Both overpredicted the absorption by more than 2 times that measured in the stirred tank. Apparently, as the solution reaches saturation, some changes to the properties of some individual species have occurred.

For example, the diffusivities of $\mathrm{Ca}^{2+}$ and $\mathrm{OH}^{-}$used by the model are those for diffusion in an infinitely dilute solution. Perhaps as the concentration of $\mathrm{Ca}(\mathrm{OH})_{2}$ is increased, the assumption of an infinitely dilute solution no longer holds, and the diffusivities of one or both of these species are affected. Although these changes have not been fully investigated and are not understood, the slurny absorption model was adjusted to yield an accurate prediction of enhancement of $\mathrm{SO}_{2}$ absorption. The adjustment, which involves reducing the diffusivity of $\mathrm{OH}^{-}$to approximately 40 percent of its referenced value, will be used further in Section 5 for validation of absorption in slurry solutions. 


\section{SECTION 5 \\ RESULTS OF EXPERIMENTS IN Ca(OH $)_{2}$ SLURRIES}

The experiments performed in $\mathrm{Ca}(\mathrm{OH})_{2}$ slurries were designed to study two factors affecting absorption, the most important of which was the amount of solids present in the slurry. $\mathrm{SO}_{2}$ absorption was measured in slurries with total $\mathrm{Ca}(\mathrm{OH})_{2}$ concentration ranging from $35 \mathrm{mM}$ to $1.0 \mathrm{M}$. Absorption of $\mathrm{SO}_{2}$ at concentrations of 500 to $5,000 \mathrm{ppm}$ into slurries containing $1.0 \mathrm{M}\left(7 \mathrm{wt}\right.$ percent) $\mathrm{Ca}(\mathrm{OH})_{2}$ or more solids was found to be controlled primarily by gas film resistance.

A second factor studied involved measuring $\mathrm{SO}_{2}$ absorption into slurries with varied reactivity. Properties of the solid $\mathrm{Ca}(\mathrm{OH})_{2}$ particles, such as surface area and particle size, are known to affect reactivity toward $\mathrm{SO}_{2}$. Thus, slurries were prepared from different sources of $\mathrm{Ca}(\mathrm{OH})_{2}$ and $\mathrm{SO}_{2}$ absorption was measured. The measurements were intended to determine how much of an effect such properties could have on the enhancement factor, and hence, their ability to control or limit absorption of $\mathrm{SO}_{2}$.

The absorption experiments in slurries also allowed for further verification of the slurry absorption model. Several conditions studied in the last chapter were determined to be important factors affecting absorption into a clear solutions of $\mathrm{Ca}(\mathrm{OH})_{2}$. The slurry experiments go further to provide data to evaluate the effect of various properties of the solids. This allows for validation of the $\mathrm{Ca}(\mathrm{OH})_{2}$ dissolution portion of the slurry absorption model.

\subsection{EXPERIMENTAL CONDITIONS}

Slurry was fed to the reactor at a rate of $205 \mathrm{~mL} / \mathrm{min}$ from an agitated mix tank. Continuous feed helped provide a steady-state condition for reaction of $\mathrm{Ca}(\mathrm{OH})_{2}$ solids and prevented buildup of 
calcium sulfite solids. All slurry tests were run at $55^{\circ} \mathrm{C}$ with $0.1 \mathrm{M} \mathrm{CaCl}_{2}$ added to the slurries. A variety of $\mathrm{Ca}(\mathrm{OH})_{2}$ concentrations and $\mathrm{Ca}(\mathrm{OH})_{2}$ sources were used.

As in the clear solution experiments, the gas phase was mixed at the maximum agitation speed of approximately $1,400 \mathrm{~mm}$. This resulted in a gas phase mass transfer coefficient of $1.5 \times 10^{-4} \mathrm{~mole} / \mathrm{s}$ $\mathrm{cm}^{2}$ bar. The liquid phase mass transter coefficient was varied by changing the liquid agitation speed. Slurry compositions and other variables are listed in Table 5-1. All concentrations of $\mathrm{Ca}(\mathrm{OH})_{2}$ Indicated in this report represent the total amount of $\mathrm{Ca}(\mathrm{OH})_{2}$ in the slurry, as opposed to the amount of $\mathrm{Ca}(\mathrm{OH})_{2}$ solids.

The total absorbed sulfur concentration in the liquid was estimated using a gas phase material balance and a liquid phase material balance, which accounted for the continuous flow of slurry through the reactor. The concentration of total sulfur was then confirmed by analyzing samples of reactor effluent by ion chromatography, as previously described.

Again, increase in liquid phase mass transfer due to solids addition is reported in terms of the enhancement factor, $\oslash$. The enhancement factor is the ratio of the measured liquid phase mass transfer coefficient, $k_{1}$ and $k_{1}^{\circ}$, the characteristic liquid phase mass transfer coefficient in the absence of chemical reactions for the conditions of the experiment. The $k^{\circ}$ for different conditions is known based on the correlations developed in Section 3.

TABLE 5-1. TEST CONDITIONS FOR $\mathrm{Ca}(\mathrm{OH})_{2}$ SLURRY EXPERIMENTS

\begin{tabular}{|c|c|c|c|c||}
\hline $\begin{array}{c}\text { Total } \mathrm{Ca}(\mathrm{OH})_{2} \\
\text { Conc. }(\mathrm{M})\end{array}$ & $\mathrm{Ca}(\mathrm{OH})_{2}$ Type & $\mathrm{SO}_{2}$ Conc. (ppm) & Liq. Agitator (rpm) & $k_{1}^{\circ} \times 105(\mathrm{~m} / \mathrm{s})$ \\
\hline 0.035 & MCB Reagent & $2,450-4,560$ & $340-1,180$ & $3.3-7.5$ \\
\hline 0.1 & MCB Reagent & $1,660-4,360$ & $650-1,280$ & $4.8-8.1$ \\
\hline 1.0 & MCB Reagent & $1,440-5,000$ & $440-1,380$ & $3.8-8.7$ \\
\hline 0.1 & Mississippl & $2,120-4,560$ & $680-1,150$ & $4.9-7.4$ \\
\hline 0.4 & Mississippi & $2,140-4,480$ & $690-1,150$ & $5.0-7.3$ \\
\hline 0.1 & $\begin{array}{c}\text { Mississippi } \\
\text { Slaked }\end{array}$ & $2,130-4,460$ & $670-1,170$ & $4.9-7.5$ \\
\hline
\end{tabular}


The value of $\varnothing$ was determined from equation (4-1). It is important to remember that $\varnothing$ is a normalized absorption rate or flux. It allows comparison of data obtained in the stirred tank reactor Independent of the value of $\mathrm{k}_{1}^{\circ}$ (or contact time) and the level of $\mathrm{SO}_{2}$ maintained in the liquid phase reactor. Because the driving force and the contact time were constantly changed within the reactor during slurry experiments, the absorption rate, $\mathrm{N}_{\mathrm{SO}_{2}}$ could not be compared from one test to another on a consistent basis.

The absorption rate, $\mathrm{N}_{\mathrm{SO}}$, was measured directly by gas phase material balance. The interface concentration, $\left[\mathrm{SO}_{2}\right]$, was calculated using the Henry's law relationship given in equation (2-10). The gas phase concentration of $\mathrm{SO}_{2}$ at the interface, $\mathrm{PSO}_{21}$, was determined by equation (2-1) and the relationship for $\mathrm{k}_{g}$ given in equation (3-8). In $\mathrm{Ca}(\mathrm{OH})_{2}$ slurries, the concentration of $\mathrm{SO}_{2}$ in the bulk phase, $\left[\mathrm{SO}_{2}\right]_{0}$, is negligible due to the instantaneous reaction of $\mathrm{SO}_{2}$.

Calculation of the enhancement factor required a combination of several measured values, each of which has a degree of error associated. Such values include mass flow meter measurements, $\mathrm{SO}_{2}$ concentrations, and measurement of $\mathrm{k}_{\mathrm{g}}$ and $\mathrm{k}_{1}$. To obtain an idea of the accuracy of $\oslash_{1}$ the estimated errors were carried through the calculations for $\varnothing$. The error associated with $\varnothing$ is presented with the test data later in this section.

In general, measurements became less precise as gas film resistance increased. This occurred typically at low $\mathrm{SO}_{2}$ concentrations and higher solids concentrations. In fact, for most experiments performed in slurries, the absorption was over 90 percent gas film controlled at $\mathrm{SO}_{2}$ concentrations less than 2,000 ppm. Accurate determination of the enhancement factor could only be made when gas film resistance was $\mathbf{8 0}$ percent or less. Some enhancement factors reported from tests with higher degrees of gas film resistance may be questionable.

\subsection{RESULTS OF SLURRY EXPERIMENTS}

The following presents the results of experiments in $\mathrm{Ca}(\mathrm{OH})_{2}$ slurries. Enhancement of $\mathrm{SO}_{2}$ absorption was measured in slurries of increasing solids concentration and in slurries made from different sources of $\mathrm{Ca}(\mathrm{OH})_{2}$. 


\subsubsection{Enhancement in Increasing Concentrations of Reagent Grade $\mathrm{Ca}(\mathrm{OH})_{2}$}

The first slurry experiments used reagent grade $\mathrm{Ca}(\mathrm{OH})_{2}$ purchased from chemical suppliers. A stock of MCB Reagent (lot 3031) $\mathrm{Ca}(\mathrm{OH})_{2}$ and Fisher Reagent (lot 883017) were available. The Fisher Reagent $\mathrm{Ca}(\mathrm{OH})_{2}$ had been received on $7 / 5 / 88$ bui was unopened. The MCB Reagent was recelved just prior to testing clear solutions containing $\mathrm{Ca}(\mathrm{OH})_{2}$ which began $7 / 11 / 89$. The difference in the age of the reagents may have had an effect on their reactivity.

Slurry containing three levels of total $\mathrm{Ca}(\mathrm{OH})_{2}$ concentration $(35 \mathrm{mM}, 0.1 \mathrm{M}$, and $1.0 \mathrm{M}$ ) were tested with these reagents. Initial experiments at these concentrations showed that absorption was greatly improved with solids present. In fact, since so much $\mathrm{SO}_{2}$ was being absorbed, the concentration level of $\mathrm{SO}_{2}$ in the reactor was very low. At the low concentrations, the absorption was gas film controlled, so determination of an enhancement factor was not possible. A mass flow meter with a higher flow capacity $(5 \mathrm{~L} / \mathrm{min})$ was installed 80 that higher $\mathrm{SO}_{2}$ concentrations in the reactor could be achieved.

After the new mass flow meter was installed, a second set of experiments at the same $\mathrm{Ca}(\mathrm{OH})_{2}$ slurry concentrations was performed. The conditions were changed such that $\mathrm{SO}_{2}$ concentrations above 2,000 ppm could be produced.

The second set of test runs in $35 \mathrm{mM} \mathrm{Ca}(\mathrm{OH})_{2}$ slurry, prepared with MCB Reagent $\mathrm{Ca}(\mathrm{OH})_{2}$, produced measurable values of $\varnothing$. Gas film resistance was moderately high. Contact times for these experiments were varied from about 1 to $2 \mathrm{~s}$. Enhancement factors measured in the $35 \mathrm{mM} \mathrm{Ca}(\mathrm{OH})_{2}$ slurry ranged from about 20 to 80 , whereas gas film resistance ranged from 23 to 65 percent.

Table 5-2 summarizes the results of this set of fest runs.

Another set of tests were performed at the higher solids concentration of $0.1 \mathrm{M} \mathrm{Ca}(\mathrm{OH})_{2}$ using the MCB Reagent stock. Again, $\mathrm{SO}_{2}$ concentration in the reactor was maintained at much higher levels to produce measurable enhancement factors. As before, contact times were varied from about 1 to $2 \mathrm{~s}$. The higher solids level in the $0.1 \mathrm{M} \mathrm{Ca}(\mathrm{OH})_{2}$ slurry resulted in enhancement factors ranging from 35 to 185 and gas film resistance which increased to the range of 34-81 percent. The largest enhancement 
TABLE 5-2. RESULTS OF TESTS PERFORMED IN $35 \mathrm{mM} \mathrm{Ca(OH})_{2} \mathrm{MCB}$ REAGENT GRADE SLURRY $\left(K_{\mathrm{g}}=1.44 \times 10^{-5} \mathrm{~mole} / \mathrm{m}^{2} \mathrm{~Pa} \mathrm{~s}\right)$.

\begin{tabular}{|c|c|c|c|c|c||}
\hline Test \# & $\begin{array}{c}S_{2} \text { Conc. } \\
(\mathrm{ppm})\end{array}$ & $\begin{array}{c}k^{0} \times 10^{5} \\
(\mathrm{~m} / \mathrm{s})\end{array}$ & $\begin{array}{c}\text { Contact Time } \\
(\mathrm{s})\end{array}$ & $\varnothing$ & $\begin{array}{c}\text { Gas Film } \\
\text { Res. (percent) }\end{array}$ \\
\hline S35R1 & 3945 & 7.5 & 0.9 & 40 & 48 \\
\hline S35R2 & 3323 & 7.5 & 0.9 & 49 & 53 \\
\hline S35R3 & 2429 & 7.5 & 0.9 & 79 & 65 \\
\hline S35R4 & 3157 & 6.7 & 1.1 & 40 & 45 \\
\hline S35R5 & 3846 & 6.7 & 1.1 & 36 & 42 \\
\hline S35R6 & 4152 & 6.7 & 1.1 & 35 & 42 \\
\hline S35R7 & 4555 & 5.3 & 1.5 & 32 & 36 \\
\hline S35R8 & 4338 & 5.6 & 1.5 & 31 & 35 \\
\hline S35R9 & 3635 & 5.6 & 1.5 & 28 & 33 \\
\hline S35R10 & 4066 & 4.9 & 2.0 & 25 & 28 \\
\hline S35R11 & 3869 & 4.9 & 2.0 & 20 & 23 \\
\hline S35R12 & 4471 & 4.9 & 2.0 & 26 & 28 \\
\hline \hline
\end{tabular}

and largest degree of gas film resistance is always achieved at lower $\mathrm{SO}_{2}$ concentrations and short contact times. The results of these experiments are summarized in Table 5-3.

A final set of tests were run using the old, unopened Fisher Reagent at $1.0 \mathrm{M} \mathrm{Ca}(\mathrm{OH})_{2,} 7$ weight percent. Unfortunately, the results of these tests were questionable and are not reported. Initially, the $1 \mathrm{~L} / \mathrm{min}$ flow meter was used and at least 4 of 7 tests were too gas film controlled to measure the enhancement factor. The flow meter was changed and plumbing modified. The reagent was kept covered and constantly stirred but over a full day passed betore testing was resumed. The remaining 5 test runs resulted in suspiciously low enhancement factors. This was probably caused by two factors. First, the reagent was old and its reactivity may have been affected. A greater factor was that it was prepared a day and a haff before it was used. This allowed for the slurry to react with $\mathrm{CO}_{2}$ In the air to form carbonate, which is less reactive toward $\mathrm{SO}_{2}$ under these experimental conditions. 
TABLE 5-3. RESULTS OF TESTS PERFORMED IN $0.1 \mathrm{M} \mathrm{Ca(OH)} / 2$ MCB REAGENT GRADE SLURRY

$\left(k_{g}=1.44 \times 10^{-5} \mathrm{~mole} / \mathrm{m}^{2} \mathrm{~Pa} \mathrm{~s}\right)$

\begin{tabular}{|c|c|c|c|c|c|}
\hline Test \# & $\begin{array}{l}\mathrm{SO}_{2} \text { Conc. } \\
(\mathrm{ppm})\end{array}$ & $k^{0} \times 10^{5}$ & $\begin{array}{c}\text { Contact Time } \\
\text { (s) }\end{array}$ & $\varnothing$ & $\begin{array}{c}\text { Gas Film } \\
\text { Res. (percent) }\end{array}$ \\
\hline So.1A1 & 3374 & 7.4 & 0.9 & 70 & 62 \\
\hline SO.1R2 & 3730 & 7.4 & 0.9 & 65 & 60 \\
\hline So.1R3 & 2756 & 7.4 & 0.9 & 99 & 69 \\
\hline SO.1R4 & 2044 & 7.4 & 0.9 & 185 & 81 \\
\hline S0.1R5 & 2390 & 6.6 & 1.1 & 96 & 66 \\
\hline So.1R6 & 3038 & 6.6 & 1.1 & 75 & 61 \\
\hline SO.1R7 & 3609 & 6.6 & 1.1 & 61 & 56 \\
\hline SO.1R8 & 3962 & 6.6 & 1.1 & 58 & 54 \\
\hline SO.1R9 & 3972 & 5.7 & 1.5 & 52 & 48 \\
\hline SO.1R10 & 3807 & 5.7 & 1.5. & 43 & 43 \\
\hline So.1R11 & 3056 & 5.7 & 1.5 & 51 & 47 \\
\hline SO.1R12 & 3574 & 4.8 & 2.1 & 35 & 34 \\
\hline SO.1R13 & 2862 & 4.8 & 2.1 & 39 & 36 \\
\hline So.1R14 & 4364 & 4.8 & 2.1 & 36 & 34 \\
\hline
\end{tabular}

The enhancement factors calculated from the two valid tests are shown in Figure 5-1. Also shown are the test results for the clear solution case of $17 \mathrm{mM} \mathrm{Ca}(\mathrm{OH})_{2}$ (no solids) presented earlier in Section 4. An increase in enhancement has resulted by increasing the solids content of the slurry. Although the $\mathrm{Ca}(\mathrm{OH})_{2}$ content was doubled from $17 \mathrm{mM}$ to $35 \mathrm{mM}$ and then nearly tripled to $0.1 \mathrm{M}$, the increase in enhancernent was not nearly as great. Enhancement increased by about 50 percent from increasing $\mathrm{Ca}(\mathrm{OH})_{2}$ concentration from $17 \mathrm{mM}$ to $35 \mathrm{mM}$, and only increased by about 25-30 percent from increasing $\mathrm{Ca}(\mathrm{OH})_{2}$ concentration from $35 \mathrm{mM}$ to $0.1 \mathrm{M}$. Apparently, adding solids * at higher initial slurry concentrations has less of an affect on enhancement than adding solids at lower intilal slurry concentrations. 


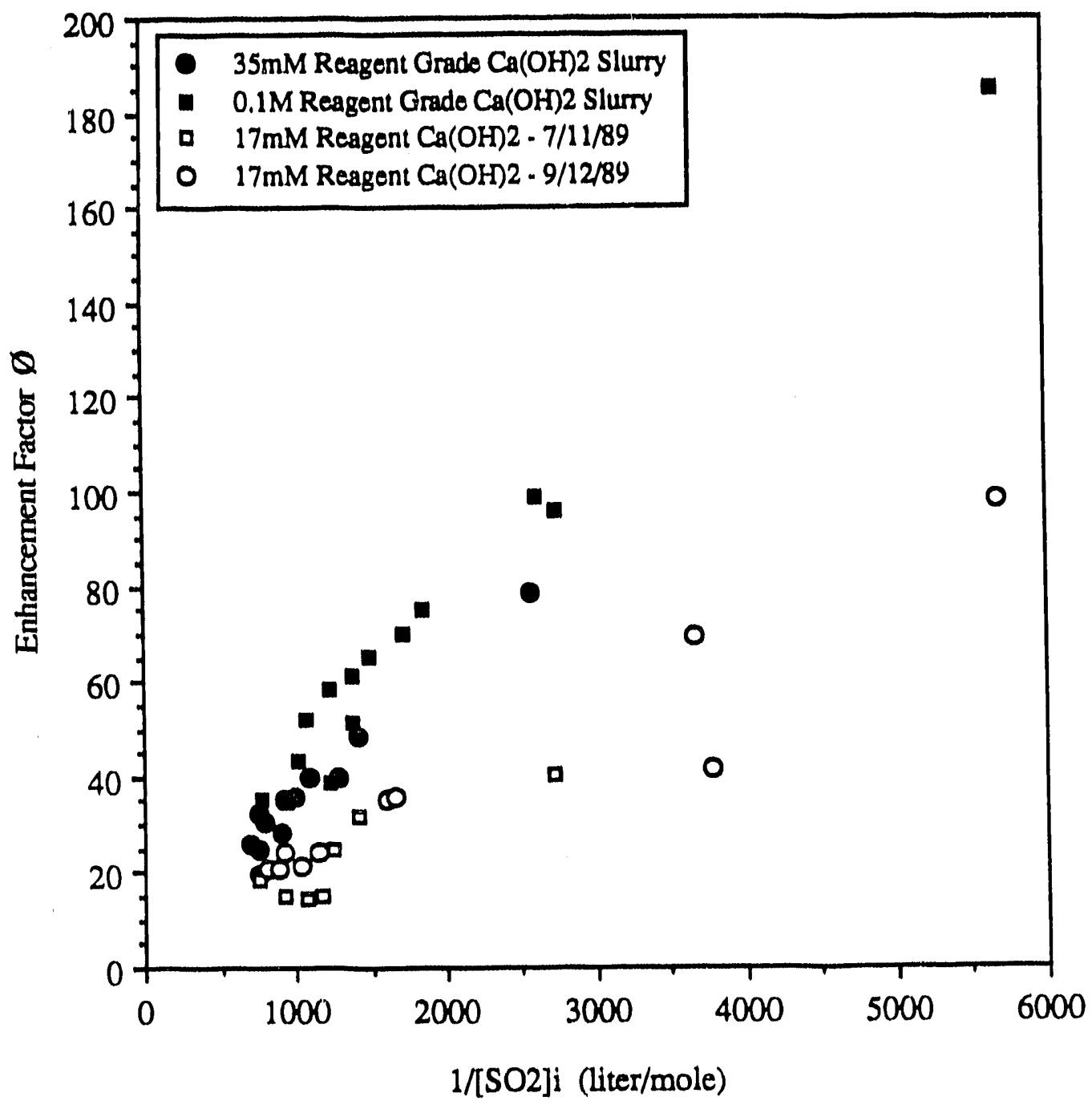

Figure 5-1. Comparison of tests performed in reagent grade slurry. 
As previously mentioned, the degree of accuracy of the enhancement factor is less as the absorption becomes more gas fllm controlled. An analysis of the expected amount of error for the enhancement faotor was made for the measurements taken duning slurry tests. Floure 6.2 shows the results of the analysls for $0.1 \mathrm{M} \mathrm{Ca}(\mathrm{OH})_{2}$ reagent grade slurry plotted in Flgure 5.1 with hilgh and low error limits designating the range of accuracy of the enhancement factors.

Error is dramatloally inoreased at higher enhancement factors. This is because the greater degree of enhancement oauses the absorption to become more gas film controlled. The largest enhanoement factor measured during this set of experiments in $0.1 \mathrm{M}$ Reagent grade $\mathrm{Ca}(\mathrm{OH})_{2}$ was 185, and the gas fllm resistance of the absorption was 81 percent. The error analysis shows that the enhanoement factor is only known to within \pm 40 percent accuraoy. Untortunately, this cannot be Improved much by improving the acouraoy of the measurements taken. The high degree of uncertainty results because $\mathrm{pSO}_{2}$ l becomes very small as the absorption approaches gas flim controlled conditions, yet it must be obtained from subtracting two large concentrations (l.e., the bulk $\mathrm{SO}_{2}$ conoentration and the amount of $\mathrm{SO}_{2}$ which is transferred to the liquid phase). Therefore, although enhanoement factors are reported for tests in which absorption was over 80 percent gas film controlled, it should be remembered that these measurements have an inherently high error.

\subsubsection{Enhancement in Slurries Made From Mississippl $\mathrm{Ca}(\mathrm{OH})_{2}$}

A supply of Mississippl $\mathrm{Ca}(\mathrm{OH})_{2}$ was purchased so that further tests could be pertormed in slurries of higher solids concentrations. Tests in slumies prepared with Mississippl $\mathrm{Ca}(\mathrm{OH})_{2}$ at three $\mathrm{Ca}(\mathrm{OH})_{2}$ concentrations were pertormed. The first had a $\mathrm{Ca}(\mathrm{OH})_{2}$ concentration of $0.1 \mathrm{M}_{1}$ so that results could be compared to the test results previously presented using $0.1 \mathrm{M} \mathrm{Ca}(\mathrm{OH})_{2}$ made with reagent grade material. The other two tests used slurry prepared at the higher $\mathrm{Ca}(\mathrm{OH})_{2}$ concentration levels of $0.4 \mathrm{M}$ and $1.0 \mathrm{M}$. Unfortunately, it was difflcult to obtain reasonable measurements of absorption with the slurry containing $1.0 \mathrm{M} \mathrm{Ca}(\mathrm{OH})_{2}$ since gas film resistance was very high, even at high $\mathrm{SO}_{2}$ concentrations. As in the case of the reagent grade material, no enhancement factors from the attempted test in slurry containing $1.0 \mathrm{M} \mathrm{Ca}(\mathrm{OH})_{2}$ were considered reportable. Table 5.4 presents 


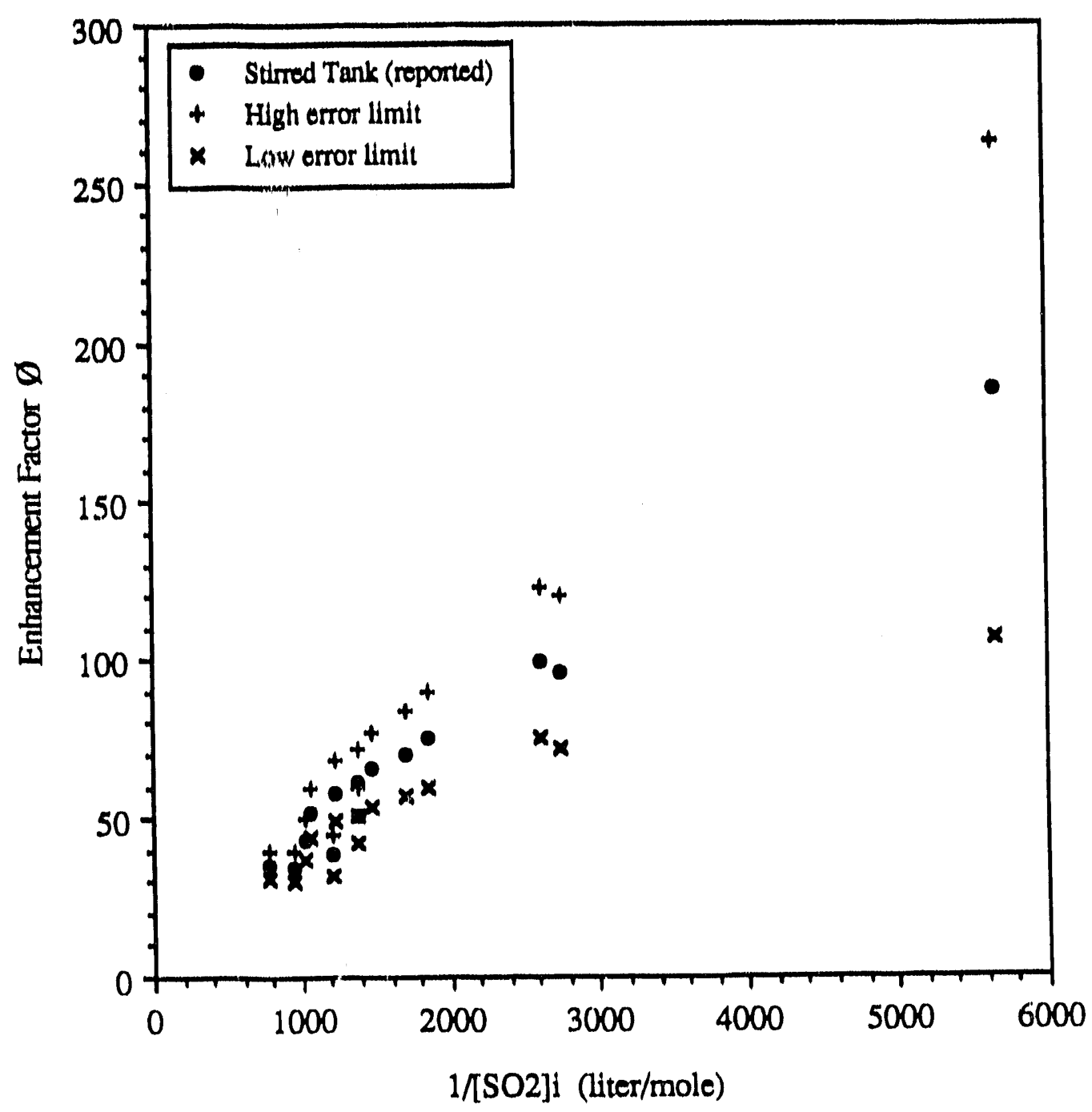

Figure 5-2. Estimated error associated with tests performed in $0.1 \mathrm{M} \mathrm{Ca}(\mathrm{OH})_{2} \mathrm{MCB}$ reagent grade slurry. 
TABLE 5-4, RESULTS OF TESTS PERFORMED $\mathbb{N} 0.1 \mathrm{M} \mathrm{Ca}(\mathrm{OH})_{2} \mathrm{MISSISSIPPI} \mathrm{Ca}(\mathrm{OH})_{2}$ SLURRY $\left(k_{\mathrm{g}}=1.42 \times 10^{-6} \mathrm{~mole} / \mathrm{m}^{2} \mathrm{~Pa} \mathrm{~s}\right)$

\begin{tabular}{|c|c|c|c|c|c|}
\hline Test \# & $\begin{array}{c}\mathrm{sO}_{2} \text { Cono. } \\
\text { (ppm) }\end{array}$ & $k^{0}\left\{\begin{array}{l}\times 10^{5} \\
m / 8)\end{array}\right.$ & $\begin{array}{c}\text { Contaot Time } \\
\text { (8) }\end{array}$ & $\varnothing$ & $\begin{array}{c}\text { Gas Film } \\
\text { Res. (percent) }\end{array}$ \\
\hline S.1M1 & 3006 & 7.4 & 0.9 & 120 & 74 \\
\hline S.1MR & 3548 & 7.4 & 0.9 & 82 & 65 \\
\hline S.1M3 & 2380 & 7.4 & 0.9 & 249 & 85 \\
\hline So.1M4 & 2866 & 6.5 & 1,2 & 97 & 66 \\
\hline So.1M5 & 2115 & 6.5 & 1.2 & 175 & 78 \\
\hline So.1M6 & 3872 & 6.5 & 1.2 & 65 & 57 \\
\hline So.1M7 & 3359 & 6.5 & 1.2 & 82 & 63 \\
\hline S0.1M8 & 3706 & 5.7 & 1.5 & 66 & 54 \\
\hline So.1Mg & 4190 & 5.7 & 1.5 & 56 & 50 \\
\hline SO.1M10 & 2574 & 5.7 & 1.5 & 86 & 61 \\
\hline So.1M11 & 2566 & 4.9 & 2.0 & 62 & 49 \\
\hline So.1M12 & 3488 & 4.9 & 2.0 & 49 & 43 \\
\hline $50.1 \mathrm{M} 13$ & 4293 & 4.9 & 2.0 & 48 & 4?. \\
\hline SO.1M14 & 4562 & 4.9 & 2.0 & 49 & 43 \\
\hline
\end{tabular}

a summary of the results for a set of test runs with Mississippl $\mathrm{Ca}(\mathrm{OH})_{2}$ slurry containing $0.1 \mathrm{M}$ $\mathrm{Ca}(\mathrm{OH})_{2}$. Again, $\mathrm{SO}_{2}$ concentrations were maintained above $2,000 \mathrm{ppm}$ to avoid gas $11 \mathrm{~m}$ controlled absorption.

For the same range of contact times of 1 to $2 \mathrm{~s}$ studied during reagent grade $\mathrm{Ca}(\mathrm{OH})_{2}$ experiments, enhancement factors ranged from about 50 to 250. Gas film resistance varied from 42 to 85 percent. As can be seen In Figure 5-3, the erihancement measured with Mississippl $\mathrm{Ca}(\mathrm{OH})_{2}$ slurry is nearly the same as that measured in the reagent sturry. Although the Mlssissippi $\mathrm{Ca}(\mathrm{OH})_{2}$ appears to yleld sllghtly greater enhancement, the difference is well within experimental error.

A summary of the results of tests pertormed in Mississippl $\mathrm{Ca}(\mathrm{OH})_{2}$ slurry containing $0.4 \mathrm{M}$ $\mathrm{Ca}(\mathrm{OH})_{2}$ are shown in Table 5-5. The test conducted at the lowest $\mathrm{SO}_{2}$ concentration of $2135 \mathrm{ppm}$ resulted in a gas film controlled absorption of about 98 percent. This made enhancement an 


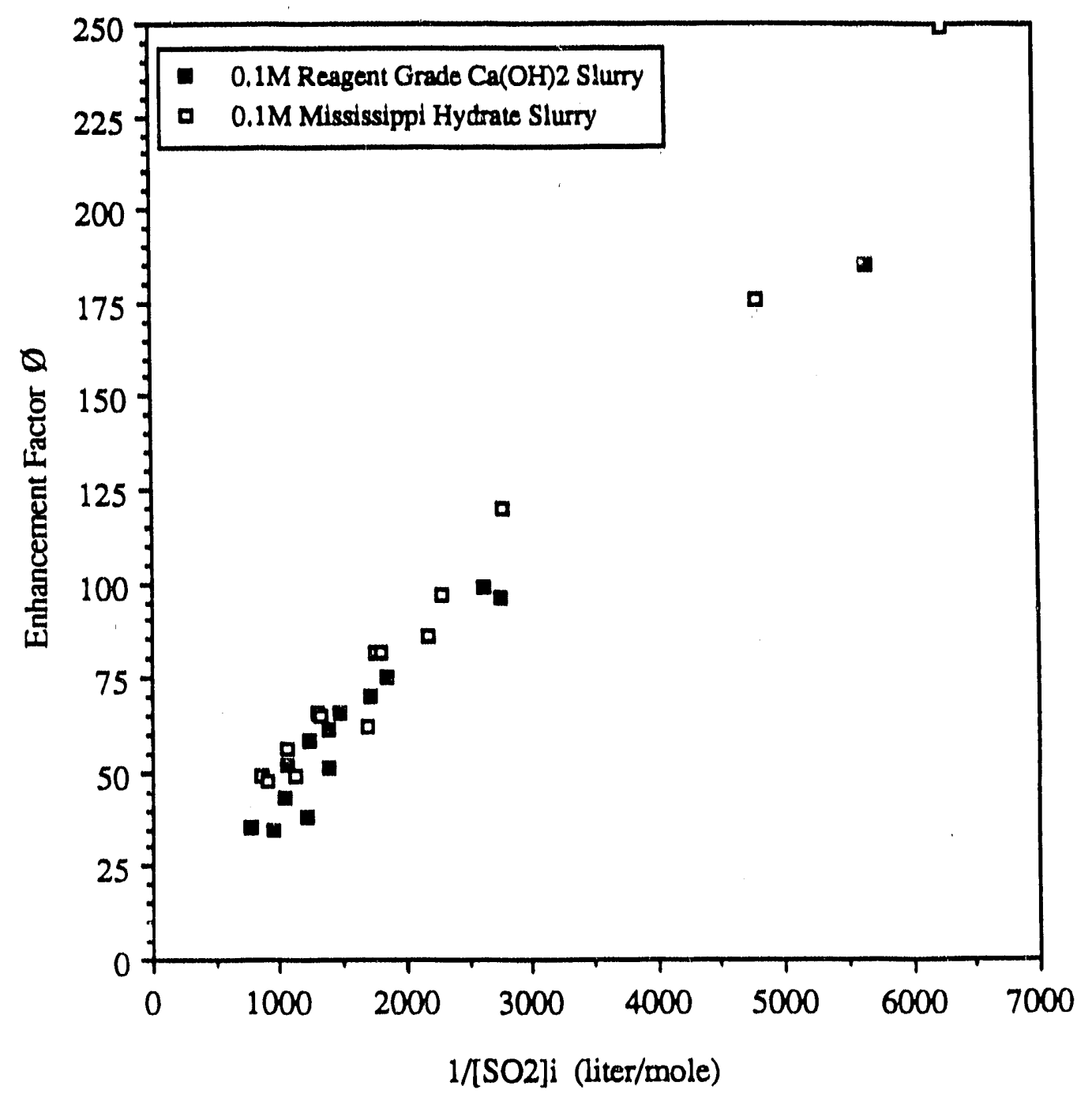

Figure 5-3. Comparison of enhancement in Mississippl hydrate and reagent grade slurry at $0.1 \mathrm{M}$ $\mathrm{Ca}(\mathrm{OH})_{2}$ 
unmeasurable parameter within reasonable experimental error. Enhancement factors that were measurable ranged from 60 to 360 . Tests run at low. rontact times ranged between 70 and 98 percent gas $\mathrm{ilm}$ controlled. Those at the longer contact s.:nes and higher $\mathrm{SO}_{2}$ concentrations ranged from about 50 to 70 percent gas film controlled.

These results show that measurement of the enhancement factor hil slurries of higher solids content would only be possible under conditions of $\mathrm{SO}_{2}$ concentrations greater than $3,000 \mathrm{ppm}$ and contact times greater than $1.5 \mathrm{~s}$. Conditions of lower $\mathrm{SO}_{2}$ concentration or shorter contact times would result in an absorption that was completely gas film controlled.

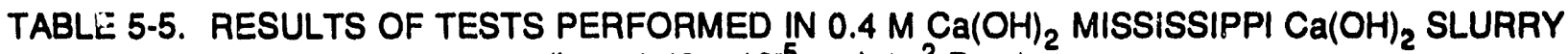
$\left(k_{\mathrm{g}}=1.42 \times 10^{-5} \mathrm{~mole} / \mathrm{m}^{2} \mathrm{~Pa} \mathrm{~s}\right)$

\begin{tabular}{|c|c|c|c|c|c|}
\hline Test \# & $\begin{array}{l}\mathrm{SO}_{2} \text { Conc. } \\
(\mathrm{ppm})\end{array}$ & $\begin{array}{c}k^{0}, \times 10^{5} \\
(\mathrm{~m} / \mathrm{s})\end{array}$ & $\begin{array}{c}\text { Contact Time } \\
\text { (s) }\end{array}$ & $\varnothing$ & $\begin{array}{c}\text { Gas Film } \\
\text { Res (percent) }\end{array}$ \\
\hline SO.4M1 & 2677 & 7.3 & 0.9 & 277 & 86 \\
\hline SO.4M2 & 2861 & 7.3 & 0.9 & 367 & 89 \\
\hline SO.4Ni3 & 3126 & 7.3 & 0.9 & 232 & 84 \\
\hline SO.4M4 & 3503 & 6.6 & 1.1 & 120 & 71 \\
\hline SO.4M5 & 3112 & 6.6 & 1.1 & 188 & 79 \\
\hline SO.4M6 & 2651 & 6.6 & 1.1 & 342 & 88 \\
\hline SO.4M7 & 2135 & 6.6 & 1.1 & - & 98 \\
\hline SO.4MB & 2688 & 5.8 & 1.5 & 146 & 73 \\
\hline So.4M9 & 3392 & 5.8 & 1.5 & 89 & 62 \\
\hline SO.4M10 & 3806 & 5.8 & 1.5 & 78 & 59 \\
\hline SO.4M11 & 4092 & 5.0 & 1.5 & 69 & 56 \\
\hline S0.4M12 & 4484 & 5.0 & 2.0 & 58 & 48 \\
\hline SO.4M13 & 4267 & 5.0 & 2.0 & 61 & 49 \\
\hline $50.4 M 14$ & 4008 & 5.0 & 2.0 & 58 & 48 \\
\hline
\end{tabular}

The results of the test with Mississippi $\mathrm{Ca}(\mathrm{OH})_{2}$ slurry containing $0.4 \mathrm{M} \mathrm{Ca}(\mathrm{OH})_{2}$ are compared to the test results from Mississippi $\mathrm{Ca}(\mathrm{OH})_{2}$ slurry containing $0.1 \mathrm{M} \mathrm{Ca}(\mathrm{OH})_{2}$ and those from tests in $35 \mathrm{mM}$ reagent gracie $\mathrm{Ca}(\mathrm{OH})_{2}$ in Figure 5-4. Again, an increase in enhancement was measured, but 
this increase was only 20 to 25 percent for a 4 -fold increase in solids concentration. Gas film resistance during these experiments was about $\mathbf{5 0}$ percent and above. It is unlikely that the stirred tank reactor can measure enhancement accurately in slurries with solids concentrations much greater than about $0.5 \mathrm{M}$.

Another attempt at measuring $\mathrm{SO}_{2}$ absorption in $1.0 \mathrm{M} \mathrm{Ca}(\mathrm{OH})_{2}$ slurry was made using the Mississippi $\mathrm{Ca}(\mathrm{OH})_{2}$ slurry. Again, the absorption was determined to be too gas film controlled to obtain measurement of the enhancement factor.

\subsubsection{Enhancement in Three Different Lime Types}

Results from two experiments performed in $0.1 \mathrm{M} \mathrm{Ca}(\mathrm{OH})_{2}$ have already been presented previously. One was made from MCB Reagent stock $\mathrm{Ca}(\mathrm{OH})_{2}$. The other was prepared using Mississippi $\mathrm{Ca}(\mathrm{OH})_{2}$. A third set of experiments was performed in $0.1 \mathrm{M} \mathrm{Ca}(\mathrm{OH})_{2}$ from another source. A supply of Mississippi pebble quicklime was obtained and slaked in the lab to make $\mathrm{Ca}(\mathrm{OH})_{2}$. Experiments were run with the different lime types to determine if measurement of the enhancement in the stirred tank is sensitive enough to show significant differences from one type to another.

Slaking is the process whereby quicklime, $\mathrm{CaO}$, is reacted with water to form $\mathrm{Ca}(\mathrm{OH})_{2}$. The reaction is quick and highly exothermic. By providing conditions such as adequate mixing and a constant high temperature of over $190^{\circ} \mathrm{C}$, the surface area, and hence, the reactivity of the product solids can be maximized. Freshly slaked lime is generally more reactive than powdered $\mathrm{Ca}(\mathrm{OH})_{2}$ because the material has not had time to agglomerate or degrade (e.g., from $\mathrm{CO}_{2}$ contamination). Therefore, the $\mathrm{Ca}(\mathrm{OH})_{2}$ particles produced by slaking are typically smaller, fresher and more reactive to $\mathrm{SO}_{2}$

The slaked Mississippi $\mathrm{Ca}(\mathrm{OH})_{2}$ slurry was prepared in the agitated mix tank generally used as the slurry feed tank. One batch of Mississippi $\mathrm{CaO}$ was slaked at a concentration of $0.1 \mathrm{M} \mathrm{Ca}(\mathrm{OH})_{2}$ over a period of approximately $1 \mathrm{~h}$. During the slaking, the temperature in the mix tank was monitored and found to achieve only $140-150^{\circ} \mathrm{C}$. Since this is not an optimum slaking temperature, it may have produced fewor reactive particles. In fact, lime slaked at this lower temperature typically results in a 


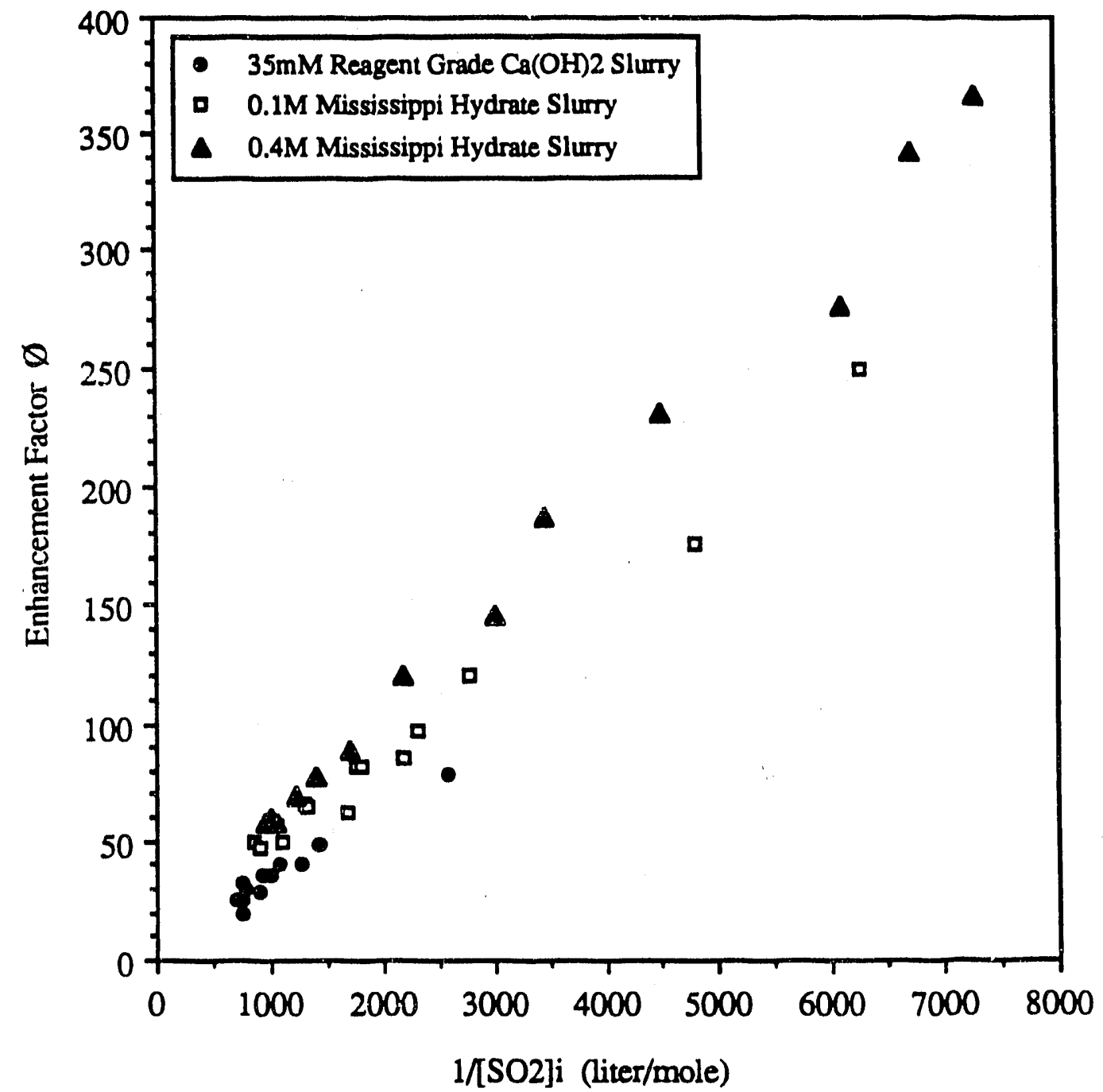

Figure 5-4. Comparison of enhancement in Mississippi $\mathrm{Ca}(\mathrm{OH})_{2}$ slurry at higher $\mathrm{Ca}(\mathrm{OH})_{2}$ concentrations. 
$\mathrm{Ca}(\mathrm{OH})_{2}$ product which has a 5-10 percent lower surface area (Boynton, 1980). The results of the test runs in slaked Mississippi $\mathrm{Ca}(\mathrm{OH})_{2}$ slurry are shown in Table 5-6.

TABLE 5-6. RESULTS OF TESTS PERFORMED IN $0.1 \mathrm{M} \mathrm{Ca(OH})_{2}$ MISSISSIPPI SLAKED LIME SLURRY

$\left(k_{\mathrm{g}}=1.42 \times 10^{-5} \mathrm{~mole} / \mathrm{m}^{2} \mathrm{~Pa} \mathrm{~s}\right)$

\begin{tabular}{|c|c|c|c|c|c|}
\hline Test \# & $\begin{array}{c}\mathrm{SO}_{2} \text { Conc. } \\
(\mathrm{ppm})\end{array}$ & $k^{0} \underset{(\mathrm{m} / \mathrm{s})}{\times 10^{5}}$ & $\begin{array}{l}\text { Contact Time } \\
\text { (s) }\end{array}$ & $\varnothing$ & $\begin{array}{c}\text { Gas Film } \\
\text { Res. (percent) }\end{array}$ \\
\hline So.1MS1 & 3653 & 7.5 & 0.9 & 71 & 62 \\
\hline So.1MS2 & 3871 & 7.5 & 0.9 & 67 & 61 \\
\hline So.1MS3 & 3012 & 7.5 & 0.9 & 118 & 73 \\
\hline So.1MS4 & 2359 & 7.5 & 0.9 & 266 & 86 \\
\hline SO.1MS5 & 2724 & 6.7 & 1.1 & 118 & 71 \\
\hline SO.1MS6 & 2126 & 6.7 & 1.1 & 166 & 60 \\
\hline So.1MS7 & 3461 & 6.7 & 1.1 & 71 & 60 \\
\hline SO.1MS8 & 3950 & 6.7 & 1.1 & 59 & 55 \\
\hline SO.1MS9 & 4182 & 6.7 & 1.1 & 55 & 54 \\
\hline So.1MS10 & 4522 & 5.7 & 1.5 & 49 & 47 \\
\hline So.1MS11 & 4403 & 5.7 & 1.5 & 47 & 46 \\
\hline So.1MS12 & 3970 & 5.7 & 1.5 & 52 & 48 \\
\hline So.1MS13 & 3436 & 5.7 & 1.5 & 58 & 51 \\
\hline So.1MS14 & 2624 & 5.7 & 1.5 & 80 & 59 \\
\hline SO.1MS15 & 3373 & 4.9 & 2.1 & 47 & 41 \\
\hline So.1MS16 & 4011 & 4.9 & 2.1 & 44 & 40 \\
\hline S0.1MS17 & 4462 & 4.9 & 2.1 & 43 & 40 \\
\hline
\end{tabular}

Figure 5-5 compares the test results of the three lime types. Significant differences in enhancement were not measured between them. An analysis of the surface area of the $\mathrm{Ca}(\mathrm{OH})_{2}$ particles in each siurry was rot performed. These results indicate that either the three limes tested had similar reactivities toward $\mathrm{SO}_{2}$ or the stirred tank reactor is capable of measuring only large differences in absorption such as those seen with changes in solids concentration. 


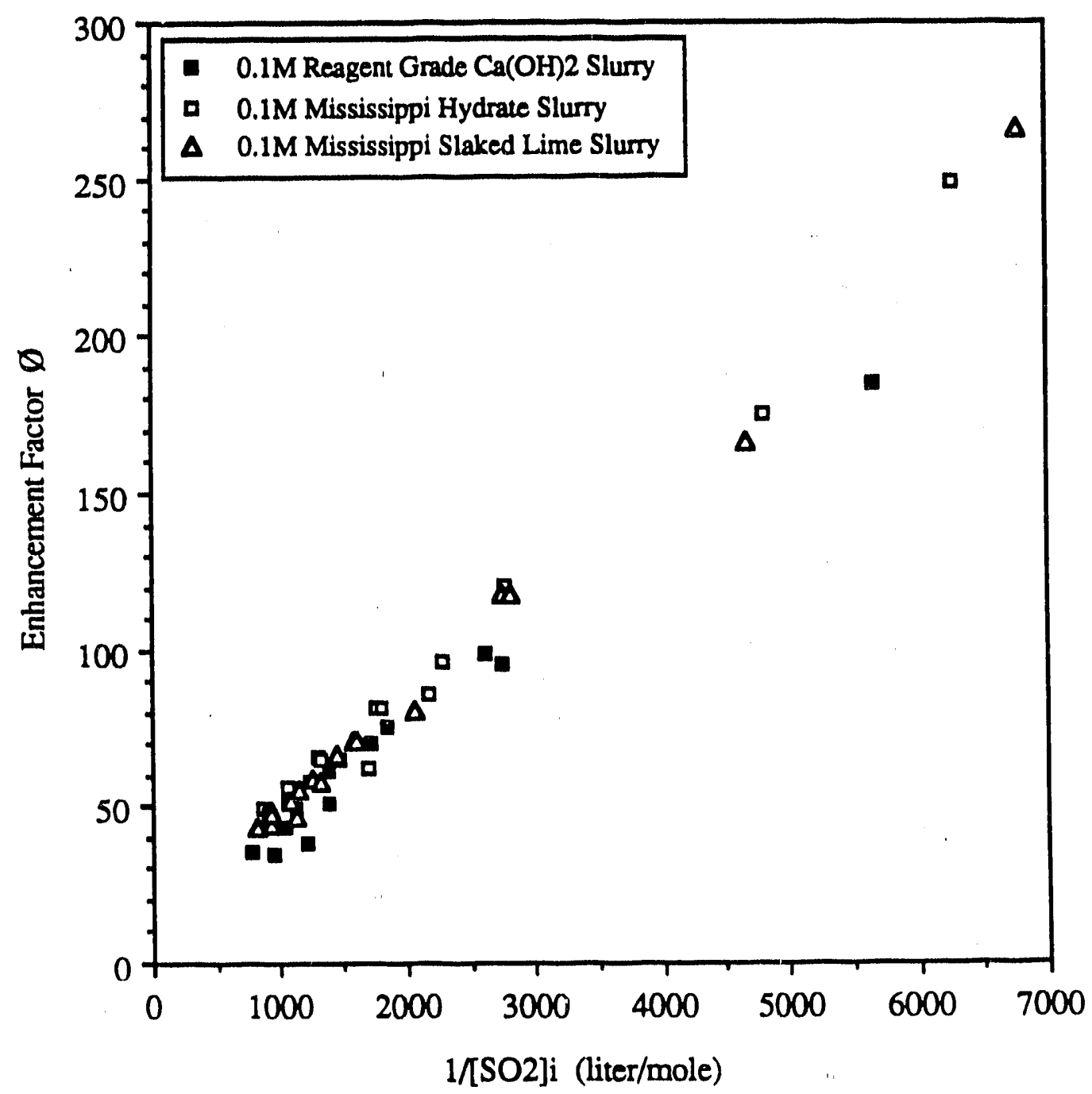

Figure 5-5. Comparison of enhancement in slurry from three different sources of $\mathrm{Ca}(\mathrm{OH})_{2}$ at $0.1 \mathrm{M}$ $\mathrm{Ca}(\mathrm{OH})_{2}$. 


\subsection{VALIDATION OF SLURRY ABSORPTION MODEL FOR $\mathrm{Ca}(\mathrm{OH})_{2}$ SLURRIES}

In Section 4, the degree of $\mathrm{SO}_{2}$ absorption enhancement predicted by the slurry absorption model was validated for several clear solution compositions. The model was validated for the solution containing $17 \mathrm{mM} \mathrm{Ca}(\mathrm{OH})_{2}$ and $0.1 \mathrm{M} \mathrm{CaCl}_{2}$ by adjusting the diffusivity of hydroxide to 40 percent of the referenced value. This adjusted $\mathrm{D}_{\mathrm{OH}}$ - was used for prediction of the enhancement in slurries reported in this section as well.

\subsubsection{Inputs that Establish Slurry Properties}

The composition of the slurry was assumed to be the same as the $17 \mathrm{mM}$ (saturated) $\mathrm{Ca}(\mathrm{OH})_{2}$ solution with additional solid $\mathrm{Ca}(\mathrm{OH})_{2}$. Therefore the input for the model resulted in the same conditions listed in Table 4-10 for the $17 \mathrm{mM} \mathrm{Ca}(\mathrm{OH})_{2}$ clear solution. Only two additional inputs were required for the slurries: solids concentration and particle size.

Solids concentration was specified as the same concentrations used in the stirred tank absorption experiments. The model was run for slurries containing total $\mathrm{Ca}(\mathrm{OH})_{2}$ at levels of $35 \mathrm{mM}$, $0.1 \mathrm{M}, 0.4 \mathrm{M}$ and $1.0 \mathrm{M}$ in $0.1 \mathrm{M} \mathrm{CaCl}_{2}$.

The particle size of $\mathrm{Ca}(\mathrm{OH})_{2}$ while in the slurry is a difficult quantity to measure. Measurement of the particle size after drying the slurry is misleading due to particle agglomeration. Particle size of dry $\mathrm{Ca}(\mathrm{OH})_{2}$ has been measured often and mean particle sizes are typically on the order of $1.5 \mu \mathrm{m}$ (Boynton, 1980). Therefore, the slurry absorption model was run at several particle sizes to determine which represent the conditions of the slurry used in the stirred tank experiments. Particle sizes of 0.5 , 1,5 and $10 \mu \mathrm{m}$ were used as input to the model.

The slurry absorption model is currently set up for no other inputs to establish the level of reactivity of the solids. Large particles are typically less reactive because the amount of exposed surface area per volume is small. When more exposed surface area is present, reaction of $\mathrm{Ca}(\mathrm{OH})_{2}$ and $\mathrm{SO}_{2}$ is increased. Therefore, by changing the particle size of the solid, the reactivity of the slurry is directly affected. 
In practice, particle size alone is not the only factor which influences the reactivity of the $\mathrm{Ca}(\mathrm{OH})_{2}$ solids in the slurry. Porosity of the particles can also increase the amount of exposed surface area, and hence, the reactivity of the sollds. This is why surface area per volume of dry $\mathrm{Ca}(\mathrm{OH})_{2}$ is typically measured and reported as an indicator of reactivity. Also, contamination of the sollds (typlcally by exposure to $\mathrm{CO}_{2}$ over long periods of time) can influence reactivity. Reagent purtty and the source of the $\mathrm{Ca}(\mathrm{OH})_{2}$ may also have some effect on reactivity.

The particle sizes used in the model may not actually represent the true particle size of the solids in the slurry. Instead, the particle size input is used to establish the relative reactivity of the $\mathrm{Ca}(\mathrm{OH})_{2}$ solids in the slurry.

\subsubsection{Enhancement Predicted by Slurry Absorption Model}

A first step in predicting enhancement in slurries with the slurry absorption model was to validate that reducing the $\mathrm{D}_{\mathrm{OH}^{-}}$by 40 percent improved the ability of the model to predict the experimental results obtained in the stirred tank. Figure 5-6 shows enhancement measured in the stirred tank for a $35 \mathrm{mM} \mathrm{Ca}(\mathrm{OH})_{2}$ slurry compared to enhancemert predicted by the slurry absorption model under three conditions. First, the model was run without adjusting the $\mathrm{D}_{\mathrm{OH}^{-}}$to 40 percent of the referenced value. As found in the case of the $17 \mathrm{mM} \mathrm{Ca}(\mathrm{OH})_{2}$ solution, the model overpiedicted enhancement by a factor of 2 . The model was then run with $\mathrm{D}_{\mathrm{OH}^{-}}$reduced by 40 percent at two different particle sizes.

By reducing $D_{O H^{-}}$by 40 percent, the slurry absorption model was able to predict the enhancement measured in the stirred tank experiments for the $35 \mathrm{mM}$ slurry. This was in fact found to improve agreement of the model with all the slumies studied. All remaining model results for slurries presented in this section were generated using the reduced $\mathrm{D}_{\mathrm{OH}^{n}}$.

Increasing the particle size of the solids from 1 to $5 \mu \mathrm{m}$ did not have a significant effect on the predicted enhancement in this slumy. The larger particle size did result in a slightly lower enhancement factor, which was expected. 


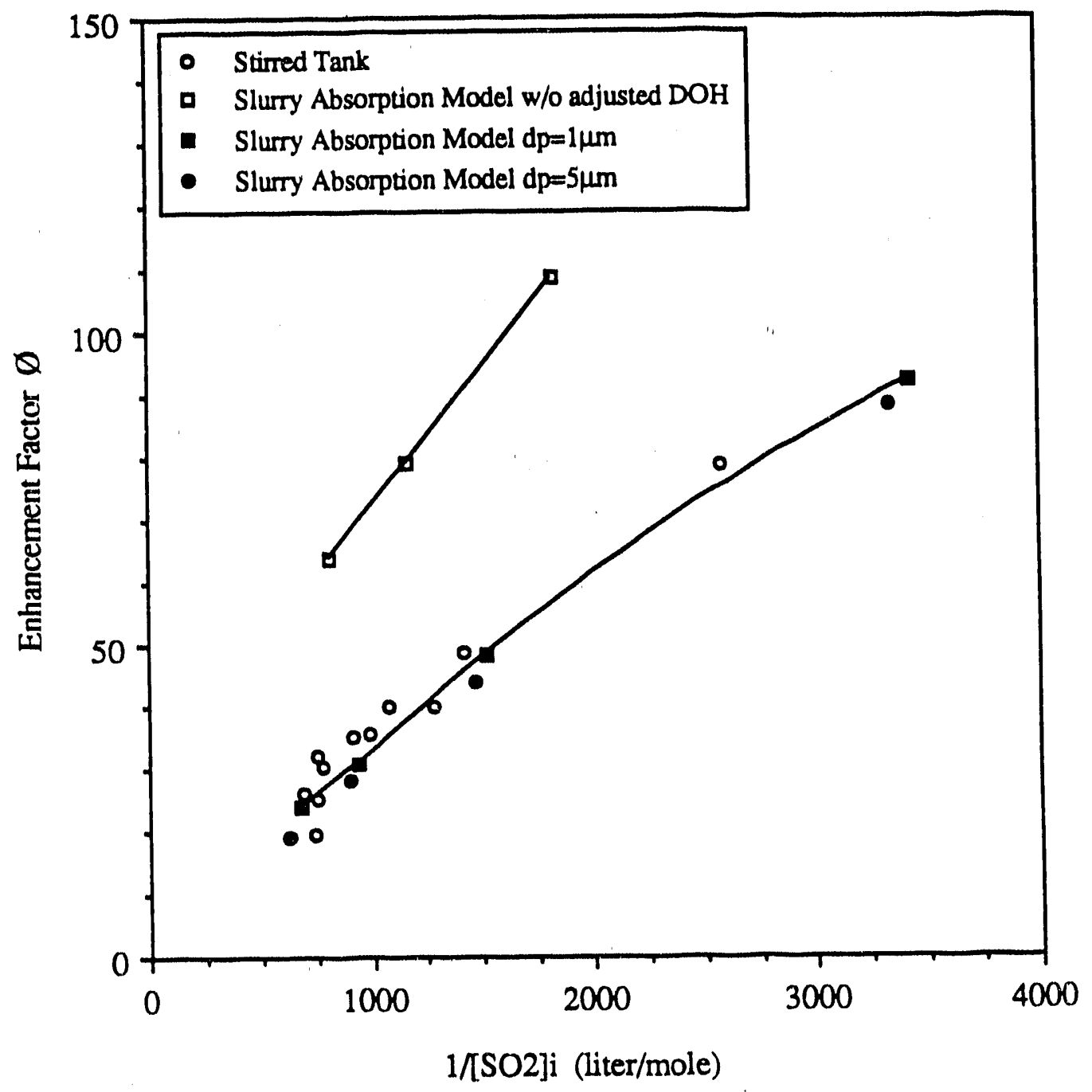

Figure 5-6. Enhancement predicted by slurry absorption model for $35 \mathrm{mM} \mathrm{Ca}(\mathrm{OH})_{2}$ slurry. 
The effect of particle size was studied in more detall for a $0.1 \mathrm{M} \mathrm{Ca}(\mathrm{OH})_{2}$ slurry since experiments with different sources of $\mathrm{Ca}(\mathrm{OH})_{2}$ were pertormed at this slurry concentration. Figure 5-7 shows the results of enhancement predicted by the model at four different particle sizes compared to experimental results trom tests in reagent grade $0.1 \mathrm{M} \mathrm{Ca}(\mathrm{OH})_{2}$ slurry.

In addition, a comparison was made between enhancement predicted at different contact times. All model results presented in this section are evaluated at a contact time of $0.9 \mathrm{~s}$. Figure 5-7 shows model results generated at a particle size of $1.0 \mu \mathrm{m}$ at a $2.5 \mathrm{~s}$ contact time. The range of contact times simulated in the stirred tank was 0.9 to $2.5 \mathrm{~s}$. It has been assumed that the enhancement factor in slurries is not a function of contact time over the range studied in the experiments. The model vertiles that this is a good assumption.

The model predicts that relatively no change in enhancement results from reducing the particle size from $1.0 \mu \mathrm{m}$ to $0.5 \mu \mathrm{m}$. However, increasing the particle size to $5 \mu \mathrm{m}$ and further to $10 \mu \mathrm{m}$ results in measurably lower enhancement. The experimental results appear to be best described by a slurry with a particle size between 5 and $10 \mu \mathrm{m}$.

The model was run at 3 different particle sizes at a slumy concentration of $0.4 \mathrm{M} \mathrm{Ca}(\mathrm{OH})_{2}$ for comparison of enhancement with that measured in the stirred tank. Figure 5-8 shows that little difference in enhancement was predicted upon increasing the particle size from 1 to $5 \mu \mathrm{m}$. A larger difference in enhancement was predicted when increasing the particle size to $10 \mu \mathrm{m}$. The few model runs at a particle size of $10 \mu \mathrm{m}$ indicate that the experimental measurements of enhancement are best predicted by a particle size of at least $10 \mu \mathrm{m}$.

The particle sizes required by the slurry absorption model for predictions that agree with the enhancement measured in the stirred tank experiments increased as solids concentration increased. In other words, when the particle size used by the model is fixed, the model predicts a greater increase in enhancement due to the addition of solids to the slurry than the stirred tank experimental results indicate. 


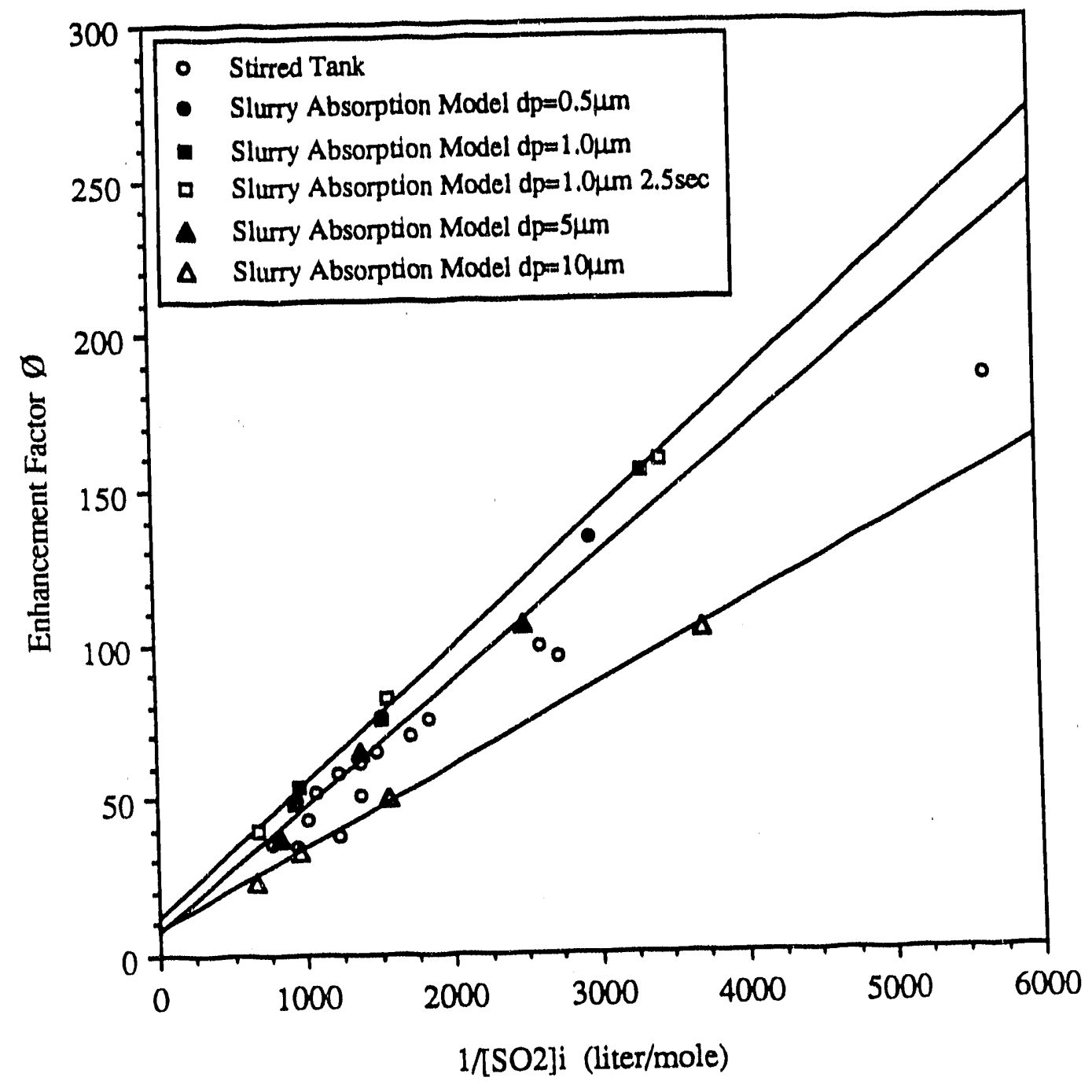

Figure 5-7. Effect of particle size on enhancement predicted by slurry absorption model for $0.1 \mathrm{M}$ $\mathrm{Ca}(\mathrm{OH})_{2}$ slurry. 


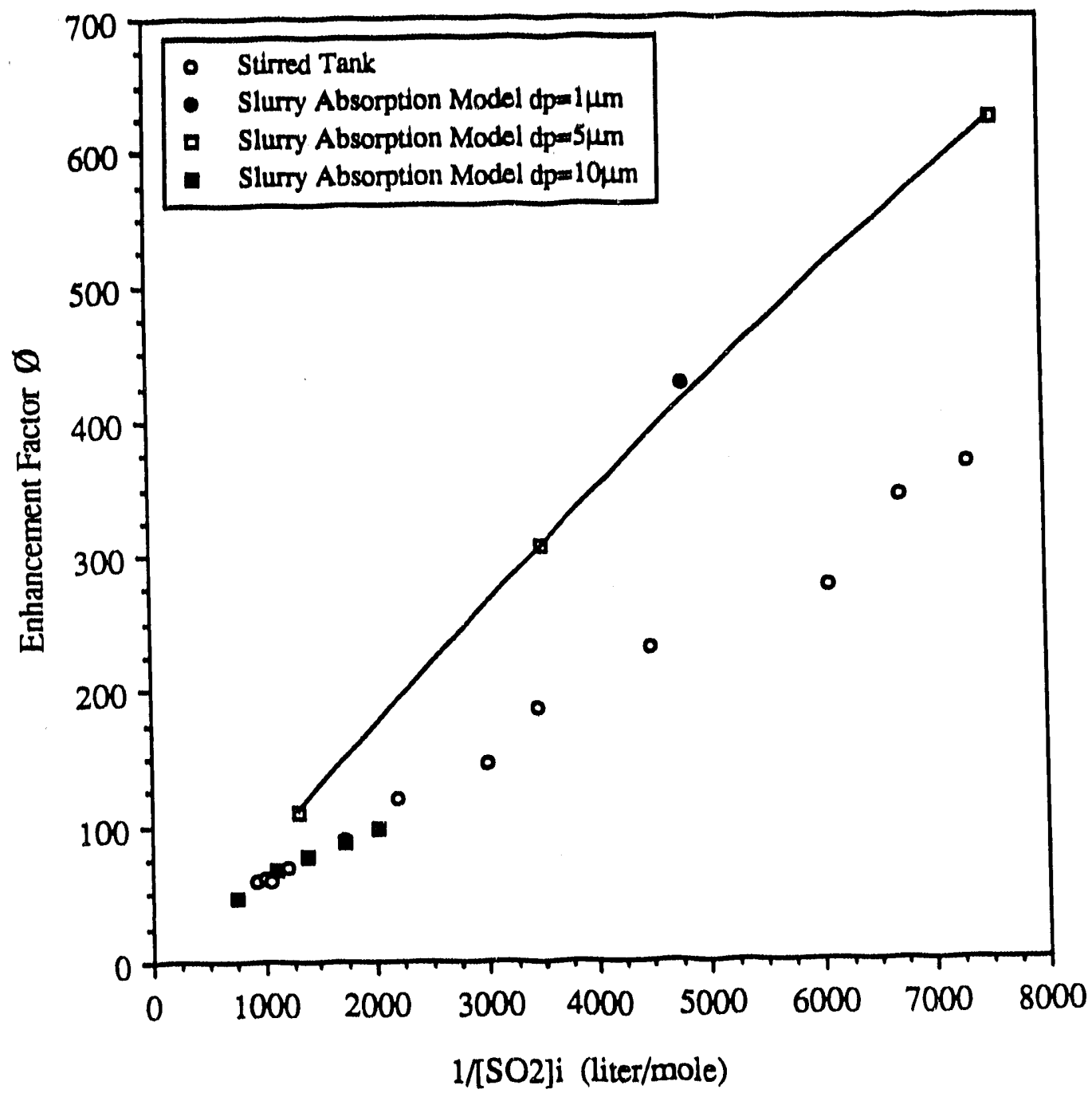

Figure 5-8. Enhancement predicted by slurry absorption model for $0.4 \mathrm{M} \mathrm{Ca}(\mathrm{OH})_{2}$ slurry. 
This conolusion is further supported by the few measurable results obtained fromi the stirred tank using $1.0 \mathrm{M} \mathrm{Ca}(\mathrm{OH})_{2}$ slurry. Most of the measurements were too gas film controlled to accurately estimate the enhanoement factors. However, three test runs indloated less than 100 percent gas fllm controlled absorption. The slurry absorption model was run with $1.0 \mathrm{M} \mathrm{Ca}(\mathrm{OH})_{2}$ slurry concentration spectlied at two particle sizes to prediot the degree of gas film control expected in this slurry. A comparison of gas fllm resistance predicted by the model with that measured in the stirred tank is made In Table 5-7.

The slurry absorption model predicts that this $1.0 \mathrm{M} \mathrm{Ca}(\mathrm{OH})_{2}$ slurry should be mire reactive than the results of the stirred lank experiments indicate. The model predioted that the absomption should have been completely gas film controlled for all $\mathrm{SO}_{2}$ concentrations less than $4,000 \mathrm{ppm}$.

\subsubsection{Sollds Settling in the Boundary Layer}

There is a possible explanation for the difference in enhancement predicted by the model and measured in the stirred tank when solids content is increased. As is the case for all slumies, $\mathrm{Ca}(\mathrm{OH})_{2}$ particles will settle due to gravity if not well mixed. Although the bulk solution was well mixed in slurry experiments in the stirred tank, the boundary layer is inherently stagnant. Dlssolved species remain present in the boundary layer for the defined contact time, but the solld particles may have settled out of the boundary layer sooner. Thus, the solid particles may not have enhanced the absorption of $\mathrm{SO}_{?}$ as much as the model would predict. The experiments showed that this effect was more pronounced at higher solids concentrations.

TABLE 5-7. PREDICTED GAS FILM RESISTANCE IN $1.0 \mathrm{M} \mathrm{Ca}(\mathrm{OH})_{2}$ SLURRY AT VARIOUS $\mathrm{SO}_{2}$ CONCENTRATIONS

\begin{tabular}{||c|c|c|c|c|c||}
\hline & \multicolumn{5}{|c|}{ SO $_{2}$ Concentration } \\
& $1,000 \mathrm{ppm}$ & $2,000 \mathrm{ppm}$ & $3,000 \mathrm{ppm}$ & $4,000 \mathrm{ppm}$ & $5,000 \mathrm{ppm}$ \\
\hline Model $1.0 \mu \mathrm{m}$ & $100 \%$ & $100 \%$ & $100 \%$ & $100 \%$ & $100 \%$ \\
\hline Model $10 \mu \mathrm{m}$ & $100 \%$ & $100 \%$ & $100 \%$ & $90 \%$ & $75 \%$ \\
\hline Stirred Tank & $100 \%$ & $85 \%$ & $80 \%$ & $\cdots$ & $\cdots$ \\
\hline
\end{tabular}


In order to judge whether this explanation is reasonable, some comparisons of settling velocttles and boundary layer thiokness were made. The boundary layer thlckness can be rough' estimated by oaloulating the penetration dlstance, $\delta_{D}$, as follows (Bird, Stewart and Lightfoot, 1960):

$$
\delta_{D}=4 \sqrt{D t}
$$

A characteristio settling velootty related to this penetration distance would be:

$$
\begin{aligned}
V_{D} & =\frac{\delta_{D}}{t} \\
\text { or } \quad V_{D} & =4 \frac{\sqrt{D}}{\sqrt{t}}
\end{aligned}
$$

Using the range of contact times avallable in the stirred tank, and a characteristio diffusivity, $D_{C a+1}$ for the caloium lon, a range of settling velocities and penetration distances can be estimated for the conditions in the stirred tank.

The slurry absorption model calculates a more precise penetration distance as a function of contact time, solids concentration and particle size. Penetration distances predicted by the model are shown in Table 5-8 for slurries exposed to $4,000 \mathrm{ppm} \mathrm{SO}_{2}$. Also shown are the maximum settling velocities calculated from the penetration distances and contact times. Any particles with sottling velocitles greater than the maximum settling velocities would settle out of the boundary layer sooner than the specifled contact time.

These model results show that the penetration distance becomes much smaller as the slurry solids content is increased. Also, the penetration distance is smaller for larger slumy particles. Solids are more likely to settle out of the boundary layer if the penetration distance is smaller. 
TABLE 5-8. PENETRATION DISTANCES AND MAXIMUM SETTLING VELOCITIES PREDICTED BY THE SLURRY ABSORPTION MODEL - 4,000 ppm $\mathrm{SO}_{2}$

\begin{tabular}{|c|c|c|c|c|}
\hline \multirow[b]{2}{*}{ Contaot Times } & \multicolumn{2}{|c|}{$\delta_{D}(\mu \mathrm{m})$} & \multicolumn{2}{|c|}{ Maximum $V_{D}\left(\mathrm{~m} / \mathrm{s} \times 10^{6}\right)$} \\
\hline & $0.90 \mathrm{~s}$ & $2.50 \mathrm{~s}$ & 0.908 & 2.508 \\
\hline \multicolumn{5}{|l|}{$\begin{array}{c}10 \mu \mathrm{m} \text { Particle } \\
\text { Slze }\end{array}$} \\
\hline $35 \mathrm{mM} \mathrm{Ca}(\mathrm{OH})_{2}$ & 85.1 & 157.6 & 94.5 & 63 \\
\hline $0.1 \mathrm{M} \mathrm{Ca}(\mathrm{OH})_{2}$ & 40.9 & 77.7 & 45.4 & 31.1 \\
\hline $0.4 \mathrm{M} \mathrm{Ca}(\mathrm{OH})_{2}$ & 13.5 & 32.0 & 15.0 & 12.8 \\
\hline $1.0 \mathrm{M} \mathrm{Ca}(\mathrm{OH})_{2}$ & 5.6 & 15.5 & 6.2 & 6.2 \\
\hline \multicolumn{5}{|l|}{$\begin{array}{c}5.0 \mu \mathrm{m} \text { Particle } \\
\text { Slze }\end{array}$} \\
\hline $35 \mathrm{mM} \mathrm{Ca}(\mathrm{OH})_{2}$ & 38.5 & 104.8 & 42.7 & 41.9 \\
\hline $0.1 \mathrm{M} \mathrm{Ca}(\mathrm{OH})_{2}$ & 28.2 & 61.3 & 31.3 & 24.5 \\
\hline $0.4 \mathrm{M} \mathrm{Ca}(\mathrm{OH})_{2}$ & 10.3 & 26.4 & 11.4 & 10.6 \\
\hline $1.0 \mathrm{M} \mathrm{Ca}(\mathrm{OH})_{2}$ & 4.0 & 13.0 & 4.4 & 5.2 \\
\hline
\end{tabular}

Some simple measurements of particle settling velocitles were made in the laboratory. A slurry of each of the three $\mathrm{Ca}(\mathrm{OH})_{2}$ types used in experiments was prepared at a $\mathrm{Ca}(\mathrm{OH})_{2}$ concentration level of $0.4 \mathrm{M}$. A small amount was poured into a $1 \mathrm{~L}$ graduated cylinder. Generally, as the partioles settled, a clear llquid front was observed. As the front dropped in the cyllnder, the time and distance was recorded. The rate of settling was constant over most of the experiment, but reached a point where it slowed considerably. At this point, the particles were heavily concantrated at the bottom of the jyllinder. Since the slurry became more concentrated as it dropped within the cyllinder, estimates of the changing concentration were made as well. Table 5-9 summarizes the results of these simple experiments.

The ineasurements show that the reagent grade $\mathrm{Ca}(\mathrm{OH})_{2}$ and the slaked Mississippi lime $\mathrm{Ca}(\mathrm{OH})_{2}$ settled faster than the Mississippl hydrate $\mathrm{Ca}(\mathrm{OH})_{2}$. However, even the Mississippl hydrate $\mathrm{Ca}(\mathrm{OH})_{2}$ slurry settled faster than the maximum setting velocities in Table 5-8 prescribe. These 
TABLE 5-9. MEASURED SETTLING VELOCITIES OF THREE SLURRY TYPES

\begin{tabular}{||c|c|c|c||}
\hline & \multicolumn{3}{|c||}{ Measured Settling Velocity, $\mathrm{V}_{\mathrm{D}}$ (m/s $\left.\times 10^{6}\right)$} \\
& Reagent Grade & Miss. Hydrate & Miss. Slaked \\
\hline$<0.4 \mathrm{M} \mathrm{Ca}(\mathrm{OH})_{2}$ & 670 & 110 & 480 \\
\hline $1.0 \mathrm{M} \mathrm{Ca}(\mathrm{OH})_{2}$ & 510 & 80 & 350 \\
\hline $2.0 \mathrm{M} \mathrm{Ca}(\mathrm{OH})_{2}$ & 210 & 56 & 130 \\
\hline
\end{tabular}

measurements appear to support the assumption that sollds may have been settling out of the boundary layer during the concentrated slurry experiments.

It is not ciear whether such behavior would be expected in an actual slurry droplet. Therefore, the model may be producing an accurate estimate of the enhancement of $\mathrm{SO}_{2}$ absorption in a slurry droplet, although it tends to overpredict the measurements taken in the stirred tank. Additional study of the behavior of solids suspended in droplets may be needed to address this issue.

\subsection{SUMMARY OF SLURRY ABSORPTION EXPERIMENTS}

The slurry absorption experiments documented the effects that increased solids content and changes to reactivity of the slurry have on $\mathrm{SO}_{2}$ absorption. The effects were reported in terms of the enhancement factor and the degree that gas film resistance controlled the absorption. In some of these experiments a completely gas film controlled absorption was achieved, thus the absorption was enhanced to the highest degree achievable in the stirred tank reactor. The results are compared and summarized below.

The results of the slurry absorption experiments were used to validate enhancement and degree of gas filkn resistanc:- predicted by the slurry absorption model. Because solid $\mathrm{Ca}(\mathrm{OH})_{2}$ is present in the slurries, these experiments were used to validate the part of the model that governs solid $\mathrm{Ca}(\mathrm{OH})_{2}$ dissolution and reaction. Conclusions that were reached regarding the model's abillty to predict the experimentally measured absorption of $\mathrm{SO}_{2}$ are also summarized belons 


\subsubsection{Effect of Solids Concentrationn on Enhancement and Gas Film Resistance in the Stirred Tank}

Slurries containing four levels of total $\mathrm{Ca}(\mathrm{OH})_{2}$ concentration were studied: $35 \mathrm{mM}, 0.1 \mathrm{M}$, $0.4 \mathrm{M}$, and $1.0 \mathrm{M}$. Addition of solids significantly enhanced the absorption of $\mathrm{SO}_{\mathrm{s}}$ in all cases. However, the increment of enhancement appeared to diminish as the slurry solids roncentration was increased. A 50 percent increase in enhancement was observed when $\mathrm{Ca}(\mathrm{OH})_{2}$ concentration was doubled from $17 \mathrm{mM}$ to $35 \mathrm{mM}$. Only 25-30 percent increase in enhancement was measured when $\mathrm{Ca}(\mathrm{OH})_{2}$ concentration was nearly tripled from $35 \mathrm{mM}$ to $0.1 \mathrm{M}$. When $\mathrm{Ca}(\mathrm{OH})_{2}$ concentration was quadrupled from $0.1 \mathrm{M}$ to $0.4 \mathrm{M}$, only $20-25$ percent increase in enhancement resulted.

Enhancement factors predicted by the slurry absorption model for absorption in each of the slurries studied are summarized in Figure 5-9. The data was taken from the model runs which best represented the stirred tank results. Enhancement factors are presented as a function of $\mathrm{SO}_{2}$ concentration. In absorption that was gas film controlled, the enhancement in the liquid phase becomes infinite and could not be measured in the stirred tank.

Few enhancement factors over 200 could be measured in the stirred tank because the absorption was too gas film controlled at that point. The model also showed gas film controlled absorption at that point, thus few enhancement factors over 200 are plotted.

The clear solution experiments in Section 4 pointed out that measurements of enhancement in slurries would not be possible with bulk gas $\mathrm{SO}_{2}$ concentrations less than 2,000 ppm because these conditions would yield a gas film controlled absorption. Initial slurry tests were limited to the range of 2,000 to $5,000 \mathrm{ppm} \mathrm{SO}$, and iests with higher slurry solids content required over $3,000 \mathrm{ppm} \mathrm{SO}_{2}$ to remain under 80 percent gas film controlled. Finally, the tests at $1.0 \mathrm{M} \mathrm{Ca}(\mathrm{OH})_{2}$ required over 4,000 $\mathrm{ppm} \mathrm{SO} \mathrm{S}_{2}$ to make accurate measurements of enhancement. The stirred tarık experiments were not able to produce meaningful enhancement factors at $\mathrm{SO}_{2}$ concentrations lower than those mentioned because the absorption was too gas film controlled.

These limitations due to gas film resistance are easily seen in Figure 5-10. The gas film resistance was datermined from the same data generated by the slurry absorption model that was 


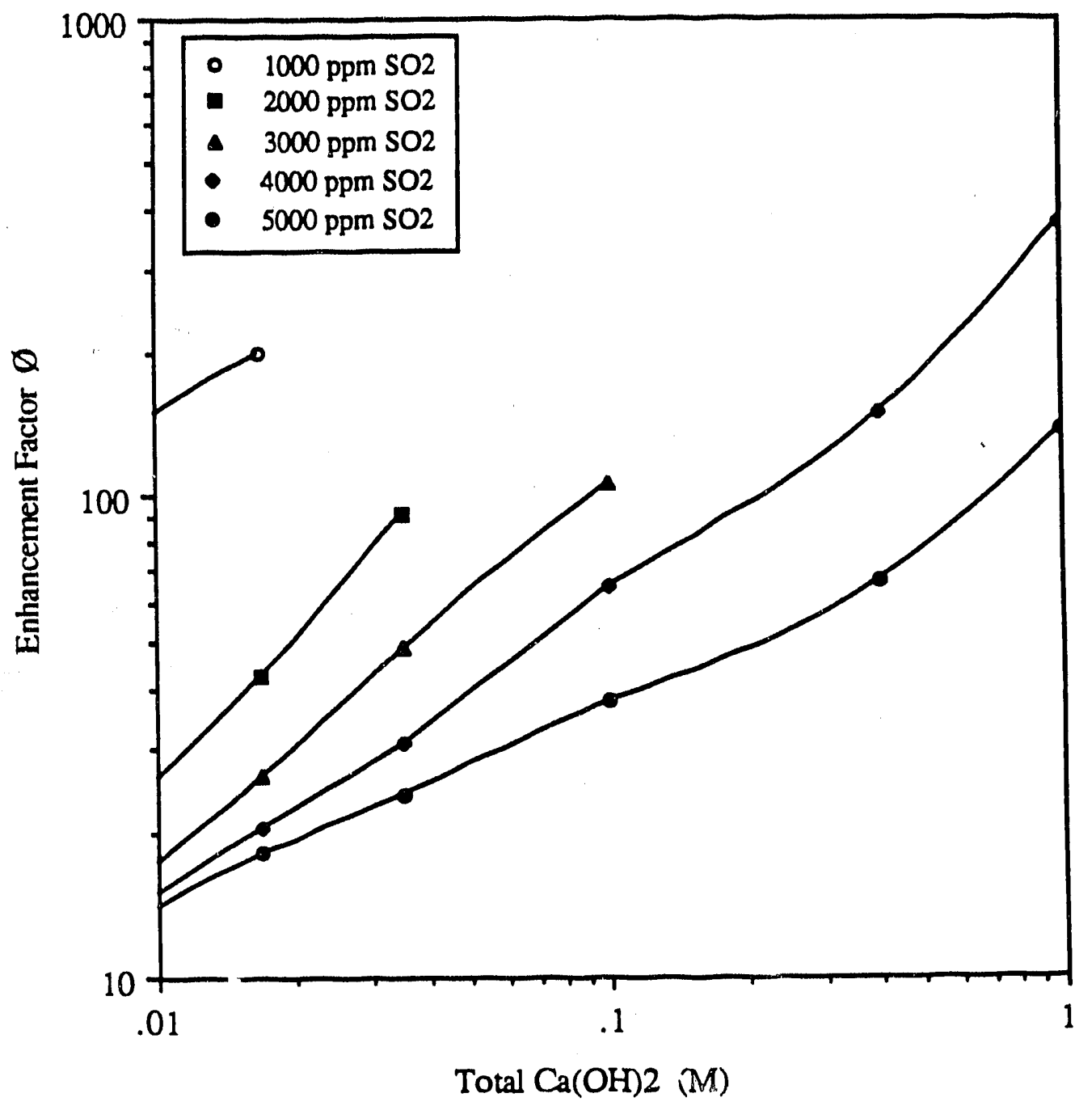

Figure 5-9. Effect of slurry $\mathrm{Ca}(\mathrm{OH})_{2}$ concentration on enhancement predicted by slurry absorption model for tests performed in the stirred tank (corresponding $d_{\text {droplet }}=800 \mu \mathrm{m}, d_{p}=5-10$ $\mu \mathrm{m}, \theta=0.9 \mathrm{~s})$. 


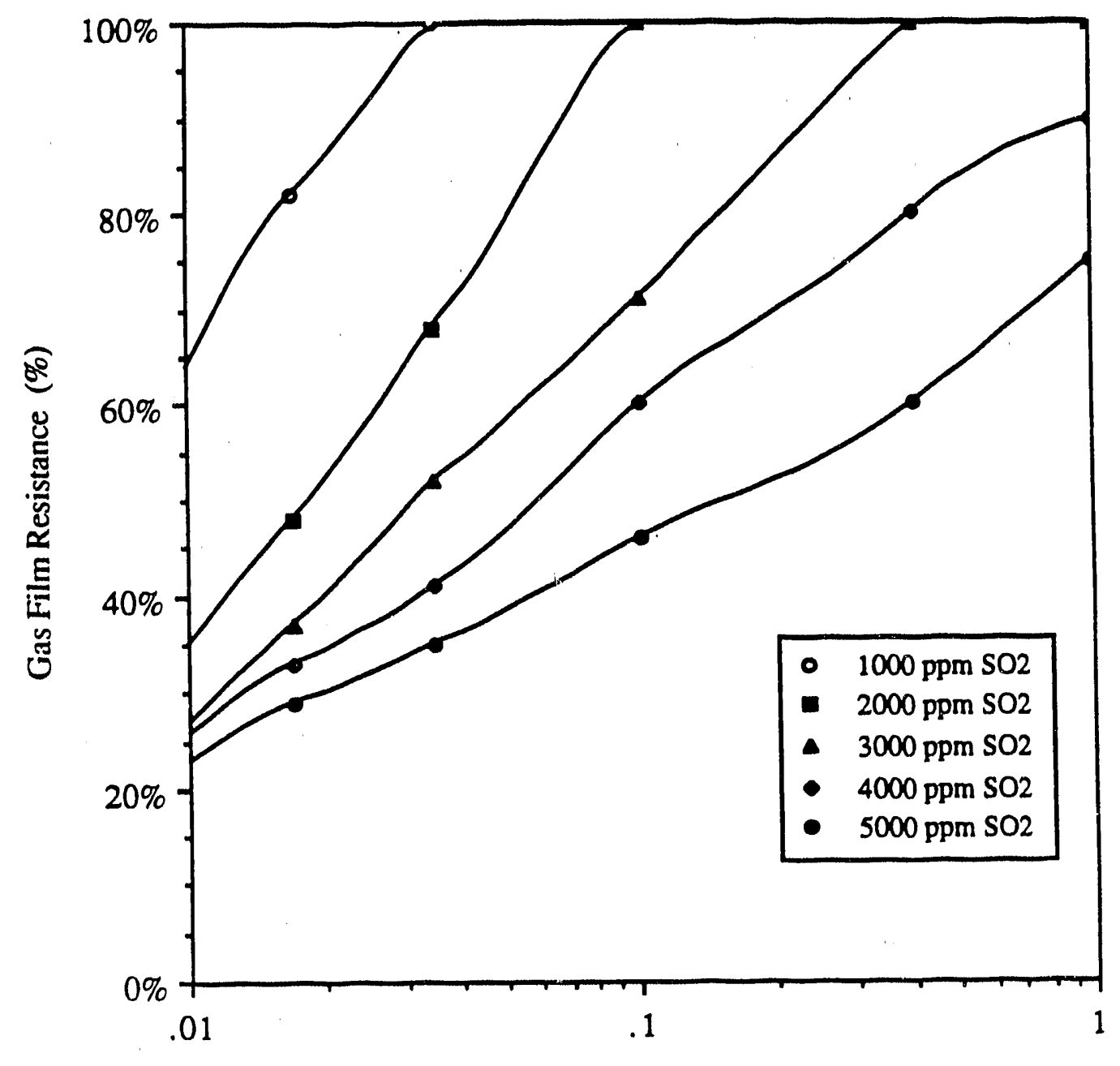

Total $\mathrm{Ca}(\mathrm{OH}) 2(\mathrm{M})$

Figure 5-10. Effect of slurry $\mathrm{Ca}(\mathrm{OH})_{2}$ concentration on gas film resistance predicted by slurry absorption model for tests performed in the stirred tank (corresponding $d_{\text {droplet }}=800$ $\left.\mu \mathrm{m}, d_{p}=5-10 \mu \mathrm{m}, \theta=0.9 \mathrm{~s}\right)$. 
plotted in Figure 5-9. The model accurately predicted where the gas film resistance became great enough to make measurement difficult in the stirred tank.

The degree of error associated with determination of the enhancement factor Increased dramatically as gas film resistance became dominant. In tests where the conditions resulted in gas film resistances of greater than 80 percent, the enhancement factor could not be determined with accuracy. As Figure 5-10 indicates, this began to limit the range of measurements that could be taken in the stirred tank, especially when solids concentration was increased to 0.4 and $1.0 \mathrm{M} \mathrm{Ca}(\mathrm{OH})_{2}$. Inaccuracy was found to be inherent in the calculation of $\varnothing$ and could not be improved much by improving the accuracy of individual measurements.

Discussion in Section 3 pointed out that the stirred tank reactor operates at a gas film mass transter coefficient that is an order-of-magnitude smaller than might be expected for a slurry droplet. Therefore, it should be remembered that the enhancement factors and gas film resistances measured in the slurry absorption experiments may not be of the same magnitude as found in a slurry droplet. However, the trends identified in the stirred tank reactor should be similar to the behavior within a slurry droplet.

\subsubsection{Effect of Solids Concentrationn on Enhancemeni aind Gas Film Resistance in a Slurry Droplet}

In order to predict the actual degree of enhancement and gas film resistance in a slurry droplet present during $\mathrm{SO}_{2}$ absorption in the in-duct injection process, the global mass transfer effects described briefly in Section 1 need to be ronsidered. So far, only the rigorous treatment of $\mathrm{SO}_{2}$ absorption, $\mathrm{Ca}(\mathrm{OH})_{2}$ dissolution, and $\mathrm{CaSO}_{3}$ crystallization has been developed. Some of the key elements to be considered in this analysis are:

1) The effects of evaporation of water are not yet considered. Therefore, the droplet is considered to have a constant size, and the solids concentration does not increase as water from the slumy evaporates. Some kind of shrinking core model must be added.

2) The version of the model that was used to predict absorption in the stirred tank was written in Cartesian coordinates. A version of the model exists in spherical coordinates but was 
not run in this validation effort. The results presented in this section were run with the stirred tank version of the model.

3) Solids distribution in the bulk liquid and in the boundary layer are not adjusted for the effects of drepsut shyinking or the potentlal for solids settling. Recirculation patterns in the droplet were not addressed.

4) The droplet size and drying time only represent an example of what might be typical. A full analysis of droplet size distributions and drying times such as proposed hy Kinsey and Harriot (1988) would require modeling droplets of different sizes and determining drying times based on a polydisperse spray.

Atthough the model has not yet been coupled with theories that address these important issues, It has addressed the basic absorption and reaction of $\mathrm{SO}_{2}$ in $\mathrm{Ca}(\mathrm{OH})_{2}$ slurries in a rigorous fashion. To illustrate how absorption in a slurry droplet will differ from the absorption in the stirred tank, the model was run with inputs that would simulate absorption in a droplet rather than absorption in the stirred tank. The only input that required changing was the value of $k_{g}$, the gas film coefficient. The $k_{g}$ was increased an order of magnitude from $1.44 \times 10^{-5}$ to $1.44 \times 10^{-4} \mathrm{~mole} / \mathrm{m}^{2} \mathrm{~Pa} \mathrm{~s}$, representing a slumy droplet of $75 \mu \mathrm{m}$.

A single droplet of $75 \mu \mathrm{m}$ would dry after about 0.5 to $0.7 \mathrm{~s}$, depending on the duct temperature, whereas this same droplet in a monodisperse spray would take as much as $1.7 \mathrm{~s}$ to dry (Kinsey and Harriot, 1988). An exact drying time cannot be estimated because it depends upon the gas flow characteristics, size distribution of other droplets in the spray, and temperature. This analysis assumes that the droplet is in slurry form (i.e., not totally dry) for at least 0.9 s, which was the contact time chosen for the model runs.

The slurry composition was assumed to be the same as in the :lurry model runs presented already in this chapter. Therefore, the input of species concentrations for the model was the same as listed in Table 4-10 for the $17 \mathrm{mM}$ (saturated) $\mathrm{Ca}(\mathrm{OH})_{2}$ clear solution, and solids concentrations were $35 \mathrm{mM}, 0.1 \mathrm{M}, 0.4 \mathrm{M}$ and $1.0 \mathrm{M}\left(7 \mathrm{wt}\right.$ percent) $\mathrm{Ca}(\mathrm{OH})_{2}$. Two higher $\mathrm{Ca}(\mathrm{OH})_{2}$ concentrations were 
modeled as well. Model runs were made at $2.0 \mathrm{M}$ (13 wt percent) and $4.0 \mathrm{M}$ (23 wt percent) $\mathrm{Ca}(\mathrm{OH})_{2} \cdot \mathrm{A} \mathrm{Ca}(\mathrm{OH})_{2}$ partiole size of $5 \mu \mathrm{m}$ was assumed.

Figures 5-11 and 5-12 present the enhancement factors predicted by these slurry droplet model runs. Figure 5-11 shows the enhancement results as a function of $\mathrm{SO}_{2}$ concentration, as most of the results have been presented in this chapter. Figure 5-12 shows the relationship of enhancement in a slurry droplet with increasing solids concentration.

For a given $\mathrm{SO}_{2}$ concentration and total $\mathrm{Ca}(\mathrm{OH})_{2}$ concentration, the enhancement predicted for a slurry droplet in Figures 5-11 and 5-12 is less than the enhancement shown in Figure 5-9 for the stirred tank. For instance, an enhancement factor of about 100 was measured in the stirred tank for a $0.1 \mathrm{M} \mathrm{Ca}(\mathrm{OH})_{2}$ slurry at $3,000 \mathrm{ppm}$. The model predicted that a slurry droplet with the same solids content at 3,000 ppm would produce an enhancement factor of about 25. The main reason for the lowier enhancement is that absorption in the slurry droplet is not nearly as gas film controlled as in the stirred tank. Figure 5-13 shows the amount of gas film resistance predicted for $\mathrm{SO}_{2}$ absoption in the slurry droplet at a 0.9 s contact time.

By increasing the gas film coefficient by an order of magnitude, the model predicts that absorption into most of the slurry compositions studied is still controlled by liquid film resistances to a great degree. In fact, most of the resulting gas film resistances were less than 20 percent.

Note that the model was run for the $2.0 \mathrm{M}$ (13 wt percent) and $4.0 \mathrm{M}$ (23 wt percent) $\mathrm{Ca}(\mathrm{OH})_{2}$ slurries as well. For gas concentrations of over $1,000 \mathrm{ppm} \mathrm{SO}$, absorption in all slurry concentrations studied, including these high solids slurries, resulted in gas film resistance less than 100 percent. Therefore, it appears that liquid film resistance is an important controlling factor in $\mathrm{SO}_{2}$ absorption in slurry droplets. This conclusion is important, since it indicates that changes to the slurry could be made to further enhance the absorption of $\mathrm{SO}_{2}$ in $\mathrm{Ca}(\mathrm{OH})_{2}$ slurries. 


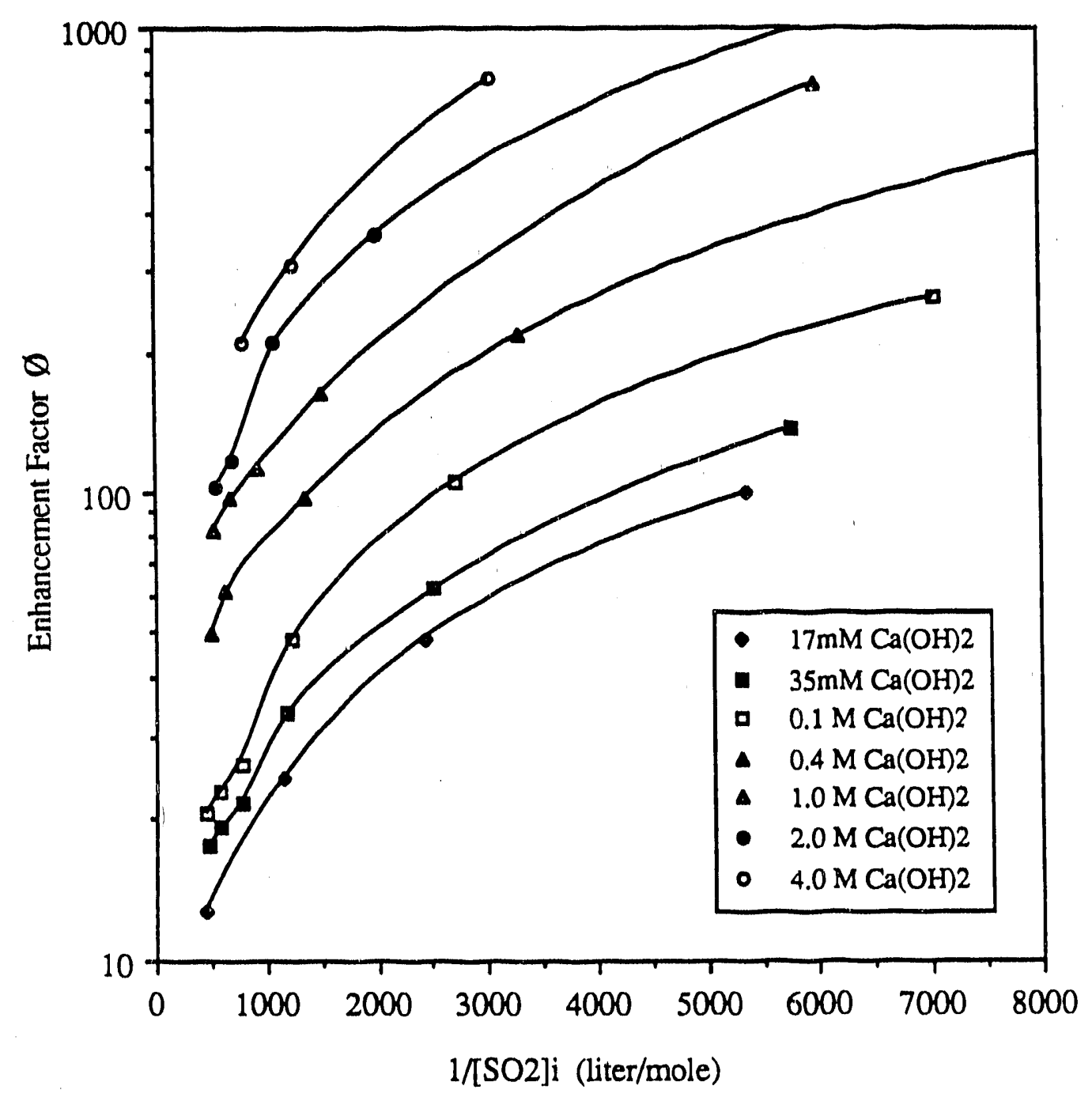

Figure 5-14. Enhancement in a slurry droplet predicted by slurry absorption model $\left(d_{d r o p l e t}=75 \mu m\right.$, $\left.d_{p}=5 \mu \mathrm{m}, \theta=0.9 \mathrm{~s}\right)$. 


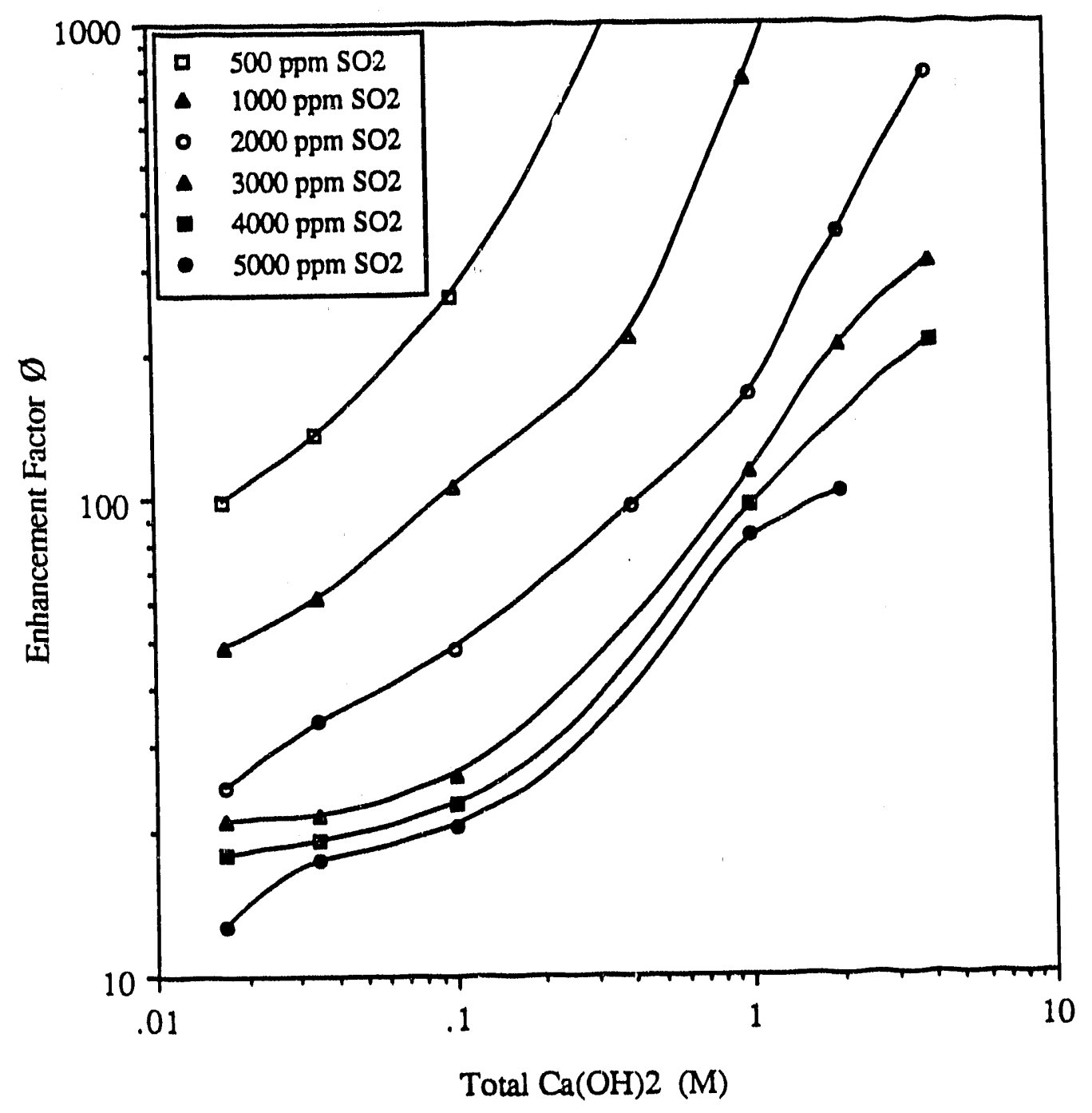

Figure 5-12. Effect $\mathrm{O} \mathrm{Ca}(\mathrm{OH})_{2}$ concentration in a slurry droplet on enhancement predicted by slurry absorption model ( $d_{\text {droplet }}=75 \mu \mathrm{m}, d_{p}=5 \mu \mathrm{m}, \theta=0.9 \mathrm{~s}$ ). 


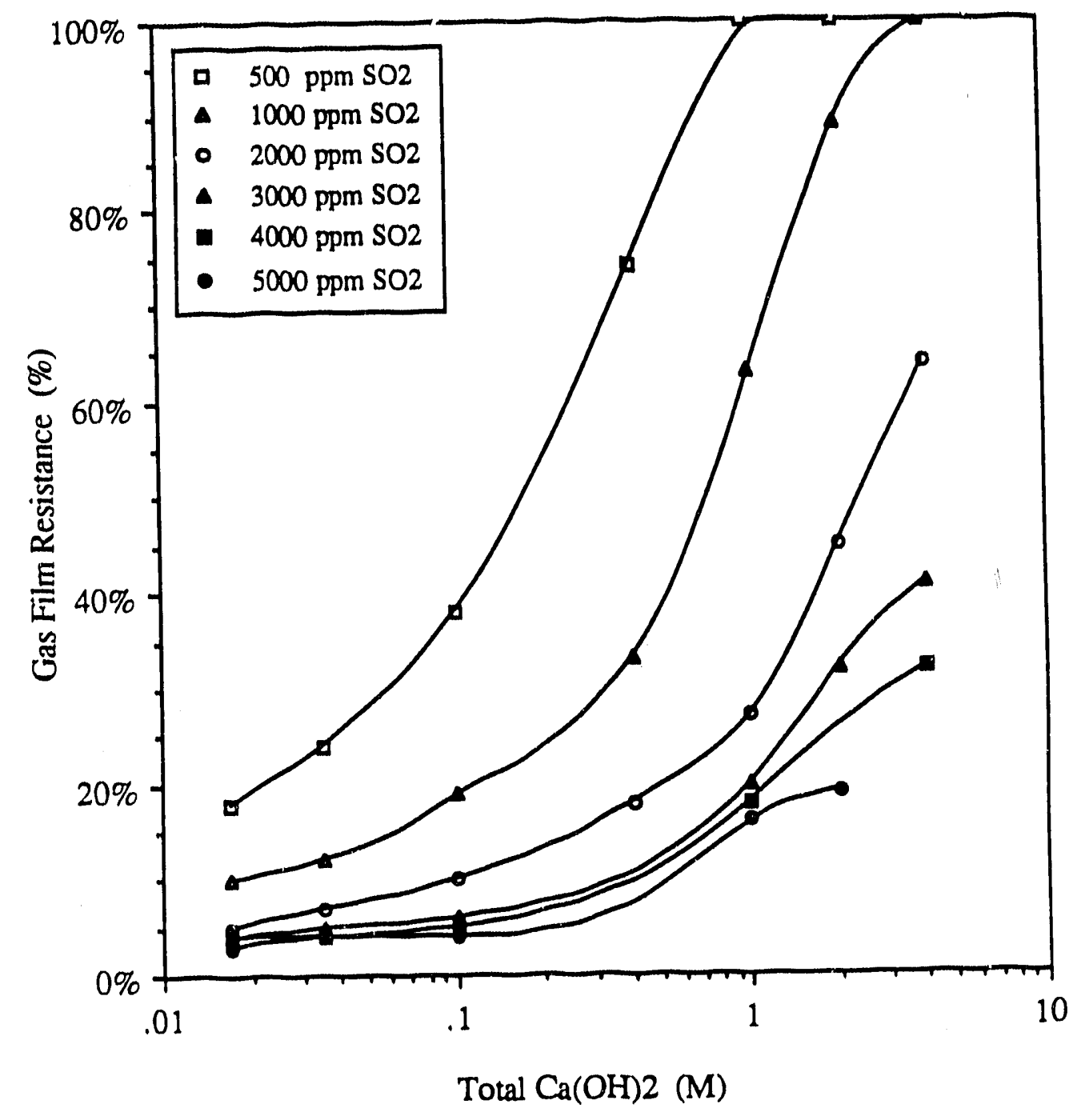

Figure 5-13. Effect of $\mathrm{Ca}(\mathrm{OH})_{2}$ concentration in a slurry droplet on gas film resistance predicted by slurry absorption model ( $d_{\text {droplet }}=75 \mu \mathrm{m}, d_{p}=5 \mu \mathrm{m}, \theta=0.9 \mathrm{~s}$ ). 


\subsubsection{Alternate Interpretation of Slurry Absorption Model Data}

As previously discussed, the prediotions made by the slurry absorption model for the case of a droplet undergoing $\mathrm{SO}_{2}$ absorption must be considered carefully. Some key olements have not yet been considered in the model to allow direct use of the results. These key elements inolude such phenomenon as droplet drying and shrinking, and expression of the model in Cartesian coordinates.

However, the model results currently provide enough information to develop a less rigorous expression of $\mathrm{SO}_{2}$ absorption in a slurry ciroplet, that is not a funotion of the droplet geometry. In this way, the effects of droplet drying and shrinking, and coordinate system used do not compromise the results. One key assumption made to simplify the expression which is developed here, however, is that the solids in the slurry droplet are uniformly dispersed throughout the droplet. As in the rigorous slurry absorption model, this simplified expression assumes that the slurry droplet is stagnant and does not circulate.

To begin this analysis, consider the spherical droplet in Figure 5-14. As the $\mathrm{Ca}(\mathrm{OH})_{2}$ is depleted by reaction, the reaction front of the droplet changes from $r_{1}$ to $r_{2}$. As absorption progresses, there will bo : change in the total dissolved sulfur, denoted $\Delta[S(I V)] . \mathrm{Ca}(\mathrm{OH})_{2}$ remains dispersed in the shrinking core of the droplet.

Gas and liquid film absomtion rate expressions were given as equations (2-1) and (2-2). These rate expressions are listed below in a slightly different form, expressing the gas and liquid film coefficients in terms of gas and liquid diffusivities of $\mathrm{SO}_{2}$ and of penetration distance. Equation (5-5) assumes a pseudo-steady-state distribution of solution species giving an effective driving force of $\Delta[S(I V)]$

$$
N_{\mathrm{SO}_{2}}=\frac{D_{g} \Delta Y_{\mathrm{SO}_{2}} A}{\delta_{D}}
$$




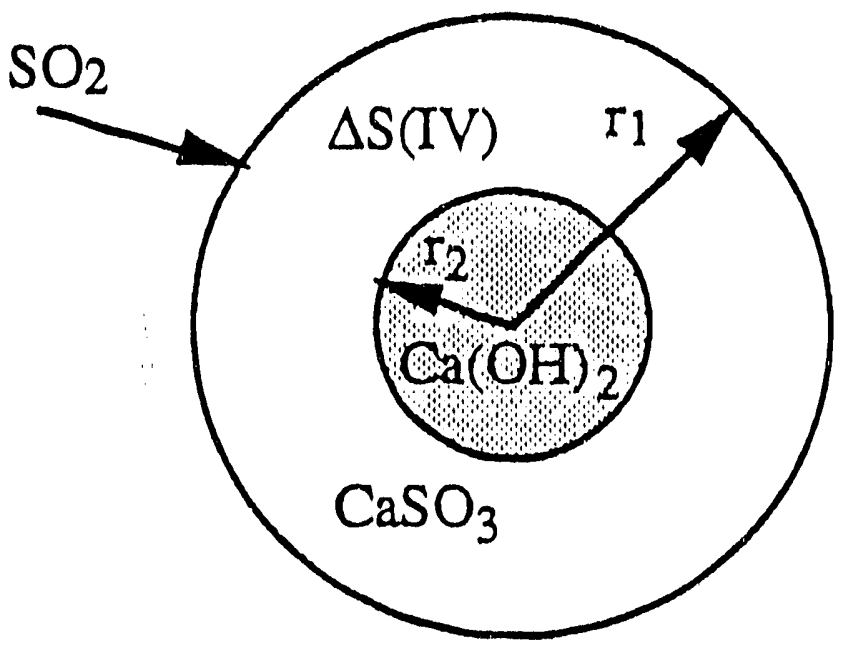

Figure 5-14. Spherical drop with shrinking core of $\mathrm{Ca}(\mathrm{OH})_{2}$. 


$$
N_{S O_{2}}=\frac{D_{1} \Delta[S(I V)] A}{\delta_{D}}
$$

Gas phase mass transfer occurs at the droplet surtace denoted by $r_{1}$. The llquld phase mass transfer occurs at the changing reaction front between $r_{1}$ and $r_{2}$. Thus, the area and penetration distance can be defined in terms of $r_{1}$ and $r_{2}$, and the resulting expressions for absorption of $\mathrm{SO}_{2}$ would be:

$$
\begin{aligned}
N_{S O_{2}} & =\frac{D_{g} \Delta Y_{S O_{2}} 4 \pi r_{1}^{2}}{r_{1}} \\
N_{S O_{2}} & =\frac{D_{1} \Delta[S(I M)] 4 \pi r_{1} r_{2}}{r_{1}-r_{2}}
\end{aligned}
$$

During the absorption, these rates must be equal at all times. By setting them equal, the following expression results:

$$
\Delta Y=\frac{D_{1}}{D_{0}} \Delta[S I M] \frac{r_{1}}{r_{1}-r_{2}}
$$

A new term, $F$, is defined to be the volume traction of $\mathrm{Ca}(\mathrm{OH})_{2}$ remaining. It is equivalent to 1- (utllization of $\mathrm{Ca}(\mathrm{OH})_{2}$ ). As applied to the spherical droplet, $F$ is expressed as:

$$
F=\frac{4 / 3 \pi r_{2}^{3}}{4 / 3 \pi r_{1}^{3}}
$$

Therefore, 


$$
F^{1 / 3}=\frac{r_{2}}{r_{1}}
$$

Substituting this expression into equation (5-8), a new expression for the amount of gas film resistance is derived.

$$
\text { Gasflim resistance }=\frac{\Delta Y_{S O_{2}}}{Y_{g}}=\frac{D_{1} \Delta[S / M]}{D_{g} Y_{g}} \frac{F^{1 / 3}}{1-F^{i / 3}}
$$

This expression oan be used to estimate the gas film resistance in a slurry droplet for any given degree of utilization of $\mathrm{Ca}(\mathrm{OH})_{2}$. The only information which must be provided is the value of $D_{1}$ $\Delta[S(I V)]$, gas diffusivity, and bulk gas concentration. Notice that the geometry of the droplet is accounted for by the substitution of the term, $F$, the fraction of $\mathrm{Ca}(\mathrm{OH})_{2}$ remaining.

The diffusivity of $\mathrm{SO}_{2}$ in $\mathrm{N}_{2}$ was given in Section 3 as $0.6 \mathrm{~cm}^{2} / \mathrm{s}$. Expressed in the units required for this equation, $D_{g}=2.2 \times 10^{-8} \mathrm{~mole} / \mathrm{m} \mathrm{s} \mathrm{Pa}$. Values of $D \Delta[S(I V)]$ havo been taken from model runs at several slurry $\mathrm{Ca}(\mathrm{OH})_{2}$ concentrations and gas $\mathrm{SO}_{2}$ concentrations. The values of $\mathrm{DI}$ $\Delta[S(I V)]$ were easily calculated by noting that:

$$
\frac{D_{1} \Delta[S(M)] A}{\delta_{D}}=k_{g} \Delta Y_{S O_{2}} A
$$

And this defines $D_{1} \Delta[S(I V)]$ in terms of gas phase properties and the penetration distance as follows:

$$
D_{1} \Delta\left[S(M)=k_{g} \Delta Y_{S O_{2}} \delta_{D}\right.
$$

The model provided the necessary gas phase concentrations and penetration distances to calculate the values of $D_{1} \Delta[S(I V)]$ shown in Figure 5-15. These are shown as a function of $\mathrm{PSO}_{2} l_{\text {, as }}$ 


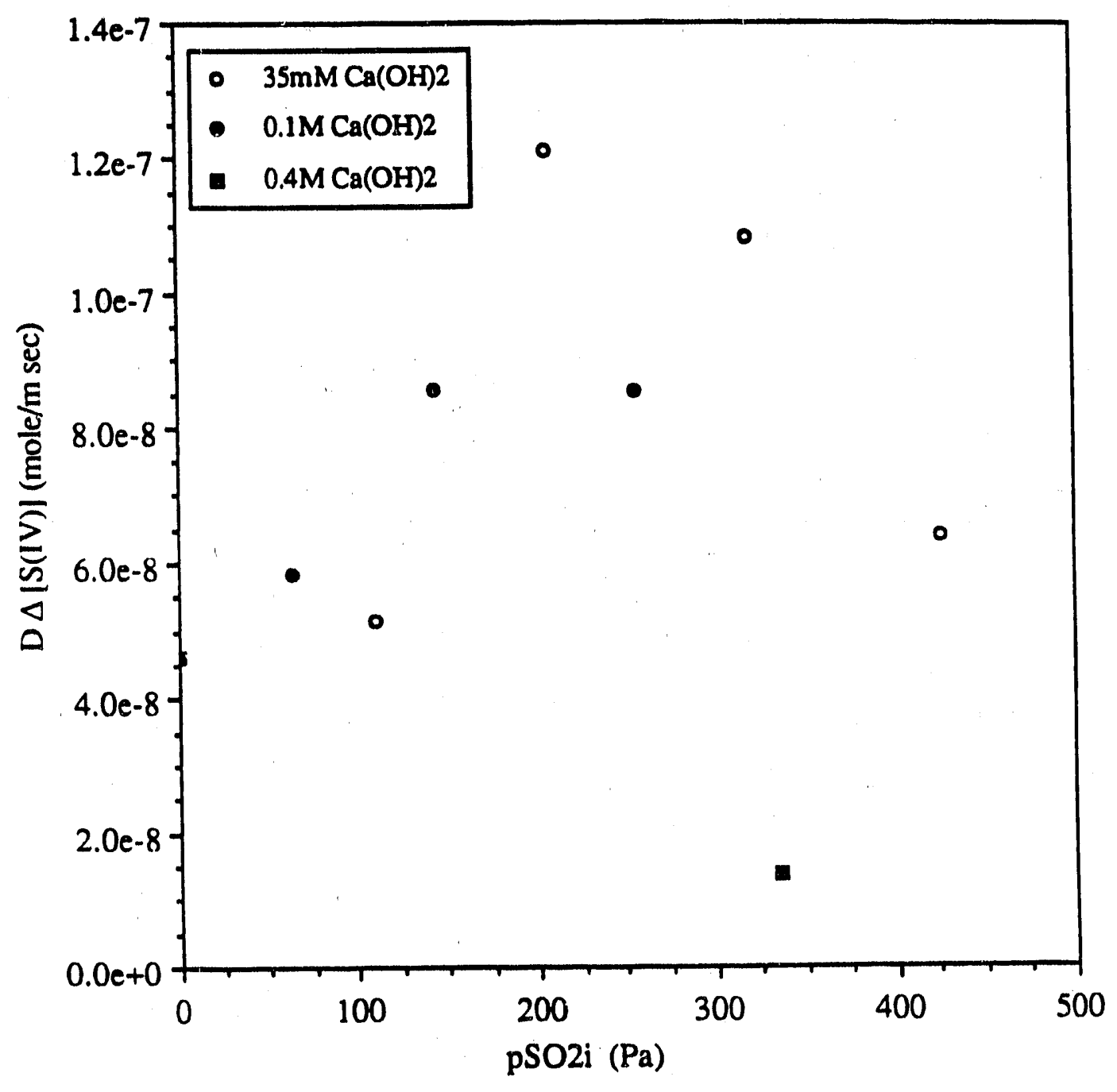

Figu'e 5-15. Values of DI $\Delta[S(I V)]$ derived from the slurry absorption model. 
well as concentration of $\mathrm{Ca}(\mathrm{OH})_{2}$ in the slurry. It does nol appear that $D_{1} \Delta[S(I V)]$ depends on the bulk gas $\mathrm{SO}_{2}$ concentration or on the slurry solids concentration.

An average value of $D_{1} \Delta[S(I V)]$ for this series of model nuns is $7.0 \times 10^{-8} \mathrm{~mole} / \mathrm{m}$ sec. Liaing this value, a general relationship for the average gas film resistance can be made in terms of utllization of $\mathrm{Ca}(\mathrm{OH})_{2}$ and bulk $\mathrm{SO}_{2}$ concentration.

$$
\text { Gasfilmresistance }(\%)=\frac{12.8 \mathrm{~Pa}}{P_{\mathrm{SO}}} \frac{F^{1 / 3}}{1-F^{1 / 3}} \times 100
$$

Figure 5-16 shows the relationship between gas film resistance and $\mathrm{Ca}(\mathrm{OH})_{2}$ utilization for several $\mathrm{SO}_{2}$ concentrations. The results show that the absorption of $\mathrm{SO}_{2}$ is primarily liquid film controlled at moderate to high levels of $\mathrm{Ca}(\mathrm{OH})_{2}$ utilization. This confirms the results determined by the slurry absorption model that were previously shown in Figure 5-13. It should be remembered, however, that the model and the expression in equation (5-14) do not account for the change in $\mathrm{Ca}(\mathrm{OH})_{2}$ concentration in the slurry droplet that occurs when evaporation is considered. Higher degrees of gas film resistance would be expected when this phenomenon is included in the analysis.

\subsubsection{Effect of Varied $\mathrm{Ca}(\mathrm{OH})_{2}$ Reactivity}

Three slurries of $0.1 \mathrm{M} \mathrm{Ca}(\mathrm{OH})_{C}$ were prepared, each using a different source of $\mathrm{Ca}(\mathrm{OH})_{2}$, and absorption of $\mathrm{SO}_{2}$ was ineasured in each slumy. Entrancement factors from the first two experiments were compared but showed that little difference in enhancement was measured. This enabled comparison of further tests performed with Mississippi $\mathrm{Ca}(\mathrm{OH})_{2}$ to those performed with reagent grade $\mathrm{Ca}(\mathrm{OH})_{2}$ since the two sources of $\mathrm{Ca}(\mathrm{OH})_{2}$ showed the same reactivity toward $\mathrm{SO}_{2}$. Another test using freshiy slaked Mississippi lime slurry at a concentration of $0.1 \mathrm{M} \mathrm{Ca}(\mathrm{OH})_{2}$ was run, but also showed little difference in measured enhancement.

Reactivity of the threg $\mathrm{Ca}(\mathrm{OH})_{2}$ slurries was not quantified by any other measurements. Measurements of particle size and surface area are difficult to make on solids which are suspended in the slurry. Drying the slurry would yield agglomerated particles, which would not be representative of 


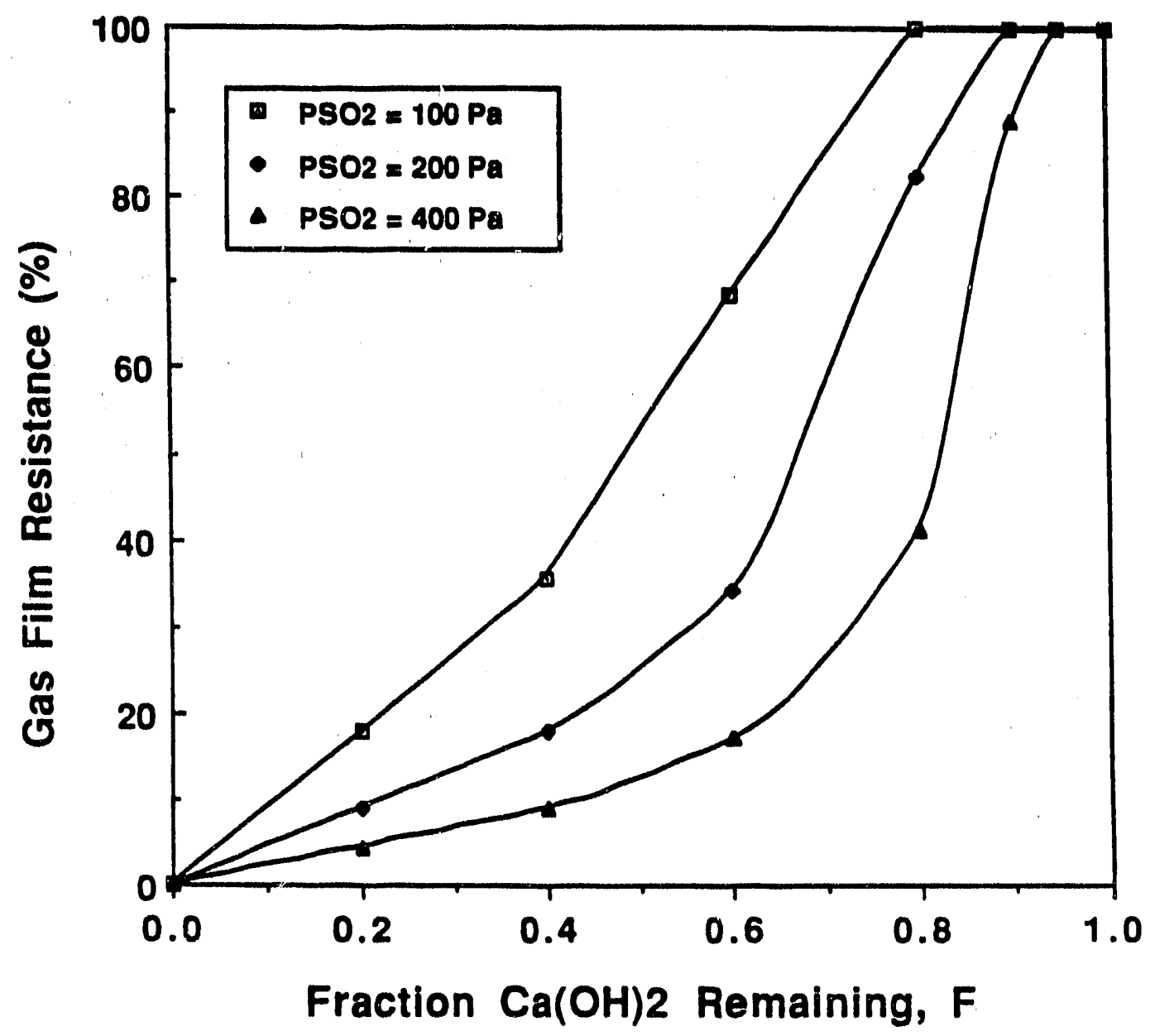

Figure 5-16. Gas film resistance as a function of $\mathrm{Ca}(\mathrm{OH})_{2}$ utilization: using $\mathrm{DI} \Delta[\mathrm{S}(\mathrm{IV})]=7.0 \times 10^{-8}$ $\mathrm{mole} / \mathrm{m} \mathrm{s}$ (equation 5-14). 
the particles as they exist in the slurry. Although properties of the particles in the three types of slurry were not measured, it is unlikely that all three types had very simllar particle sizes, surface areas, and other properties which influence reactivity toward $\mathrm{SO}_{2}$. It is more likely that enhancement, as measured in the stirred tank, is not very sensitive to changes in properties of $\mathrm{Ca}(\mathrm{OH})_{2}$ particles.

\subsubsection{Slurry Absorption Model Validation}

Only two inputs to the slurry absorption model determine the nature of the slurry: solids concentration and particle size. The remaining inputs to the model were assumed to be the same as for the $17 \mathrm{mM} \mathrm{Ca}(\mathrm{OH})_{2}$ solution. The stirred tank experimental results in $35 \mathrm{mM} \mathrm{Ca}(\mathrm{OH})_{2}$ slurry supported the use of a diffusivity of the hydroxide lon reduced to 40 percent, as suggested by clear solution experiments in $17 \mathrm{mM} \mathrm{Ca}(\mathrm{OH})_{2}$.

The model was run at conditions representing the stirred tank for the slurry concentrations of $35 \mathrm{mM}, 0.1 \mathrm{M} 0.4 \mathrm{M}$, and $1.0 \mathrm{M} \mathrm{Ca}(\mathrm{OH})_{2}$ using several particle sizes. Experimentally determined enhancement factors and those predicted by the model agreed well for the slurries of less than $0.1 \mathrm{M}$ $\mathrm{Ca}(\mathrm{OH})_{2}$. Assuming that a particle size on the order of 1 to $5 \mu \mathrm{m}$ is reasonable for $\mathrm{Ca}(\mathrm{OH})_{2}$ slurry, the model overpredicted the enhancement measured in the stirred tank with slurries containing over $0.1 \mathrm{M}$ $\mathrm{Ca}(\mathrm{OH})_{2}$.

Experimental results showed that the amount of enhancement attributed to adding inore solids appeared to diminish as the slurry solids concentration was increased. In other words, the increases in enhancement were not proportional to the additional amount of solids added. The slurry absorption model predicted this behavior also, but it predicted that the slurries should have been more reactive than the results of the stirred tank experiments indicated. One explanation for this discrepancy is that solids may have been settling out of the boundary layer during experiments. Enhancement measured in the stirred tank would then be low as solids content was increased, since the model does not account for this behavior. It is currently not known whether solids settling influences absorption in slurry droplets. 
In many cases, the model predicted that changes in particle size produced only minor differences in the enhancement factor. Changing the particle size from 1 to $5 \mu \mathrm{m}$ showed little effect on enhancement for slumies of $35 \mathrm{mM}, 0.1 \mathrm{M}$ and $0.4 \mathrm{M} \mathrm{Ca}(\mathrm{OH})_{2}$. This appears to confirm that such changes in particle size or surface area may have little effect on the enhancemert factor. This supports the conclusions drawn eartier from the comparison of the three types of $\mathrm{Ca}(\mathrm{OH})_{2}$ studied. 


\section{SECTION 6 \\ COMPUTER MODELING}

\subsection{MODEL}

The model includes three rate phenomena which all depend on the solution composition:

- Dissolution of $\mathrm{Ca}(\mathrm{OH})_{2}$

- Crystallization of $\mathrm{CaSO}_{3}$

- Absorption of $\mathrm{SO}_{2}$

These rates cannot be separated from each other. To calculate the dissolution rate and the crystallization rate, we need the bulk solution composition which depends on the amount oi absorbed $\mathrm{SO}_{2}$ and vice versa.

\subsubsection{Equilibria}

The model assumes instantaneous equilibrium of the species $\mathrm{H}^{+}, \mathrm{H}_{2} \mathrm{O}, \mathrm{OH}^{-}, \mathrm{SO}_{2}, \mathrm{HSO}_{3}^{-}$and $\mathrm{SO}_{3}{ }^{2-}$. This assuription gives the following equilibria which apply throughout the liquid.

$$
\begin{aligned}
& K_{1}=\frac{a_{H^{+}} a_{H S O_{3}^{-}}}{a_{S_{2}}} \\
& K_{2}=\frac{a_{H^{*}} a_{S O_{3}^{2-}}}{a_{H_{S O}^{-}}} \\
& K_{I V}=a_{H^{+}} a_{\mathrm{OH}^{-}}
\end{aligned}
$$


The liquid is saturated with $\mathrm{SO}_{2}$ at the gas liquid interface.

$$
H=\frac{P_{\mathrm{SO}_{2}}}{a_{\mathrm{SO}_{2}}}
$$

The mudel takes into account two ion pairs $\mathrm{CaOH}^{+}$and $\mathrm{CaSO}_{3}{ }^{\circ}$.

$$
\begin{aligned}
& K_{\mathrm{CaOH}^{+}}=\frac{{ }^{a} \mathrm{Ca}^{2+} a_{\mathrm{OH}^{-}}}{a_{\mathrm{CaOH}^{+}}} \\
& K_{\mathrm{CaSO}_{3}^{0}}=\frac{{ }^{a} \mathrm{Ca}^{2+} a_{\mathrm{SO}_{3}^{2-}}}{{ }^{a} \mathrm{CaSO}_{3}}
\end{aligned}
$$

At the $\mathrm{Ca}(\mathrm{OH})_{2}$ surface the following equilibria is assumed to be valid:

$$
K_{\mathrm{spCa}(\mathrm{OH})_{2}}=a_{\mathrm{Ca}^{2}}+a_{\mathrm{OH}^{-}}^{2}
$$

The solubility product of calcium sulfite is equal to:

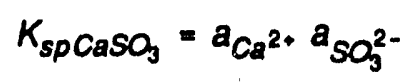

Equilibrium constants, activity coefficients and the initial bulk concentrations of the slumy are calculated by the Bechtel Modified Radian Equilibrium Program, BMREQ (Epstein, 1975; Lowell et al., 1970). The BMREQ program is only called once as the equilibrium constants and activity coefficients are assumed to be approximately constant throughout the absorption process.

\subsection{2 $\mathrm{Ca}(\mathrm{OH})_{2}$ Dissolution}

The $\mathrm{Ca}(\mathrm{OH})_{2}$ dissolution rate is calculated by steady state mass transfer theory. The $\mathrm{Ca}(\mathrm{OH})_{2}$ particles are assumed as spherical particles in an infinite stagnant solution. We also assume the electrical potential gradient to be very small so the diffusion constants are constant. The differential 
material balance for total calcium at steady state in spherical coordinates gives, if it is assumed that there is no precipitation of calcium sulfite in the liquid film:

$$
\sum_{i=1}^{3}-D_{i} \frac{\partial}{\partial r}\left[r^{2} \frac{\partial C l}{\partial r}\right]=0 \quad i=\mathrm{Ca}^{2+}, \mathrm{CaOH}^{+}, \mathrm{CaSO}_{3}^{0}
$$

Similar material balances can be set up for the sum of S(IV) species and for the charge. The net production of $\mathrm{S}(\mathrm{IV})$ is zero if there is no precipitation of $\mathrm{CaSO}_{3}$, and it is also assumed that the net production of charge is equal to zero. Substituting $y=d / 2 r$, where $d$ is the particle diameter and $r$ is the distance from the center of the sphere, transforms the niaterial balances into very simple differential equations. The differential material balances for total calcium, S(IV) species and for the charge can easily be integrated to the following expressions:

$$
\begin{gathered}
D_{\mathrm{Ca}^{2}+} C_{\mathrm{Ca}^{2+}}+D_{\mathrm{CaOH}^{+}} C_{\mathrm{CaOH}^{+}}+D_{\mathrm{CaSO}_{3}^{\circ}} C_{\mathrm{CaSO}_{3}^{\circ}}=\alpha_{1}+\beta_{1} y \\
D_{\mathrm{SO}_{2}} C_{\mathrm{SO}_{2}}+D_{\mathrm{HSO}_{3}^{-}} C_{\mathrm{HSO}_{3}^{-}}+D_{\mathrm{SO}_{3}^{2-}} C_{\mathrm{SO}_{3}^{2-}}+D_{\mathrm{CaSO}_{3}} C_{\mathrm{CaSO}_{3}}=\alpha_{2}+\beta_{2} y \\
2 \mathrm{D}_{\mathrm{Ca}^{2+}} C_{\mathrm{Ca}^{2+}}+D_{\mathrm{CaOH}^{+}} C_{\mathrm{CaOH}^{+}}+D_{\mathrm{H}^{+}} C_{\mathrm{H}^{+}}-D_{\mathrm{OH}^{-}} C_{\mathrm{OH}^{-}} \\
-D_{\mathrm{HSO}_{3}^{-}} C_{\mathrm{HSO}_{3}^{-}}-2 D_{\mathrm{SO}_{3}^{2-}} C_{\mathrm{SO}_{3}^{2-}-D_{\mathrm{C}^{-}}-C_{\mathrm{Cl}^{-}}}=\alpha_{3}+\beta_{3} y
\end{gathered}
$$

where $\alpha_{1}$ and $\beta_{1}$ are integration constants

There is no flux of S(IV) species and the flux of charge is equal to zero since the electrical gradient is assumed to be negligible. Constants $\beta_{2}$ and $\beta_{3}$ are therefore also equal to zero. Constants $\alpha_{1}, \alpha_{2}$ and $\alpha_{3}$ are calculated from the boundary conditions in the liquid bulk. When $\alpha_{1}, \alpha_{2}$ and $\alpha_{3}$ are determined, the constant $\beta_{1}$ can be calculated from the boundary condition at the $\mathrm{Ca}(\mathrm{OH})_{2}$ surface by assuming equation (6-7) to be valid, giving the following equations: 


$$
\begin{aligned}
& \beta_{1}=\sum_{i=1}^{3} D_{i}\left(C_{i s}-C_{i b}\right)=D \Delta C \quad i=\mathrm{Ca}^{2+}, \mathrm{CaOH}^{+}, \mathrm{CaSO}_{3}^{\circ} \\
& \sum_{i=1}^{4} D_{i} C_{i}=\sum_{i=1}^{4} D_{i} C_{i b} \quad i=\mathrm{SO}_{2}, \mathrm{HSO}_{3}^{-}, \mathrm{SO}_{3}^{2-}, \mathrm{CaSO}_{3}^{0} \\
& \sum_{i=1}^{n} z_{i} D_{i} C_{i}=\sum_{i=1}^{n} z_{i} D_{i} C_{i b} \quad n=\text { all species present }
\end{aligned}
$$

where index $s$ refers to the $\mathrm{Ca}(\mathrm{OH})_{2}$ surface and index $b$ refers to the liquid bulk.

These equations nuake it possible to calculate the flux of total calcium, 2D $\Delta \mathrm{C} / \mathrm{d}\left(\mathrm{mol} / \mathrm{m}^{2} \mathrm{~s}\right)$, from given bulk concentrations and equation (6-7). The dissolution rate from one sphere can be written as $2 \pi \mathrm{dD} \Delta \mathrm{C}$ (mol/s). Due to the dissolution of $\mathrm{Ca}(\mathrm{OH})_{2}$, the volume of the $\mathrm{Ca}(\mathrm{OH})_{2}$ particles will decrease. The dissolution rate is thus time dependent since the mass transfer area of $\mathrm{Ca}(\mathrm{OH})_{2}$ decreases with time.

$$
\begin{gathered}
-\frac{d V}{d t}=\frac{2 \pi d}{\rho_{m}} D \Delta C \\
V(t)=V_{0}\left(1-\frac{8}{d_{0}^{2} \rho_{m}} \int_{0}^{t} D \Delta C(t) d t\right)^{1.5}
\end{gathered}
$$

where $V_{0}$ is the initial volume of the spheres with diameter $d_{0}\left(m^{3}\right)$ and $\rho_{m}$ is the molar density of $\mathrm{Ca}(\mathrm{OH})_{2}\left(\mathrm{~mol} / \mathrm{m}^{3}\right)$

For a polydisperse size distribution, where $\varnothing_{j}$ is the fraction of total initial particle volume with initial diameters from $d_{j}$ to $d_{j+1}$, the change in total volume is: 


$$
V_{\text {tot }}(t)=V_{\text {tot }} \sum_{j=1}^{N}\left[\varnothing_{j}\left(1-\frac{8}{\rho_{m}} \frac{1}{d_{j} d_{j+1}} \int_{0}^{t} D \Delta C(x, t) d t\right)^{1.5}\right]
$$

The consumption of hydroxide lons is not uniform through the slurry during the $\mathrm{SO}_{2}$ absorption. Near the gas-liquid interface, the concentration of $\mathrm{Ca}(\mathrm{OH})_{2}$ decreases quickly, whereas closer to the liquid bulk where the $\mathrm{pH}$ still is high the concentration of $\mathrm{Ca}(\mathrm{OH})_{2}$ decreases slowly. The dissolution rate is thus dependent on both time, $t$, and the distance, $x$, from the glas liquid interface.

$$
\begin{aligned}
& R_{d}(x, t)=\frac{\rho_{m}}{V_{s / u m y}} \frac{d V_{\text {tot }}}{d t} \\
& R_{d}(x, t)=\frac{12 C_{0}}{\rho_{m}} D \Delta C(x, t) \sum_{j=1}^{N}\left[\varnothing_{j} \frac{1}{d_{j} d_{j+1}}\left(1-\frac{8}{\rho_{m}} \frac{1}{d_{j} d_{j+1}} \int_{0}^{1} D \Delta C(x, t) d t\right)^{0.5]}\right. \\
& C_{0}=\rho_{m} \frac{V_{\text {tot }}}{V_{\text {slumy }}}
\end{aligned}
$$

where $R_{d}(x, t)$ is the dissolution rate and $\left(\mathrm{mol} / \mathrm{m}^{3} \mathrm{~s}\right)$ and $\mathrm{C}_{0}$ is the initial molar concentration of $\mathrm{Ca}(\mathrm{OH})_{2}$ $\left(\mathrm{mol} / \mathrm{m}^{3}\right)$.

\subsection{3 $\mathrm{CaSO}_{3}$ Crystallization}

Calcium sulfite will precipitate in the liquid film during the absorption. The supersaturation of $\mathrm{CaSO}_{3}, \mathrm{RS}_{\mathrm{CaSO}}$, is defined as:

$$
R S_{\mathrm{CaSO}_{3}}=\frac{a_{\mathrm{Ca}^{2}}+a_{\mathrm{SO}_{3}^{2-}}}{K_{s p} \mathrm{CaSO}_{3}}
$$


If the magnitude of the supersaturation is below unity, calcium sulfite will dissolve instead of preciphate. The crystallization/dissolution rate, $R_{c}$ can be written as a function of the supersaturation of $\mathrm{CaSO}_{3}$ (Tseng and Rochelle, 1986; Gleason and Rochelle, 1987):

$$
R_{0}=1.6210^{-1} \exp (-5153 / T)\left(R S_{\mathrm{CaSO}_{3}}-1\right)^{n} A / R S_{\mathrm{CaSO}_{4}} \quad\left(\mathrm{~mol} / \mathrm{m}^{3} \mathrm{~s}\right)
$$

where $A$ is the BET surface area of calcium sulfite per volume slurry.

Tseng and Rochelle found the crystallization rate to be second order relative to the supersaturation of $\mathrm{CaSO}_{3}, n=2$. Gleason and Rochelle (1987) found the reaction order to be 3 instead of 2. The cubic dependence was especially significant for high supersaturations. In this modeling work the exponent 3 was chosen because of high supersaturations of calcium sulfite near the gas-liquid interface during the absorption process. From Gleason's data, the rate constant should be approximately the same even though the reaction order in Tseng's equation is changed from 2 to 3. The value of the supersaturation of calcium sulfate is set at 0.025 . The BET surface area of calcium sulfite is assumed to be $10 \mathrm{~m}^{2} / \mathrm{g}$. The total area of calcium sulfite per volume of slurry is calculated from the following equation:

$$
A=10 \bar{M}_{\mathrm{CaSO}_{3}} C_{\mathrm{CaSO}_{3}} \quad\left(\mathrm{~m}^{2} / \mathrm{m}^{3}\right)
$$

where $\overline{\mathrm{M}}_{\mathrm{CaSO}}$, is the molar weight for $\mathrm{CaSO}_{3}, 120 \mathrm{~g} / \mathrm{mol}$.

The crystallization rate, $R_{c}$, is in the same way as the dissolution rate of $\mathrm{Ca}(\mathrm{OH})_{2}$ a function of both time, $t$, and the distance, $x$, from the gas liquid interface.

\section{$6.1 .4 \mathrm{SO}_{2}$ Absorntion}

The absorption of $\mathrm{SO}_{2}$ is modeled with the penetration model, which assumes that liquid elements rise from the turbulent bulk liquid up to the gas liquid interface, where the elements are exposed for the same length of time, $\theta$, before being replaced by liquid of the bulk composition. Initially, the concentration of dissolved gas in the liquid element is uniform, $C_{0}$, and, internally, the element is considered to be stagnant. When the element is exposed to the gas at the surface, the 
concentration in the liquid at the gas-liquid interface is $C_{j}$, which is the equilibrium solubility of the gas in the liquid. During the time $\theta$, the liquid element is subject to unsteady-state diffusion of solute in the $x$ direction (Danckwerts, 1970, Treybal, 1980).

The unsteady state material balance for each species is:

$$
\begin{gathered}
\frac{\partial C_{l}}{\partial t}=-\nabla d_{1}+r_{i} \\
J_{l}=z_{i} D_{1} \frac{F}{R T} C_{1} \nabla \varnothing-D_{i} \nabla C_{l}
\end{gathered}
$$

where $\nabla$ is the first spatial derivative and $j_{j}$ is the flux. The flux consists of two terms, one due to an electrical potential gradient, $\nabla F$, and the other due to a concentration gradient, $\nabla C$. The electrical potential gradient can be calculated by assuming the total flux of charge being equal to zero (Glasscock, 1988).

$$
\nabla \varnothing=\frac{R T}{F} \frac{\sum_{i=1}^{n} z_{i} D_{i} \nabla C_{i}}{\sum_{i=1}^{n} z_{i}^{2} D_{i} C_{i}} \quad n=\text { all species present }
$$

All the material balances with S(IV) species are combined to one differential equation, and all the material balances involving calcium species are combined. By doing this, we do not have to use rate constants fixed at arbitrarily high values for the equilibrium reactions.

$$
\begin{gathered}
\frac{\partial C_{\text {SIM }}}{\partial t}=\sum_{i=1}^{4}\left(D_{i} \nabla^{2} C_{i}-z_{i} D_{i} \frac{F}{R T} \nabla\left(C_{i} \nabla \varnothing\right)\right)-R_{d}(x, \eta) \\
i=S_{2}, \mathrm{HSO}_{3}^{-}, \mathrm{SO}_{3}^{2-}, \mathrm{CaSO}_{3}^{\circ} \\
\frac{\partial C_{\mathrm{Ca} \text { IOt }}}{\partial t}=\sum_{i=1}^{3}\left(\begin{array}{c}
\left.D_{i} \nabla^{2} C_{i}-z_{i} D_{i} \frac{F}{R T} \nabla\left(C_{i} \nabla \varnothing\right)\right)-R_{d}(x, t)+R_{d}(x, t) \\
i=\mathrm{Ca}^{2+}, \mathrm{CaOH}^{+}, \mathrm{CaSO}_{3}^{\circ}
\end{array}\right.
\end{gathered}
$$




$$
\frac{\partial C_{C l}}{\partial t}=D_{C l} \nabla^{2} C_{C l}+D_{C l} \frac{F}{R T} \nabla\left(C_{C l} \nabla \varnothing\right)
$$

This way of treating the problem is more advantageous because it reduces the number of differential equations to be solved. The concentration profiles of $S(I V)$ and total calcium can be treated more effectively than, for example, the concentration profile of hydrogen lon. The hydrogen ion concentration profile is very steep at some points in the liquid film and flat at other regions, depending on the buffering species present, whereas the S(IV) and total calcium profiles should have a constant gradient. Individual concentrations can be calculated from the S(IV), total calcium, chloride concentrations and by assuming the sum of charge to be equal to zero. Dive to the unsteady-state absorption, the interfacial concentration of $\mathrm{SO}_{2}$ will not be constant even though the partial pressure of $\mathrm{SO}_{2}$ in the gas bulk is constant. The absorption rate of $\mathrm{SO}_{2}$ is equal to the sum of $\mathrm{S}$ (IV) fluxes at the gas liquid interface. This must also be equal to the flux of $\mathrm{SO}_{2}$ in the gas filrn.

$$
\begin{gathered}
N_{S_{2}}=J_{S I M} \\
k_{g}\left(P_{S O_{2}}-P_{S O_{21}}\right)=\sum_{i=1}^{4}\left(z_{i} D_{i} \frac{F}{R T} C_{i} \nabla \varnothing-D_{i} \nabla C_{i}\right) \\
i=\mathrm{SO}_{2}, \mathrm{HSO}_{3}^{-}, \mathrm{SO}_{3}^{2-}, \mathrm{CaSO}_{3}^{\circ}
\end{gathered}
$$

The flux of calcium and chloride must be equal to zero at the gas liquid interface.

$$
\begin{gathered}
0=\sum_{i=1}^{3}\left(z_{i} D_{i} \frac{F}{R T} C_{i} \nabla \varnothing-D_{i} \nabla C_{i}\right) \quad i=\mathrm{Ca}^{2+}, \mathrm{CaOH}^{+}, \mathrm{CaSO}_{3}^{\circ} \\
0=-D_{C l} \frac{F}{R T} C_{C l} \nabla \varnothing-D_{C l} \nabla C_{C l}
\end{gathered}
$$

At $t=0$, when the liquid element is brought up to the interface the whole liquid element is assumed to be in equilibrium with a given $\mathrm{SO}_{2}$ loading. The initial conditions and the boundary conditions are accordingly: 


$$
\begin{gathered}
\text { is } x \geq 0 \\
C_{S(I V)}=C_{S(I V) 0} \\
C_{C a \text { tot }}=C_{C a \text { tot } 0} \\
C_{C I}=C_{C l 0} \\
x=0 \\
\text { flux of S(IV) - equation (37) } \\
\text { flux of Ca tot - equation (38) } \\
\text { flux of chloride - equation (39) } \\
x=\infty \quad C_{S(I V)}=C_{S(I V) 0} \\
C_{C a \text { tot }}=C_{C a \text { tot } 0} \\
C_{C I}=C_{C I 0}
\end{gathered}
$$

Index 0 refers to the initial slurry bulk conditions.

The absorption rate will vary with time. At the start when the liquid element is brought up to the surface, the absorption rate is large since the interfacial concentration of $\mathrm{SO}_{2}$ is small. As the absorption proceeds, the concentration of $\mathrm{SO}_{2}$ at the gas-liquid interface increases and the absorption rate decreases. The average absorption rate, which is what we measure from the stirred tank reactor experiments, is calculated from:

$$
\pi_{\mathrm{SO}_{2}}=\frac{1}{\theta} \int_{0}^{\theta} N_{\mathrm{SO}_{2}} d t
$$

where $\theta$ is the total contact time 


\subsubsection{Numerical Solution}

The computer code is wititen in FORTRAN 77 and is available both on a VAX computer and on a Cray computer. In onder to solve the differential equations that describe the absorption process, the dissolution rate of $\mathrm{Ca}(\mathrm{OH})_{2}, R_{d}$, and the crystallization rate of $\mathrm{CaSO}_{3}, \mathrm{R}_{c}$, need to be calculatet.

The dissolution rate is a function of the flux of total calcium from the $\mathrm{Ca}(\mathrm{OH})_{2}$ surface. The flux of total calcium is equal to the sum of concentration differences of the calcium species between the $\mathrm{Ca}(\mathrm{OH})_{2}$ surface and the bulk, multiplied with the diffusion constants, D $\Delta C$. D $\Delta C$ is calculated from equations (6-13) to (6-14) by using the equilibria equations $(6-1)$ to $(6-3)$ and assuming the liquid to he saturated with $\mathrm{Ca}(\mathrm{OH})_{2}$ at the $\mathrm{Ca}(\mathrm{OH})_{2}$ surface.

To solve the pquation system for the concentrations at the $\mathrm{Ca}(\mathrm{OH})_{2}$ surface, all the concentrations are expressed in the concentrations of hydrogen and sulfite, by using the equiliuria equations. That reduces the equation system down to two nonlinear equations, $f_{1}=0$ and $f_{2}=0$. These equations are solved iteratively according to the method of Gauss-Newton:

$$
\begin{aligned}
& f_{1}\left(C_{H^{+} N+1}, C_{S O_{3}^{2-N+1}}\right)=f_{1}\left(C_{H^{+} N}, C_{S O_{3}^{2-N}}\right)+\left(C_{H^{+} N+1}-C_{H^{+N}}\right)\left(\frac{\partial f_{1}}{\partial C_{H^{+}}}\right)_{N} \\
& +\left(C_{\mathrm{SO}_{3}^{2-N+1}}-C_{\mathrm{SO}_{3}^{2-N}}\right)\left(\frac{\partial f_{1}}{\partial C_{{S O_{3}^{2-}}^{2-}}}\right)_{N} \\
& f_{2}\left(C_{H^{+} N+1}, C_{S O_{3}^{2-N+1}}\right)=f_{2}\left(C_{H^{+} N}, c_{S O_{3}^{2-N}}\right)+\left(C_{H^{+} N+1}-C_{H^{+} N}\right)\left(\frac{\partial t_{2}}{\partial C_{H^{+}}}\right)_{N} \\
& +\left(C_{\mathrm{SO}_{3}^{2-N+1}}-C_{\mathrm{SO}_{3}^{2-N}}\right)\left(\frac{\partial f_{2}}{\partial C_{\mathrm{SO}_{3}^{2-}}}\right)_{N}
\end{aligned}
$$

The above equations can be rewritten accordingly: 


$$
\begin{aligned}
& C_{H^{+} N+1}\left(\frac{\partial f_{1}}{\partial C_{H^{+}}}\right)_{N}+C_{\mathrm{SO}_{3}^{2-N}+1}\left(\frac{\partial f_{1}}{\partial C_{S O_{3}^{2-}}}\right)_{N}=-f_{1}\left(C_{H^{+} N} \cdot C_{\mathrm{SO}_{3}^{2-N}}\right) \\
& +C_{H^{+} N}\left(\frac{\partial f_{1}}{\partial C_{H^{*}}}\right)_{N}+C_{\mathrm{SO}_{3}^{2-N}}\left(\frac{\partial f_{1}}{\partial C_{\mathrm{SO}_{3}^{2-}}}\right)_{N} \\
& C_{H^{+} N+1}\left(\frac{\partial f_{2}}{\partial C_{H^{+}}}\right)_{N}+C_{S O_{3}^{2-N+1}}\left(\frac{\partial f_{2}}{\partial C_{S O_{3}^{2-}}}\right)=-t_{2}\left(C_{H^{+} N}, C_{S O_{3}^{2-N}}\right) \\
& +C_{H^{+N}}\left(\frac{\partial f_{2}}{\partial C_{H^{*}}}\right)_{N}+C_{S O_{3}^{2-N}}\left(\frac{\partial f_{2}}{\partial C_{S O_{3}^{2-}}}\right)_{N}
\end{aligned}
$$

This is a linear equation system which is easily solved by Gauss-elimination. The difficult step is to choose suitable starting values of $\mathrm{C}_{\mathrm{H}^{+}}$, and $\mathrm{C}_{\mathrm{SO}_{3}}$, for the theration.

When $D \Delta C$ is determined, the dissolution rate is calculated from equation (6-20). Notice that $D \Delta C$ has to be calculated for every $(x, t)$. The dissolution rate is a function of both the actual $D \Delta C$ and $\mathrm{D} \Delta \mathrm{C}$ integrated from 0 to $\mathrm{t}$. The crystallization/dissolution rate of $\mathrm{CaSO}_{3}$ rate is calculated from equation (6-23). Equations (6-20), (6-23), the equilibrium equations, and the given initial and boundary conditions are needed to solve the differential equations (6-28) to (6-30). The coupled nonlinear differential equations are solved by using orthogonal collocation on finite elements in the spatial dimension (Finlayson, 1980).

Orthogonal collocation transforms the partial differential equations in $t$ and $x$ into ordinary differential equations in $\mathrm{t}$. Orthogonal collocation on finite elements involves division of the spatial region into suitable elements, smaller near the gas-liquid interface and larger near the liquid bulk. Each element is then divided into a number of collocation points.

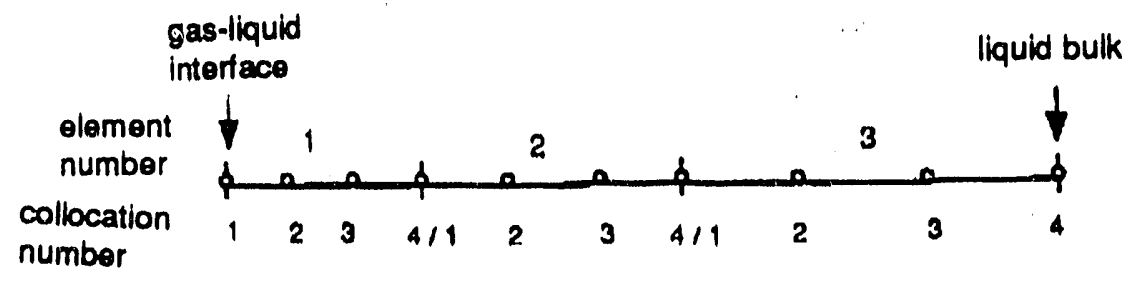


The first and the second spatial derivative at any of these collocation points can be expressed in terms of the value of the function at the collocation points in that epecific element. For example, the derivative of hydrogen bon is calculated as a polynomial of the hydrogen lon concentrations at the collocation points in that element.

$$
\begin{aligned}
& Y=A Y \\
& Y=B Y
\end{aligned}
$$

where A. and $B$ are $n \times n$ mairices with the coefficients in the collocation polynomials; $Y$ is a vector with the function values at the collocation points $\left(y_{1}, y_{2}, \ldots, y_{n}\right) ; Y^{\prime}$ and $Y^{\prime \prime}$ are vectors with the first and second derivatives at the collocation points $\left(y_{1}^{\prime}, y_{2}^{\prime}, \ldots, y_{n}^{\prime}\right)$ and $\left(y_{1}{ }^{\prime \prime}, y_{2}{ }^{\prime \prime}, \ldots, y_{n}{ }^{\prime \prime}\right)$

The coetticients in matrices $A$ and $B$ are calculated by a FORTRAN package DJACOBI. By introducing orthogonal collocation on finite elements the number of equations to be solved is increased, but PDE are transtormed to ODE which makes the equations much easier to solve. At the collocation points representing the gas-liquid interface and the liquid bulk, there are three equations respectively for the boundary conititions, and there are three ODE at the other collocation points that are not shared between two elements. At the collocation points that are in common for two elements, $C_{S(I V)}, C_{C a \text { tot }}$ and $\mathrm{C}_{\mathrm{Cl}}$ must have continuous derivatives.

$$
\left(\frac{\partial C_{i}}{\partial x}\right)_{x_{k}^{-}}=\left(\frac{\partial C_{i}}{\partial x}\right)_{x_{k}^{*}}
$$

This set of coupled ordinary differential algebraic equations is integrated through time by the FORTRAN package DDASSL.

Because the spatial region goes from zero to infinity, spatial transformation needs to be done. With the transformation suggested by Versteeg (1987), the calculation domain is restricted to the interval given by the penetration depth. 


$$
r=\operatorname{ert}\left(\frac{x}{\sqrt{4 D_{H^{+}} t}}\right)
$$

$$
\begin{aligned}
& x=0 \rightarrow r=0 \\
& x=\infty \rightarrow r=1
\end{aligned}
$$

This transformation has its origin in the analytical solution of the one-dimensional diffusion problem. The maximum diffusion coefficient (hydrogen) is chosen in the transformation. The time is transformed according to the following equation:

$$
\tau=\left(\frac{1}{\theta}\right)^{p .5}
$$

This transformation is especially helpful in the beginning of the integration when $t$ is very small. The concentration of all the individual species $\mathrm{H}^{+}, \mathrm{SO}_{2}, \mathrm{Ca}^{2+}$, etc. are calculated from the concentrations of $S$ (IV), total calcium, and chloride and by acsuming the sum of charge to be equal to zero. The equation system is reduced to two equations by expressing the concentrations in terms of hydrogen and sulfite. The nonlinear equation system is then solved Heratively according to the method of Gauss-Newton, described above.

Because of the spatial transformation, the collocation points are moving in space $(x)$ when $t$ is changing.

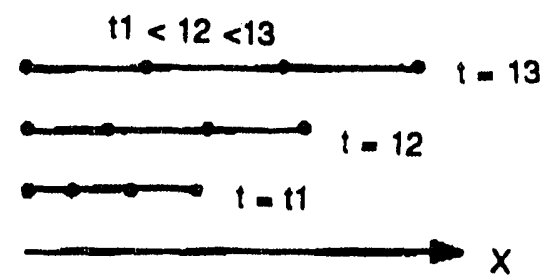


To calculate the dissolution rate of $\mathrm{Ca}(\mathrm{OH})_{2}$ at the collocation points for a different $t$ the value of the integral, $D \Delta C$ ot, must be estimated at the new $x$ points. This can be done with a spline interpolation or with a linear approximation from the values corresponding to the earlier $t$. Both methods have been tested and gave approximately the same result. The linear approximation was chosen to reduce the computer time. The integral, $D \Delta C$ of, is updated for each new time by the method of Euler. Euler is not the most accurate integration model, but since this integration is done at the same time as DDASSL is solving the differential Gquations, it is difficult to introduce a more sophisticated model. Updating of the concentration of $\mathrm{CaSO}_{3}(8)$ is done in a similar way. The gas film resistance is calculated as the average absorption rate divided by $k_{\mathrm{g}}$ and $\mathrm{P}_{\mathrm{SO}}$.

$$
\frac{\overline{\mathrm{SO}_{2}}}{k_{\mathrm{g}} P_{\mathrm{SO}_{2}}}=1-\frac{P_{\mathrm{SO}_{2}}}{P_{\mathrm{SO}_{2}}}
$$

The gas film resistance is thus a normalized flux which makes it possible for us to compare resuits for cases with different $\mathbf{P}_{\mathrm{SO}_{\mathbf{2}}}$ ancl different mass transfer coetficients. The gas film resistance is also a ratio between the average flux anj the maximum flux for that specific case. If the absorption is totally gas film controlled, the gas film resistance is equal to one, and the absorption rate can not further be increased by any chemical reaction in the absorbing liquid. A gas film resistance of 50 percent implies that, up to this point, the slumy has absorbed 50 percent of the amount that could have been absorbed if the process was totally gas film controlled.

The modeling results are often presented as a function of contact time. The contact time is the time the liquid element stays at the gas liquid interface before it is transported back to the liquid bulk and is related to the liquid mass transfer coefficient by the following equation based on the penetration theory.

$$
k_{l}=2 \sqrt{\frac{D_{1}}{\pi t}}
$$


Trie contact time can also be thought of as the contact time for a slumy droplet in a spray dryer if the droplet is considered to be siagnant.

Another variable, called the penetration distance, is used. This is the distance from the gas liquid Interface to the point where the concentration of $\mathrm{Ca}(\mathrm{OH})_{2}(\mathrm{~s})$ is half of the concentration of $\mathrm{Ca}(\mathrm{OH}))_{2}(\mathrm{~s})$ in the liquid bulk. This distance also defines the size of the liquid film since almost all the concentrations are maintained at the bulk conditions as long as $\mathrm{Ca}(\mathrm{OH})_{2}(\mathrm{~s})$ is present. The penetration distance is also a measure of the amount of consumed lime.

\subsubsection{Modeling Conditions}

Equilibrium constants, activity coefficients and the initial bulk concentrations of the slurry are calculated by the Bechtel Modified Radian Equilibrium Program, BMREQ (Epstein, 1975). The BMREQ program is only called once as the equilibrium constants and activity coefficients are assumed to be approximately constant throughout the absorption process.

For a given $\mathrm{pH}$ value, the program calculates the other concentrations assuming that the solution is in equilibrium with $\mathrm{Ca}(\mathrm{OH})_{2}(\mathrm{~s})$ and $\mathrm{CaSO}_{3}(\mathrm{~s})$. The chloride concentration is iterated until the charge balance is valid.

The slurry conditions for the modeling results are given in Tables 6-1 and 6-2. The bulk concentrations of the ions have been the same for all the modeling results presented in this report. The initial concentration of $\mathrm{CaSO}_{3}(\mathrm{~s})$ was also kept constant at $10 \mathrm{moVm}{ }^{3}$. The concentration of $\mathrm{Ca}(\mathrm{OH})_{2}(\mathrm{~s})$ was varied from 0 to $1,000 \mathrm{moV}^{3}$. The partial pressure of $\mathrm{SO}_{2}$ ranged from 500 to 5,000 ppm. The reactivity of $\mathrm{Ca}(\mathrm{OH})_{2}(\mathrm{~s})$ was varied by changing the particle size of $\mathrm{Ca}(\mathrm{OH})_{2}(\mathrm{~s})$ from 0.5 to $5 \mu \mathrm{m}$. Values of the equilibrium constants are listed in Table 6-3. The $\mathrm{K}_{\mathrm{Sp}}$ of $\mathrm{CaSO}_{3}$ was set at 55 percent of the BMREQ value.

During these calculations, two values of $\mathrm{k}_{\mathrm{g}}, 1.1 \times 10^{-3}$ and $1.1 \times 10^{-4} \mathrm{~mol} / \mathrm{m}^{2} \mathrm{~s} \mathrm{~Pa}$ have been used. These correspond to a slurry droplet size of 10 and $100 \mu \mathrm{m}$, respectively. The corresponding droplet size is calculated from a Sherwood number equal to two. 


$$
\frac{k_{c} d_{p}}{D}=2
$$

The above equation is valid for a slurry droplet when the droplet reaches the same velocity as the surrounding gas. In a spray dryer, the droplets reach the terminal velocity almost immediately. When the fluid around the droplet is stagnant, mass transfer occurs only by molecular diffusion, (Shenwood et al., 1975). The diffusivity of $\mathrm{SO}_{2}$ in a flue gas is $1.5 \times 10^{-5} \mathrm{~m}^{2} / \mathrm{s}$ (Jozewicz and Rochelle, 1984). The gas film coefficients $\left(k_{g}\right)$ corresponding to slurry droplets of $10 \mu \mathrm{m}$ and $100 \mu \mathrm{m}$ are $1.067 \mathrm{E}-3$ and 1.067E-4 mol/m² Pa s, respectively.

TABLE 6-1. TYPICAL BULK SOLUTION COMPOSITION AND ACTIVITY COEFFICIENTS

\begin{tabular}{|c|c|c|}
\hline Species & $\begin{array}{c}\text { Concentration } \\
(\text { mol/m })^{3}\end{array}$ & $\begin{array}{c}\text { Activity } \\
\text { Coefficient }\end{array}$ \\
\hline $\mathrm{H}^{+}$ & $0.3060 \mathrm{E}-8$ & 0.8457 \\
\hline $\mathrm{OH}^{-}$ & $0.34563-2$ & 0.8113 \\
\hline $\mathrm{SO}_{2}$ & $0.9219 \mathrm{E}-15$ & 1.0088 \\
\hline $\mathrm{HSO}_{3}{ }^{-}$ & $0.3171 \mathrm{E}-5$ & 0.8116 \\
\hline $\mathrm{SO}_{3}{ }^{-}$ & $0.9131 \mathrm{E}-1$ & 0.4340 \\
\hline $\mathrm{Ca}^{2+}$ & $0.1454 \mathrm{E}-2$ & 0.4449 \\
\hline $\mathrm{CaSO}_{3}{ }^{\circ}$ & 0.9058 & 1.0088 \\
\hline $\mathrm{CaOH}^{+}$ & $0.6414 \mathrm{E}-1$ & 0.8113 \\
\hline $\mathrm{Cl}^{-}$ & 0.7509 & 0.8068 \\
\hline $\mathrm{RS}_{\mathrm{CaOH} / 2}$ & & 1.0 \\
\hline $\mathrm{RS}_{\mathrm{CaSO}}$ & & 1.0 \\
\hline
\end{tabular}

TABLE 6-2. RANGE OF SLURRY CONDITIONS

\begin{tabular}{|c|c|}
\hline $\mathrm{Ca}(\mathrm{OH})_{2}(\mathrm{~s})$ & $0 \cdot 1,000 \mathrm{~mol} / \mathrm{m}^{3}$ \\
\hline $\mathrm{CaSO}_{3}(\mathrm{~s})$ & $10 \mathrm{~mol} / \mathrm{m}^{3}$ (always) \\
\hline $\mathrm{pm} \mathrm{Ca}(\mathrm{OH})_{2}$ & $0.135 \mathrm{E}-5 \mathrm{mil} / \mathrm{m}^{3}$ \\
\hline$d_{p}$ & $0.5-5 \mu \mathrm{m}$ \\
\hline
\end{tabular}


TABLE 6-3. EQUILIBRIUM CONSTANTS AT $55^{\circ} \mathrm{C}$

\begin{tabular}{|c|c|c|c||}
\hline & Activity Based & Concentration Based & Units \\
\hline Henry & 218 & 220.1 & $\mathrm{~Pa} \mathrm{~m} / \mathrm{mol}$ \\
\hline $\mathrm{KSO}_{2}$ & 7.17 & $1.053 \mathrm{E}-2$ & $\mathrm{molm}^{3}$ \\
\hline $\mathrm{KHSO}_{3}$ & $3.99 \mathrm{E}-5$ & $0.8813 \mathrm{E}-4$ & $\mathrm{molm}^{3}$ \\
\hline $\mathrm{KW}$ & $7.3 \mathrm{E}-8$ & $0.1058 \mathrm{E}-6$ & $\left(\mathrm{molm}^{3}\right)^{2}$ \\
\hline $\mathrm{KCaOH}$ & 34.86 & $0.7835 \mathrm{E}-2$ & $\mathrm{molm}^{3}$ \\
\hline $\mathrm{KCaSO}$ & 0.28 & $0.1466 \mathrm{E}-1$ & $\mathrm{~mol}_{3}$ \\
\hline $\mathrm{KSPCaSO}$ & $5.1 \mathrm{E}-3$ & $0.1328 \mathrm{E}-1$ & $\begin{array}{c}\left(\mathrm{mol} \mathrm{m}^{3}\right)^{2} \\
\text { BMREQ value }\end{array}$ \\
\hline $\mathrm{KSPCa}(\mathrm{OH})_{2}$ & 0.256 & $0.1735 \mathrm{E}-5$ & $\left(\mathrm{~mol} / \mathrm{m}^{3}\right)^{3}$ \\
\hline
\end{tabular}

\subsection{MODELING RESULTS}

\subsection{1 $\mathrm{Ca}(\mathrm{OH})_{2}$ Reactivity}

The reactivity of $\mathrm{Ca}(\mathrm{OH})_{2}$ has been altered by changing the particle size of the $\mathrm{Ca}(\mathrm{OH})_{2}$ particles in the slurry. The particle size ranged from $0.2 \mu \mathrm{m}$ to $5 \mu \mathrm{m}$. Figures 6-1 and 6-2 show how the gas film resistance varies with contact time for different $\mathrm{Ca}(\mathrm{OH})_{2}$ reactivities. In the modeling of the results in Figure 6-1, $k_{g}$ was set at a value corresponding to a $100 \mu \mathrm{m}$ slurry droplet. The corresponding droplet size for the results in Figure 6-2 is $10 \mu \mathrm{m}$.

Initially all the resistance to mass transfer is concentrated in the gas film since the concentration of $\mathrm{SO}_{2}$ in the liquid is approximately zero. During the absorption, hydrogen ions are produced and $\mathrm{Ca}(\mathrm{OH})_{2}$ dissolves to neutralize the formed hydrogen lons. If the dissolution of $\mathrm{Ca}(\mathrm{OH})_{2}$ is not fast enough or if the concentration of $\mathrm{Ca}(\mathrm{OH})_{2}$ approaches zero, the $\mathrm{pH}$ at the gas liquid interface decreases, and the gas film resistance decreases.

The dissolution rate of $\mathrm{Ca}(\mathrm{OH})_{2}$ increases with decreasing $\mathrm{pH}$ so the consumption of $\mathrm{Ca}(\mathrm{OH})_{2}$ will be largest close to the gas-liquid interface. Because of the nonuniform consumption of $\mathrm{Ca}(\mathrm{OH})_{2}, a$ concentration profile of $\mathrm{Ca}(\mathrm{OH})_{2}$ is formed. When the concentration of $\mathrm{Ca}(\mathrm{OH})_{2}$ close to the gas liquid interface eventually becomes zero, calcium lons have to be transported from the region where $\mathrm{Ca}(\mathrm{OH})_{2}$ 


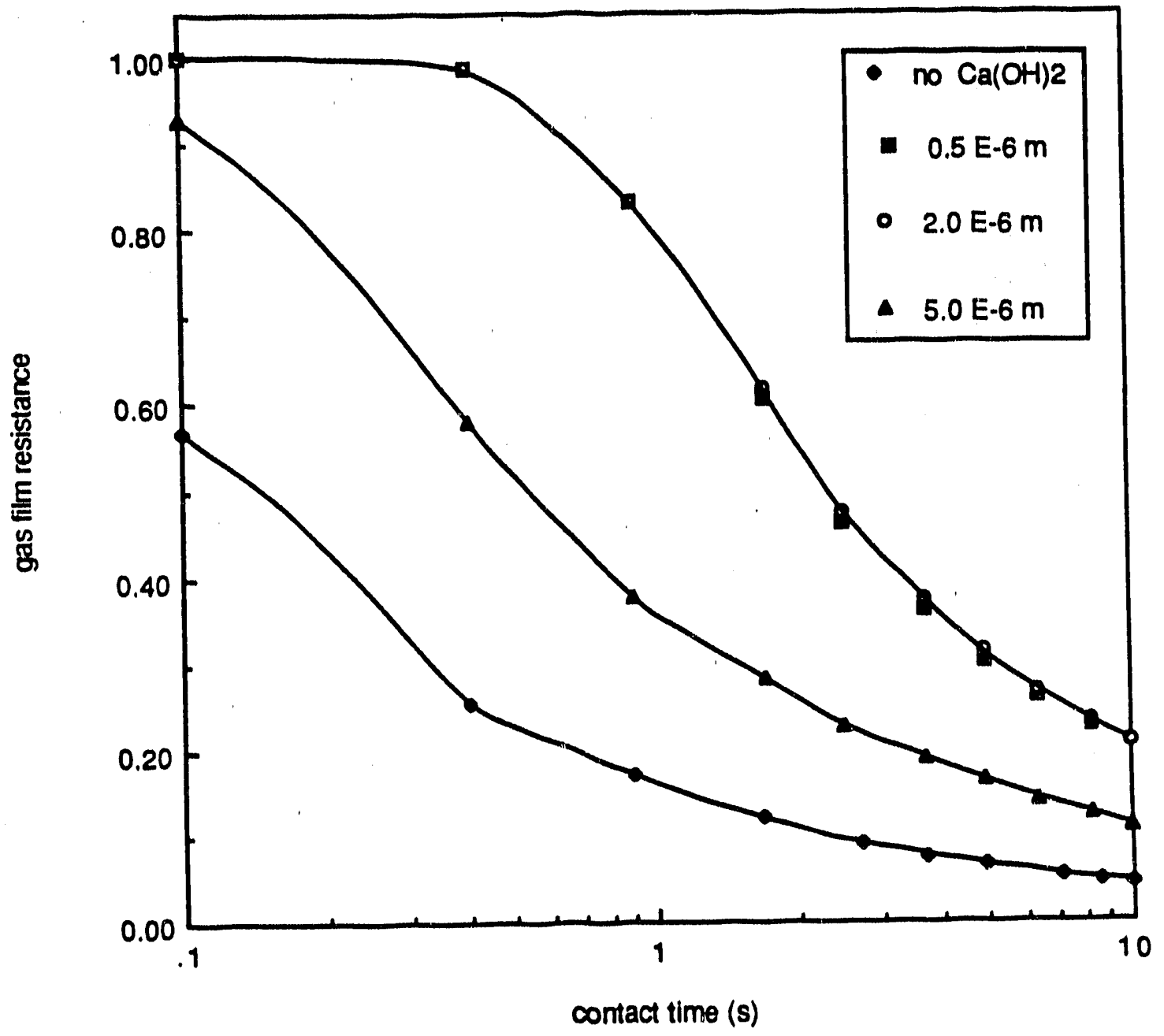

Figure 6-1. The gas film resistance versus the contact time. The different curves correspond to different particle sizes of $\mathrm{Ca}(\mathrm{OH})_{2}, 200 \mathrm{~Pa} \mathrm{SO}_{2}, \mathrm{O}$ and $200 \mathrm{molm} \mathrm{m}^{3} \mathrm{Ca}(\mathrm{OH})_{2}, 100 \mu \mathrm{m}$ droplet, $0.5-5.0 \mu \mathrm{m} \mathrm{Ca}(\mathrm{OH})_{2} ; 0.1-10 \mathrm{~s}$ contact time. 


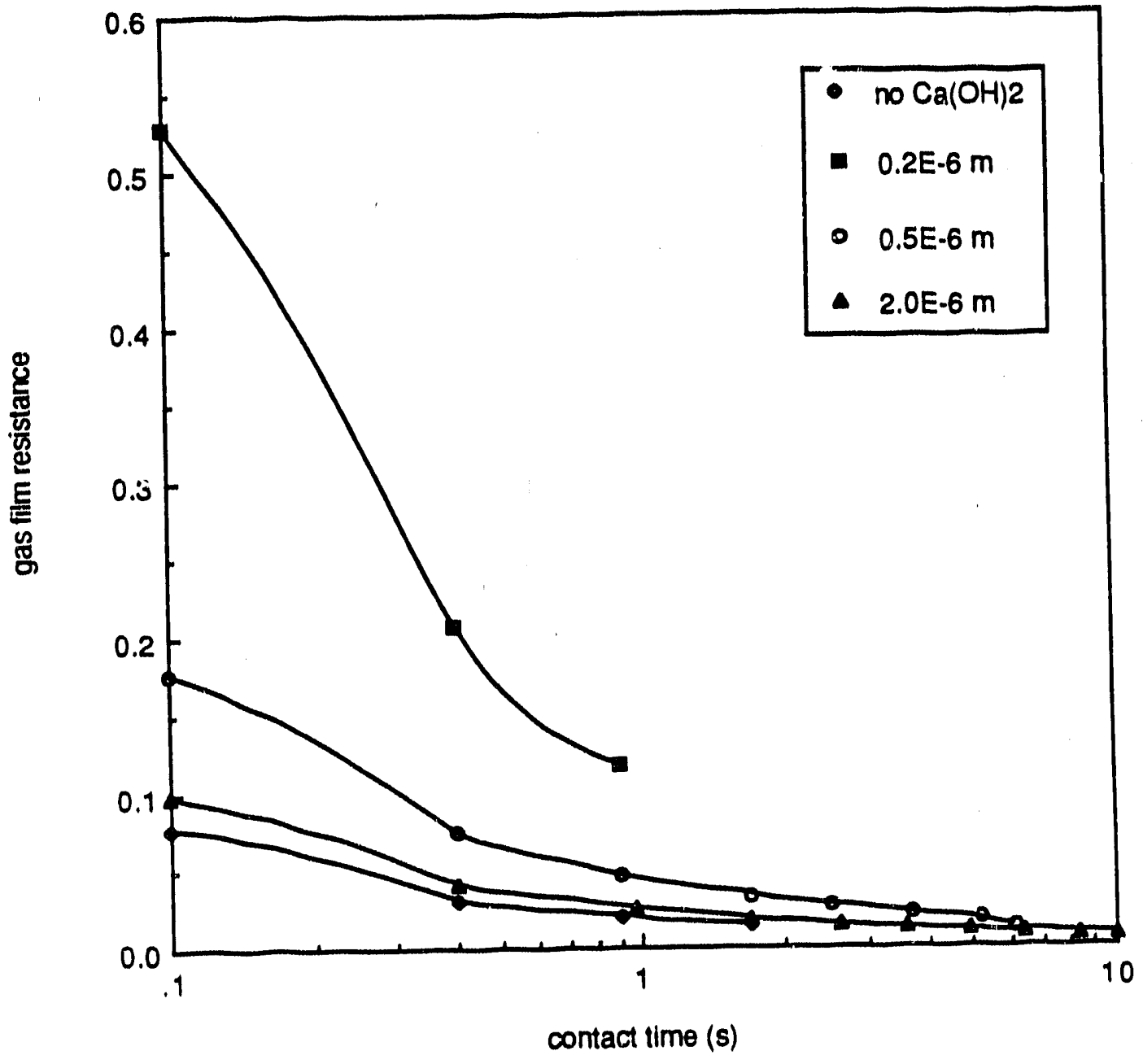

Figuri 6-2. The gas film resistance versus the contact time. The difterent curves correspond to different particle sizes of $\mathrm{Ca}(\mathrm{OH})_{2}, 200 \mathrm{~Pa} \mathrm{SO}, 0$ and $200 \mathrm{molm} \mathrm{m}^{3} \mathrm{Ca}(\mathrm{OH})_{2}, 10 \mu \mathrm{m}$ droplet, $0.5-5.0 \mu \mathrm{m} \mathrm{Ca}(\mathrm{OH})_{2}, 0.1-10 \mathrm{~s}$ contact time. 
still remains toward the gas liquid interface to react with $\mathrm{SO}_{2}$. The gas film resistance is then less dependent on the reactivity of $\mathrm{Ca}(\mathrm{OH})_{2}$ since there also must be a transportation of calclum. The concentration profile of $\mathrm{Ca}(\mathrm{OH})_{2}$ becomes steeper with time since the dissolution rate is larger where there is a low $\mathrm{Ca}(\mathrm{OH})_{2}$ concentration. The steeper the $\mathrm{Ca}(\mathrm{OH})_{2}$ profile is, the less dependent is the actual absorption rate on the reactivity of $\mathrm{Ca}(\mathrm{OH})_{2}$. When a step-concentration profile of $\mathrm{Ca}(\mathrm{OH})_{2}$ is developed, the gas-liquid concentration of $\mathrm{SO}_{2}$ is almost constant, which implies that the absorption rate of $\mathrm{SO}_{2}$ is approximately stable. The absorption process has reached a form of steady-state. The reactivity of $\mathrm{Ca}(\mathrm{OH})_{2}$ thus has less significance for a large contact time in a spray scrubber or for a small $k_{1}$ in the stirred tank. This can be seen in Figures 6-1 and 6-2.

The absorption rate can be increased up to a certain point by decreasing the particle size of $\mathrm{Ca}(\mathrm{OH})_{2}$. In Figure 6-1, the absorption rate is increased when the particle size is decreased from $5 \mu \mathrm{m}$ to $2 \mu \mathrm{m}$, but the absorption rate is not increased when the particle size goes from $2 \mu \mathrm{m}$ to $0.5 \mu \mathrm{m}$. The reason for this is that $2 \mu \mathrm{m} \mathrm{Ca}(\mathrm{OH})_{2}$ is reactive enough to neutralize all the formed hydrogen lons, in other iwords to react with all absorbed $\mathrm{SO}_{2}$ to calclum sulfite. After $0.4 \mathrm{~s}$, a sharp consentration profile of $\mathrm{Ca}(\mathrm{OH})_{2}$ is formed and the absorption is less dependent on the reactivity. The same sharp concevitration profile is formed for $0.5 \mu \mathrm{m}$ as for $2 \mu \mathrm{m}$.

fror a smaller slurry droplet size, corresponding to a smaller value of $\mathrm{k}_{\mathrm{g}}$, the $\mathrm{Ca}(\mathrm{OH})_{2}$ has to be more reacilive to increase the absorption rate, Figure 6-2. The relation between $\mathrm{Ca}(\mathrm{OH})_{2}$ reactivity and $k_{g}$ is thus important parameter. This relation can be expressed as an quotient between the particle size of $\mathrm{Ca}\left(\mathrm{O}, \mathrm{H}_{2}\right)_{2}$ and the slurry droplet size.

\subsubsection{Coricentration Profiles Without $\mathrm{Ca}(\mathrm{OH})_{2}(\mathrm{~s})$ in the Liquid Bulk}

Figures 6-3 and 6-4 show the concentration profiles for an absorption case without any $\mathrm{Ca}(\mathrm{OH})_{2}(\mathrm{~s})$ in the liquid bulk. These profiles take $1.6 \mathrm{~s}$ to be formed, and they correspond to an instantaneous gas film resistance of 45 percent. The partial pressure of $\mathrm{SO}_{2}$ is $2,000 \mathrm{ppm}$ and $\mathrm{k}_{\mathrm{g}}$ is $1.1 \times 10^{-4} \mathrm{~mol} / \mathrm{m}^{2} \mathrm{~s} \mathrm{~Pa}$. 


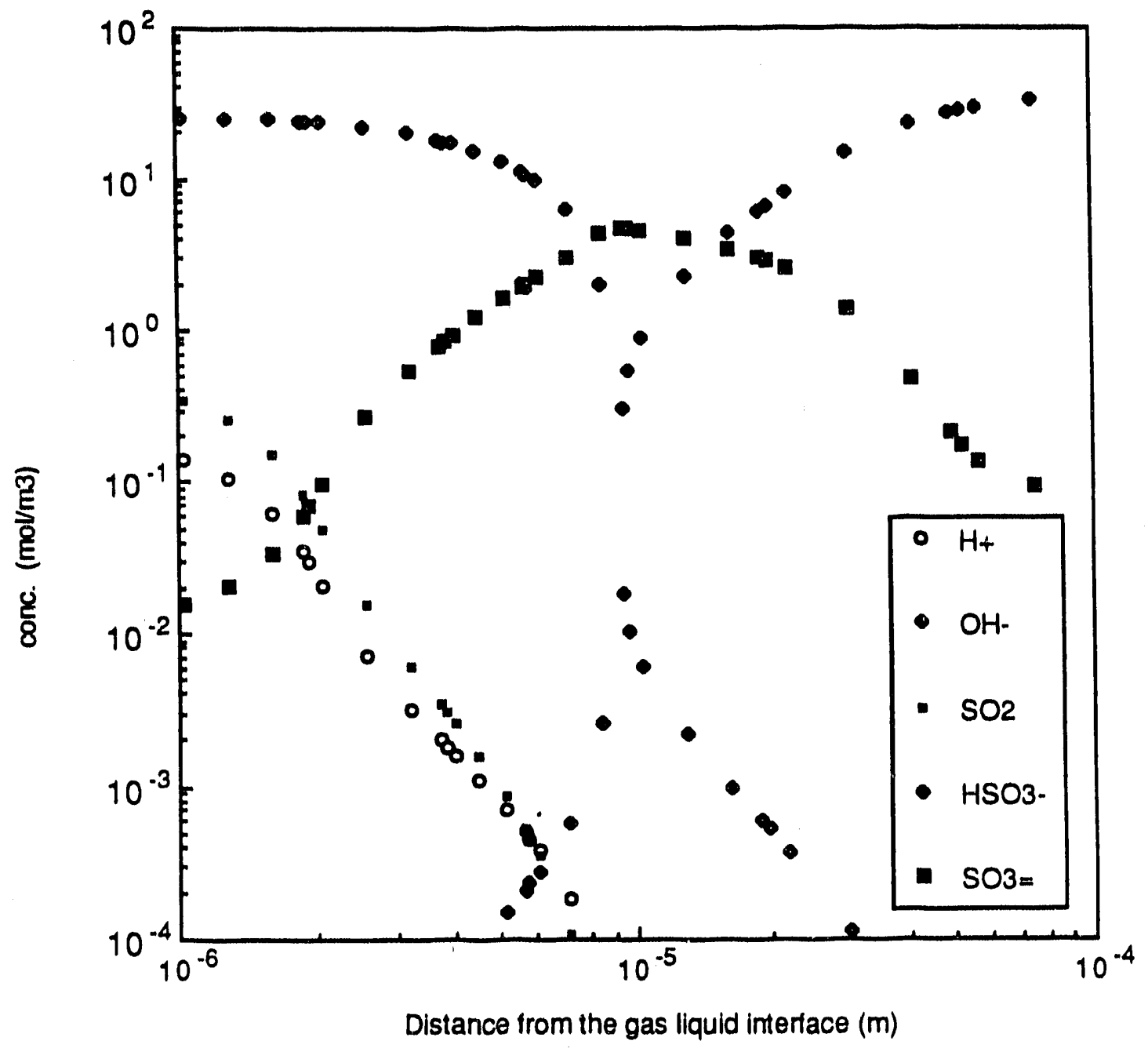

Figure 6-3. Concentrations profiles corresponding to 45 percent gas film resistance. No $\mathrm{Ca}(\mathrm{OH})_{2}$ (s) in the liquid bulk. $200 \mathrm{~Pa} \mathrm{SO}, 100 \mu \mathrm{m}$ droplet, 1.6 sec contact time. 


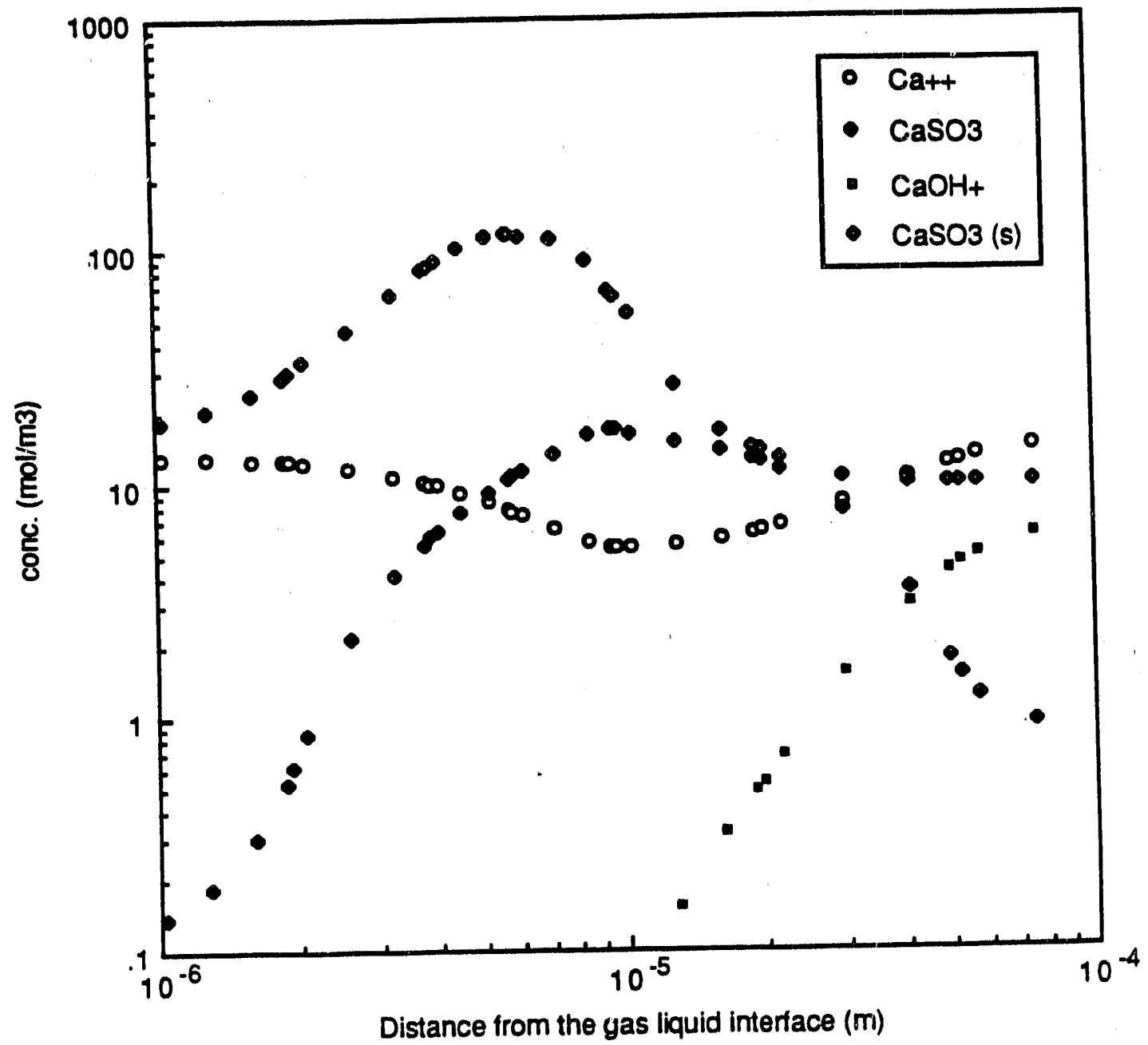

Figure 6-4. Concentration profiles corresponding to a gas film resistance of 45 perce, it. No $\mathrm{Ca}(\mathrm{OH})_{2}$ (s) in the liquid bulk. $200 \mathrm{~Pa} \mathrm{SO}_{2}, 100 \mu \mathrm{m}$ droplet, $1.6 \mathrm{sec}$ contact time. 
From Figure 6-3, we can see that $\mathrm{SO}_{2}$ reacts instantaneously with water at the gas-llquid interface to form hydrogen lons and bisulfite ions. The absorbed $\mathrm{SO}_{2}$ also reacts with some sulfite forming bisulfite. These two reactions enhance the absorption rate of $\mathrm{SO}_{2}$ since they decrease the concentration of $\mathrm{SO}_{2}$ in the liquid. The $\mathrm{SO}_{2}$ and $\mathrm{H}^{+}$concentration decreases rapidly with the distance from the gas-liquid interface. At a distance approximately $10 \mu \mathrm{m}$ from the gas-liquid intierface, there is a drastic change in pH. The concentration of hydroxide increases, and the hydroxide ions react with bisulfite ions to form sulfite. Therefore the sulfite concentration increases and the bisulfite concentration decreases.

Figure 6-4 shows the profiles for the lons involving calcium and the two ion pairs. The $\mathrm{Ca}^{2+}$ is approximately constant throughout the liquid film, the ion pairs $\mathrm{CaOH}^{+}$and $\mathrm{CaSO}_{3}{ }^{\circ}$ follow the profiles of $\mathrm{OH}^{-}$and $\mathrm{SO}_{3}{ }^{2+}$, respectively. Approximately 50 percent of the sulfite lons are present as the ion pair $\mathrm{CaSO}_{3}{ }^{2-}$. There is also some precipitation of $\mathrm{CaSO}_{3}(\mathrm{~s})$ since sulfite is produced during the absorption.

\subsubsection{Concentration Profiles With $\mathrm{Ca}(\mathrm{OH})_{2}(\mathrm{~s})$ in the Bulk Liquid}

Figures 6-5 and 6-6 show the profiles for the same absorption case as above when the bulk concentration of $\mathrm{Ca}(\mathrm{OH})_{2}(\mathrm{~s})$ is $500 \mathrm{~mol} / \mathrm{m}^{3}$. These profiles also correspond to a gas film resistance of 45 percent, but, since the presence of $\mathrm{Ca}(\mathrm{OH})_{2}(s)$ maintains a high gas film resistance a longer time, it takes $8.1 \mathrm{~s}$ until these profiles are formed. Figure 6-5 with the profiles of $\mathrm{H}^{+} / \mathrm{OH}^{-}$and $\mathrm{SO}_{2} / \mathrm{HSi}_{3}{ }^{-} / \mathrm{SO}_{3}{ }^{2-}$ looks approximately the same as Figure 6-3. The increase in pH is occurring closer to the gas-liquid interface in Figure 6-5, $5 \mu \mathrm{m}$ instead of $10 \mu \mathrm{m}$, but otherwise there is no significant difference between Figure 6-5 and Figure 6-3.

It can be seen from Figure 6-6 that $\mathrm{Ca}(\mathrm{OH})_{2}(\mathrm{~s})$ is totally consumed at the gas liquid interface. There is no $\mathrm{Ca}(\mathrm{OH})_{2}(\mathrm{~s})$ until the distance from the gas-liquid interface exceeds $50 \mu \mathrm{m}$. The concentration of $\mathrm{Ca}^{2+}$ is approximately constant throughout the film. The $\mathrm{CaSO}_{3}$ ion pair has a significant concentration due to a very large supersaturation of calcium sulfite. A significant amount of $\mathrm{CaSO}_{3}(\mathrm{~s})$ precipitates during the absorption, since $\mathrm{Ca}^{2+}$ lons are formed from the dissolution of 


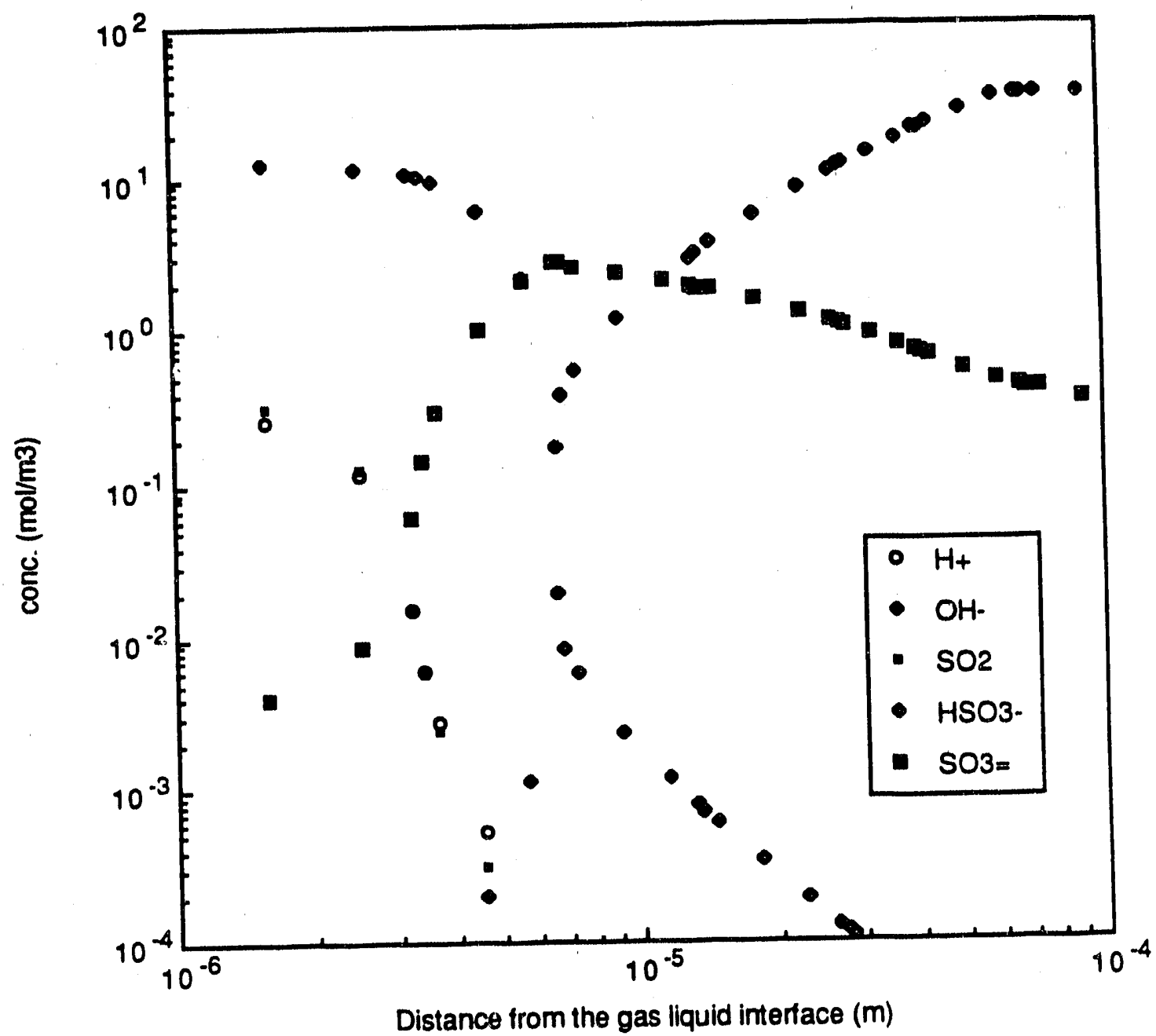

Figure 6-5. Concentration profiles corresponding to 45 percent gas film resistance with $\mathrm{Ca}(\mathrm{OH})_{2}(\mathrm{~s})$ in the liquid bulk. $200 \mathrm{~Pa} \mathrm{SO}_{2}, 500 \mathrm{moVm}^{3} \mathrm{Ca}(\mathrm{OH})_{2}, 100 \mu \mathrm{m}$ droplet, $2.0 \mu \mathrm{m} \mathrm{Ca}(\mathrm{OH})_{2}, 8.1$ sec contact time. 


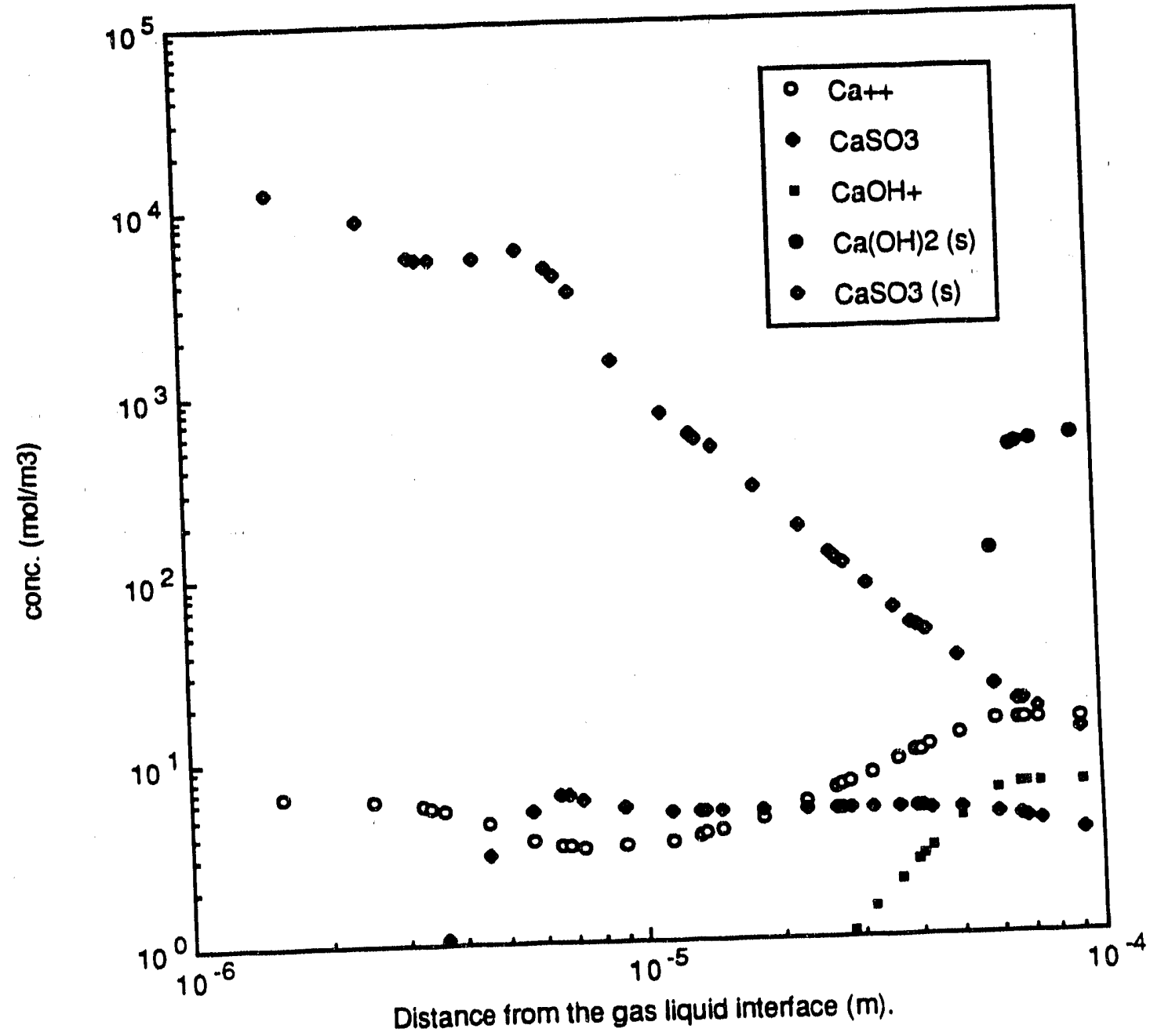

Figure 6-6. Concentration profiles corresponding to 45 percent gas film resistance with $\mathrm{Ca}(\mathrm{OH})_{2}(\mathrm{~s})$ in the liquid bulk. $200 \mathrm{~Pa} \mathrm{SO}_{2}, 500 \mathrm{~mol} / \mathrm{m}^{3} \mathrm{Ca}(\mathrm{OH})_{2}, 100 \mu \mathrm{m}$ droplet, $2.0 \mu \mathrm{m} \mathrm{Ca}(\mathrm{OH})_{2}, 8.1$ sec contact time. 
$\mathrm{Ca}(\mathrm{OH})_{2}(\mathrm{~s})$ and $\mathrm{SO}_{3}{ }^{2-}$ ions are formed from the reaction between $\mathrm{SO}_{2}$ and $\mathrm{OH}^{-}$ions. It is significant that $\mathrm{CaSO}_{3}$ crystallizes close to the gas-liquid intertace where no $\mathrm{Ca}(\mathrm{OH})_{2}(\mathrm{~s})$ is present.

Flgure 6-7 shows how the concentration profile of $\mathrm{Ca}(\mathrm{OH})_{2}(8)$ varies with contact time. The $\mathrm{Ca}(\mathrm{OH})_{2}(\mathrm{~s})$ is consumed during the absorption, making the $\mathrm{Ca}(\mathrm{OH})_{2}(s)$ front move away from the gas liquid intertace. Figure 6-7 can also exemplity the penetration distance. For a contact time of $0.4 \mathrm{~s}$, the penetration distance is equal to $10 \mu \mathrm{m}$.

\subsubsection{Partial Pressure of $\mathrm{SO}_{2}$ at the Gas-Liquid Interface}

During the absorption of $\mathrm{SO}_{2}$ into a sturry of calcium hydroxide, the partial pressure of $\mathrm{SO}_{2}$ at the gas-liquid interface increases, causing the absorption rate to decrease. At the start of the absorption, $P_{\text {SO21 }}$ is equal to zero when the absorption process is gas film controlled. When $P_{\text {SO21 }}$ increases, the absorption rate decreases, and the absorption becomes more liquid film controlled. The partial pressure of $\mathrm{SO}_{2}$ at the interface starts to increase when all the hydroxide lons are consumed close to the interface.

Figure 6-8 shows how the $\mathrm{P}_{\text {SO2i }}$ varies with contact time for the same conditions as in Figure 6-5 and 6-6. The different numbers in Figure 6-8 correspond to the penetration distance for that contact time. The driving force for mass transfer, which is the difference between the two curves of $\mathrm{P}_{\mathrm{SO} 2}$ and $\mathrm{P}_{\mathrm{SO} 21}$, is large for small contact times but decreases with increasing time. The absorption is totally gas film controlled up to $1 \mathrm{~s}$, or to a penetration distance of $20 \mu \mathrm{m}$. After $1 \mathrm{~s}, P_{\text {SOzil }}$ starts to increase, and the gas film resistance decreases. The $P_{\text {SO2i }}$ increases quickly up to $1500 \mathrm{ppm}$.

Thereafter, a kind of steady state is developed where the $\mathbf{P}_{\text {SO21 }}$ is approximately constant even though the penetration distance increases from 45 to $70 \mu \mathrm{m}$. After about $6 \mathrm{~s}$, the average gas film resistance is $\mathbf{5 0}$ percent, while the instantaneous gas film resistance is only $\mathbf{2 5}$ percent.

\subsubsection{Effects of $\mathrm{Ca}(\mathrm{OH})_{2}(\mathrm{~s})$ Concentration}

Figure 6-9 shows how the gas film resistance varies with different concentrations of $\mathrm{Ca}(\mathrm{OH})_{2}(\mathrm{~s})$. The partial pressure of $\mathrm{SO}_{2}$ is $2,000 \mathrm{ppm}$, and $\mathrm{k}_{\mathrm{g}}$ is $1.1 \times 10^{-4} \mathrm{moVm}{ }^{2} \mathrm{~s} \mathrm{~Pa}$. The reactivity of $\mathrm{Ca}(\mathrm{OH})_{2}(\mathrm{~s})$ is $5 \mu \mathrm{m}$. At higher concentrations of $\mathrm{Ca}(\mathrm{OH})_{2}(\mathrm{~s})$, it takes a longer time for the $\mathrm{Ca}(\mathrm{OH})_{2}(\mathrm{~s})$ 


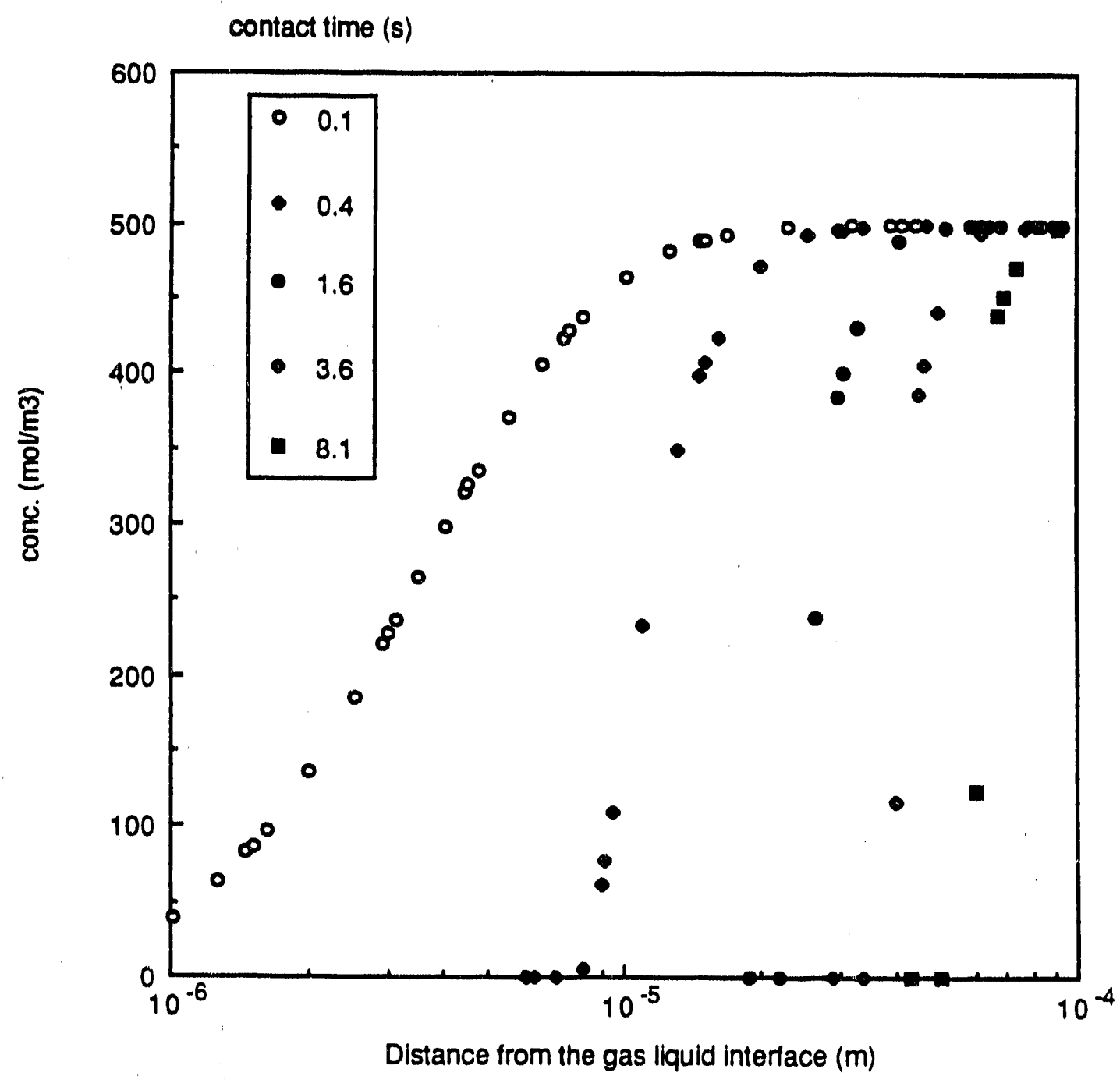

Figure 6-7. Concentration profiles of $\mathrm{Ca}(\mathrm{OH})_{2}$ (s). $200 \mathrm{~Pa} \mathrm{SO}_{2}, 500 \mathrm{moVm} \mathrm{m}^{3} \mathrm{Ca}(\mathrm{OH})_{2}, 100 \mu \mathrm{m}$ droplet, $2 \mu \mathrm{m} \mathrm{Ca}(\mathrm{OH})_{2}$. 


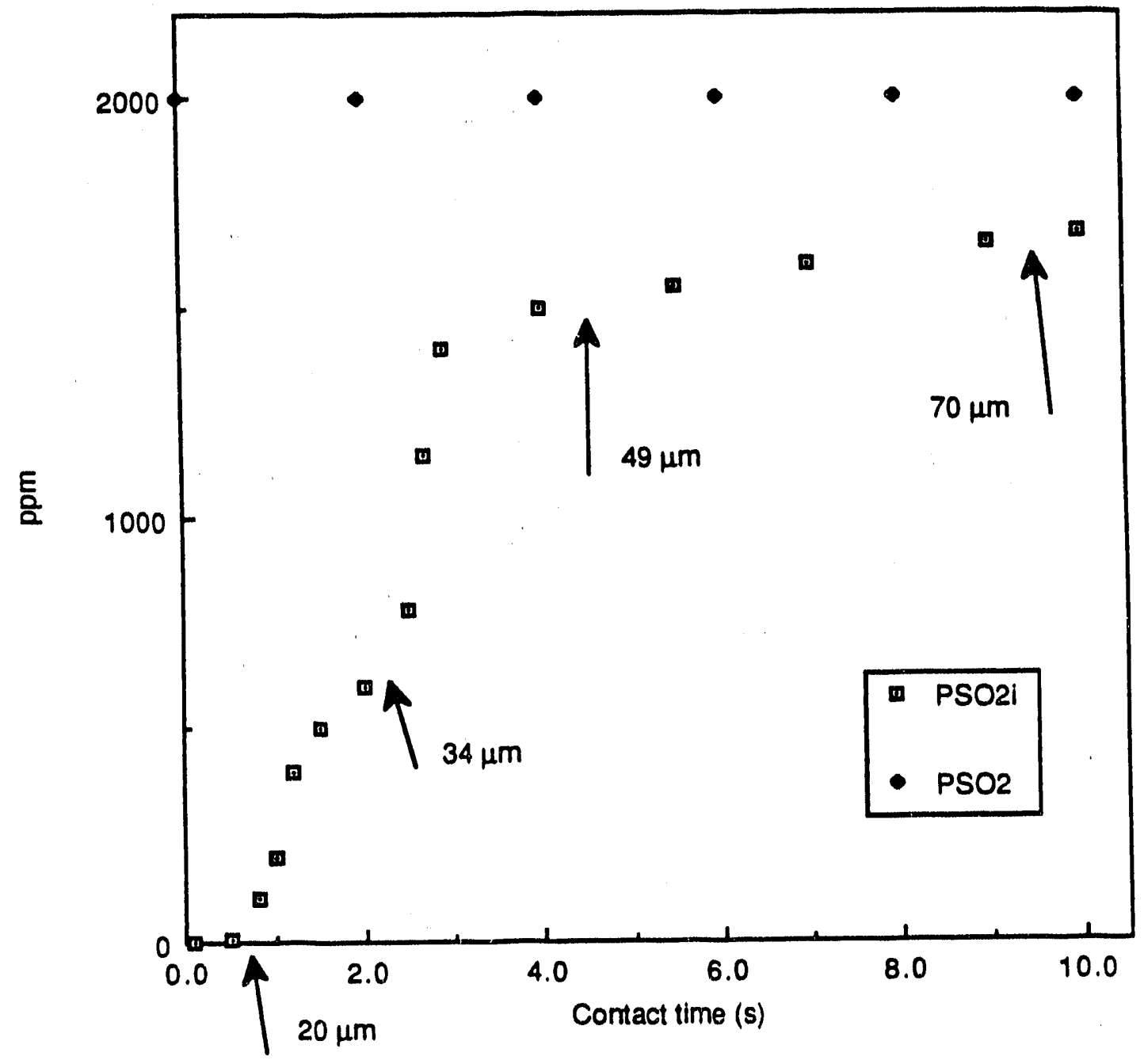

Figure 6-8. The partial pressure of $\mathrm{SO} 2$ at the gas-liquid intertace as a function of contact time. The numbers are corresponding penetration depths. $200 \mathrm{~Pa} \mathrm{SO}_{2}, 500 \mathrm{molm} \mathrm{m}^{3} \mathrm{Ca}(\mathrm{OH})_{2}, 100$ $\mu \mathrm{m}$ droplet, $2 \mu \mathrm{m} \mathrm{Ca}(\mathrm{OH})_{2}$. 


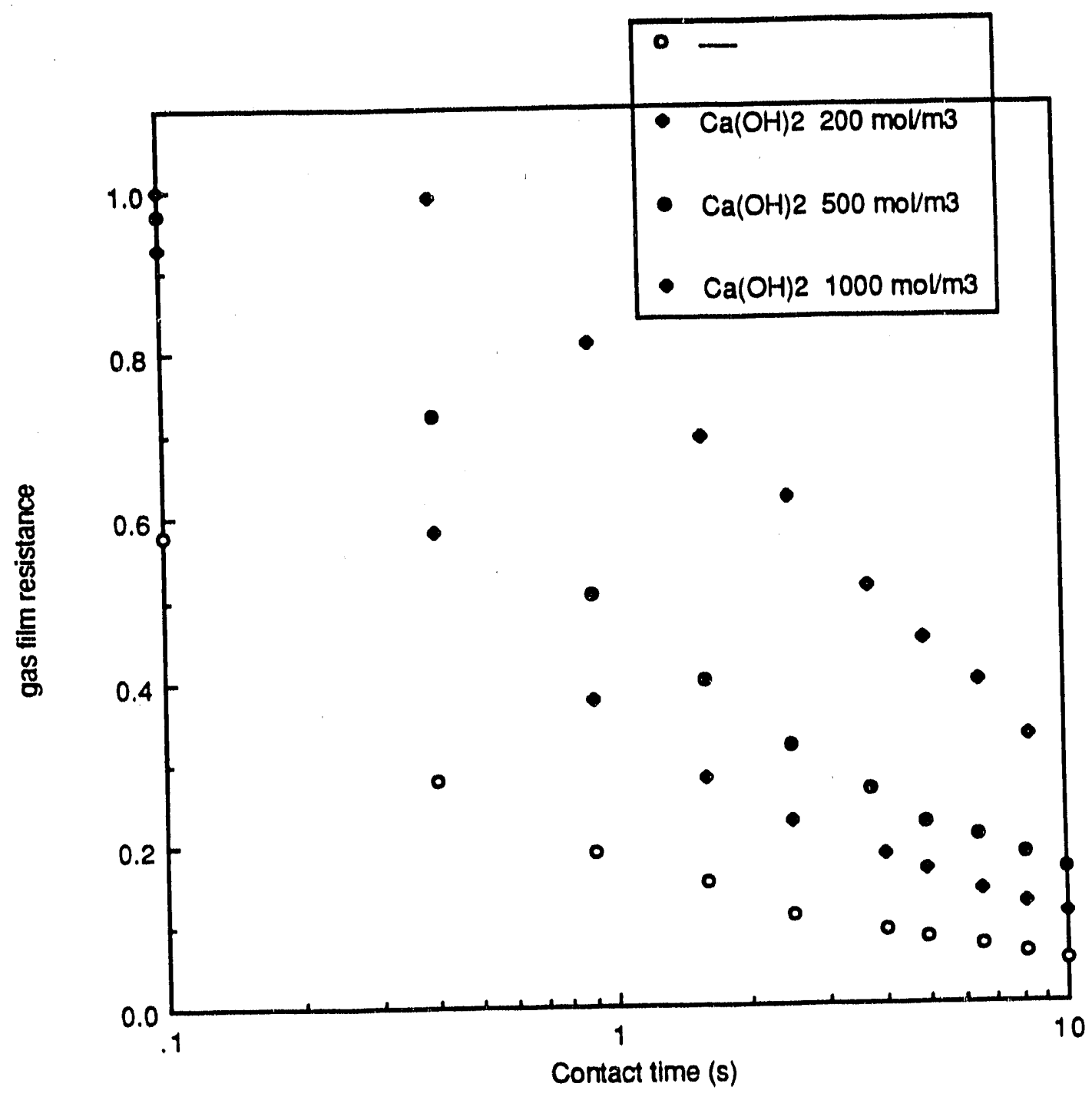

Figure 6-9. Gas film resistance versus contact time for different concentrations of $\mathrm{Ca}(\mathrm{OH})_{2}(\mathrm{~s}) .200 \mathrm{~Pa}$ $\mathrm{SO}_{2}, 100 \mu \mathrm{m}$ droplet, $5 \mu \mathrm{m} \mathrm{Ca}(\mathrm{OH})_{2}$. 
front to move away from the gas-liquid interface, which mec.zs that the absorption can be maintained at a high rate for a longer time. When there is no $\mathrm{Ca}(\mathrm{OH})_{2}(8)$ present in the liquid bulk, the gas film resistance is only 60 percent after $0.1 \mathrm{~s}$, whereas for a $\mathrm{Ca}(\mathrm{OH})_{2}(8)$ concentration of $1,000 \mathrm{~mol} / \mathrm{m}^{3}$, the gas film resistance is larger than 60 percent up to a contact time of 68 . Similar results are given in Figure 6-10 for a particle of $2 \mu \mathrm{m}$.

\subsubsection{Effects of Different Partial Pressures of $\mathrm{SO}_{2}$}

Figure 6-11 shows how the gas film resistance varies with different partial pressures of $\mathrm{SO}_{2}$ in the bulk gas. The concentration of $\mathrm{Ca}(\mathrm{OH})_{2}(\mathrm{~s})$ is $500 \mathrm{~mol} \mathrm{~m}^{3}$ and $k_{b}$ is $1.1 \times 10^{-4} \mathrm{molm} \mathrm{m}^{2} \mathrm{~s} \mathrm{~Pa}$. The reactivity of $\mathrm{Ca}(\mathrm{OH})_{2}(\mathrm{~s})$ corresponds to a particie size of $2 \mu \mathrm{m}$. Al higher partial pressures of $\mathrm{SO}_{2}$, more $\mathrm{SO}_{2}$ is absorbed and the $\mathrm{Ca}(\mathrm{OH})_{2}(\mathrm{~s})$ is consumed faster.

\subsubsection{Effects of $\mathrm{Ca}(\mathrm{OH})_{2}(\mathrm{~s})$ Reactivity}

Figures 6-12 and 6-13 show how the $\mathrm{Ca}(\mathrm{OH})_{2}(\mathrm{~s})$ reactivity affects the absorption rate of $\mathrm{SO}_{2}$. The gas film resistance is plotted versus the ratio between $k_{b}$ and $k_{y}$ for a $k_{g}$ corresponding to a $100 \mu m$ slurry droplet in Figure 6-12, and for a $k_{g}$ corresponding to a $10 \mu \mathrm{m}$ slurry droplet in Figure 6-13. The partial pressure of $\mathrm{SO}_{2}$ is $2,000 \mathrm{ppm}$, and the concentration of $\mathrm{Ca}(\mathrm{OH})_{2}(8)$ is $200 \mathrm{~mol} / \mathrm{m}^{3}$. By plotting the gas film resistance versus $k_{g} / k_{p}$, the results would have been the same for different values of $k_{g}$. all the reactions were instantaneous. Since the crystallization of $\mathrm{CaSO}_{3}(\mathrm{~s})$ and the dissolution of $\mathrm{Ca}(\mathrm{OH})_{2}(\mathrm{~s})$ have finite rates, the results shown in the two graphs are somewhat different. A contact time of $1 \mathrm{~s}$ for a $100 \mu \mathrm{m}$ slurry droplet corresponds to a contact time of $0.01 \mathrm{~s}$ for a $10 \mu \mathrm{m}$ slurry droplet. It follows that if the droplet size is decreased one order-of-magnitude, the contact time is decreased with two orders-of-magnitude needed to get the same ratio between $k_{g}$ and $k_{f}$.

A higher reactivity increases the absorption rate. A higher reactivity also gives a faster dissolution rate, which can keep the $\mathrm{pH}$ at the gas liquid interface at a higher value as long as there is $\mathrm{Ca}(\mathrm{OH})_{2}(\mathrm{~s})$ present. 


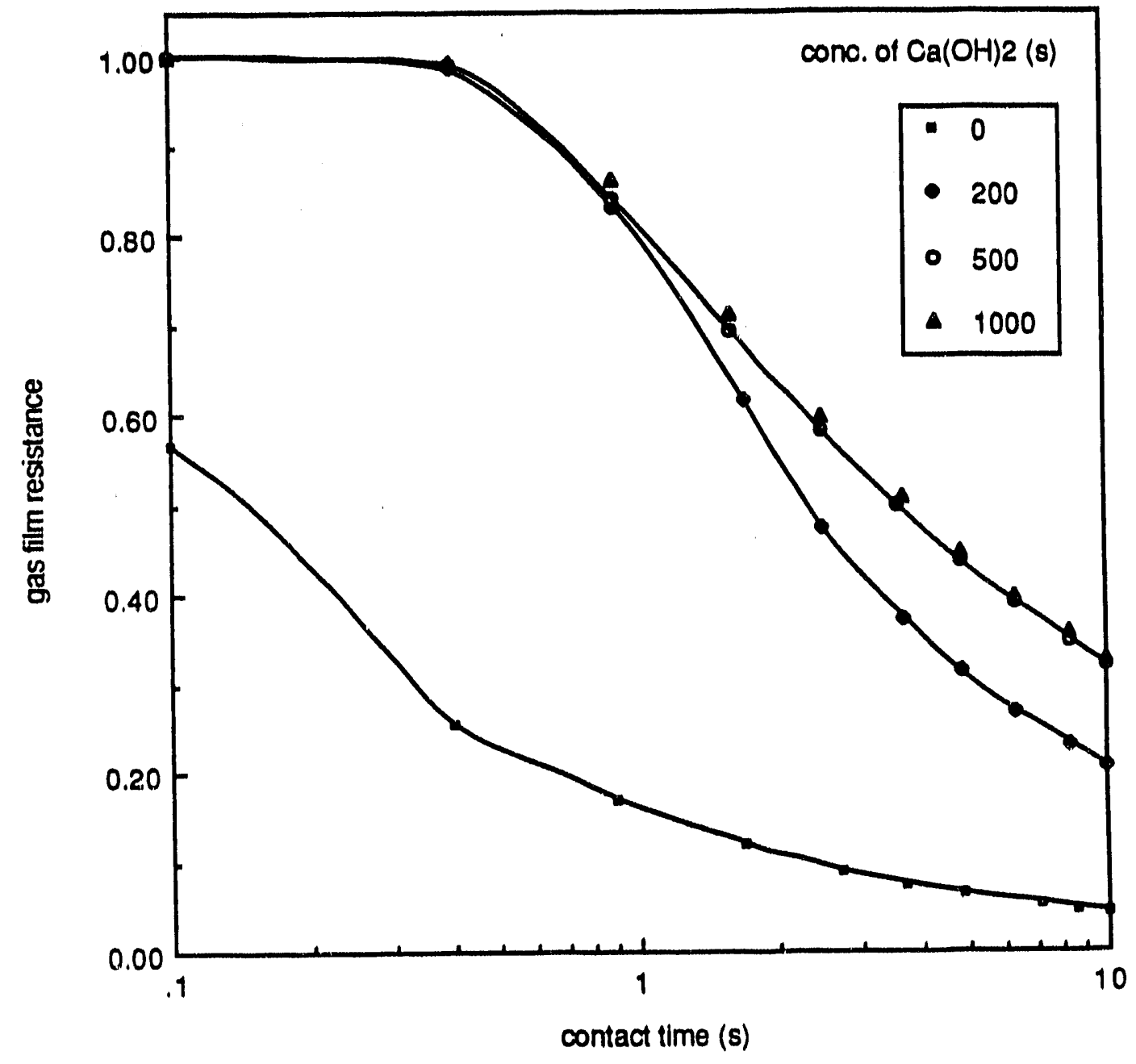

Figure 6-10. The gas film resistance versus contact time for different $\mathrm{Ca}(\mathrm{OH})_{2}(\mathrm{~s})$ concentrations. $200 \mathrm{~Pa} \mathrm{SO}_{2}, 0-1,000 \mathrm{~mol} / \mathrm{m}^{3} \mathrm{Ca}(\mathrm{OH})_{2}, 100 \mu \mathrm{m}$ droplet, $2 \mu \mathrm{m} \mathrm{Ca}(\mathrm{OH})_{2}, 0.1-10 \mathrm{se0}$ contact time. 


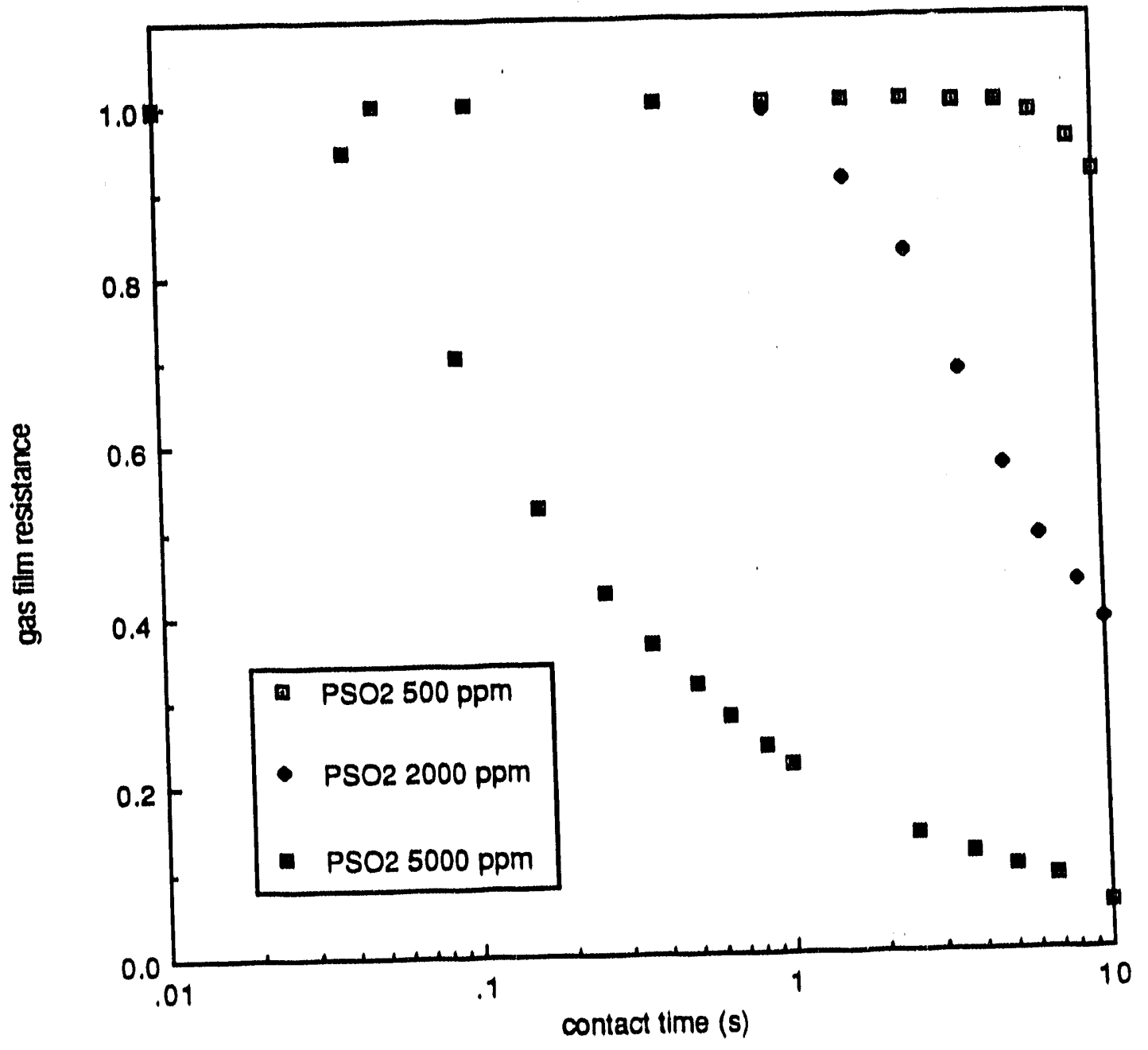

Figure 6-11. The gas film resistance versus contact time for different partial pressures of $\mathrm{SO}_{2}$. $50-500 \mathrm{~Pa} \mathrm{SO}{ }_{2}, 500 \mathrm{molm}^{3} \mathrm{Ca}(\mathrm{OH})_{2}, 100 \mu \mathrm{m}$ droplet, $2 \mu \mathrm{m} \mathrm{Ca}(\mathrm{OH})_{2}$. 


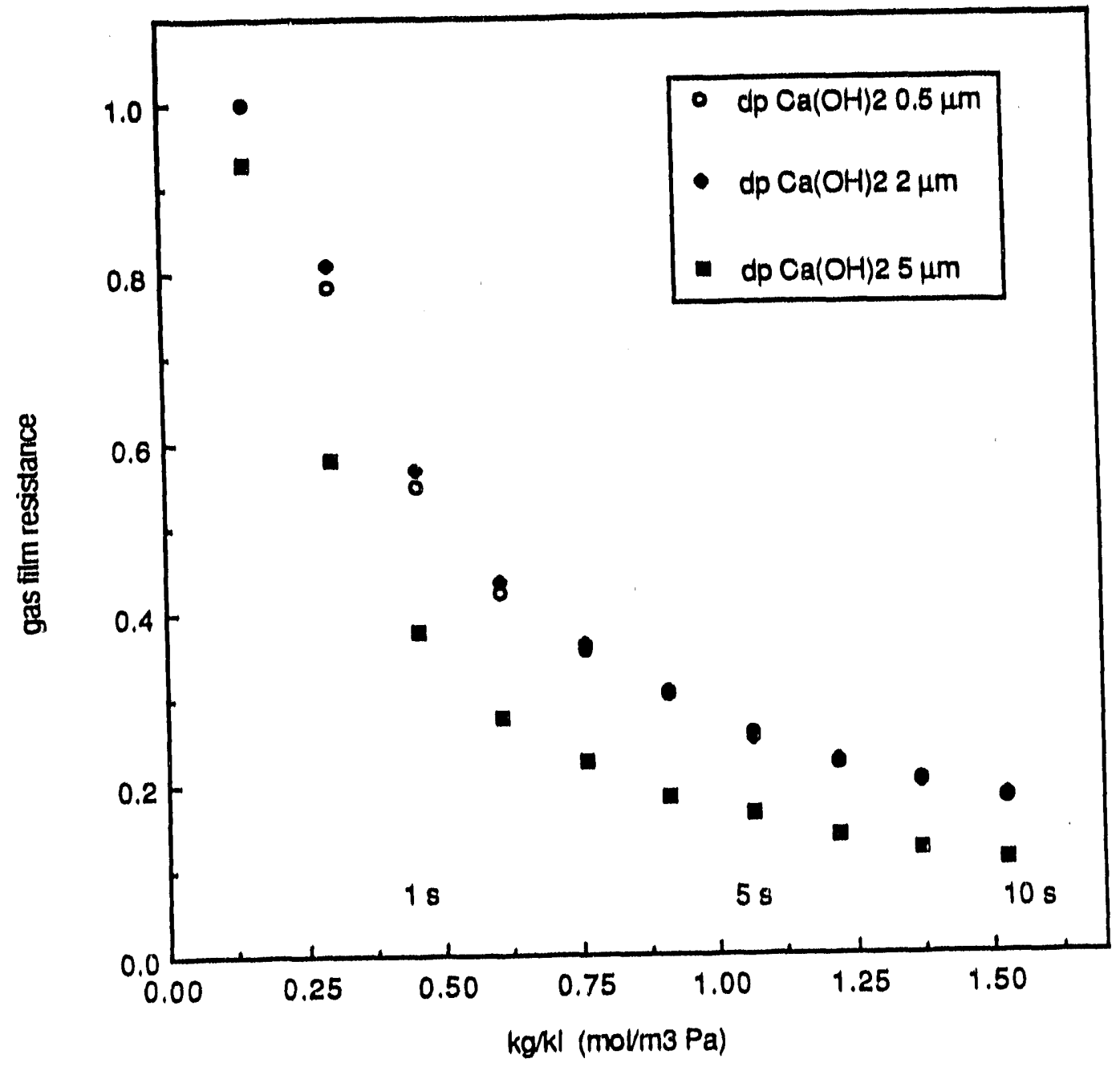

Figure 6-12. Gas film resistance versus the ratio between $k_{g}$ and $k_{1}$ for different reactivities of $\mathrm{Ca}(\mathrm{OH})_{2}(\mathrm{~s})$. $\mathrm{k}_{\mathrm{g}}$ corresponds to a $100 \mu \mathrm{m}$ droplet. $200 \mathrm{~Pa} \mathrm{SO} \mathrm{S}_{2}, 200 \mathrm{~mol} / \mathrm{m}^{3} \mathrm{Ca}(\mathrm{OH})_{21}$ $100 \mu \mathrm{m}$ droplet, $0.5-5 \mu \mathrm{m} \mathrm{Ca}(\mathrm{OH})_{2}$. 


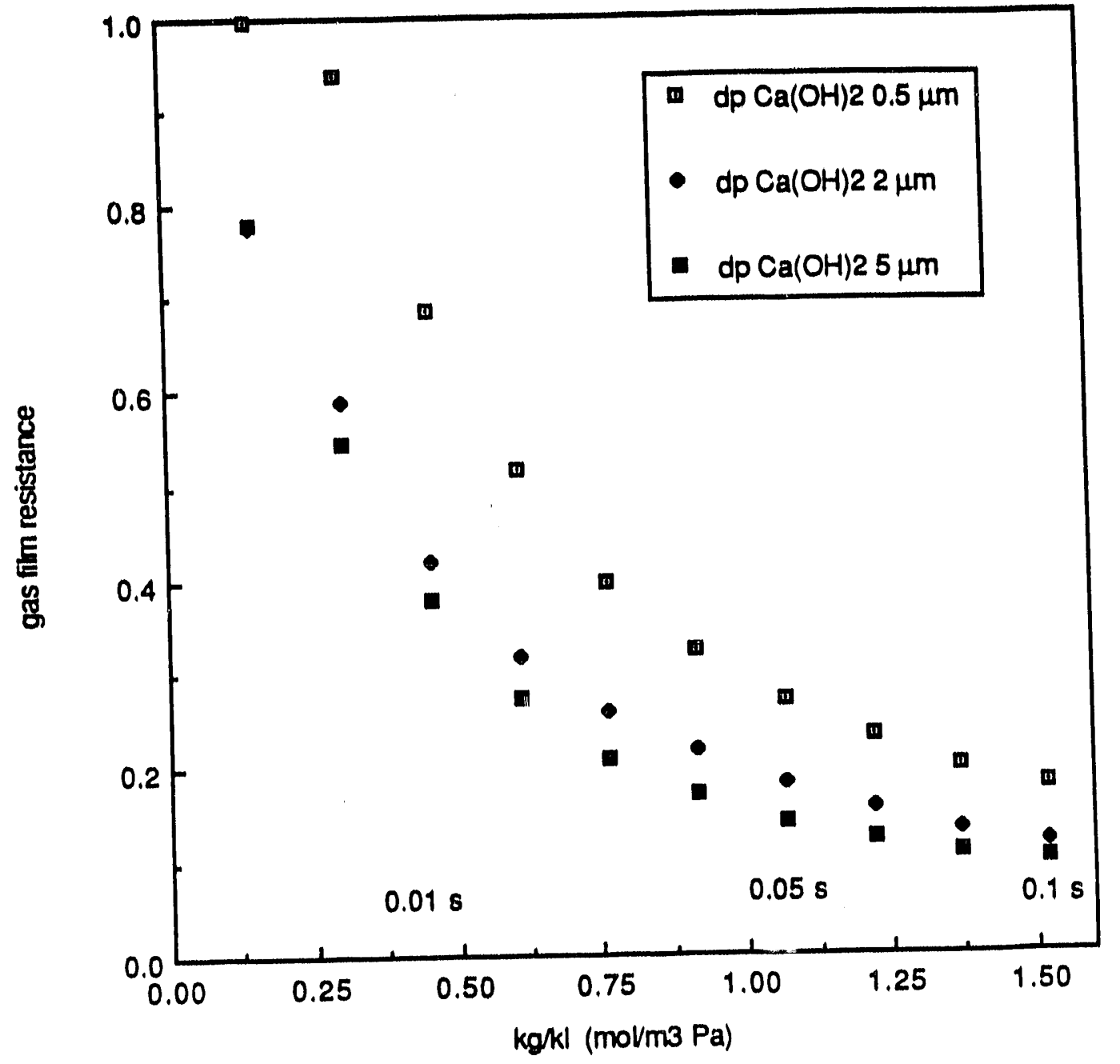

Figure 6-13. Gas film resistance versus the ratio between $k_{g}$ and $k_{1}$ for different reactivities of $\mathrm{Ca}(\mathrm{OH})_{2} . k_{\mathrm{g}}$ corresponds to a $10 \mu \mathrm{m}$ droplet. $200 \mathrm{~Pa} \mathrm{SO}_{2}, 200 \mathrm{molm} \mathrm{m}^{3} \mathrm{Ca}(\mathrm{OH})_{2}, 10$ $\mu \mathrm{m}$ droplet, $8.5-5 \mu \mathrm{m} \mathrm{Ca}(\mathrm{OH})_{2}$. 


\subsubsection{Penetration Distance}

Figures 6-14 and 6-15 show how the gas film resistance varies with the penetration distance for different reactivittes of $\mathrm{Ca}(\mathrm{OH})_{2}(s)$. The results in Figure 6-14 are modeled with a $\mathrm{k}_{\mathrm{g}}$ corresponding to a $100 \mu \mathrm{m}$ slurry droplet, and the results in Figure 6-15 correspond to a $10 \mu \mathrm{m}$ slurry droplet. The partial pressure of $\mathrm{SO}_{2}$ is $2,000 \mathrm{ppm}$, and the concentration of $\mathrm{Ca}(\mathrm{OH})_{2}(\mathrm{~s})$ is varied from 200 up to $1,000 \mathrm{~mol} / \mathrm{m}^{3}$.

For a given penetration distance, only the reacthity of $\mathrm{Ca}(\mathrm{OH})_{2}(\mathrm{~s})$ is of importance for the gas film resistance. The concentration of $\mathrm{Ca}(\mathrm{OH})_{2}(\mathrm{~s})$ affects how fast the penetration distance increases with time, but for 100 percent utilization of the lime, the average absorption rate is only dependent on the reactivity and not dependent on the concentration of $\mathrm{Ca}(\mathrm{OH})_{2}(s)$.

For the lower $k_{g}$, the absorption is totally gas film controlled as long as the penetration distance is smaller than $10 \mu \mathrm{m}$. For the larger $k_{g}$, the absorption rate is more dependent on the reactivity of $\mathrm{Ca}(\mathrm{OH})_{2}(s)$. For the low reactivity, $5 \mu \mathrm{m}$, the absorption is liquid film controlled even though the penetration distance is zero.

For a $100 \mu \mathrm{m}$ slurry droplet, the maximum penetration distance would be $50 \mu \mathrm{m}$ corresponding to a 100 percent utilization of the lime, meaning a gas film resistance of about 60,50 and 30 percent for the three different reactivities. The maximum penetration distance in a $10 \mu \mathrm{m}$ slurry droplet is $5 \mu \mathrm{m}$, which gives a gas film resistance of 40,20 and 10 percent for the three reactivities in Figure 6-15. It is not reasonable to assume a $\mathrm{Ca}(\mathrm{OH})_{2}$ particle size of $5 \mu \mathrm{m}$ in a slurry droplet of $10 \mu \mathrm{m}$. Figures 6-14 and 6-15 only demonstrate how different reactivities affect the absorption rate for different values of $\mathrm{k}_{\mathrm{g}}$. For a smaller slurry droplet corresponding to a higher $k_{b}$, it is more important that $\mathrm{Ca}(\mathrm{OH})_{2}$ is more reactive, or the dissolution rate will not "keep up with" the rate that hydrogen lons are produced during the absorption, and the gas film resistance will accordingly decrease.

Figure 6-16 shows that the partial pressure of $\mathrm{SO}_{2}$ also has an effect on the gas film resistance for a given penetration depth. For a larger $\mathrm{P}_{\mathrm{SO} 2}$, the absorption rate is faster since the driving force is larger. For this reason, the lime has to be more reartive to give a high gas film resistance. For a $\mathrm{P}_{\mathrm{SO}}$ 
equal to $500 \mathrm{ppm}$, the absorption is gas film controlled when the penetration distance is smaller than 5 $\mu \mathrm{m}$, whereas for a $P_{S O 2}$ of 5,000 ppm the absorption is liquid film controlled even for very smiall penetration distances. 


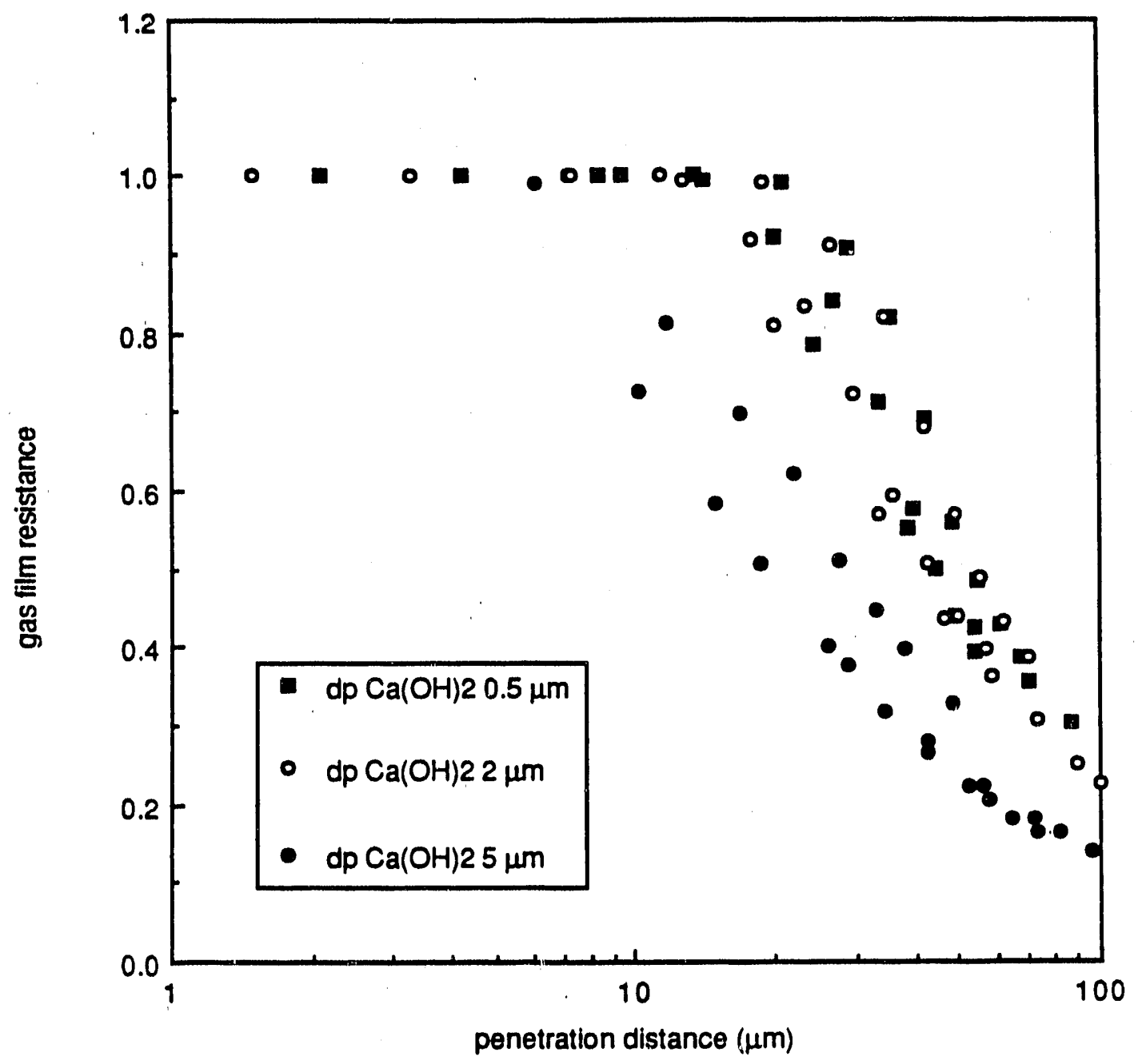

Figure 6-14. Gas film resistance versus penetration distance. $200 \mathrm{~Pa} \mathrm{SO}, 200-1,000 \mathrm{~mol} / \mathrm{m}^{3}$ $\mathrm{Ca}(\mathrm{OH})_{2}, 100 \mu \mathrm{m}$ droplet. 


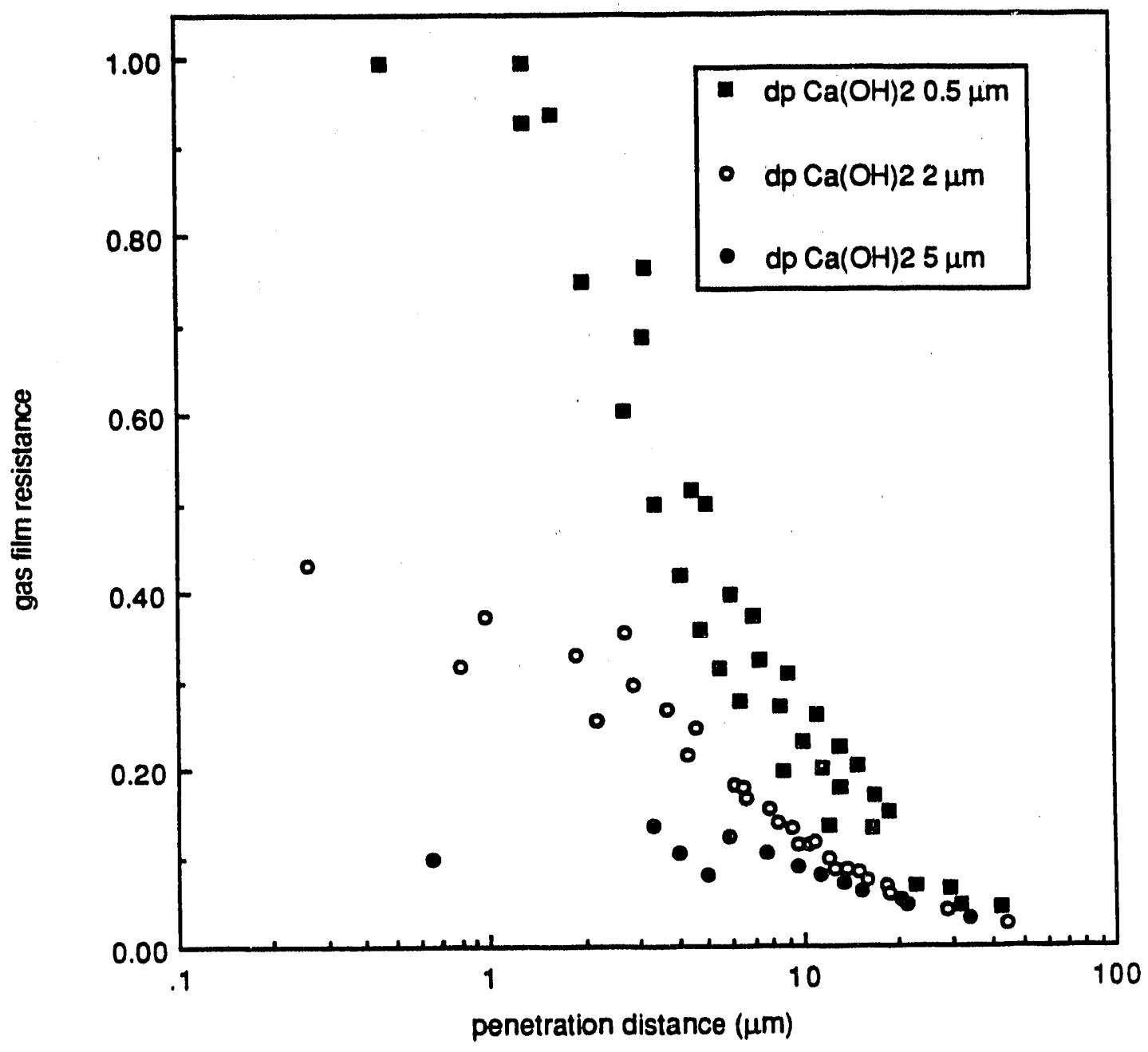

Figure 6-15. Gas film resistance versus penetration distance. $200 \mathrm{~Pa} \mathrm{SO}, 200-1,000 \mathrm{~mol} / \mathrm{m}^{3}$ $\mathrm{Ca}(\mathrm{OH})_{2}, 10 \mu \mathrm{m}$ droplet. 


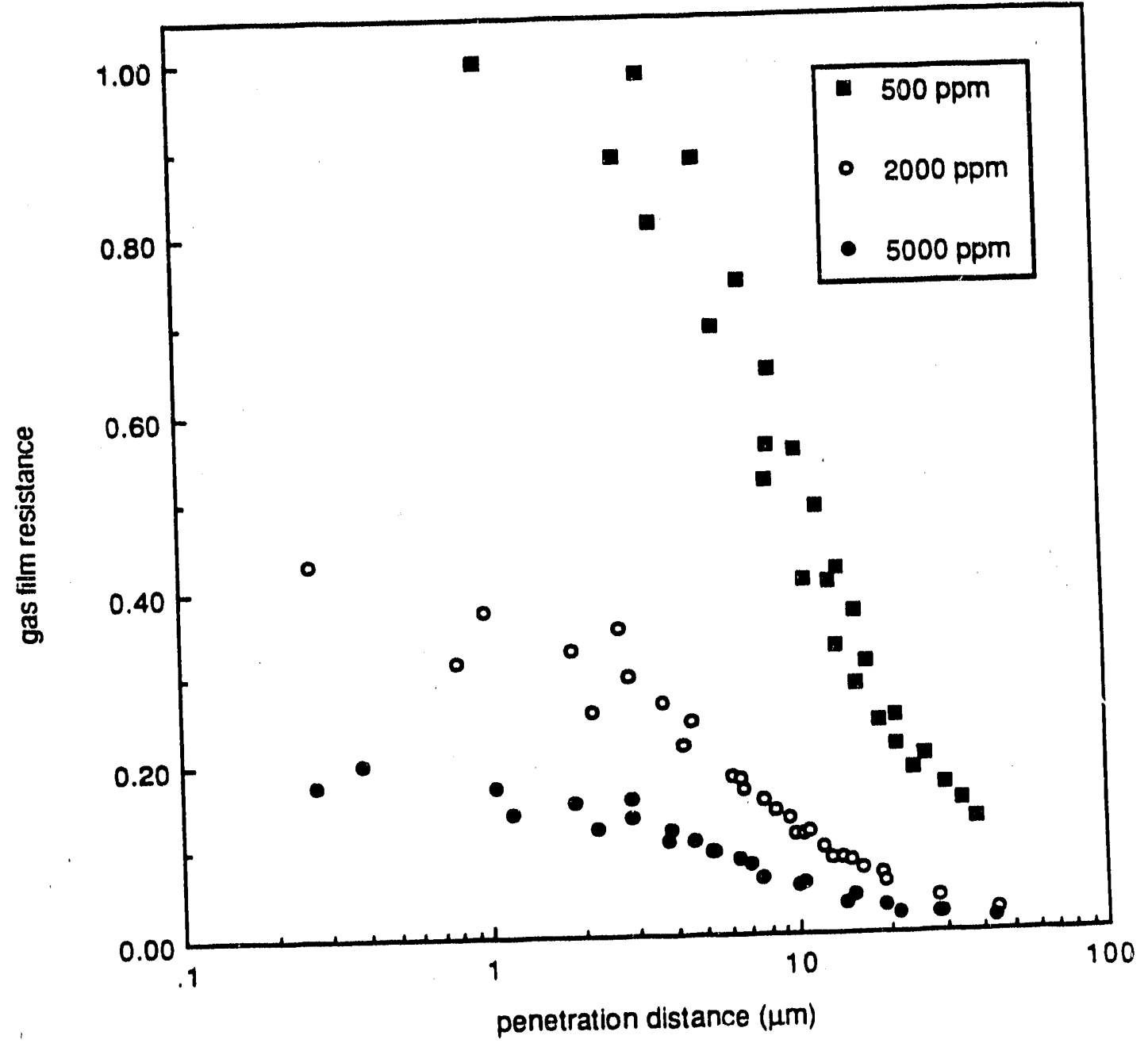

Figure 6-16. Gas film resistance versus penetration distance for different partial pressures of $\mathrm{SO}_{2}$. 50-500 Pa SO $2,200-1,000 \mathrm{~mol} / \mathrm{m}^{3} \mathrm{Ca}(\mathrm{OH})_{2}, 10 \mu \mathrm{m}$ droplet, 0.5-5 $\mu \mathrm{m} \mathrm{Ca}(\mathrm{OH})_{2}$. 


\section{SECTION 7}

\section{CONCLUSIONS AND RECOMMENDATIONS}

The theory, experiments and modeling activities of this research allowed for many conclusions to be made about absorption of $\mathrm{SO}_{2}$ into $\mathrm{Ca}(\mathrm{OH})_{2}$ slurries, and validation of the slurry absorption model. Below is a summary of the conclusions that have been discussed throughout the preceding sections of this report.

During the course of this research, a number of areas which require additional study were identitied. Several additional experiments are recommended to address assumptions made here. Recommendations are also made for modifying the slurry absorption model.

\subsection{MASS TRANSFER THEORY}

1. The surface renewai theory is the best avallable mass transfer model to use for describing the absorption of $\mathrm{SO}_{2}$ into $\mathrm{Ca}(\mathrm{OH})_{2}$ sturries. Applied as the penetration theory (assuming constant contact times for slurry elements), absorption of $\mathrm{SO}_{2}$ into slurries can be accurately predicted.

2. The enhancement factor (normalized flux) is a valuable basis for comparison of absorption. It was proven to be independent of contact time (or $\mathrm{k}_{1}^{\circ}$ ) but strongly dependent on $\mathrm{SO}_{2}$ concentration.

\subsection{STIRRED TANK REACTOR EXPERIMENTS}

1. The stirred tank was designed to maximize the gas film mass transfer coefficient, $k_{g}$, so that mass transfer would be similar to that of a slurry droplet, and experiments would not 
be gas film controlled. However, $k_{b}$ was an order-of-magnitude less than expected for a droplet, and some experiments were gas film controlled.

2. The liquid film coefficient, $k_{\%}^{\circ}$, measured in the stirred tank, represented reasonable contact times between 0.7 and $6.6 \mathrm{~s}$. For the range of slumy concentrations studied, $k^{\circ}$, did not vary due to increased solids content (l.e., greater viscosity). Corrections to $k^{\circ}$, may need to be made to slurries with greater than $1.0 \mathrm{M} \mathrm{Ca}(\mathrm{OH})_{2}$ solids.

3. Changes to the bulk solution lonic strength of a $17 \mathrm{mM}$ (saturated) $\mathrm{Ca}(\mathrm{OH})_{2}$ solution did not show measurable changes to the enhancement factor for $\mathrm{SO}_{2}$ absorption.

4. Gas film resistance began to control absorption of $\mathrm{SO}_{2}$ in the reactor when enough solid $\mathrm{Ca}(\mathrm{OH})_{2}$ were added to the $\mathrm{Ca}(\mathrm{OH})_{2} / \mathrm{CaCl}_{2}$ solution to form a slurry. Measurement of enhancement factors for $\mathrm{SO}_{2}$ absorption in sturries could not be made at $\mathrm{lW}_{2} \mathrm{SO}_{2}$ concentrations because gas film resistance was too high.

5. If experiments resulted in greater than 80 percent gas film controlled absorption, enhancement factors could not be calculated accurately. Thus, enhancement factors greater than about 200 could not be measured accurately in the stirred tank.

6. Enhancement measured from stired tank experiments in clear solutions compared well with the surface renewal theory solutions proposed by Chang and Rochelle (1979) except for the case of a $17 \mathrm{mM} \mathrm{Ca}(\mathrm{OH})_{2}$ solution.

7. Addition of $\mathrm{Ca}(\mathrm{OH})_{2}$ solids greatly enhanced $\mathrm{SO}_{2}$ absorption, although the increment of enhancement measured in the stirred tank diminished as the slurry solids concentration was increased.

8. Enhancement measured in slurry prepared from three different sources of $\mathrm{Ca}(\mathrm{OH})_{2}$ was virtually the same. Pilot of full-scale test data are needed to confirm that there is no significant difference in reactivities among the three $\mathrm{Ca}(\mathrm{OH})_{2} \mathrm{~s}$. 


\subsection{MODEL VALIDATION}

1. The slumy absorption model predioted enhancement factors that compared well with both the surface renewal theory solutions proposed by Chang and Rochelle (1979) and with the measured enhancement from clear solution experiments in the stirred tank. However, both the model and the surface renewal theory solutions overpredicted enhancement that was measured in the stirred tank for the case of a $17 \mathrm{mM} \mathrm{Ca}(\mathrm{OH})_{2}$ solution.

2. Adjusting the diffusivity of hydroxide, $\mathrm{D}_{\mathrm{OH}^{-}}$, to 40 percent of the referenced value allowed the model to more accurately predict enhancement in the $17 \mathrm{mM} \mathrm{Ca}(\mathrm{OH})_{2}$ solution and in slurries. Adjusting $\mathrm{D}_{\mathrm{OH}^{-}}$did not signiticantly change the enhancement predicted by the model for dilute $\mathrm{Ca}(\mathrm{OH})_{2}$ solutions.

3. The model predicted the enhancement of $\mathrm{SO}_{2}$ absorption measured in the stirred tank for slurries of low solids content, but predicted higher enhancement than measured in the stirred tank for slumies of high solids content. Experimental data might be influenced by solids settling in the boundary layer, but it is unclear whether this occurs in droplets.

4. The model predicted little difference in enhancement for changes in particle size (reactivity) of $\mathrm{Ca}(\mathrm{OH})_{2}$ unless the particle size is changed by an order-of-magnitude. This supports that enhancement is not sensitive to changes in the reactivity of the solids unless the reactivity is grossly different, as found also in stirred tank experiments.

\subsection{IMPLICATIONS FOR A SLUURRY DROPLET}

1. Enhancement factors for $\mathrm{SO}_{2}$ absorption in a slumy droplet would be lower than those measured in the stirred tank under similar conditions because of the difference in $\mathrm{k}_{\mathrm{g}}$. Depending on the size of the droplet, enhancement factors for a slurry droplet may be only about 25 percent of the values reported for the stirred tank.

2. Under the experimental conditions studied in this research, absorption of $\mathrm{SO}_{2}$ in a slurry droplet is controlled primarily by liquid film resistances. However, under commercial conditions, gas film resistance is expected to dominate. 
3. The slurry absorption model predicted that, for slumies of up to 23 weight percent $\mathrm{Ca}(\mathrm{OH})_{2}$, absorption in a slumy droplet could be less than 100 percent gas film controlled in gases containing over $1,000 \mathrm{ppm} \mathrm{SO}_{2}$.

\subsection{COMPUTER MODELING}

Although this is not a model of a slumy droplet, It seems probable that the absorption of $\mathrm{SO}_{2}$ into a slurry of $\mathrm{Ca}(\mathrm{OH})_{2}$ is, in most cases, gas film controlled. The contact time when the liquild film resistance becomes important is often too long to be practical. For example, in a spray dryer drying of the droplet is so fast that the absorption process, as long as the droplet is wet, will be gas film controlled. When the water has evaporated, other processes determine the absorption rate. The only time the liquid film resistance can be of importance is when we have very unreactive lime in small droplets.

\subsection{RECOMMENDATIONS FOR ADDITIONAL STUDY}

1. Experiments should be performed to verity the $\mathrm{CaSO}_{3}$ crystallization part of the slurry absorption model.

2. A physical reason for the low measured enhancement in the $17 \mathrm{mM} \mathrm{Ca}(\mathrm{OH})_{2}$ solution should be determined. This should explain why the adjustment of $D_{O H}$ - must be made for the model to accurately predict the measured enhancement. Additional experiments may be needed.

3. Experiments should be run in the stirred tank using solutions which might eliminate the effects of solids settling in the boundary layer. Solutions of higher viscosity might be considered. Such experiments would help validate the slurry absorption model beiter for slurries of high solids content.

4. It should be determined, through experimentation whether solids settling influences absorption in slurry droplets. 
5. Code in the slurry absorption model could be modified so that it converges on solution of the absorption rate more rellably. Also, calculations for the enhancement factor could be added directly to the model.

6. The slurry absorption model is presently confloured 80 that solutions containing cations other than $\mathrm{Ca}^{2+}\left(1 . e ., \mathrm{Na}^{+}\right)$can be considered. However, the model has difflculty running for such solution compositions and needs to be modilied.

7. The slumy absorption model should be coupled with the necessary theories which account for evaporation of water, solids distribution in the bulk liquid and in the boundary layer, and representative droplet sizes and drying times.

8. Experiments using buffer additives, such as those studied by Chang and Rochelle (1979, 1982) and Weems and Rochelle (1981) could be performed in slurries to measure improvements in enhancement and validate the slurry absorption model for the effects of buffers. 


\section{SECTION 8}

\section{REFERENCES}

Alper, E., W.D. Deckwer, and Danckwerts, P.V., "Comparison of Effective Interfacial Areas With the Aotual Contact Area for Gas Absorption in a Stirred Cell," Chemical Engineering Solence, 35, 1263 (1980).

Babu, M., J. College, R. Forsythe, R. Herbert, D. Kanary, D. Kerivan, and K. Lee, "5-MW Toronto HALT Pllot Plant Testing - Final Test Results," DOE Contract DE-AC22-85PC81012 (1988).

Bechtel Inc., "Desulfurization of Flue Gas by the Confined Zone Dispersion Process," Draft Final Report, DOE Contract DE-AC22-85PC81009 (1988).

Bin, A.K., "Mass Transfer to the Free Interface in Stirred Vessels," Chemical Engineering Communication, 31, 155-183 (1984).

Bird, R.B., W.E. Stewart and E.N. Lightfoot, Transport Phenomena, John Willey \& Sons, Now York, N.Y. (1960).

Bllx, G., Z. Physiol. Chem., 178, 109 (1928).

Boynton, R.S., Chemistry and Technology of Lime and Limestone, 2nd edition, John Wiley and Sons, New York, NY (1980).

Chan, P.K.R., and G.T. Rochelle, "CaCO3 Dissolution in $\mathrm{SO}_{2}$ Scrubbing Solution Mass Transfer Enhanced by Chemical Reactions," masters thesis, the University of Texas at Austin (1981).

Chang, C.S. and G.T. Rochelle,"Effect of Organio Acid Additives on $\mathrm{SO}_{2}$ Absorption Into $\mathrm{CaO} / \mathrm{CaCO}$ Slumies," AlChE Joumal, 28, 2 (1982).

Chang, C.S. and G.T. Rochelle, "SO Absorption into $\mathrm{NaOH}$ and $\mathrm{Na}_{2} \mathrm{SO}_{3}$ Aqueous Solutions," presented at the AlChE National Moeting, Philadelphia (1980). 2, (1981)

Chang, C.S., and G.T. Rochelle, "SO ${ }_{2}$ Absorption Into Aqueous Solutions", AlChE Journal, 27,

Chang, C.S., "Mass Transfer With Equillibrium Chemical Reaction, Sulfur Dioxide Absorption in Aqueous Solutions," Ph.D. dissertation, The University of Texas at Austin (1979).

Damle, A.S., "Modeling of $\mathrm{SO}_{2}$ Removal in Spray-Dryer Flue-Gas Desulfurization System," prepared for the U.S. EPA, contract no. EPA-600/7-85-038 (1985). 

(1955).

Danckwerts, P.V., "Gas Absorption Accompanied by Chemioal Reaction," AlChE Joumal, 1, 456

Danckwerts, P.V., "Gas Absorption with Instantaneous Reactlon," Chemical Engineering Solence, 23, 1045 (1968).

Danckwerts, P.V., Gas-Llquid Reactions, MoGraw.HIII, Now York (1970).

Danckwerts, P.V., "Signifloance of Llquild-Film Coeftloients in Gas Absorption," Industrial and Engineering Chemistry, 43, 1460 (1951).

Energy and Environmental Research Corp., "Global Approach for Enhanoed Mass Transter Effects In-Duct Flue Gas Desulfurization Processes, In-Duot Slurry Droplet Model," Toploal Report No. 2 prepared for US. Department of Energy, Pittsburgh, contraot no. DE-AC22-88PC88873 (1989).

Epstein, M., "EPA Alkaline Sorubbing Test Faollity: Summary of Testing Through Ootober 1974", prepared for the U.S. EPA, contrant no. EPA 650-2-75-047 (1976).

Giovanni, D.V., R.G. Rhudy, J. MCCarthy, and R. Giles, "Technioal and Economlo Evaluation of HYPAS," presented at the $18 t$ Combined FGD and Dry $\mathrm{SO}_{2}$ Control Symposium, St. Louls, $\mathrm{M}(1988)$

Gleason, C.L. and Rochelle, G.T., "Dissolution and Crystallization of Calolum Sulfte Platelets", presented at the AIChE National Meeting, Houston, Texas (1987).

Harriot, P.,"Mass Transler to Pantloles: Part I. Suspended in Agttated Tank8", AlChE Journal, 8, 93-102 (1962).

Higble, R., "The Rate of Absorption of a Pure Gas into a Still Llquid During Short Perlods of Exposure," Transactions of AlChE Journal, 31, 365 (1935). $147(1978)$

Hikita, H., S. Asal and H. Nose, "Absorplion of Sultur Dioxide Into Water", AlChE Journal, 24, 1,

Hiklta, H., S. Asal and T. Tadashl, "Absorption of Sulfur Dloxide Into Aqueous Sodium Hydroxide and Sodlum Sulfite Solutions," AIChE Joumal, 23, 4, 538 (1977).

Hirschfelder, J.O., C.F. Curtiss and R.B. Bird, Molecular Theory of Gases and Liquids, John Wiley and Sons, New York, NY (1964).

Holstvoogd, R.D., K.J. Ptasinsky and W.P.M. van Swaall, "Penetration Model for Gas Absorption With Reaction in a Slurry Containing Fine Insoluble Particles," Chemlcal Engineering Solence, 41, 867-873 (1986).

Huasheng, L., and F. Wenchi, "Kinetics of Absorption of Nitric Oxide in . iqueous Fe(II)-EDTA Solution", Ind. Eng. Chem. Res., 27, 5 (1988).

Jozewioz, W. and G.T. Rochelle, "Modeling of $\mathrm{SO}_{2}$ Removal by Spray Dryers," presented at the Plitsburgh Coal Conference (1984).

Karlsson, H.T., and J. Klingspor, "Tentative Modeling of Spray-Drying Scrubbing of $\mathrm{SO}_{2}$," Chemical Engineering Technology, 10, 2, 104 (1987). 
Kinsey, M. and P. Harrlott, "Modeling the Gas and Llquild Resistances in the Dry Sorubbing Process for $\mathrm{SO}_{2}$ Removal," presented at the Third Annual Pittsbungh Coal Conference (1986).

Kinsey, M.K., and P. Harriott, "Effects of Droplet-Slze Dlstrbution on the Dry Sorubbing Process for Flue Gas Desulfurtzation," presented at the AlChE Natlonal Meetinu, Washington D.C. (1988).

Kosinskl, A.A. and C.J. King, "The Inftuence of Dlftusivity on Llquild Phase Mass Transter to the Freo Intertace in a Stirred Vessel," AlChE Joumal, 12, 109 (1966).

Larsson, E., B. Adell, Z. Anorg. Chem., 196, 354 (1931).

Lee, J.J., "Numerical Modeling of Direct Sorbent Injeotlon for SO, Removal," prepared for the Universily of Tennessee Space Institute, American Chemloal Soclety - Division of Gas and Fuel Chemistry (preprints), 33, 2, 120-125 (1988).

Malbodl, M., T.L. Pearson, R.M. Counce, and W.T. Davis, "Simulation of Spray Dryer Absorber for Removal of $\mathrm{SO}_{2}$ from Flue Gases," presented at the Tenth Symposium on Flue Gas Desulturization, 1, EPRI CS.5167 (1987).

Markarov, S.Z., and 1.1. Vol'nov, Izv. Sektora Fiz-Khim. Anal., Inst, Obshoh. Neorgan. Khim., Akad Nauk, SSSR, 25, 320 (1954).

MoGulre, L.M., "Sulfur Doxide Absontion Experiments in Calolum Hydroxide Slurries," M.S. Thesis, The Universitty of Texas at Austin, Austin, Texas, December 1990.

Mlyachl, M., A. Iguchl, S. Uohlda, K. Kolde, "Effect of Solid Particles in Liquid Phase on Llquild-side Mass Transter Coetflieient", Canadlan Journal of Chemical Engineering, 59, 690-691 (1981).

Olander, D.R., "Simultaneous Mass Transfer and Equilibrium Chemical Reaotion," AIChE Journal, 6,2, $233(1960)$.

Peaceman, D.W." "Llquid-Side Resistance in Gas Absorption With and Without Chemical Reactlon," Sc.D. Thesis, Massachusetts Insttute of Technology, Cambridge, MA (1951).

Perry, R.H., and C.H. Chilton, "Prediotion and Correlation of Physical Propertles," Chemical Engineer's Handbook, 5th edition, McGraw-Hill Book Company, New York, NY (1973).

Quicker, G., E. Alper, and W.D. Deckwer, "Gas Absorption Rates in a Stirred Cell With Plane Interface in the Presence of Fine Particles," The Canadlan Journal of Chemical Engineering, 67, 32-38 (1989).

Ramachandran, P.A., and M.M. Sharma, "Absorption With Fast Chemical Reaction in a Slurry Containing Sparingly Soluble Fine Particles," Chemical Engineering Sclence, 24, 1681 (1969).

Sada, E. et al., "KInetios of Absorptions of Lean Sultur Dloxide into Aqueous Slurries of Calolum Carbonate and Magnesium Hydroxide," Chemical Engineering Solence, 36, 149-155 (1981)

Sada, E., H. Kumazawa and M.A. Butt, "Single and Simultaneous Absorptlons of Lean $\mathrm{SO}_{2}$ and NO2 Into Aqueous Slurries of $\mathrm{Ca}(\mathrm{OH})_{2}$ or $\mathrm{Mg}(\mathrm{OH}) 2$ Particles," Journal of Chemlcal Engineering of Japan, 12, 111-117 (1979). 
Sada, E., H. Kumazawa and M.A. Butt, "Single Gas Absorption With Reaction in a Slumy Containing Fine Particles", Chemical Engineering Solence, 32, 1165-1170 (1977).

Sada, E., H. Kumazawa, N. Hayakawa, I. Kudo and T. Kondo, "Absorption of Nin Aqueous Solutions of KMnO4," Chemical Engineering Solence, 32, 1171-1175 (1987).

Sada, E., H. Kumazawa, "Some Consideration on Chemlcal Absorption into a Slurry Containing Fine Catalyst Particles," Chemical Engineering Sclence, 37, 945-948 (1982).

Sada, E., H. Kumazawa, Y. Yamanaka, I. Kudo and T. Kondo, Kinetics of Absorption of Sulfur Dloxide and Nitric Oxide in Aqueous Mixed Solutions of Sodlum Chiorite and Sodium Hydroxide," Joumal of Chemical Engineering of Japan, 11, 4, 276-282 (1978).

Samuel, E.A., K.R. Murphy, and A. Demlan, "A 12-MW Pilot Study of In-Duct Sorubbing (IDS) Using a Rotary Atomizer," Final Report, DOE Contract DE-AC22-85PC81010 (1989). (1975).

Sherwood, T.K., R.L. Pigtord and C.R. Wilke, Mass-Transfer, MoGraw-Hill Inc., New York, N.Y.,

Stromblad, C. and G.T. Rochelle with Acurex Corporation. "Theoretical Approach for Enhanced Mass Transfer Effects - In-Duct Flue Gas Desulfurtzation Processes - Quarterly Report No. 4," prepared for the U.S. Department of Energy, Plttsburgh, under Contract No. DE-AC22-88PC88874 (1989). (1980).

Treybal, R.E., Mass-Transfer Operations, 3rd Edition, McGraw-Hill Inc., Now York, N.Y.,

Uchida, S., and C.Y. Wen, "Rate of Gas Absorption Into a Slurry Accompanied by Instantaneous Reaction", Chemical Engineering Science, 32, 1277-1281 (1977).

Uchida, S., H. Moriguchi, H. Maejima, K. Koide and S. Kageyama, "Absorption of Sulfur Dioxide Into Limestone Slurry in a Stirred Tank Reactor", Canadian Joumal of Chemical Engineering, 56, 696-697 (1978).

Uchida, S., K. Koide, and M. Shindo, "Gas Absomption With Fast Reaction Into a Slurry Containing Fine Particles", Chemical Engineering Science, 30, 644 (1975).

Versteeg, G.F., P.M.M. Blauwhoff and W.P.M. Van Swaail, " The Effect of Diffusivity on Gas-Liquid Mass Transter in Stirred Vessels. Experiments at Atmospheric and Elevated Pressures," Chemlcal Engineering Sclence, 42, 5, 1103-1119 (1987).

Vivian, J.W., "Absorption of $\mathrm{SO}_{2}$ Into Lime Slurries: Absorption Rates and Kinetics," prepared for the U.S. EPA, contraot no. EPA-650/2-73-047 (1973).

Weems, W.T., "Enhanced Absorption of Sulfur Dioxide by Sulfite and Other Buffers," masters thesis, The University of Texas at Austin (1981).

Whitman, W.G., "Preliminary Experimental Confirmation of the Two-Fllm Theory of Gas Absorption," Chem. Met. Engineering, 29, 146-148 (1923).

Yoon, H., P.A. Ring, and F.P. Burke, "Coolside Abatement Technology: 1-MW Field Tests", presented at Coal Technology '85, Pittsburgh, PA (1985). 

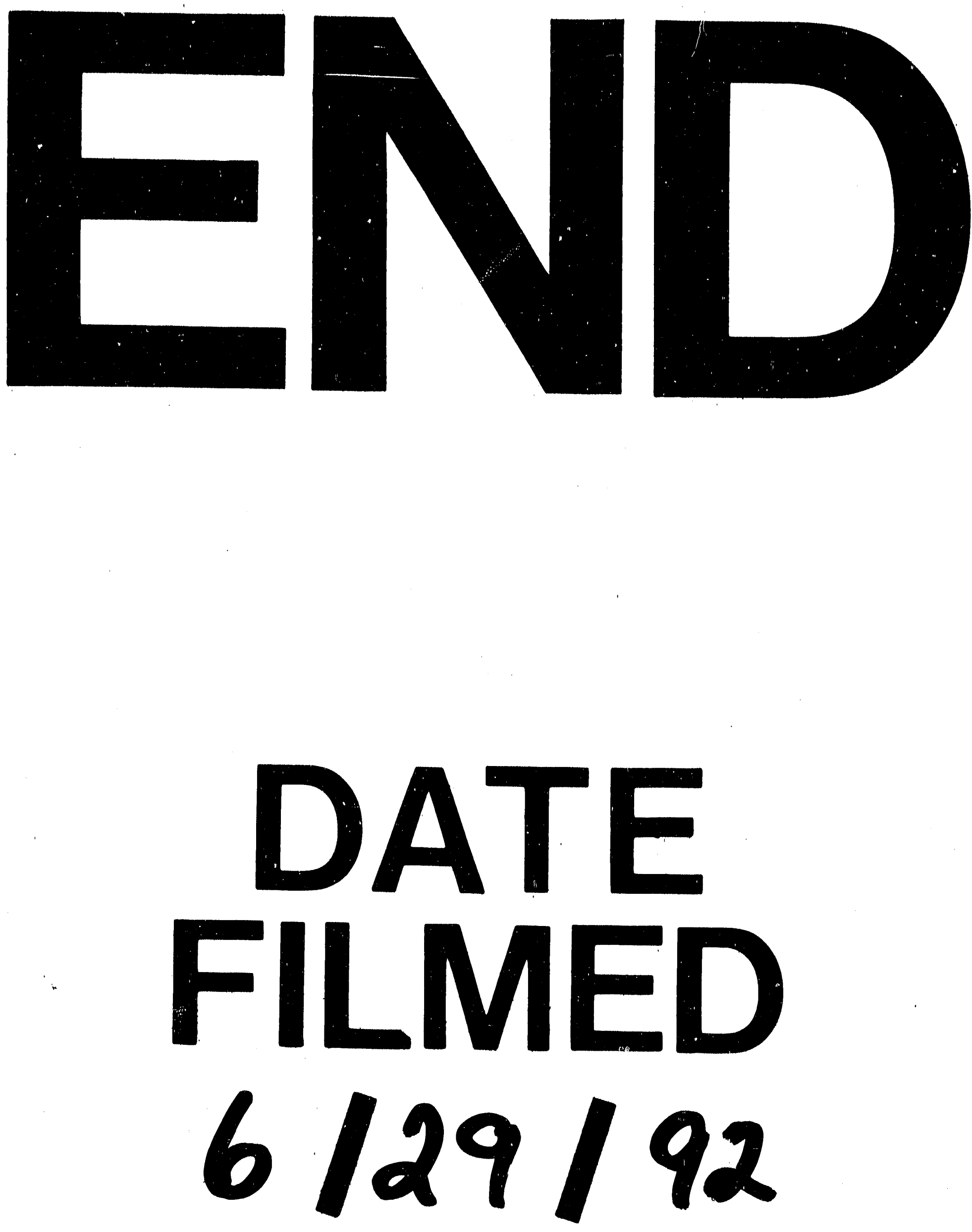